\title{
PRAKTIKUM DER \\ GEWEBEPFLEGE ODER EXPLANTATION BESONDERS DER GEWEBEZÜCHTUNG
}

\author{
VON
}

DR. PHIL. RHODA ERDMANN

PRIVATDOZENT DER PHILOSOPHISCHEN FAKULTÄT AN

DER FRIEDRICH WILHELMS - UNIVERSITÄT ZU BERLIN

MIT IOI TEXTABBILDUNGEN

VERLAG VON JULIUS SPRINGER. BERLIN

1922

QP

88

E 75 



\title{
PRAKTIKUM DER \\ GEWEBEPFLEGE ODER EXPLANTATION BESONDERS DER GEWEBEZÜCHTUNG
}

\author{
VON
}

DR. PHIL. RHO DA ERDMAN N

PRIVATDOZENT DER PHILOSOPHISCHEN FAKULTÄT AN

DER FRIEDRICH WILHELMS - UNIVERSITÄT ZU BERLIN

MIT IOI TEXTABBILDUNGEN
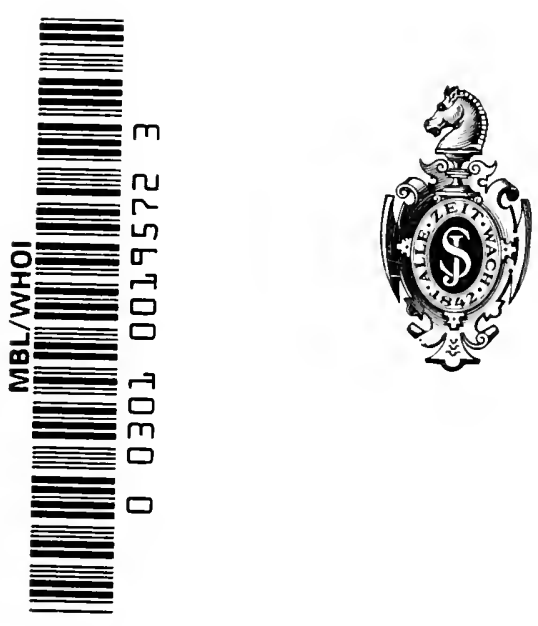

VERLAG VON JULIUS SPRINGER B BERLIN 1922 
ALLE RECHTE INSBESONDERE DAS DER ÜBERSETZUNG

IN FREMDE SPRACHEN, VORBEHALTEN.

COPYRIGHT 1922 BY JULIUS SPRINGER IN BERLIN. 


\section{DEM BEGRÜNDER \\ DER ENTWICKLUNGSMECHANIK WILHELM ROUX \\ IN DANKBARER ERGEBENHEIT}




\section{Vorwort.}

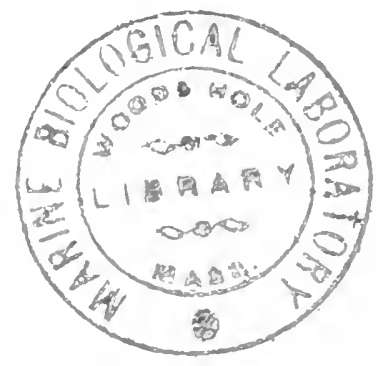

Diese Einfühmong in tie Methotik der Gewebepflege int der erste Versuch, diese Methode in weitere Kreise zu verbreiten. Schon auf der Cniversität soll der werdencle biologisehe Forseher sie kemen kenen, damit er später bei Inangriffnahme eigener Arbeiten frei ïber sie verfïgt. Nach fast zweijährigem Kursbetrieb hat sich in mir die Überzeugung entwickelt, dab cinc Einführung in die Gewebepflege im Cniversitäsunterrichtsbetrieb nötig und möglich ist. Wit sehr einfachen Nittehn und anf elementare Art habe ich Gawebepflege erfolgreich lehren kömmen. Bis jetzt wurle the Methore in Forschungs-Instituten von Person zu Person geleht, und dabei stand eine reiche Apparatur und viel Assistenz zur Verfügung. Das hinderte früher unct auch jetzt vielfach die Ausbreitung dieser so wichtigen Methole. Der Forseher braueht natïrlich melm Assistenz, reichere Apparatur, bessere Einrichtungen als ich sie hier anfgezählt habe. Aber. was mir so wichtig erwheint, daB diese Methode cin Gemeingut aerer wirk, die in Zukunft biologiseh forsehend arbeiten wollen, kamn, wie man hier sicht, auf verhältnismäBig einfache Weise, mit billigen Mitteh erreicht werden.

Zwar steekt die Methode der ,Gewebepflege im Explantat" noch in den Kinderschuhen. Sie wird aber in Zukunft bestimmt sein, gleiehberechtigt neben die anderen Methoden der kausalanalytisehen Forsehming zu treten, wemn viele Köpfe und viele Häncle an ihrer Vervollkommmmg arbeiten. Es ist erst ein Anfang dazu gemacht.

Wie notwendig ein so allgemeines Kennenlemen der Methodik ist. beweist die Geschichte des Wissenszweiges, nämlich der Entwicklungsmeehanik (Entwicklungsphysologie), aus welcher die Gewebepflege, und enger die Gewebezüchting hervorgegangen ist. Die Entwicklumgsmechanik, populär auch experimentelle Entwicklungslehre genannt, umfaßt eine Reihe ron Disziplinen, die manches in der Nethodik gemeinsam haben, aber sich doch in der spezietten Fragestellung und in der Art ihrer Lösung unterscheiden. Wir sprechen z. B. ron Transplantations- und Explantationsmethoden in der kausalanalytisehen Forsehung. Sic beide haben als Material lebende Organismen, Organe, Organteile, Gewebe und Zellen, mit denen experimentiert wird. Bei ihnen ist das Sehieksal des Explantates oder des Transplantates die Hauptsache und nicht aueh das des Organismus, aus welehem sie entmommen sind, wie es bei Regenerationsexperimenten der Fall ist. Die Explantation hat schon eine lange Geschiehte hinter sieh und zeigt, daß jeder nene Wissenszweig sich seine Methodik schafft. Diese Methode wurde 1884 von IV. Roux (Gesamm. Abhandl. II, S. 247) erdaeht, indem er mit Hilfe von Heraussehneiding 
der Merdullarplate des Hïhnchens und Beobachtung der weiteren Entwicklung in einer warmen Kochsalzlösmng kausalanalytisch ernittelte, daB der SchhuB des Mechullarrohres nicht nach HIs durch den Druek der wachsenden Nachbarteile der Merhularplatte, sondern dureh Selbstschlub dieser Platte erfolgt. Dies war das erste kausalanalytische Experiment. in den ROLX zur Lösung eines bestimmt gestellten morphologischen Problems diese Methorle anwandte. Es folgte von demselben Forscher 1893 (1I, S. 986-995; Arch. f. Entwiekl.-IIech. I u. III) die Isolation von Furchungszellen des Frosches in Hühnereiweiß oder in einer ${ }^{1 / 2}$ proz. Kochsalzlösung. Hierbei wurde die gegenscitige Näherung del Zellen (Zytotropismus), die flächenhafte Vereinigung zu gesehlossenen Komplexen, die nachträgliche Umordnung und das Wiederaustreten ron Zellen aus dem Verbande im analytisehen Experiment beobachtet; kurz, alle Erscheinungen dor Zytotaxis, deren weitere Erforschung jetzt ein grobes Gebiet in der Gewebepflege eimnimmt.

In den lotzten 20.Jahren, seit den Arbeiten von Harrison, Burrows, CARrfl 11. a. hat die Explantation von Geweben sich hoch entwiekelt. Wenn auch HarRison seine Experimente aus entwicklungsmechanischen Gründen angestellt hat, so sind jetzt wieder viele Arbeiten erschienen, die die Methode der Gewebepflege anwenden und doch nur rein deskriptiv arbeiten. Das liegt natürlich daran, daß cest die wichtige Frage nach der Art eines analysierbaren Nährmediums restlos gelöst werden sollte. Diese Lösung fehlt noch. Aber ist sie erst erreieht, so wird auch die Methode der Explantation, besonders der Gewebeexplantation für die kausalanalytische Forsehung von hochbedeutendem Nutzen sein, wie ja auch erst durch die Transplantation nach dem Erseheinen von Borns, Barfurths, Braus', Harrisons, Morgans, Drieschs, Herbsts u. a. Arbeiten und den Arbeiten ihrer Schüler eine Renaissance der Zoologie aufging, nachdem nach Roux' Vorgang bewußt kausalanalytiseh zu experimentieren begonnen worken war.

So muß auch mehr und mehr die Zellenlehre aus einer deskriptiven Wissenschaft eine experimentelle und allmählich auch kausalanalytische werden. Deshall) ist die Methode der Gewebezïchtung zu pflegen; um die Erhaltungs- und Gestaltungsfunktionen der lebenden Zelle und des lebenden Gewebes unter verschieden experimentell gesetzten Umständen auszulösen und qualitativ zu beeinflussen.

Berlin-Wilmersdorf, Juni 192:.

RHODA ERDMAN. 


\section{Inhaltsverzeichnis.}

Umgrenzung des Arbeitsgebietes . . . . . . . . . I

Anfzählung und Beschreihme der uotwendigen Apparate. . . . 4

1. Veränderung der Zellformen in versebiedenen Medien 6

A. Gewinnen der Kulturmedien . . . . . . . . . . . . 6

B. Ausetzen der Kulturen . . . . . . . . . . . . . . 16

C. Besbichten nut Pflecen der Kulturen . . . . . . . . . . . 19

II. Lebensäuberungen ter Zellon und Gewebe in verschiedenen lledicll . . . . . . . . . . . . . 29

A. Answanderung der eingepflanzten Zellen gezeigt an der Milz . 38

B. Umbilelung der Knochenmarkzellen . . . . . . . . . . . . 42

C. Phagozytose und Erseheinungen der Riesenzellenbildung . . . 45

D. Zellteilung der lebenden Zelle und Darstelhug ihrer lnhaltskörper . . . . . . . . . . . . . . . . . . . . 47

E. Erscheinungen des Zelltodes . . . . . . . . . . . . . 51

1II. AuBerungen eehten Wachstums.......... . 56

A. Eelste Wachstumersebeinungen des embryonalen Bindegewebes und Umban des en wadrenen Bincleqewebes. . . . . . . . . . 56

B. Echtes Wachstum des embryonalen Nuskelgewebes mol Abund Umban der erwachenen Inusulatur. . . . . . . . . . 6s

C. Echtes Wachstum der Epithelgebilele, gezeigt an dem embryonalen Epithel und Verhalten der erwachsenen Schilddrüsen uncl Geschlechtsdrüsen . . . . . . . . . . . . . it

IV. Ablanf progressiver und regressirer Vorgänge . . . S4

A. Verhalten der Sinnesepithetien in dem Kulturmedinm . . . . . s4

B. Verhalten der nervören Elemente . . . . . . . . . . . . . $\$ 9$

C. Verhalten des Herzklappengewebes . . . . . . . . . . . . . 96

V. Nutzbarmaehung der llethode der Gewebezächtung zur Lösung nochstrittiger Fragen. . . . . . . 100

Zusammenstellung des Materials und der einschlägigen Literatur . 112 



\section{Umgrenzung des Arbeitsgebietes.}

Zum Beginn soll der Begriff, Explantation", der 1905 von W. Roux gejräigt wurde, oder Gewebejflege im Explantat kurz definiert werden, damit die gestellte Aufgabe abgegrenzt werden kann. Gewebepflege zerfällt in: die Pflege des Ganzexplant a tes-Totalexplantates und die Pflege des Teilexplantates-Partialexplantates.

Im Ganzexplantat wird verschiedenes Material gepflegt, mitunter auch geziichtet. Die Ganzexplantation beschätigt sich mit der Pflege des ganzen oder fast des ganzen Organismus, die Teilexplantation mit der von Organen, Organteilen, Geweben, Zellen, die, von dem Mutterorganismus entfernt, in ein nichtlebendes Kulturmedium zu kurzer oder länger dauernder Lebenderhalt ung eingefïhrt werden.

Die Ganzexplantate werden wir in diesen Übungen nicht behandeln. Dic Ausplanzung des zentralen Teiles von Hühnerkeimen, die durch Roux ls8t ausgeführt, ron Hühnerkeimen dureh WorTHER und WHipple 1912, von ganzen Keimblasen des Kaninchens dureh BracHeT 1913, sowie die Erhaltung des zu früh geborenen menschlichen Kindes gehören zur Ganzexplantation. Zu dem Ganzexplantat aus dem Muttertier oder aus dem Ei steht im Gegensatz das Teilexplantat, das aus dem Organismus genommen ist (Opper, 1914, S. 93). Die Pflege der Ganzexplantate unterscheidet sich aber nicht prinzipiell von der, welche wir den Teilexplantaten widmen. Der Zusammenhang zwischen dem Organismus und dem ihm entnommenen Teile ist bei dem Teilexplantat enger, infolgedessen ist die Gewebepflege schwieriger. Gewebepflege in Teilexplantat wollen wil kurz einfach ,Gewebezüchtung" nemnen, wenn wir uns bewuBt bleiben, daß nicht alle Gewebepflege Gewebezïchtung ist, demn Züchtung bedeutet Vermelo r m g. Nicht jedes gepflegte Teilexplantat vermelnt sich. Es finden Ab- und Umbauerseheinungen in ihm statt, die von großer Wichtigkeit sind, aber doeh hinter der Gewebezüchtung im strengen Sime an Bedeutung zurïcktreten. bei der cin quantitatives $W$ a c hist u m der Ze 11 elemente muter mitotischen Erscheinungen Voraussetzung ist.

Noch ein Wort zur Stellung der Explantation zur Thansplantation. Bei der Transplantation ist das Wichtige, da 8 das transplanticrte Gewebestüek mit einem anderen, lebenden Organismus rerbunden wird, wïhrend wir bei der Explantation das explantierte Gewebestück mit einem nicht lebenden Kulturmedium umgeben. Die 'Transplantation von Hautstïckchen, Gelenken, Sehnenbïndern aus dem Geber in den Geber selbst wieder nennen wir , autoplastische Transplantation". Die Transplantation aus dem Geber in einen speziesgleichen 
Empfänger nennen wir , ,homoioplastische Transplantation“, die Transplantation ron dem Geber in einen speziesfremden Empfänger nennen wir „heteroplastische Transplantation“. Wir werden manche Erfahrungen, die bei der Transplantation im Laufe des letzten Vierteljahrhunderts gemacht worden sind, zum Vergleiche mit den Ergebnissen, die wir bei der Explantation, also unserer eigentliehen Aufgabe, erzielen, heranzielien.

Ieh habe noch hinzuzufügen, daß die Transplantationen jetzt, nach dem Erfolg, in ,Implantation“ und ,Interplantation“"zerfallen. Werden die Gewebestücke dauernd erhalten und kann das Gewebestïck seine Gewebefunktion ausüben, so sprechen wir mit Roux von Implantation (Beispiel: funktionierendes Kniegelenk, Lexer). Wenn das Transplantat das aber bei der Übertragung gelebt haben muß, während der Transplantation nur vorübergehend als Brücke oder Leitung dient und später durch körper-eigenes Gewebe wenigstens in dieser Form ersetzt wird, sprechen wir mit OPPEL von Interplantation oder funktioneller Substitution (Haut bei Säugetieren).

Bei der Explantation war das Überraschende, daß Teile eine Zeitlang fortleben, naehdem sie von dem Organismus, zu dem sie zuvor gehörten, abgetrennt waren (OpPes, 1914, S.9). Dies Verfahren hat man anfangs auch naeh Nebenumständen der Technik, ,in-vitroKultur", „Deckglaskultur", später nach den Forschern, welche die Methode sehr verbessert und ihr allgemeinere Anwendbarkeit versehafft haben, ,Harrison-Carrelsche Kultur" genannt.

Mir ist es nicht lieb, wenn der Ausdruck, ,Kultur" ohne weiteres gebraucht wird. Der Begriff ,Kultur" hat eine so eng umgrenzte Definition in der Bakteriologie erhalten, daß es nur zu Begriffsverweehshungen führt, wenn wir von, ,in-vitro-Kultur" sprechen. „Kultur" im Sinne der Bakteriologen bedeutet, daß die eingepflanzten Bakterien jahrelang weitergezüchtet werden können, sieh also in der Kultur vermehren und aus derselben Kultur überimpfen lassen. Wenden wir diese Begriffe an für die Explantation, so folgt daraus, daf wir Gewebe in ein Medium pflanzen, dann, nachdem es gewachsen ist, Teile des neuentstandenen Gewebes in ein neues Medium bringen, wiederholt Teile von diesem neuen Gewebe umpflanzen und dies ad infinitum fortsetzen. Von dem eingepflanzten Stüek darf keine Zelle erhalten bleiben. Dies ist bis jetzt nur ein einziges Mal von Carrel und seinem Mitarbeiter Ebeling erreicht. worden, welche den größten Erfolg mit dem Verfahren erzielt haben. Jüngst ist auch Fischer I922 dasselbe für embryonales Epithelgewebe gelungen.

CARREL hatte embryonales Gewebe aus einem 8 Tage alten Hühnerembryo in Blutplasma und Embryonalextrakt gezüchtet und alle $\mathbf{3 - 5}$ Tage dieses Medium erneuert, nachdem das Stïckchen, welches er eingepflanzt hatte, in Ringerscher Lösung gewaschen worden war. Dureh den ständigen Wechsel des Mediums, den Carrel selbst ungefähr zwei Jahre lang durehführte, gab er dem Gewebe den für dasselbe nötigen Nährstoff, und dureh das Waschen entfernte er die Abbaustoffe. Sein Mitarbeiter Ebeling setzte dies fort, und ihm ist es möglieh gewesen, von derselben Ausgangskultur Zellen zu züchten, die noch heute, nach 
ne un Jahren, leben. l(h betone noch einmal, dies war mesenehymales, also embryonales Gewebe, das sich, wie bekannt, durch eine große Wachstumstendenz auszeiehnet. Dieses Experiment ist noeh nicht wiederholt worden. Erst jetzt, im Jahre 1922 ist es gelungen. Epithelzellen drei Monate lang zu züchten, und zwar hat Fischer nach vielen Versuchen durch einen glïcklichen Zufall ein wenig Trisepithel, das noeh an der Linse sitzt, rein züchten kömnen. So ist nicht nur die embryonale Mesenchymzelle, sondern auch dic embryonale Epithelzelle bis jetzt während längerer Zeiträume züchtbar. Dies ist also eine wirkliehe Kultur.

Es ist eine unglückliche Angewohnheit der Forscher, dic bis jetzt auf dem Gebiete der Gewebezüchtung gearbeitet haben, von neuen Generationen zu sprechen, jedesmal, wenn sie das Gewebestück in ein neues Medium setzen. Man sollte von einer Zahl von Generationen nur sprechen, wenn man zahlenmäßig feststellen kann, wie oft die Ausgangszelle, welche mit clem Gewebestück in das Plasmamedium gesetzt wurde, sich geteilt hat. Das ist bis jetzt noeh nicht einwandfrei geschehen, und wir wollen lieber sagen: wir können Abkömmlinge der explantierten Zellen, z. B. durch 300 maligen Nährmedinmweehsel, jahrelang in vitro erhalten. Es bleibt also eine noeh unerfüllte Aufgabe, die Zahl der sich bildenden Zellgenerationen im Explantat festzustellen.

Aber wir würden die Aufgabe der Gewebezüchtung zu eng fassen, wenn wir uns nur darauf beschränkten, Zellen in das Nährnedium zu verpflanzen, von denen wir annehmen, daß sie sich periodiseh teilen können, sondern wir müssen aueh alle jene Gewebe des erwachsenen Körpers in den Kreis unserer Betraehtungen zichen, dic crst ans einem Latenzzustand erweckt werden müssen, die von den Zellprodukten, wie Bindegewebsfibrillen, Muskelfibrillen, befreit werden müssen, um dann unter Umständen sich wieder neu zu teilen. Während also die eine Seite der Gewebepflege sieh mit embryonalen und vielleieht mit Geschwulstzellen befaßBt, besehäftigt sich die Gewebepflege weiter mit dem Abbau und den Veränderungen, die die erwachsene Zelle im Zuehtmedium erleidet. Wir dürfen hier aber nicht den Ausdruek, ,iberlebend “ anwenden, weil, wenn auch diese Zelle überlebend erseheint, sie doch wirklich lebend ist. Das Nervengewebe im erwachsenen Körper z. B. teilt sich für gewöhnlich auch nicht, nur unter bestimmten Bedingungen kommt es bei der Regeneration zur 'Teilung, und doch sagen wir nicht daß das Gehirn in unserem Körper überlebend ist, sondern es ist lebend. Die Grenzen sind natürlich sehr verwischt und sehwer feststellbar.

Die erste Gruppe von Erseheinungen spielt sich in den ausgewanderten oder in den neugewachsenen Zellen ab. Die zweite Gruppe geht auch in dem Gewebekomplex, welehen wir in das Plasmamedium tun, selbst vor. Bis jetzt hat man sich meistens mit den auswandernden und sich neubildenden Zellen besehäftigt. Erst in den letzten Jahren hat man auch dic anderen Phänomene in den Kreis der Betraehtungen gezogen, wic z. B. den Abban der Muskel- und Bindegewebe und elastisehen Fasern. Wir werden uns zuerst mit folgender Gruppe von Erseheinungen befassen, und zwar werden wir aus didaktisehen Gründen die Ver- 
änderungen des erwachsenen Kaltblütlerepithels, dann LebensäuBerungen der Zellen, weiter das Verhalten des embryonalen Binde-, lluskel-, Epithel- und Nervengewebes der Warmblütler während der Züchtung betrachten, $11 \mathrm{~m}$ dann zu den Ersehcinungen an dem erwaehsenen Gewebe ïberzugehen. Es ist wichtig, genau jede Zellart zu studieren,

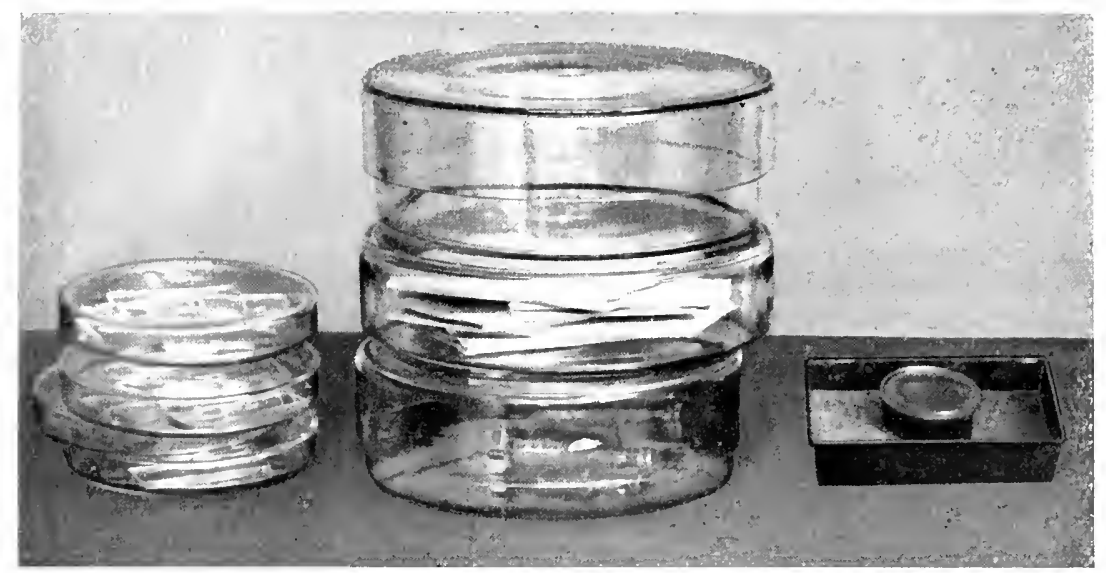

Abb. 1 zeigt das zur Plasmaentnahme und zum Ansetzen der Kulturen notwendige Instrumentarium.

damit später, wenn man aus verschiedenen Zellarten zusammengesetzte Gewebe betraehtet, schon Normen gefunden sind, wie sich z. B. die Bindegewebszelle, die Epithelzelle im Plasmamedium rerhalten. Nach diesen vorbereitenden Bemerkungen, die unsere Aufgabe begrenzt haben, nehmen wir die Züchtung der Froschhaut vor, nachdem wir das dazu nötige Instrumentarium und die dazu nötigen Lösungen vorbereitet haben.

\section{Aufz:ihlıng und Beschreibung der notwendigen Apparate.}

Der Operationsra $u$ m soll eine Zentrifuge mit nicht $\mathrm{zu}$ geringer Umdrehungszahl, ungefähr 2-3000 Umdrehungen in der Minute also keine Handzentrifuge - , einen Thermostaten, der auf $38^{\circ} \mathrm{C}$ gestellt mil womöglich elektriseh geheizt wird, einen Eisschrank und einen praktisehen Operationstisch enthalten. Das Arbeitszimmer muß außer der in den Laboratorien gebräuchlichen Einrichtungen einen kleinen Trockensterilisator haben. Das Institut bedarf eines Autoklaven, und wenn das nicht möglieh, eines Dampftopfes. Der Kurs selbst erfordert für 4-6 Teilnehmer an Glasinstrumenten:

6 große Glasschalen, Durchmesser etwa $23 \mathrm{~cm}$, Höhe etwa $8 \mathrm{~cm}$ (je 3 davon werden bei jeder Operation gebraucht),

24 Drigalski-Schalen,

48 Petri-Schalen,

3 kleine Schalen mit eingesehliffenem Deckel,

12 dickwandige Zentrifugengläser,

12 diekwandige Reagenzgläser, 
12 dickwandige Reagenzgläser (Länge ctwa $10 \mathrm{~cm}$, Durchmesser etwa $7 \mathrm{~mm}$ für kleine 'Tiere; Länge etwa $10 \mathrm{~cm}$, Durchmesser etwa $13-14 \mathrm{~mm}$ für größere 'Tiere),

100 Stück hohlgeschliffene Objektträger (Durchmesser $20 \mathrm{~mm}$, 'Tiefe $1,5 \mathrm{~mm}$ ),

runde oder eckige Deckgläscr, die die Öfnnung des Objektträgers bedecken (2:2 $\mathrm{mm}$ Durchmesser, Dicke 0,20-0,22 $\mathrm{mm}$ ) (es werden auch Jieascheiben empfohlon, sie sind gut zu benutzen, wenn man das wachsende Gewebe nicht mit starken Vergrößerungen beobachten will).

6 Plasmaentnahmepipetten (nach Eromax, Abb. 2a),

(5 Tropfempipetten (nach Erdmand, Abb. 2h),

LuErsche Spritzen, 3 zu $2 \mathrm{cem}, 3$ zu 3 oder $4 \mathrm{ccm}$, mit nicht zu engen Kanïlen.

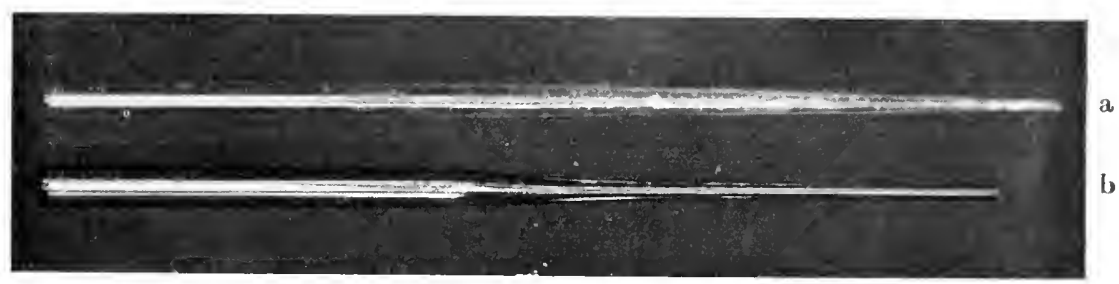

Abb. 2. a) Plasmaentnahmepipetten. b) Tropfenpipetten zum Ansetzen der Kulturen.

Alle Glassachen sind vor Gehrauch tagelang zu wässern und in Wasser zu halten. Beim Reinigen soll jede Säure vermieden werden, nur durch Wässern, Kochen und Reinigen mit Gänscfedern werden die Glasgofäße saubergehalten. Falls die Gefäße nicht gebraucht werden, sind sie in häufig zu rechselndem Leitungswasser aufzubewahren.

Besonders wichtig ist das Reinigen der Deckgläschen. Man hält sich für diesen Zweek ein kleines Porzellantiegelchen bereit, das aber zu nichts anderem benutzt werden soll. Darin kocht man die neuen Deckgläschen in reinem Wasser auf und gibt ganz zuletzt einen Schuß Alkohol hinzu, um alle etwa vorhandenen fettigen Bestandteile zu lösen. Man läBt dann die Deckgläschen im Wasser soweit abkiihlen, daB man sie anfassen kann, und poliert dann rorsichtig - da die Gläschen sehr dünn sind und leicht zerbreehen - jedes einzelne Deckgläschen, bis es ganz trocken und blank ist. Das Tuch, welches man zum Putzen nimmt, muß gesäunt und von glatter Leinwand sein, damit keine Fusselchen auf den Deckgläsern bleiben. Zuletzt poliert man jedes einzelne Deckgläschen mit japanischem seickempapier naeh; dieses haltbare, nicht fasernde Soidenpapier ist in den Gesehäften für medizinische Bedarfsartikel zu liaufen.

Auch das Reinigen der Kanülen erfordert Sorgfalt; sie müssen vor und nach Gebrauch ausgekocht und getrocknet werden; es darf sich kein Rost bilden. 
An Metallinstrumenten sind außer den für jede kleine Tieroperation ïblichen, noch besondere Scheren, Pinzetten oder Klammern erforderlich, die für jede Operation, je nach der Tiergattung, verschieden sind und später noch beschrieben werden.

Fïr das Ansetzen der Gewebekulturen sind für jeden Praktikanten unbedingt nötig:

I kleine auseinandernehmbare Schere,

- Nadeln, ganz aus Metall,

2 kleine Lanzetten, ganz aus Metall,

1 sehr kleine Pinzette ohne Rillen mit stumpfen Enden $(6-8 \mathrm{~cm}$ lang),

1 KüHnsche Pinzette.

Die Deckgläser stellt und reinigt jeder Praktikant selbst.

Sämtliche Glasinstrumente sind von der Firma ,Labag“, LaboratoriumsAusrüstungsgesellsehaft, Gebrüder Mueneke \& Klönne \& Müller, Berlin NW 40, Platz vor dem Neuen Tor la (Einzelverkauf: Luisenstraße 49), zu beziehen.

\section{Veränderung der Zellformen in verschie- denen Medien.}

Die zuerst zu lösende A ufgabe ist die Züehtung der Haut des erwachsenen Frosches in versehiedenen Medien, um die Veränderungen der Zellform in ihrer Abhängigkeit von der Konsistenz des Mediums kemnen zu lernen. Die Froschbaut soll in folgenden Medien gezüchtet werden:

a) in Froschplasma, in Hühnerplasma;

b) in Ringerlösung, in Augenkammerwasser und verschiedenen Kombinationen dieser Medien.

In drei verschiedene, zeitlich getrennte Aufgaben zerfällt unsere Arbeit. Wir haben:

A. Die Kulturmedien zu gewinnen;

B. Die Kulturen anzulegen und zu pflegen;

C. Die Kulturen zu beobachten und die auftretenden Erscheinungen zu deuten.

Alle Arbeiten sind gleich wiehtig.

Aus didaktisehen Gründen empfiehlt es sich, mit der Züchtung vonKaltblïtlergeweben zu beginnen, weil die Hände des Praktikanten sich erst einarbeiten müssen und weil bei Kaltblütlern die Plasmagewinnung leiehter ist als bei Warmbliitlern. Trotzdem der Froseh sieh seiner Kleinheit wegen nicht empfiehlt, ist es nicht zu vermeiden, die einheimischen Frosehspezies zu verarbeiten, da Frösehe von allen Wirbeltieren am billigsten sind.

\section{A. Gewinnen der Kulturmedien.}

Die Bereitung des Froschplasmas macht zuerst Schwierigkeiten, weil das Blut steril aus dem relativ kleinen Herzen eines einheimischen Frosches entnommen werden mul. Eine Stunde vor der Operation 
werden die Zentrifugenröhrehen, die Röhrehen für das gewonneno Plasma und die Pipetten zur Plasmaentnahme mit Paraffin ausgekleidet. Man verfährt auf folgende Wrise:

Drei große Sehalen (s. Abb. I) werden sterilisiert und 5 Tüeher, ungefähr 45-50 cm im Quadrat, die aus kräftigen, nicht fasernden Stoffen verfertigt sein müssen. Es ist nötig, daß diese 'lücher gesäumt und absolut heil sind, damit keine Fasern stören. Hat man einen Dampfsterilisator, so ist es riehtig und rorgesehrieben, die Tïeher in ihm zu sterilisieren und die Sehalen in einem Troekensterilisator. Hat man keinen Dampfsterilisator zur lerfügung, so sterilisiert man die 'Tüeher rorsiehtig im Troekensterilisator. Jlan läßt die Schale ctwas abkühlen und nimmt sie halb warm heraus und stellt sie auf den Tiseh, auf dem man seine Vorbereitungen treffen will. Das zur Auskleidung benutate Paraffin, 4-26 Schmelzpunkt, muB am Tage rorher filtriert werden und zwar stets in Gefäßen, die nur füı diese Arbeit bestimmt sind. Ehe diese GefäBe in Gebrauch genommen waren, sind sie in Wasser ansgekoeht und cinen Tag in fließendem Wasser gehalten worden. Das Vaselin, dunkelgelbes sog. amerikanisehes, das zur Auskleidung der Spritzen bei der Blutentnahme gebraueht wird, muß aueh vorher filtriert werden und fraktioniert sterilisiert worden sein. Es ist praktiseh, sich vielleicht 2 Pfund im Autokłaven sterilisiertes Vaselin in größeren Glasgefäßen fertig zum Gebrauch hinzustellen, und dann kleinerc, auch vorher sterilisierte Gefäße für den jeweiligen Gebrauch zurechtzumachen. Wir brauchen das Vaselin nur, wenn wir die jetzt zu beschreibende Methode der Blutentnahme anwenden. Sollten wir das Blut mit Hilfe eines Glashebers direkt in die Zentrifugenröhrehen spritzen, wie es bei manehen Tieren möglich ist, so fällt für diesen ersten Teil der Mediumgewinnung der Gebraueh des Vaselins ganz fort (s. S. 1.), Abb. 8).

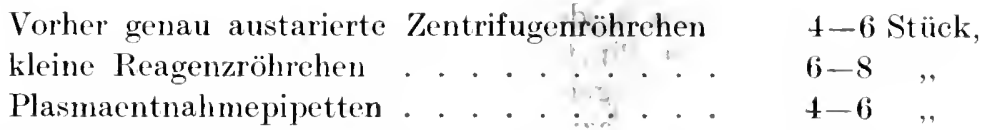

werden in das halbflüssige Paraffin gelegt, nachdem sie vorher nach Vorsehrift vorbereitet worden sind (s. S. 5). Man läßt sie ein paarmal aufkochen und schwenkt sie mit einer ausgeglïhten Pinzette oder einer großen Schere im Paraffin. Es ist dringend zu raten, nicht von der Arbeit fortzulaufen, da bei der leichten Entzündlichkeit der Paraffingase sehnell eine Entzündung eintreten kann. Falls ein Abzug vorhanden ist, wird natürlich nur zu raten sein, unter diesem beim Paraffinieren zu arbeiten. Während des Erhitzens hat man auf einer erhöhten Rolle ein steriles Tueh aus der Sehale ausgebreitet, das als Widerlager der ausgekleideten Röhrehen dient. Haben die Röhrchen tüchtig aufgekoeht, so nimmt man zuerst, nachdem man jecles einzelne noehmals in Paraffin tüehtig umgesehwenkt hat, die Zentrifugenröhrehen einzeln heraus und legt sie zum Ablaufen auf das Widerlager. Am bequemsten ist es, wenn man die Flanme mit dem kochenden Paraffin und dlas Widerlager auf demselben Tische hat. Naehdem nun die Zentri- 
fugenröhrchen gut mit Paraffin ausgekleiclet sind, werden sie noeh warm in clas vorbereitete Tuch gepackt. Die T'ïcher sind in Form ron Tasehen eingeschlagen, so dab die Zentrifugenröhrehen in die Tasche eingelegt werden können (Abb. 3). Es ist darauf zu achten, daß die Röhrehen nieht aneinander stoßen, weil sie dam, sowie das Paraffin erkaltet, aneinander kleben. Die Röhrehen werden damn zusammen eingeschlagen, das 'Tueh mit einer Steeknadel zusammengesteekt und hierauf das Tueh in einer sterilen Schale sofort auf Eis gestellt. Der gleiche Vorgang wiederholt sich nun für die Reagenzröhrehen und für die Pipetten. Es ist darauf zu achten, daß die Pipetten nicht verstopft sind. Es ist gut, sie beim Auskleiden zuerst mit der Spitze nach unten zu kehren und sie dann umzudrehen, so daß von den Spitzen aus das überschüssige Paraffin abläuft. Auch sie werden auf das Widerlager, das nach jeder einzelnen

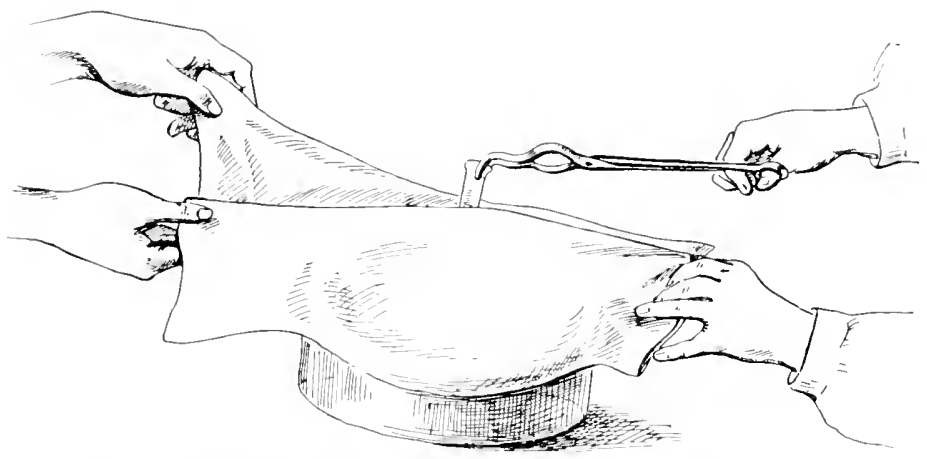

Abb. 3. Tasche, in welche die it Paraffin ausqekleideten Zentrifugenröhrchen hineingeschoben werden. Siehe Text S. 8 .

Operation, also Auskleicen der Zentrifugenröhrehen, der Plasmaaufnahmreöhrehen und der Pip.tten, mit einem neuen, sterilen Tuch bedeckt wird, zum Ablaufen gelegt und dam schnell, in ein Tuch eingepackt, auf Eis gestellt. Dazu passende, ausgekochte Gummihütchen werden aufgepaBt und bereit gestellt. Sie sollen frei ron Wasser sein.

Noch wichtiger als das Auskleiden der Glasinstrumente ist das Ausvaselinieren der LuERschen Spritze. Dieses stellt an die Kunstfertigkeit der Praktikanten einige Ansprüche. Das Vaselin ist, wie üblich, verflüssigt worden. Während dieser Zeit hat man die LuERsche Spritze in Sodawasser ausgekoeht, naehdem man die zu brauchenden Kanülen ausgeprobt hat. Man prüt jede Kanüle auf ihre Schärfe und Glätte und reibt sie unter Umständen mit Sehmirgelpapier ab oder sehleift sie auf einem Schleifstein mit Rillen.

Für jede Tierart sind besondere Kanülen erforderlich. Alle sollen ein ziemlich weites Lumen haben, da das Vaselin sonst die Öffnungen verstopft. Für den Frosch werden kleine, kurze Kanülen gebraucht, für das Huhn etwas feinere, längere, sehr spitze Kanülen, für das Meersehweinchen etwas dickere, ein wenig abgestumpfte Kanülen, für die Ratte die gleichen Kanülen wie für den Froseh. Man hat auch Spritzen 
mit ausweehselharem Konus, doeh lasien sich diese nicht so gut auskleiden und reingen. Es ist gut, mehrere Spritzen auszurasclinieren, so dab man bei der Blutentnahne öfter sine neur, ciscokählte spritze gobrawchen kann.

Die Abbildungen 4-7 zoigen die nacheinander folgenden Stadien der Blutentnahme beim Frosch, Rana esculenta.

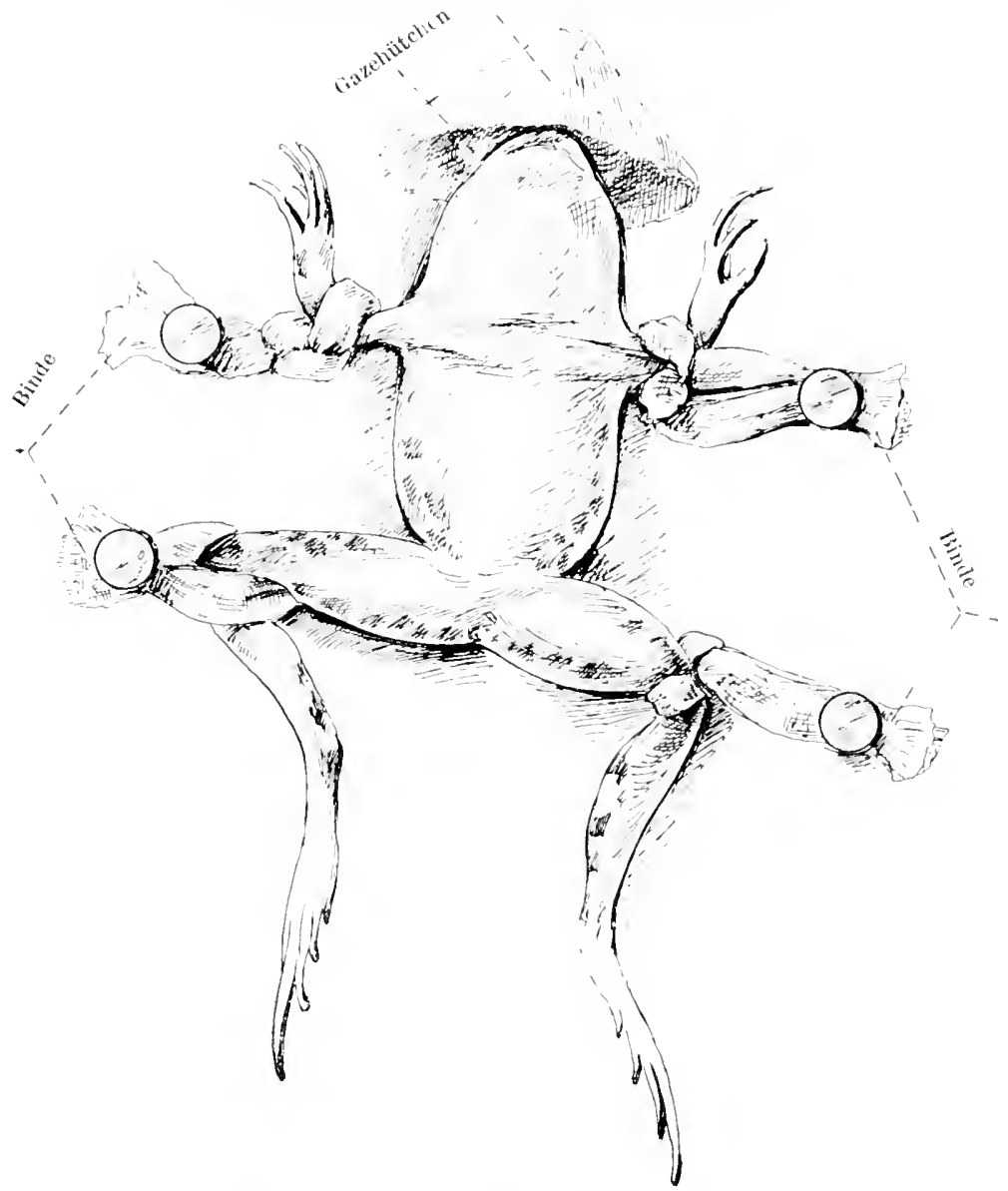

Abl. 4. Des zur Narkose vorbereitete Froseh ist festgebunden. Original, siehe Text.

Die Spritzen werden mit Vaselin ausgekleidet, das man, wie schon früher besehrichen ist, gefiltert und im Autoklaren sterilisiert hat. Während der Zeit, die zum Auflösen des Vaselins, das auf einer Schüssel mit Sand gesehieht, gebraucht wird, sind, wie gesagt, die Spritzen in Sodawasser mitsamt den Kanülen, die vorher aufgepaßt und auf ihre Durehlässigkeit probiert worden sind, ausgekocht. Man spritzt das anhaftende und in der Spritze sitzende Wasser gut und griundlich 
aus, ohne aber die Spritze zu sebr abkïhlen zu lassen. Man zieht nun ein wenig des flüssigen Vaselins in die Spritze ein und läBt es wieder zurüekfließen und tut dasselbe ein paarmal hintereinander, um alles Wasser aus der Spritze zu entfernen. Das mit Sodawasser vermischte Vasclin lïBt man nicht das erste Mal beim Ausspritzen wieder in das Vaselingefä $B$ fließen. Sodann zieht man wieder ein Teil Vaselin in der Spritze hoch, hält nun die Spritze mit der Kanüle nach oben geriehtet und zieht den Stempel langsam zurüek; das Vaselin läuft auf diese Weise durch die ganze Spritze. Man drückt nun don Stempel leise nach oben, indem man ihn hin- und herdreht, so daß ringsum an den Innenseiten der Spritze alle Stellen mit Vaselin dïnn bedeckt sincl. Zuletzt spritzt man das Vaselin zurück in das Gefäß und zieht noch einmal ein klein wenig frisehes heißes Vaselin in die Spritze, mit dem man besonder's die Kanüle auskleidet, was schnell gesehehen muB, damit das Vaselin heiß und flüssig beim Hoehziehen bleibt, sonst verstopft sich die Kanüle sehr leieht. Ist alles gut ausgekleidet, so läBt man den Stempel ein wenig zurüeksinken, soweit er von selbst gleitet, und legt die so zureehtgemaehte Spritze in einer sterilen Sehale auf Eis. Die Lüeke, die dureh das Zurïekziehen des Stempels entstanden ist, läBt einen Luftraum zwisehen Kanüle und Stempel bestehen, der das Zusammenkleben verhindert, auBerdem hat man beim Ingebrauehnehmen der Spritze diese Luftsehieht, die ja steril ist, um sie dureh die Kanüle zu stoßen, ehe man in das Herz einsticht. Es passiert dann nicht, daß man das Herz infolge der verschlossenen Kanüle zerstieht und das strömende Blut nieht in die Spritze bekommt. In die Sehale, die zum Aufbewahren der ausgekleideten Kanïlen dient, lege man besser ein steriles Tueh, das man faltet, um die Spritzen zu stützen. Die Spritzen liegen darauf ruhiger als auf dem glatten Glasboden.

Für die Plasmagewinnung selbst wählt man zur Operation mögliehst große Tiere und läßt sie sieh vom Händler friseh gefangen bringen, denn Tiere, die lange im Zimmer und ohne Nahrung gehalten worden sind, haben für die Plasmagewinnung zu wenig Blut.

Der Froseh wird vor der Operation gut abgeseift und unter fließendem Wasser ordentlich abgespült. Man spannt ihn dann auf einem Kork-oder Holzbrett auf (Abb. 4, siehe S.9). Um zu vermeiden, daB unnütz Blut fließt, soll man auch nicht, wie üblieh, die Beine mit Nadeln ansteeken, sondern sie werden mit Verbandstoffstreifen festgebunden und diese erst angesteekt auf dem Brett. Die Hinterbeine werden einzeln oder zusammengebunden befestigt, die Enden der Binde sehneidet man kurz hinter dem Knoten ab und nagelt dieses Ende mit einer Kopierzweeke gut fest. Die Beine darf man nicht zu loeker zusanmenbinden, sonst maeht sich der Froseh aus der Bandage frei, wiederum darf nieht $\mathrm{zu}$ fest angezogen werden, da man damn das Blut staut. Die Vorderbeinehen umbindet man, ein jedes für sich, ebenfalls mit schmalen Binden und steekt sie ausgebreitet links und reehts fest auf das Brett an. Auf diese Weise hat der Frosch eine gute Lage für die Operation; auf dem Rüeken, Hinterbeine zusammengebunden, Vorderbeine ausgebreitet aufgesteekt. Wenn man dieses Aufspannen geschiekt maeht, liegt das Tier meist 
schr ruhig, daß es nur einer schr sehwachen Narkose beim Einsehneiden bedarf. Dies ist für die spätere Züchtung von Wert: starke Chloroformnarkose hemmt das Wachstum des Gewebes, das später in das gewonnene Plasma eingepflanzt wird.

Man bedarf beim Froseh nur wenig Instrumente beim Operieren: 2-3 Pinzetten, 1 - o größere zum Festhalten der Haut beim Einschneiden, I kleinere mit stumpfen Enden, die zum Festhatten oder besser als Widerstand für das Herz dienen soll, 2-3 Péansehe Klammern, 2 Knopfseheren (eine größcre für die äubere Haut, eine kleinere zum Öffnen der Körperhöhle).

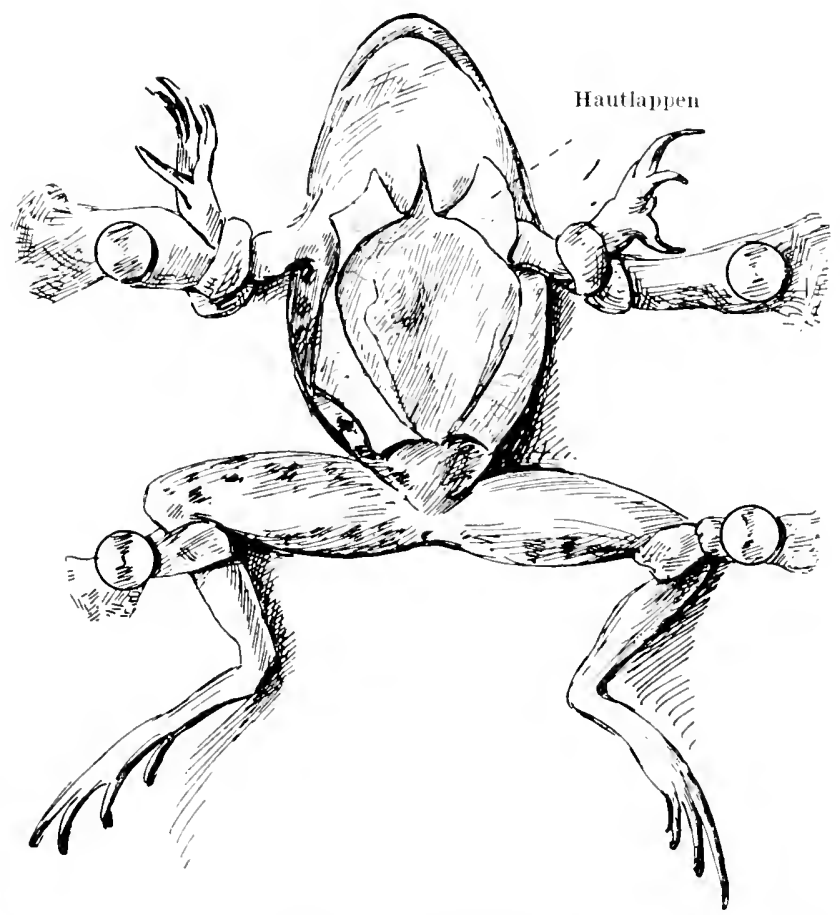

Abb. 5. Der narkotisierte Frosch zeigt die Freilegung der ventralen Muskulatur. Original, siehe Text.

Die Glasinstrumente müssen vor der Operation wenigstens $1 / 2$ Stunde auf Eis gekïhlt worden sein. Während die Metallinstrumente koehen, füllt man ein größeres und 3-4 kleine Gefäße - etwa Wasscrgläser mit gehaektem Eis und stellt sie bis zum Gebrauch wieder auf das Eis zurück.

Bevor man mit der Operation beginnt, muß der Frosch eine leiehte Narkose bekommen, die nur, wie sehon erwähnt, so sehwaeh sein soll, daß der Froseh das Einsehneiden nieht fühlt und still liegt; ganz kurz vor dem eigentliehen Öffnen der Leibeshöhle soll man die Narkose beginnen. Einige Operateure narkotisieren überhaupt nieht. Man öffnet 
dann dem Frosch das Maul und spert es dureh einen eingesebobenen Keil weit anf, die starke Atemtätigkeit hört dann auf und das Tier liegt so still, dal.3 man ohne Narkose operieren kann. Sobald das Tier ganz ruhig liext. lreht man mit einer Pinzette die Bauchhaut hoch, sehneidet mit dem spitzen Ende der Knopfsehere einen kurzen Sehnitt ein und öfnet dann die äufere Haut der Körperhöhle durch einen Mittelsehnitt,

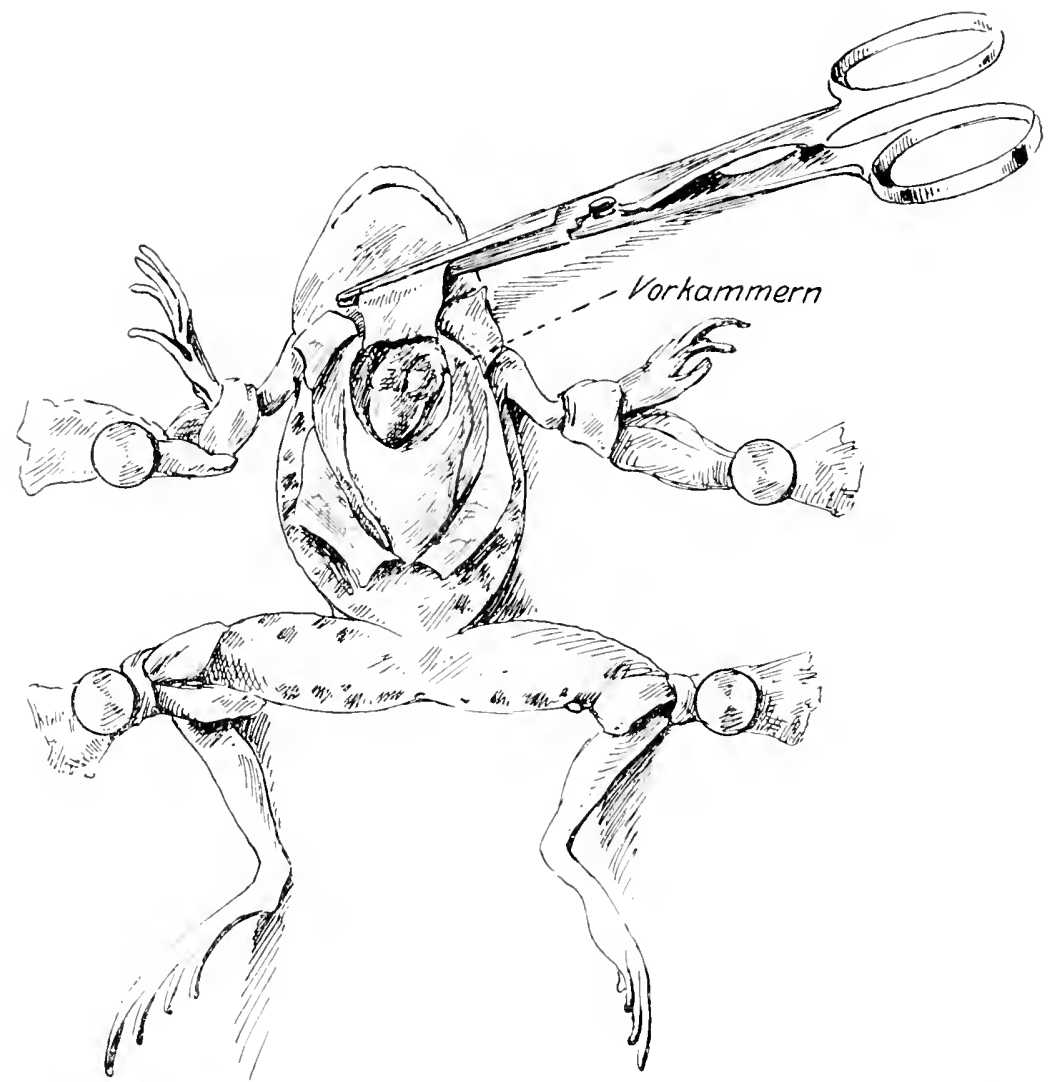

Abb. 6 zeigt die öffnung der Körperhöhle, besonders ist auf die Form des Einschnittes zu achten. Original, siehe Text.

indem man das stumpfe Ende der Schere nach unten hält, um kein Gewebe zu verletzen. Man sucht dann an den Hautlappen Stellen, an denen man diese senkreeht einsehneiden kann, ohne größere Gefä Be zu verletzen. Diese kleinen, seitwärts hängenden Hautlappen klemmt man mit je einer PÉaNsehen Klammer reehts und links fest, um die Fläche für das Einsehneiden in die Körperhöhle freizubekommen. (Abb. 5.) Naehdem man das Operationsfeld mit steriler physiologiseher Kochsalzlösung, die entspreehend dem Kaltblütlerblute nur $0,7 \% \mathrm{NaCl}$ enthält, zur Reinigung übergossen hat, sehneidet man in den Brustkorb ein. Mit 
einer Pinzette hebt man vorsichtig das Stemum auf und sticht stumpf mit der kleineren Knopfsehere behutsam ein, sehneidet darauf stumpf links und rechts rom Sternum die Rippen ein und klemmit diesen Deckel nach dem Kopfentle hin mit einer PÉAschen Klammer fest. Man sieht nun das Herz im Perikard ror sich liegen. (Abb.6.) Es sind bei der Plasmagewinmung zwei Personen nötig, eine, die das Tier narkotisiert und die gekïhlten GefäBe beranholt, und die andere, die in das Herz rinzustechen und das gewonnene Blut schnell zu zentrifugieren hat. Sobald also das Herz freiliegt es ist umnötig und zeitraubend, beim Froseh den Herzheutel zu öfnen -, sticht man mit der eisgekühlten Spritze (Abb. T) ein und zieht schnell möglichst viel Blut aus dem sehlagenden Herzen auf. Inzwischen muB die zweite Person die Zentrifugenröhrchen rom Eis herbeiholen, steril mit Stopfen versehlie Ben und sie, im Augenblick, wem das Blut hineingespritzt wirk, in das größere Gefäß bringen, das eine aus geklopftem Eis und Seesalz eben hergestellte Kältemischung enthält. Es darf in jedes Zentrifugenröhrchen mur soviel Blut eingefüllt werden, daß alles Blut in cter Kältemischung steht. Nun wird sehnell zentrifugiert, erst 3/4 Minute, dann 1 Minute, indem man zwischendurch die Röhrchen in neu bereitete Kältemischung in kleinere Giläser zum erneuten Kühlen stellt. Hat man eine Zentrifuge, in der die Zentrifugemröhrehen clirekt in Eis zentrifugiert werden könmen, so ist das Unterbrechen beim Zen-

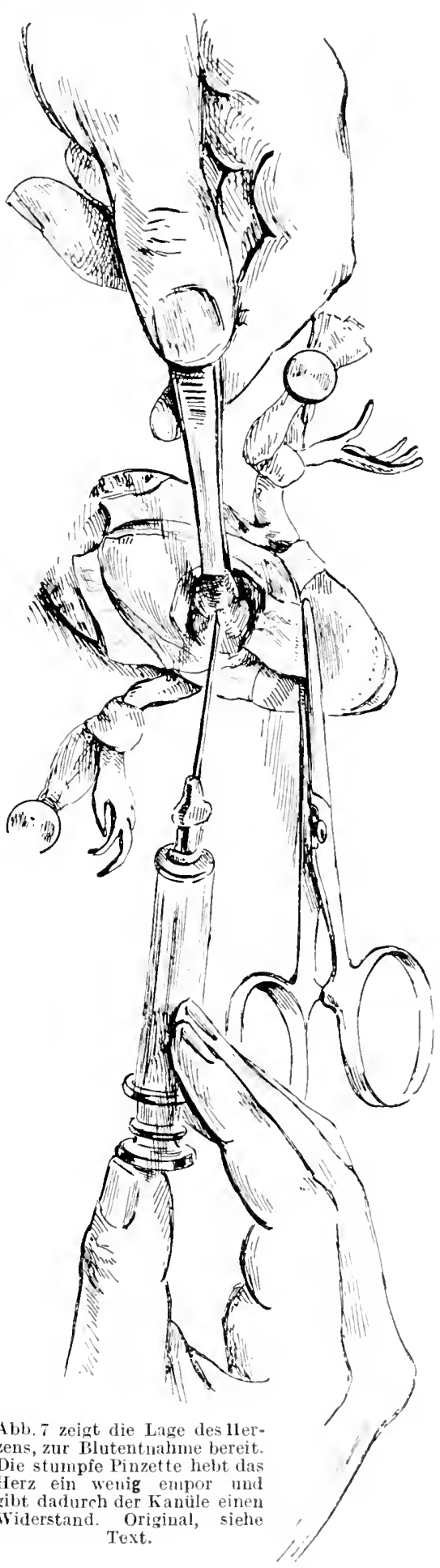


trifugieren nicht nötig. Jede weitere Blutmenge, die noch nach dem zuerst gewonnenen, aus dem wieder voll geschlagenen Herzen aufgezogen wird, muß wieder in die Kältemischung gestellt werden, so lange, bis sie zentrifugiert werden kann. Das Plasma setzt sich als helle Flüssigkeit über dem Blut in den Zentrifugenröhrchen ab und wird mit ebenfalls eisgekühlten Pipetten (siehe Abb. 2a S.5) abgesaugt und in die ebenso vorbereiteten Plasmaaufnahmeröhrchen gebracht. Diese verwahrt man zuletzt in einem Wasserglas, das ein wenig Kältemischung enthält, versieht dieses Glas mit Namen, Datum usw. und hält das Ganze bis zum Verbrauch im Eisschrank. Alle nötigen Handgriffe, auch das Öffnen des Tieres, müssen schnell und sicher geschehen, es darf kein Augenblick vergeudet, kein Handgriff umnütz gemacht, beim Operieren kein Blut unnütz vergossen werden. Alle notwendigen Gegenstände sollen einwandfrei vorbereitet und im rechten Augenblick zur Hand sein. Nan probiere auch kurz vor Beginn der Operation die Zentrifuge aus, damit sie nicht im rechten Augenblick versagt, auch soll man für die Pipetten, die man zum Absaugen des Plasmas benutzt, gut passende, ausgekochte Gummihütchen zureehtlegen und diese nur für diesen einen Zweck verwahren. Solange das Herz noch pulsiert und sich wieder mit Blut füllt, kann man auch versuchen, Blut aufzusaugen, jedoch ist das beim ersten Einstechen gewonnene das beste für die Plasmagewinnung; das später gewonnene Blut gerinnt oft in der Zentrifuge. Daß das, was man beim Abpipettieren gewinnt, auch wirklich Plasma ist, zeigt die flüssig zurückbleibende Substanz, sobald geronnener Blutkuchen im Zentrifugenröhrchen zurïckbleibt, hat man nicht Plasma, sondern Serum gewonnen.

Die für die erste Übung außer dem Frosehplasma kereit gestellten Medien und Waschflüssigkeiten sind: Augenkammerwasser, KaltblütlerRinger, physiologische Kochsalzlösung für Kaltblütler, und evtl. Lösung 753, eine kolloidale Ringerlösung nach Lresegang an Stelle der RingerLösung oder Locke-Lewis-Lösung fïr Kaltbliitler.

Die Gewinnung des Augenkammerwassers. Der Froseh wird, genau so, als ob man ihn zur Operation vorbereitet, ordentlich abgeseift und mit fließendem Wasser abgespült. Das Augenkammerwasser wird mit einer vorher ausgekochten Spritze entnommen, die eine sehr feine Kanüle haben muB. Ein kleines, steriles Gläschen zum Aufbewahren des gewonnenen Materials stellt man sich auf dem Arbeitstische bereit. Man sticht in das Auge schnell und leicht ein, am besten etwas seitlich in die Augenkammer, und zieht im gleichen Augenblick, in dem man die Kanüle einsticht, die Spritze auf. Durch das Platzen der feinen Augenhaut spritzt das Kammerwasser in einem feinen Strahl hoch auf, und nur durch sehr schnelles Aufziehen gelingt es, diesen mit der Spritze aufzufangen. Man spritzt das gewonnene Material in das bereitstehende Gläschen, das nicht mit Paraffin ausgekleidet sein darf, und muß in den meisten Fällen auch aus dem anderen Auge das Kammerwasser gewinnen, weil es sonst zu wenig für das Ansetzen einer größeren Anzahl 


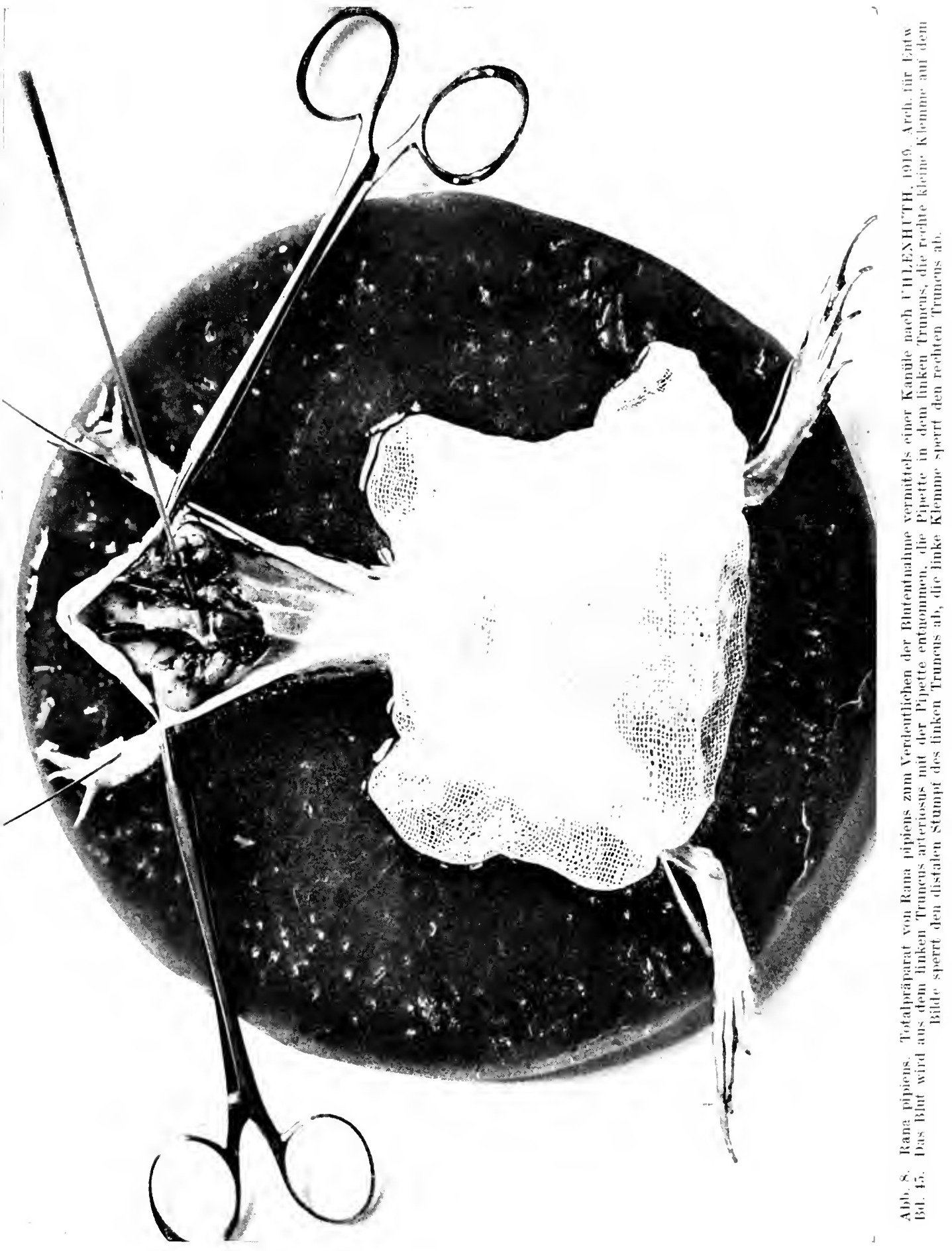


vom Kulturen ist. Die gebranchten Frösche setzt man wieder in den Behälter zuriick, da nach einiger Zeit sieh das Kammerwasser ernenert.

Loceke-Lewis-Lösung für Kalt. bliitler.

$\mathrm{NaCl} 0,7$

$\mathrm{K}(10,042$

$\mathrm{C}^{\mathrm{a} \mathrm{Cl}} \mathrm{Cl}_{2} 0.025$

$\mathrm{NaHCO} 0,02$

Dextrose 0.25

Aqua dest. 90,0
R ingersehe Lösung 1 ür Kaltblütler.

$\mathrm{NaCl} 0.7$

K Cl 0,025

( $\mathrm{aC} \mathrm{C} \mathrm{l}_{2} \mathrm{O}, 3$

Aqua dest. 100,0

Physiologische Kochsalz-

lösung für Kaltblütler.

$\mathrm{NaCl} 0,7$

Aqua dest. 100,0

Alle diese Lösungen sind ror Gebrauch zu filtrieren und im Dampltopf zu sterilisieren.

Es hat sich weiter bei Kaltbliitlermaterial noeh eine kolloidale Ringerlösung, ,Lösung 753* nach LIEsEGANG, gut bewälırt, besonders zum Auswaschen der Gewebe. Die Zusammensetzung dieser Lösung ist von den Merzwerken, Frankfurt a. M., nicht bekannt gegeben worden, man kann sie nur ron dort fertig beziehen. Sie wird in kleineren und größeren Ampullen gebrauchsfertig von den Merzwerken geliefert.

Natülich ist die elsen gesehilderte Methode der Plasmaentnahme nieht die einzige, die geült wird. Es gibt vicle andere. So nimmt UHLENHUTH eine paraffinierte Kaniile und stieht sie in den reehten Vorhof von Rana ein, naehdem die zuführenden Gefäße abgeklemmt sind (Abb. 8). Uhlenнuth nimmt eine gerade angespitzte Glaspipette, Thomson eine gebogene. Jeder hat tür sein bestimmtes Objekt die Wege zu finden. die ihn zum Ziele führen.

\section{B. Ansetzen der Kulturen.}

Sind alle Medien und Lösungen vorbereitet, so kann man mit dem Ansetzen der Kulturen beginnen. Die Glasgefäße, welehe man für das Ansetzen gebraucht, sind am besten kurz vor Gebrauch im Troekensterilisator $\mathrm{zu}$ sterilisieren, man sterilisiert $1 / 2$ Stunde und läßt vor dem Besehicken mit Nährmedien und Gewebestïeken die Glassachen wieder abkïhlen. Es sind folgende Glassachen nötig

Hohlgesehliffene Objektträger, die in Drigalskisehalen eingelegt werden, in jede Schale etwa 4-7 Stück, je nach der Größe; cine Anzahl Petrisehalen; eine Anzahl kleinere Doppelsehalen; eine versehlossene Hülse mit Pipetten zur Entnahme und zum Auftropfen der Nährmedien. Diese Pipetten sind (siehe Abb. 2 b, S. 5) für diesen Zweek allein zu gebrauchen und dürfen nie mit Farben oder Säuren in Berührung kommen. Man läßt sie passend für die Plasmaröhrehen zureehtblasen, so daß die 
Kapillare der Pipette bis auf ten Boden des Plasmaröhrehens reicht und man jeden Tropfen des manchmal spärlichen Naterials aufpipet. tieren kann.

AuBerdem braucht man noch Deckgläser in genügenter Menge, die man in einer kleinen Doppelschale sterilisiert, nachrlem sie, wie vorher schon beschrieben worden ist, sehr peinlich gereinigt und geputzt sind,

Das Ansetzen der Kulturen sollte an einem 'Tisch geschehon, der nur für diesen Zweek verwendet wird. In einem Laboratorium, in tem dies nicht möglieh ist, muß man dann den Tisch, auf dem man arbeiten will, abräumen, reinigen und mit sauberem Papier bedecken, es dürfen keine Farben, Säuren ofler rerunreinigte Kulturen usw. in der Näle oder auf dem Arbeitstische selbst bleiben. Man stellt sich die oben aufgeführten Glassachen auf dem Tisch zureeht (Abb. I S. 4), auBerdem a uf einer Flamme (die möglichst mit sjarbrenner versehen sein soll) ein Sandbad mit einem kleinen VaselingefäB, cine Vaselinpipette, eine KüHxsche Pinzette, die allein von allen Instrumenten, welehe zum Ansetzen der Kulturen Verwentung finden, ausgeglüht werden darf, da sie nicht mit den Gewebestückchen in Berührung kommt. Alle anderen lnstrumente werden ausgekucht und zugedeckt auf den Tisch gestellt. An Instrumenten braucht man:

1-2 kleine Sicheren, die auseinander genommen werden können, zum Zerschneiden rler Gewebestücke; 1 -2 Lanzetten und einige Nadeln und eine feine Pinzette zum Zerzupfen der Gewebestückchen. Das Material, von dem man Kulturen ansetzen will, und das Nährmedium bleibt, bis man es zur Arbeit braucht, auf Eis. Das Vaselin wirel aufgelöst und dam ïber der klein gestellten Flamme stehengelassen. Die sterilisierten Glassachen und die Hülse mit Pipetten stellt man ebenfalls auf dem Tische, an dem man arbeitet, zureeht. Von dem abgeseiften und mit Ringer alogespülten Frosch schneiden wir ein Stïck Rückenhaut scharf heraus. Die Rückenhant ist geeigneter, da die Bauchhaut durch den Reichtum an Bindegewehe zu lederartig ist.

Die Gewebestücke, die man zur Gewebekultur verwendet, verwahrt man in einem sterilon Schälchen, evtl, in Risgerseher Lösung, wie die Froschhant auf. Naehdem die Gewebe aus dem lebenten 'Tierkörper entnommen sind, bringt man sie schnell auf Eis, damit die Funktionen des lebenden Gewebes bis zum Einsetzen in das Kulturmedium unterbrochen werden und erst durch den Aufenthalt in dem Kulturmedien wieder in Funktion treten. Das Auswaschen der Gewebe in Ringerseher Lösung vor dem Eimbringen in das Medium geschieht, damit diese vollkommen steril in das Medium gelangen und vielleicht anhaftende Blutkörperchen entfernt werden.

Nachdem man die Vorarbeiten beendet hat und alle nötigen Dinge handlich bereit gestellt hat, hegimnt man mit dem Einsetzen der Gewehe, wobei man bei jeder Art von Geweben streng alle aseptischen Regeln beachten wnd beim Warmblïtlermaterial besonders schmel] arbeiten muB, um die Funktion der Gewebe nicht zu lange zu unterbrechen. Bei Kaltblütlern, die später ja in Zi m me remperatur wachsen, 
ist diese Reged insoweit wichtig, als dureh schnelles Arbeiten gröbere Möglichkeiten gegehen sind, steril zu arbeiten. Die Gewche, ron denen jecle Art einen besonderen Molus der Entuahme und Vorbehandlung erfordert, werden also mit lixaERscher lösung ansgewaschen und mit sterilen Instrumenten zu sehr kleinen stäckchen zersehnitten. Von dieson kleinsten stïckchen bringt man die betreffenden, die man zur Gewebekultur verwenden will, nochmals in Rivaresche Lösung. Die Deckgläser breitet man mit einer ansgeglïhten KüHxschen Pinzette in Potrischalen aus, wohei man die Schale so wenig wie möglich öfnet. So viele beckgläser legt man in eine Petrischale, wie man in der dazn gehörigen brigalskischale objektträger ausgebreitet hat. Auf diese Decekgläschen bringt man die ausgewaschenen, in frischer Ringerlösung liegenden fiewehestückchen, die nun so sehnell wie möglich mit dem Nährmedium heschickt werden müssen. Nienals dürfen die Gewehestïckchen trocken werelen. Wenn Plasma als Nährmedium verwentlet wird, muß man sorgen, dals es bis zu dicsem Augenblicke, in dem man es braucht, aufgetaut ist. Es muls daher, wemn man mit den Kulturenansetzen beginnt, aus der Kältemischung herausgenommen mol in einem trockenen Gefäß auf den Arbeitstisch gestellt werden. Genügt dies noch nicht, um das Plasma aufzutanen, so hält man es am besten eine Zeitlang in del warmen Hand. Bei Verwendung von anorganisch bereiteten Nährmedien ist dies nicht nötig, weil diese flüssig sind und gleich verwondet werden können. Für jedes Nährmedium - falls man sich bei einem Male Kulturen ansetzen versehiedener bedient hat man eine neue Pipette zu verwenden. Nan darf nie mit derselben Pipette ron einem Nährmedium ins andere hincingehen. Die Pipetten sollen gutsitzende ausgekochte Gummihüchen haben, damit sie besonders hei Plasma - geringe Mengen von Nährmedium noch aufsaugen könmen. Dic Stückchen sind jetzt also auf dem Deckglas. und ein jecles ist mit einem Tropfen Nährösung beschickt. Alle Handgriffe haben dabei so zu geschehen, dab die Petrischale möglichst wenig geöffnet wird; beim Hochheben des Deckels verfährt man am besten so, daB die seite, die dem Arbeitenden zugekehrt ist, bedeckt bleibt und der Atem die Kulturen nicht treffen kann. Die Schale wird, wenn alle Stïckchen mit Plasma orler anderem Medium beschickt sind, zugedeckt auf die heite gestellt, und man versieht jetzt die Objektträger, die man zum Auflegen der fertigen Deckgläschen verwendet, mit Vaselinringen. Mit einer nicht zu feinen Pipette umgibt man die Vertiefung der Objektträger mit einem Rande ron heißem Vaselin, das nicht so flüssig sein darf, daß es breit in die Verticfung des Objektringes amsläuft. Es mub rings um die Vertiefung einen festen, sehmalen Wall bilelen, der die Deekgläser und damit die Kulturen gegen die Aubenluft abschließt und dadurch das Austroeknen der Gewebe verhütet. Die Deckgläser mit dem im Nährmedium liegenden Material faßst man mit der ansgeglühten KüHsschen Pinzette an, so daß der 'Tropfen sich oben befindet, man drückt die Sichnäbel der Pinzette fest zu und kehrt die Hand sehnell um und setzt das Deckgläschen mit rem jetzt in (ler Mitte als spitzer Tropfen nach unten hängenden Material auf den Vaselinrand des Objekt- 
trägers. Das Gewehestïck hängt num in der Höhlung des (ohjekt trägerss. nach oben dureh das l)eckglas mut ringsum elureh ten Vascelinand gegen das Austrocknen mel Eindringen ron Luftrerumreinigungen geschüzt. Zuletzt sieht man alle fertiggestellten Kulturplatten nowhmals nach, flückt noch einmal fest an den Vaselinmand an ofler bessert ihn, wo es nötig erscheint, noch aus. Be.j War mblüt les material verführt man dabei so, dab man jede fertige Platte auf einige Augenblicke in den Thermostaten stellt, sehon, um die Gewehe nieht so lange der Aubentemperatur auszusetzen. und tann auch, weil sich in tem wiecler weichergewordenen Vaselimante die Deckgläser hesser festdrücken und dieser sich besser nachfüllen läbt. Sehr häufig ist ressucht worden, die Methode des hängenten Tropfens insoweit mmzuändern, dab man in Röhrchen oder in gröbese Kammem, die luftelicht mit Vaselin verschlossen werden, Gewelestücke zur Züchtung bringt. Dicses Vurfahren ist dann zu empfehlen, wem man das wathencle Gewebe nicht unter dem Mikroskop mit starken Vergröberungen beobachten will und wenn man Wert darauf legt, so große Stïcke wie möglich zu züchten. Dem Lurfang der Stücke ist eine Grenze gresetzt, die nach der Gewebeart variiert. Lockeres Gewebe. wie Drïsengewebe, in dessen Spalten das Nähruedium leicht eindringen kann, kann in größeren Stücken gezüehtet wercien, wie z. B. das sehr dichte Gewebe der Herzklappe. Für spätere Implantations- oder Immunisations-Experimente kam man klcincre Röhrehen oder kleinere Kammen, in die man melnere Stücke nebeneinander pflanzen kann, benutzen. Es lassen sich aber bei ciniger Coung ea. 200 Kulturen in 2 Stunden auch nach der Deckglas-Methode anlegen.

Alle Pijetten, die gebraucht worlen sind, müssen sofort in Gefäße mit kaltem Wasser gestellt werelen, da das Plasma sonst an den Innenwänden festhängt und man dieses nur sehr schwer losbekommen würde. Jan soll alle Gefäße, die bei dem Ansetzen der Kulturen rerwendet werden, nach Gebrauch stets in kaltem Wasser verwahren. Zum Reinigen werden sie in reinem Wasser kalt angesetzt und zum Kochen gebracht, soweit es dïnne Glassachen sind, die stärkeren Schalen wäscht man heiß aus. Kein Gefä B, das zur Züchtung von Kulturen benutzt wird, darf nebenher zu anderen Zwecken genommen werden. Farben und Säuren mïssen streng davon fern gehalten werden. Nur von absoluten Sauberkeit, strenger Trennung der Züchtungsgefäße ron anderen, guter Haltung der Metallinstrumente, die bei noch feineren Arbeiten von Mikroglasinstrumenten ersetzt werden (SPEMANx in Abderhaldens Handbuch der biologischen Arbeitsmethoden, . Mikro-chirurgische Operationstechnik", Bd. $Y$, Teil 3, Heft 1 , S. 15-17), und beim Ansetzen der Kulturen rom schnellen, sauberen Arbeiten hängt ein beträchtlicher 'Teil des Erfolges ah.

\section{Beobachten und Pílegen der Kulturen.}

Ehe wir an unsere eigentliche Aufgabe herantreten, zïchten wir zuerst einige Stiickehen Froschhaut in Froschplasma und Augen- 
kammerwasser allein (1. Ubung), um die vielen Einzelheiten des Ansetzens der Kulturen uns ganz zu eigen zu machen, um Schnelligkeit später sehon erworben zu haben und um fähig zu sein, bei dem ersten ausgedehnten Experiment die ron jedem Praktikanten begangenen individuellen Fehler auszumerzen. Auch ist soviel erst am lebenden Objekt ganz am Beginn der Zïebtung zu beobachten und das Einsehen in das lebende Objekt zu üben, da ja leider das
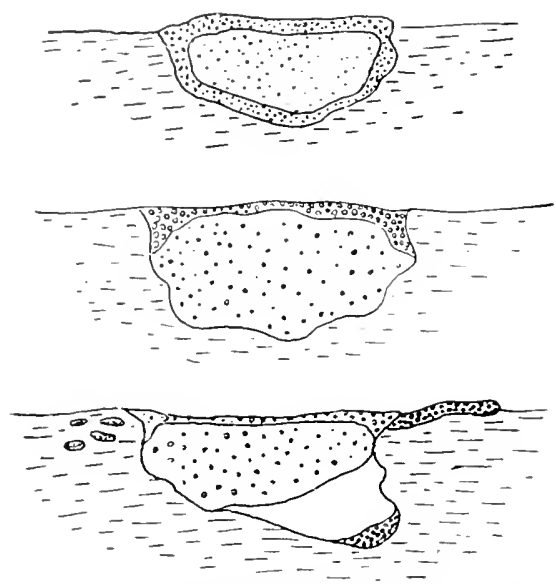

Ab). 9. Schnitt turch eine Gewebekultur. Ausbildun und Veränderung der Wachstmmszolie und Bildumg ther in das P'asmamedium eindringenden Zellstränge. Nach Champy 1!13. La presse médicale.

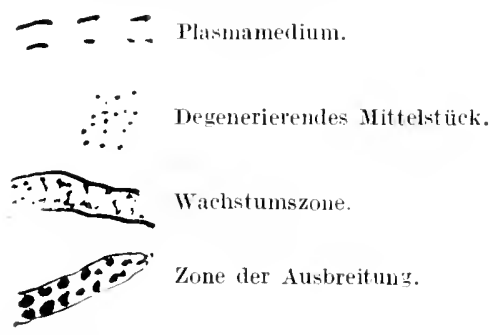
Das Hinzufügen des Augenkammerwassers ließ den halbflüssigen Plasmatropfen schnell gerimnen, dies kamn unter Umständen allein schon durch die Hinzufügung des Gewebestüekchens geschehen. Das Augenkammerwasser ist dem Muskelextralit, der häufig frïher verwendet wurde, vorzuziehen, weil es leichter steril gewonnen werden kamn und wie dieser eine gerinnungsfördernde Wirkung auf die im Plasma noch enthaltenen fibrinogenen Substanzen ausiibt.

Der Tropfen ist halbstarr und mit einem der Tertiefung des Objektträgers zugekehrten Oberflächenhäutehen versehen, das ein Aneinanderfließen des 'Tropfens hindert, falls die Deckgläschen fettfrei sind. Staub- 
sicher in den Drigalskischalen, an einem nicht zu hellen Ort, werden die Kulturen in Zimmertemperatur aufhewaht.

Die sehematisehe Zeichnung lehrt (Abh.9S.20), was für Veränderungen wir zu erwarten haben, das Auswanden der Zellen, diesich teilen kömmen in Rundhof oder Sichleier, das Vordringen rom Zellschichten zuerst in alle Teile des Mediums, in die primäre Wachstumszone, und später ein Absterben ron Zellen in dieser und ein Vordringen ron Zellsehichten mehr zur Oberfläche des Tropfens in die sckundäre Wachstumszone In der llitte bleibt unverändert der nicht reichlich mil dem Medium in Berïhrung kommende Teil des Gewebestückehens, der meistens nekrotisch wird, falls dass Stückchen zu groß oder das Gewcbe zu fest ist. Bei der Froschhaut ist Nekrose des Imnern selten, bei Warmblütlergewebe häufig.

Es kamn nicht genug darauf hingewiesen werden, da B, ehe das Zü.chten der Froschhaut beginnt, alle Elemente der Froschlaut bis aufs genaueste studiert werden und daß bei der Züchtung die vorher er-

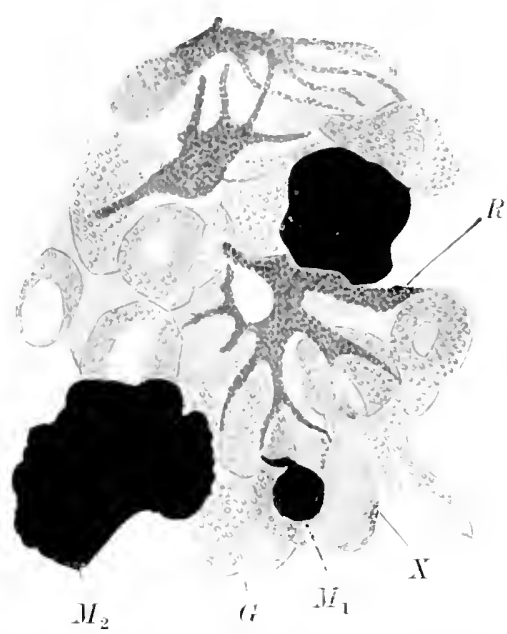

Ab. 1\%. Rana fusca nach W. J. SCHMIDT. 1920. (Auat. Hefte, MERK EL und BONNET, 58. Bu.) Rotzellen $(R)$, tielbzellen $(\boldsymbol{T})$, Melanophoren $\left(y_{1}\right.$ u. $\left.H_{2}\right)$ und Guanophoren $\left(G^{\prime}\right)$ aus ler Rückenhaut eines Weibchens (Balsamtotalpräparat). Die unter der Basalzelle gelegene schicht ist eingestellt.

kannten einzelnen Zellelemente, also hier Epithelzellen, Drüsenzellen, Basalzellen, kleine Melanophoren, große Melanophoren, Guanophoren, Lipophoren genau verfolgt werden. Die beigegebenen Bilder orientieren uns ausreichend über die einzelnen Elemente.

Man mache es sich zur un umstößlichen Regel, die zytologische Struktur des eingepflanzten Gewebes zuerst kennen zu lemen, hier also der Froschhaut. Die beigegebenen Flachpräparate, Abb. 10 und 11 , zeigen die einzelnen Bestandteile, wie sie bei Aufsieht uns entgegentreten, der Schnitt, Abb. 12, die Zellschichtenfolge der Frosehhaut.

Nachdem das eingepflanzte Stüek sich gut ausgehreitet hat, wird es gezeichnet und gemessen. Nach wenigen Stunden sicht man schon einige Basalzellen aus dem Rand sich hervorbewegen. Nach ein oder mehreren Tagen hat sich diese Schicht der Zellen vergrößert. Diese Neubildung oder der primäre Rand besteht aus Basalzellen in überwiegender Masse, kleinen Melanophoren und einigen wenigen Guanophoren. Ab und zu hat sich eine dem Bindegewebe eigene Chromatophore in das Plasmamedium gestreckt; man sieht deutlich die verzweigten Ausläufer, in denen sich die Pigmentkömer bewegen.

Schon gleich nach der Einpflanzung, aber auch oft später, kann sich ein Epithelhäutchen, das aus den oberen verhornten Schichten der 
Froschhant besteht und das schon vorgebiklet war, als rlieses Häutchen in das Medium gelegt wurde, lösen. Es hleilst ohne Wachstumserscheinungen in dem Nedium liegen: selbst wemn es in neues Medium ver-

L.

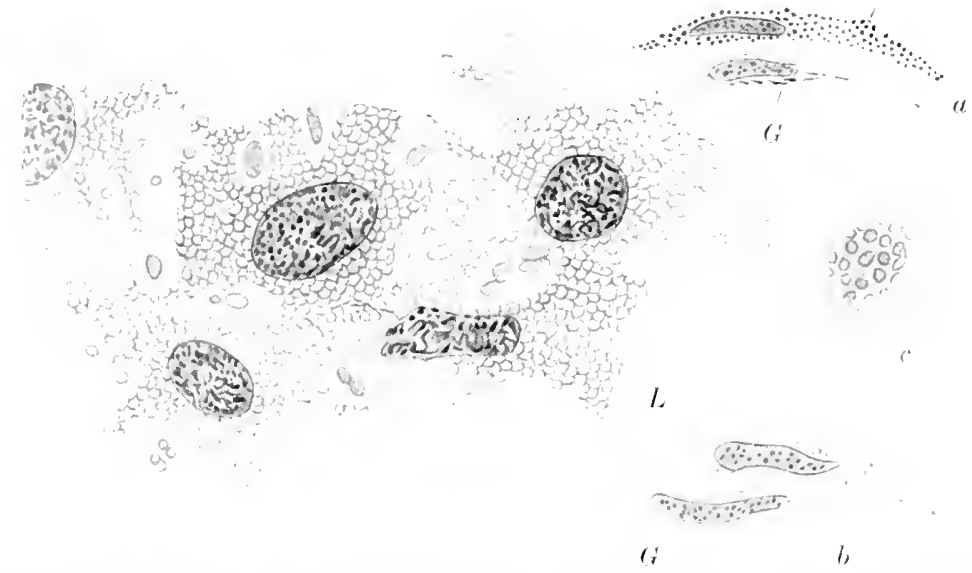

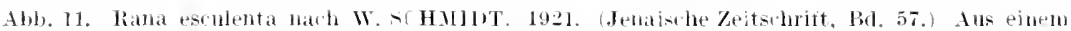
mit Flemmings temisch tixierten mol mit Palpenheims llethylgrim-Pyronin gefärbten Querschnitt der liükenhant. a u. $b$. Xantholenkisom im Durchschnitt; Kern der Guanophore (b) unt der Lipophore $(L)$. In den dianophoren die Kristalle, in der Lipophore (a) die Granula sicht.

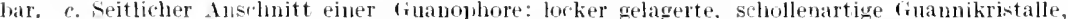
Fern matt durchshmmend, die Gruple von Gunnhhon nach einem mit FLEMMINGS Gemisch fixierten, mit polychromen llethylenblau mil bisin gefärbten Flachschnitt der Rückenhaut.

pflanzt wird, behält es seine Struktur und Form unverändert. Verhornte Epidermiszellen und kleine Melanophoren setzen es zusammen. Diese Häutung des explantierten Stückes kann sich wiederholen. Sie

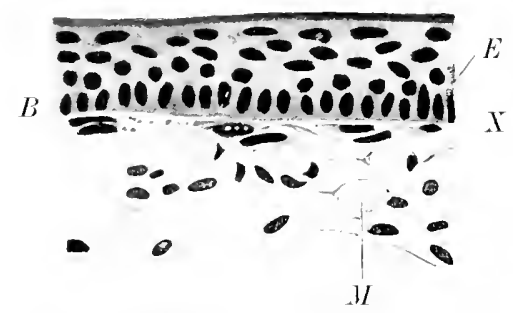

Ahb. 12. Rana esculenta nach W. J. SCHMIDT. (Arch. für Zellforsh. Bol. 19.) Querschnitt durch den oberen Teil der Haut Coter dem Evithel $\langle E)$ die subleht ter Xantholenkosomen (.X). darunter im Bimlegewebe J durch chlor gebleichte Melanophoren in Statimm der Ballung. entspricht einem dem Froschorganismus geläufigen Vorgang, der in der Kultur nur ïberstïrzter und in kürzeren Perioden sich vollzieht.

Während dor nächsten Tage der Züchtung erscheint nun auch der sogenamnte sckundäre Rand um das Explantat herum, während der primäre Rand aus mehreren Zellschichten bestand, breiten sich dieselben Zellarten, of thne Zusammenhang, in dem reiehlich zur Verfïgung stehenden Medium aus. Je älter die Kultur wird, je zusammenhängenter kamn diese Schicht werden, so dab sie während der nächsten Tage wic ein runder Schleier das Crsprungsgewebe umgibt.

Die Form der Zellen hat sich auch jetzt geändert. Wir züchteten dieses Stück ja in Froschplasma und Augenkammerwasser. Daher war es nicht nötig, vor acht Tagen das Medium zu weehsehn, vorausgesetzt, daß die Kultur nicht trübe erschien. Fand sich reichlicher Zelldetritus, 
so mußte das Medium sofort gewechselt werden. Dies geschicht. indem man tas Stückchen vorsichtig aus dem Nedimm herausnimmt, es in Ringerlösmng auswäscht und es damn wietler auf ein neues Deckgläschen mit nevem Medium einpflanzt. Is ist ratsam, als zweites Medium nicht sofort wiederFroschplasma und Augen. kammerwasser zu nehmen, sondern vielleicht das Stïck einen Tag in LOCKE-LEWIS-Lösung zu lassen, weil es sich hierdurch von allen anhaftenden Unreinigkeiten befreit, und es damn erst wieder in das gleiche Medium zu tun. Dieser Wechsel

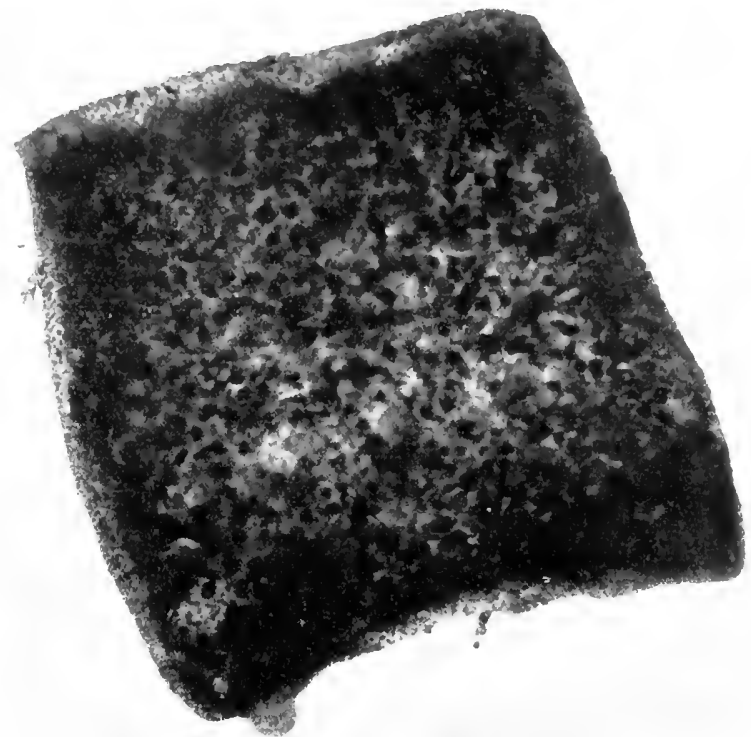

Abb. 13. Rana pipiens nach E. CHLExHITH. 1914. (Journ. exp. Ved., Vol, 20.) Riickenhatut drei stunden in Froschplasma, Hühnerplasma und Froschmuskelextrakt ausgepflanzt. Bildung der sog. primären Randschicht. Die kleinen Punkte in diesem sind die Zellkerne, die gröberen die kleinen Melanophoren. Photogramm nach gefärbtem Präparat.

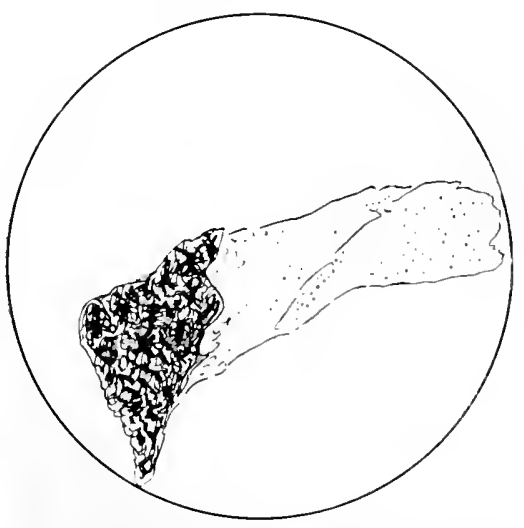

Abb. 14. Aluösung des Epiłlermishäutcheıs von der Obertläche der Froschihaut, kurz nachdem sie in Gewebekultur gesetzt ist. Skizze nach dem Leben. (R. GASSUL, 1922, irch. f. Entw. im Druck.)

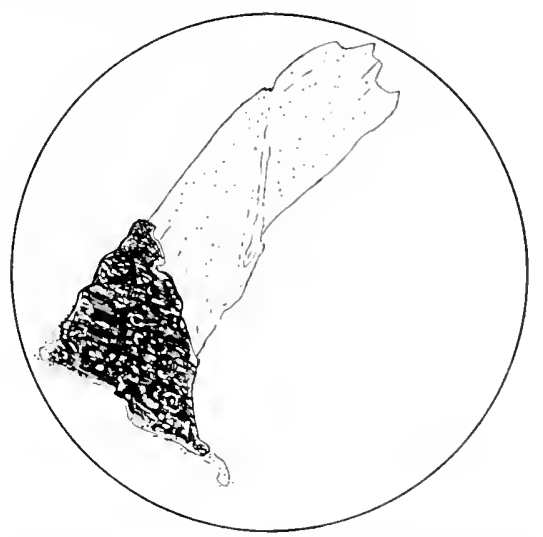

Abb. 15. Epłłermishäutchen, das unverïndert selbst nach Umptlinzung bleibt. Skizze nach dem Leben. (R. GASsUL. 1922.)

von Zïchtung und Reinigung kam sich nun je nach dem Aussehen des Stïckes wiederholen. Besser ist es, weniger oft $\mathrm{zu}$ wechseln, da mit 
jeder Änderung die schon gebildeten Zellen, soweit sie nicht mit der Ursprungshaut in Verbindung stehen, wieder zerstört werden. Hat sich sehon ein großer, sekundärer Hof gebildet, so kann man auch nur

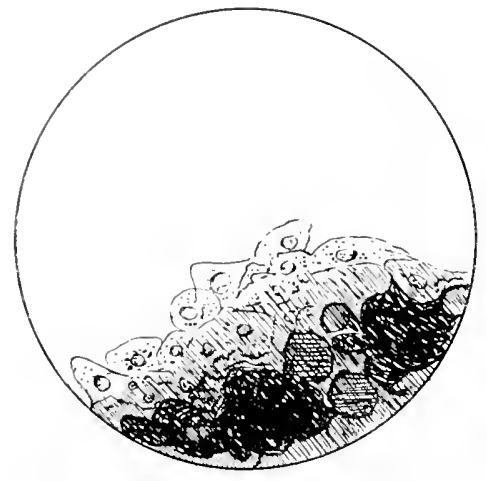

Abb. 16. Beginnende Epithelbewegung und Auswanderung der implantierten Froschhaut. Skizze nach dem Leben. (R. (iAsIT L, 192:.)

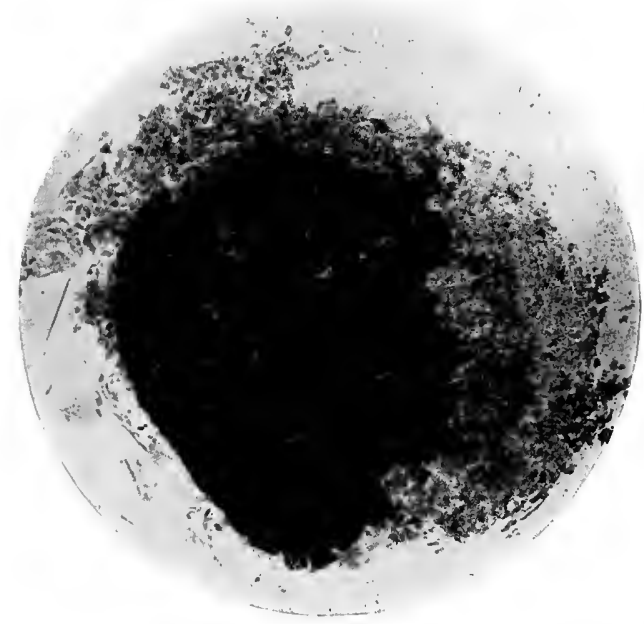

Abl. 18. Ungepflauztes Präparat, 4 Wochen alt, reichliche Zellvermehrung und Schichtenbildung. (IIikrophotogr. nach GASSUL, 1922. Gefärbtes Präparat.)

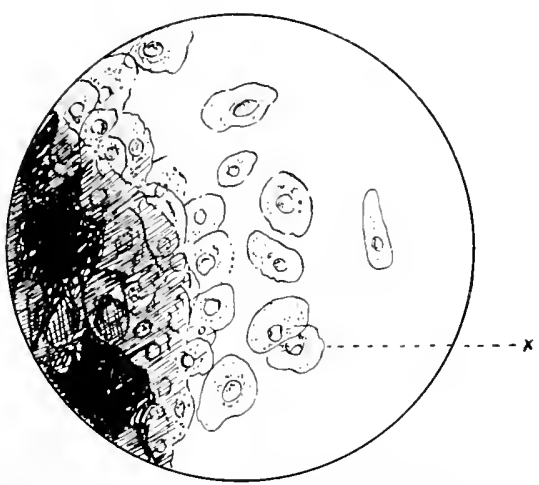

Abb. 17. Ansuewanderte Epithel- und Basalzellen im 4 Tage alten Präparat. Skizze nach dem Leben. (R. GASSUL, 1922.)

die Kulturflüssigkeit mit der Pipette absaugen und neue Nährflüssigkeit hinzusetzen. Die schönsten Präparate erzielt man gewöhnlich, wenn man nach dem ersten oder zweiten Tage weehselt und dann den Kulturen eine Woehe Ruhe gönnt. Will man die Frosehhaut woehenlang züchten, so muß man bedenken, daß naeh jedem unvorsichtigen Wechsel sich erst der primäre und dann der sekundäre Rand neu bilden, daß aber gewöhnlich die zweite Bildung nicht so reichlich ausfällt wie die erste. Das eingepflanzte Frosehhautstückehen ist während dieser Zeit durchsichtiger geworden, zum Zeichen, daß die Zellen, die den primären Rand bilden, zum Teil aus den Zellschichten stammen, welche die Haut des Frosehes bildeten.

In den ersten Tagen der Züchtung teilen sich diese Zellen amitotiseh. Später erst findet die Zellvermehrung durch regelrechte Mitosen 
statt, die deutlich im lebenden Präparat mit Immersion nachzuweisen sind und sich auch leieht färberisch (Ab). 19) darstellen lassen. Es empfichlt sich, Totalpräparate und Schnitt präparate in bestimm ten Abständen ron diesen Stiiekchen herzustellen, Konservierung mit ORTHseher Flüssigkeit und Färbung mit Hämatoxylin, und wenn man die Chromatophoren darstellen will, Fixierung mit 96 proz. Alkohol und Nachfärbung mit alkoholisehem Safranin sind zu empfehlen. Beim Konservieren mubs darauf geachtet werden, daß das Stückehen mit dem Medium zusammen konserviert wird. Es gelingt am besten, wenn man miteiner feinenKapillarpipette, nachdem man vorsiehtig den Tropfen mit dem Deekgläschen

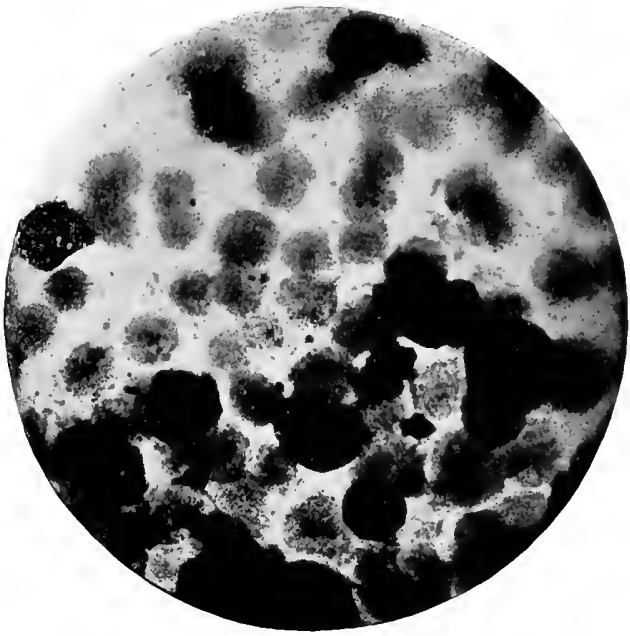

Abb. 19. In Teilung befindliche Zellen in einem 28 Tage alteu, in Froschplasma und Augenkammerwasser gezüchteten Präparat. (Mikrophotogr. gefärbtes Präparat R. (GASSLL, 1922.)

umgedreht hat, die Konservierungsflüssigkeit an den Rand des 'Tropfens ringsherum verteilt und langsam mit dem Konservieren bis zur Mitte vorgeht. Ist das Plasma sehr fest, was die Regel nur bei Züchtung in Hühnerplasma und Frosehplasma ist, so kann man das Deckgläschen sehwimmend auf die Konservierungsflüssigkeit legen. Es kommt hauptsächlich darauf an, a lle ausgewanderten und neugebildeten Zellen mit zu konservieren. Dies gelingt erst nach einiger Ühung. Das Einbetten gesehieht in der ïblichen Weise; am besten nimmt man für die letzten Stufen Chloroform-Alkohol, Chloroform-Paraffin usw. Man nuß aber darauf achten, daß die Haut beim Einbetten nieht zu lange in den betreffenden Flüssigkeiten liegt, weil sie sonst zu hart wird. Feine Schnitte der explantierten Froschhaut färben sich am besten mit Delafield, wobei die Zeitdauer des Verweilens in der Farbe ausprobiert werden muB. Sind die Gewebe, wie die nekrotischen inneren Teile des explantierten Stückes, schon tot, so ist keine Kernfärbung möglich. Sehr oft wird sich nur der Zellinhalt diffus färben. In den Randpartien sind Mitosen damn leieht nachzuweisen. Vielleicht sind Basalzellen, die sproßartig aus dem eingepflanzten Stüek in das Medium hineinwachsen, $\mathrm{zu}$ sehen, die Guaninkörner in sich aufgenommen haben, manche auch rote Blutkörperchen und sonstigen Zelldetritus. Die runden Zellen sind fast alle Abliömmlinge der Basalzellenschicht und der darïberliegenden Epithelschichten. Daß wirklich die ausgewanderten Zellen von den Schichten der Haut, die über den Basalzellen liegt, 
stammen, kamn dadurch bewiesen werden, daß ein solehes explantiertes Hautstïck wieder implanticrt wird. Ein Schnitt dureh ein solches implanticrtes Explantat (siche Gassul 1920) zeigt verminderte Anzahl Zellschiehten üher der Basalzellschicht.

Die Rolle des Enterhautbindegewebes im Froschhautexplantat ist moch nicht ganz geklärt. CHLеxнiтn behauptet, dab das Bindegewebe

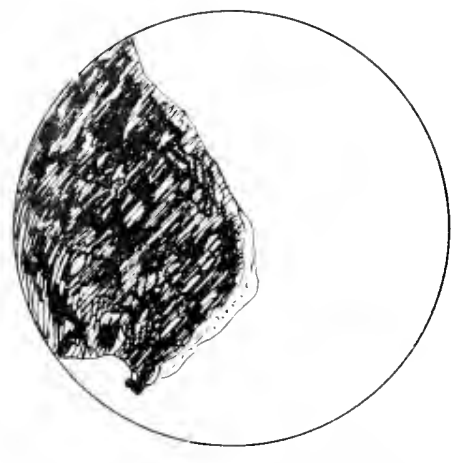

Ab). - 0 zeigt das Auswachsen des Bindegewebes ans der Hant von Rana esculenta in drei nacheinamier folgenten stadien. Mikrophotogr. nach R. IASst 1920. liefärbtes Total präjoarat.

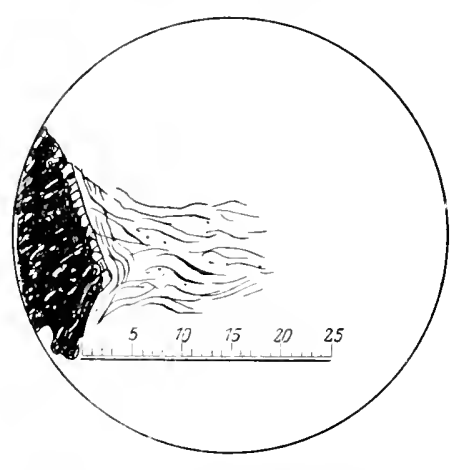
des Leopardfrosehes keine oder nur geringe Wachst umserscheinungen zeigt. Das Bindegewebe der hier gebranchten Rana esculenta zeigt besonders in Froschlymphe oft Wachstumserseheinungen, the sich nachweisen lassen (siche Abl, 20, 21, 22). Die Wundstellen der Bindegewebsfasern verdieken sich, kleinere Kerne lassen sich im Leben beobachten. Durch Apposition verlängern sich die Fasern nach der Peripherie hin, und die Kerne verteilen sich in ziemlich regelmäßigen Abständen in dieser ausgewachsenen Faser. Das Längenwachstum erfolgt zögernd. In beigegebenen Bilde ist ein Faserbündel abgebildet, das sich in 19 Tagen $11 m$

Abb. 21 u. 22 zeigen das Auswachsen des Bindegewebes aus der Hant von liana esculenta in drei macheinander folgenden stadien. Mikrophotogr. nach R. lissUL, 1922, liefärbtes Totalpräparat.

2.) "1 vergrößert hat. Eine Regelmäßigkeit, wann die Bindegewebe, wann die Epithelgewebe am stärksten auswachsen kömnen, ist nicht fest. gestellt. Es scheint nicht an den verwandten Kulturmedien zu liegen.

Verhaltender Froseh hat in festen, halbflïsigen und ganzflüssigen Medien. 2. Ubung. Während destudiums der Frosehhaut, die sich nur in Plasmamedium und Augenkammerwasser befand, sind die anderen jetzt zu brauchenden Medien vorbereitet und sterilisiert. Außer den früher fertiggestellten Medien brauchen wir noch Hühnerplasma, das aber erst später von clen Kursisten selbständig hergestellt wird. Jetzt wird es geliefert. Man hat also für die zweite Ċbung vorrätig: 
Höhnerplasma, Foschplasma, Augenkammerwasser und Rixeresche Lösung für Kaltblütler. Man stelle sieh 3 Mischungen her:

$1 / 2$ Teil Froschplasma und Augenkammerwasser,

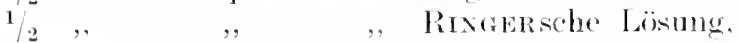

$1 / 3$, Hühne'plasma, ", Teil Foschplasma und " Teil Augenkammerwasser.

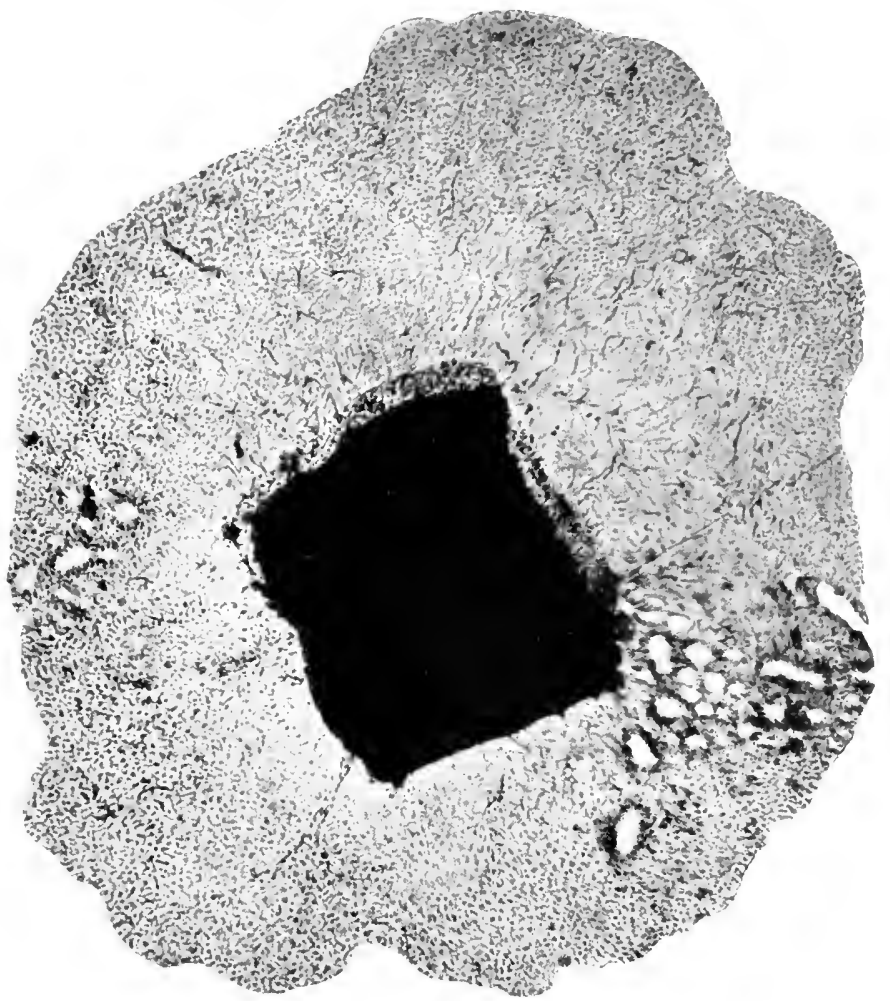

Abb. 2:3. Rückenhaut von Rana pij:ens nach E. CHLExHUTH. (Journ. exp. Med. 1914, Vol. 20.) Photogramm nach dem Leben, 48 Stunden nach der Explantation. Zuchtmedium wie bei Präp. auf Bild 13. Zweischichtenbildung an drei seiten des Explantats sichtbar.

Man behält noch zum Ansetzen einiger Kontrollkulturen ein wenig reines Froschplasma übrig. Damn setze man in der Weise, wie auf S. 17 beschrieben ist, Kulturen an, vielleicht $2+$ Kulturen:

3 Kulturen in reinem Frosehplasma,

3 ,, , , , Hühnerplasma,

3 , , . , , Angenkammerwasser,

3 , , , Ringerscher lösung,

3 ,, , Frosehplasma und Augenkammerwasser,

3 ", , Froschplasma und Rixgerscher Lösung,

3 .. ,. Pingerscher Lösung und Augenkammerwasser,

3 ,, , Hühner-, Froschplasma und Augenkammerwasser. 
Hat man wrnig Plasma und Augenkammorwasser, so kann man dirckt heim Ansetzen mit mehreren Tropfenpipetten dic Nischung vornehmen.

Gewöhmlich züchten wir. den natürlichen Verhältnissen möglichst entsprechend, in halbflïssigen Medien, also hier entspricht Froschplasma und Augenkammerwasser einem solehen. Frosch-, Hïhnerplasma und Augenkammerwasser gemischt stellen cin festes Medium vor, die anderen Jodien sind mehr oder minder flïssig. Hühner-

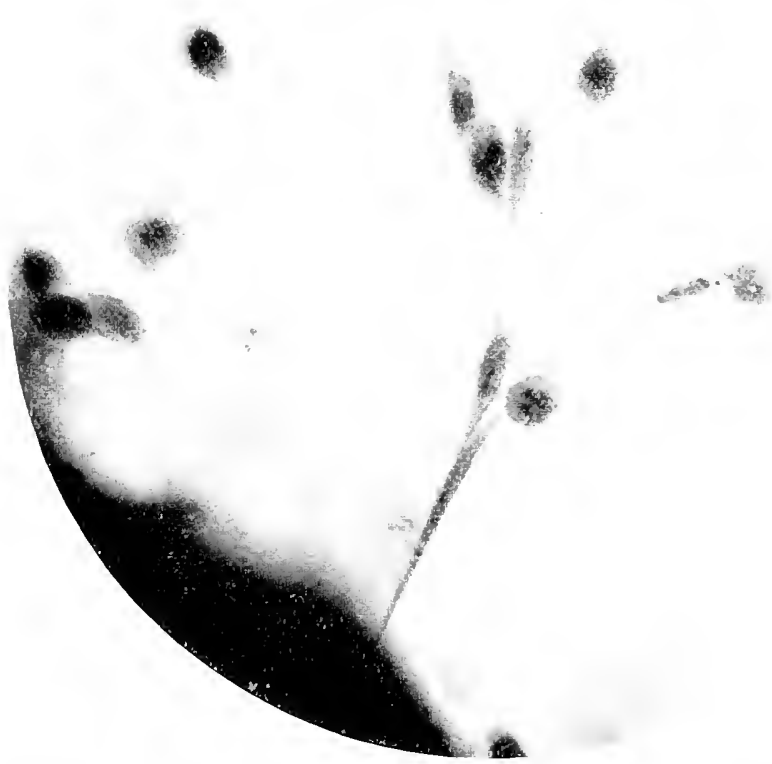

Abb. 24 wie Abb. 23, aber nach gelärbtem Präparat in einem sich verflüssigenden Medium. Die Formverinklerung der Ep:thelzellen in diesem ist deutlich.

plasma allein ist ein sehr starres Mcdium, Ringersche Flüsigkeit allein ein absolut flüssiges Medium und für die Kultur unbra uchbar. Beide werden nur als äuberste Kontraste verwandt. In dem einem können die Zellen nicht sich fortschieben, da kein Widerstand vorhanden, in dem stcifen Hühnerplasma ist dies auch nicht möglich, da das Medium zu starr ist und infolgedessen der Widerstand zu groß. Auswanderung von Zellen und Zellteilung sind hier fast nicht vorhanden, höchstens sind in das flüssige Medium einige durch das Zerschneiden des Gewebes aus dem Zusammenhang gelöste Zellen hineingeschwemmt, aber nicht aktir hinausgewandert. 
Die Epithelzellen haben in einem festen Medium gewöhnlich polyedrische Gestalt, ron oben gesehen sind sic polygonal, im sehnitt kubiseh; die Gröbe des Hofes ist gering, er hesteht aus einer dichten Membran, erst nach 14 'Tagen, wenn sich das 1 ledium verflïssigt, nehmen dir Zellen eine langgestreekte Form an den äubersten känlern des Hofes an.

In einem habblüssige medium hildet sich cin sehr groBer Hof ron Zellen, die um dasstück herum noeh polygonal sind und zusammenhängen. Je weiter nach auben man dic Zellen beobachtet, je loser wird ihr Zusammenhang, je langgestreekter wird ihe Form, einzeln wandernsie damn in das noch unverbrauchte Nedinm hinaus. Nach 20 tägiger Züchtung sind viele Zellen stabartig und das Zcllplasma ist von schammiøer Struktur.

Ineinem flüssigen Mechum (Augenkammerwas:er) nchmen alle Zellen zuerst eine gestreckte Gestalt an, die sich sehon nach wenigen stunden ( 18 stunden) in eine runde verwandelt, in welcher die \%elle bis zu ihrem 'Tode verhart. Zu einer echten Hofbildung kommt es nicht, überall hin werden Zellen und Zellschleier getrieben. Alle diese Veränderungen können num in dem sich im Laufe der Zeit stets verflüssigendem Plasmamedium früher oder später in einer Kultur beobachtet werden.

Weiter haben wir genau das Schieksal der einzelnen Zallarten rer. folgt und gefunden:

Die großen Melanophoren teilen sich nicht in der Gewebeziichtung. Nachdem sie den ersten Tag sich au-gestreckt haben, ziehen sie sich im Verlauf der nächsten Tage zurammen und bleiben im Stadium der Ballung bis zu ihrem Tode, der oft sehr spät erfolgt. Sind sie gestorben, so werden die kleinen Pigmentkörnchen von vielen anderen Zellarten phagoeytiert. Dies ersehwert natürhch das Erkennen der anderen Zellgruppen. Die kleinen Melanophoren sind oft in aktiver Bewegung anzutreffen. Die Cuanophoren teilen sieh sicher, Basalzellen und Driisenzellen ebenfalls, Ep ithelzellen, soweit sie noeh nicht verhornt sind. Cber das Schick-al des Bindegewehes ist weiter oben berichtet, doch tritt bei Rana esenlenta nicht das ein, was UhLenHuTH von dem Bindegewebe des Rana pipiens erzählt. Сhleshuth findet. daß das Bindegewehe inaktiv bleibt und von den Epithelzellen überwuchert wird, so daß nach mohrwöchentlicher Züchtung eine Hohlkngel entsteht, die innen aus dem inaktiven Bindegewebe, auben ans neugebildeten Epithelzellen besteht. Es sollte hier an der lebenden Epithelzelle gezeigt werden, daß ihre Form eine Funktion der Festigkeit des Mediums ist und dab die Sebnelligkeit der Auswanderung ron Zellschichten und Zellen durch den gleichen Faktor bedingt ist.

\section{Lebensäußerungen der Zellen und Gewebe in verschiedenen Medien.}

Unter LebensäuBerungen der Zelle während ihres Verweilens in dem Kulturmedium sind zwei Gruppen zu unterseheiden, solche, die der Zelle auch im früheren Gewebsverbande eigen sein würden und 
solche, die sich in dem Kulturmedium new oder ermeut zeigen. Als Zeichen des auch in der neuen Comgebung weiter ablaufenden Zellgeschehens werden die Fortsatzbildung der Zellen, die aktive Wanderung, die Fähigkeit zu phagozytieren, die sofortige Bildung ron indirekten Teilungsfiguren bei embryonalen Zellen, das Durchführen der Zelldurehschnürung und die Weiterbildung der schon rorhandenen Zellstrukturen angesehen werden müssen.

Als Zellgesehehen, das sich nur in dem neuen Medium abspielt, werden wir dic Entelifferenzierung oder den Abban des Gewebes oder des Zollinhaltis ansehen und das fortgesetzte Teilen des sich nicht abgebaut habenden, oder wenn das vorkommen sollte, das fortgesetzte Teilen der abgebauten, erwachsenen im Gewebererbande sich nieht teilenden Zelle, das Auftreten direkter oder indirekter Teilungen, weiter das Neubilelen von Zellstrukturen in vorher abgebauten Zellen, wenn auch das letztcre Plänomen noch anzweifelbar int.

Als Anpasinges- oder auch als Alsterbeerseheinungen werden die Speicherung von Fett, Fettsäuren, und die Bildung ron Vakuolen und for sog. Degenerationsgranula angesehen werden müssen, wenn sie nicht gewöhnlich in der Zelle rorkommen.

In diesem Abschnitte sollen einzeln das Auswandern, das Sichum. wandeln, das Sichteilen von lebenden Zellen der versehiedensten Art in versehiedenen Medien beschrieben werden und die Fähigkeit dor Zelle zur Riesenzellbildung und zur Phagozytose experimentell gezeigt werden. Dabei wird die Beohachtung der lebenden Zelle mit ihren Inhaltskörpern und die Darstellung derselben besonders betont. Ein Versuch wird gemacht, lebende und tote Zellen zu merseheiden. Zu diesem Zweck werden wir uns erst die Mediumgewinnung bei Warmblütlern, Vögehn oder Säugern ganz zu cigen maehen und nachdem erst die Plasmagewinnmug der Sänger, als die leichtere Operation, beherrscht wird, lernt man auch Vogelplasma gewimnen. Die Katze ist wohl clas gecignetste Objekt zum Beginn, die Ratte das selnwerste, la Katzenplasma nicht so empfindlich ist wie Rattenplasma, das mitunter schon in der Pipette gerimnt.

lch gebe einige kurze Anleitungen für die später zu brauchenden Tierarten Katze, Ratte, Huhn, Meersehwein, Maus, Hund und Menseh.

Katzenplasma: Die Katze muß vor der Operation narkotisiert werden. Man setzt sie entweder unter eine Glasglocke, in die zugleich ein mit Chloroform getränkter Wattebausch gebracht wird, oder man fertigt besser aus einem Stïck Verbandstoff eine Maske, in die man zwisehen trockener Watte das mit Chloroform getränkte Wattestück hinemlegt, ähnlich wie bei der Narkose beim Mensehen und kontrolliert den Fortgang der Narkose durch Prüfen der Herzschläge. Wählt man dieses Verfahren, so muB man vorher die Katze an allen vier Pfoten an den Operationstisch anbinden und eben vor Beginn der eigentlichen Operation narkotisieren. Hat man keinen kräftigen Diener zur Hand, so narkotisiert man leicht unter der Glasglocke an und bindet dann zweeks tieferer Narkose das Tier fest. Die Narkose soll so tief sein, daß das Tier still- 
liegt, jesloch soll jedes umnütz starke Narkotisieren vermieden werden, weil Gewebe von stark narkotisierten Tieren schlecht wächst und $7 u$ starkes Narkotisieren auch nachteilig auf das Plasma selbst einwirkt. Es müssen reichlich viel Röhrehen und guolie Röhrelen zum Auffangen des Bhutes und des Plasma fertiggestellt werden, chenso mulb ein reichliches lnstrumentarium bereit sein. Jan gebraucht: mehrere gut-

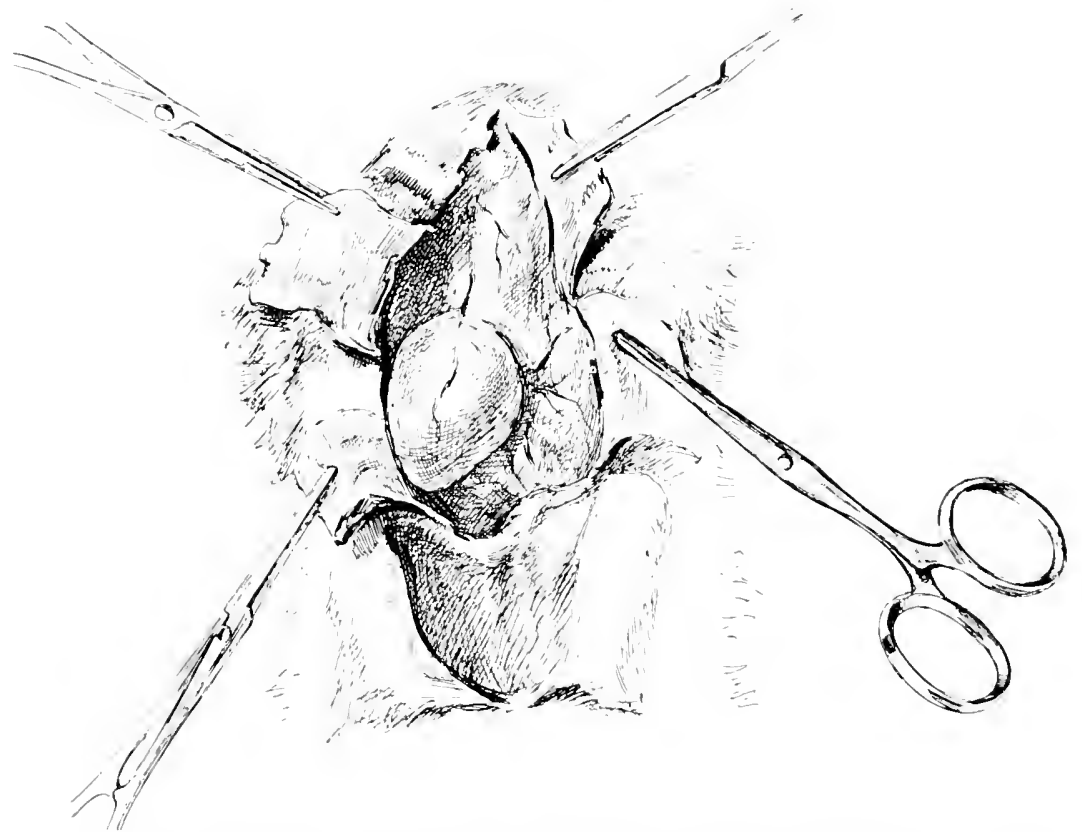

Abb. 25. Katze, Brustkorb geofinet, Herz freigelegt, Perikarl geoffnet. Es ist darauf zu achten, ha $B$ die batchhöhle gevihlossen bleibt. siehe Text (original).

geschliffene Knopfscheren, Klammem zum Festklemmen des geöffneten Brustkorbes, grobe und kleinere Pinzetten, dabei eine mittelgroße Pinzette mit stumpfen Enden zum Hochheben des Herzens. Die Haut wird am Brustkorb mit Sublimat abgerieben, über dem Brustbein cingeschnitten, zur Seite geklappt und festgeklemmt. Die freigclegte Muskulatur wird mit Ringerseher Lösmng abgespült. Nun helt man vorsichtig das Stermm hoch am Processus xiphoideus und sehneidet mit dem stumpfen Ende der Knopfichere nach unten mittels eines Mediansebnittes in den Brustkorb ein bis nahe an den Hals. Die beiden Hälften des Brustkorbes (Ab). 25) werden durch einen Transversakehnitt weiter geöffnet, wobei man die dort liegenden GefäBe beachten muB und so unblutig wie möglich arbeiten soll, und clamn zur Seite hin festgeklenmt. Man soll so rasch wie möglich arbeiten, damit man die Narkose nicht zu lang auszudehnen brawcht und sehnell in das schlagende Herz cinstechen kamn. Mit einer kleinen Knopfschere eröfnet man den Herzbentel, stiitzt das Herz von unten mit der stumpfendigen Pinzette und 
sticht mit der Kanüle in den Ventrikel ein. Es ist gleich, an weleher Stelle man einsticht, da durch das Einsteehen mit der verhältnismäbig starken Kanüle der Ventrikel so heftig verletzt wird, daß ron jecler Stelle das Blut in die spritze einströmt (Abb. 26).

Alle weiteren Hantgriffe erfolgen genau so, wie sie sehon beim Frosch heschrieben sind, mit dem wiehtigen Untersehied, daß noch

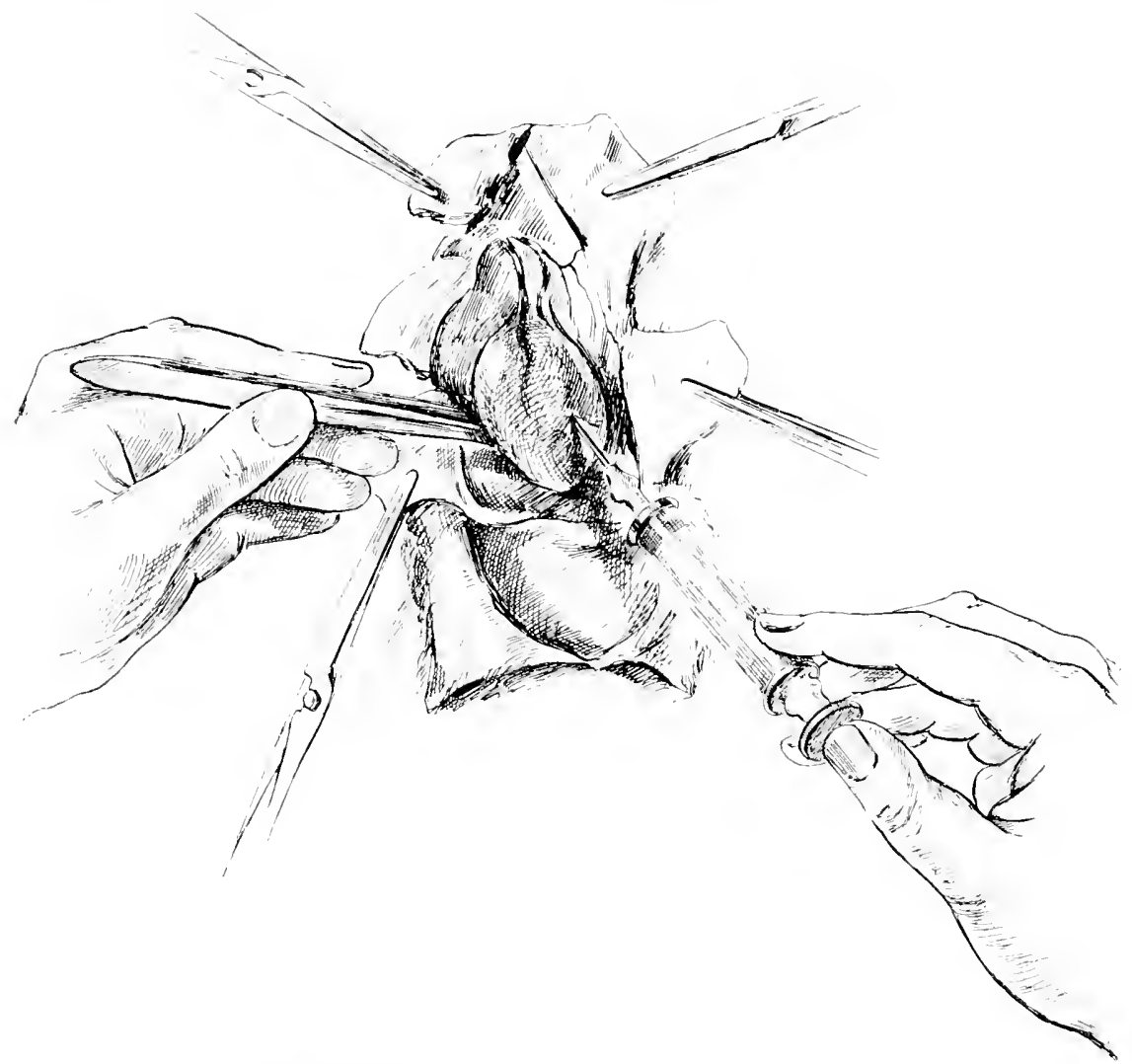

Abb. 26. Katze. Der Moment der Blutentuahme, Es ist darauf zu achten, daß die spitze der Kanüle nicht das Herz durchsticht und da $B$ der Stempel der Spritze erst hochgehoben wird, wenn die Nalel gut in das Herz eingefüht ist. Siehe Text (Original).

größere Schnelligkeit notwendig ist, eine Hauptbedingmng zur Gewinmung einer guten und reiehliehen Menge Plasma. Zwisehen Blutentnahme und Zentrifugieren darf höehstens ein Zeitraum von Sekunden vergehen. Das gewonnene Plasma wird in die sehon frïher beschricbenen dickwandigen Reagenzröhrehen abpipettiert, steril versehlossen. Gebraueht man das Plasma nieht gleieh, so kommt es in eine Gefrierlösung, die man einen Tag über den anderen weehselt. Bei heißem Wetter muß jeden Tag geweehselt werden. Das Plasma ist bis zu acht Tagen lang brauchbar. Wenn man Versuche anstellt, bei denen 
es auf eine bestimmte Hydrogen-Ionen-Konzentration ankommt, soll es besser vermieden werden, vorher gewonnenes Plasma zu gebrauehen.

Bei großen Tieren wird man zur Plasmagewinnung nur dam das Herz benutzen, wenn selsr viel Plasma gebraueht wird (etwa zu Kurszweeken). Sonst empfiehlt es sieh, Blut aus der Karotis zu entnehmen, nachdem das Gefä $B$ mobilisiert und das Blut gestaut worden ist. Dieses Verfahren erfordert jedoch größere Übung und ist für Kurszwecke nieht ratsam, weil eben oft, falls nicht sehr sehnell gearbeitet wird, das Blut gerinnt. Ieh lasse den Kursisten selbst von Anfang an alle Operationen ausführen und ziehe deshalb zuerst die Blutgewinnung aus dem Herzen vor.

Beim Hund entnimmt man das Blut für dic Plasmagewinnung aus der vorderen Brustrene mittels einer vaselinierten Hohlsonde. Das zuerst ausfließende Blut läßt man unbenutzt, da leieht gerinnmugsfördernder Gewebssaft mit einfließt, der durch das Einführen des Sebneppers in die Venenwand mit in das Blut gelangen kann. Das später quellende Blut läßt man in die paraffinierten Röhrchen einströmen und verfährt weiter in der schon gesehilderten üblichen Wrise.

Bei der Blutentnahme vom Kaninchen ist die allgemeine übliche Art, aus der Ohrvene Blut zu gewinnen zur Plasmabereitung nur selten mit Erfolg angewendet. Es währt zu lange Zeit, ehe man genïgend Blut erhält. Bei dieser verhältnismäßig langsamen Entnahme erwärmt die Hand zu stark die eisgekïhlte Spritze, und in den meisten Fällen gerimnt das Blut sehon beim Zentrifugieren. Will man das Tier schonen, so muß man auch hier die Karotis freilegen; die beste Art der Gewinnung bleibt immerhin das Einstechen in das sehlagende Herz. Auch bei Herzpunktion, sei es z. B. ein Meersehweinchenherz, das man punktiert, ist im allgemeinen die Blutentnahme bei diesem Verfahren zu langsam. Vielleicht aber läßt sich diese sparsamste Methode noch ausbauen.

Die Punktion kann in folgender Weise (nach FrIEBös) ausgeführt werden: Man schneidet über dem Herzen die Haare ein wenig ab und reibt die Hautstelle mit Jod ein. Man tränke die ausvaselinierte Nadel mit Paraffinum liquidum und steche mit der Spritze wie äblich in das Herz ein. Auch hier nehme man nicht das erste Blut, weil vielleicht Gewebssaft in ihm enthalten sein kann.

Aus Sparsamkeitsrücksichten werden oft trage nde Tiere zur Plasmagewinnung benutzt, man meint, zugleich mit der Plasmagewinnung, auch die Embryonen verwenden zu können. Ich möchte dies Verfahren nur dann empfehlen, wenn das Tier erst im Beginn der Trächtigkeit sich befindet. Stark trächtige Tiere erweisen sich für die Narkose sehr ungeeignet. Auch habe ich oft empiriseh festgestellt, daß das Wachstum im Plasma tragender Tiere sehr minimal ist. Vielleicht aber ist auch das bei diesen Tieren nötige starke Narkotisieren die Ursache, da B Gewebe in dem Plasma tragender Tiere nieht wachsen.

Bei der Ratte und dem Meerschweinchen verfahre man zur Blutentnahme aus dem Herzen wie bei der Katze beschrieben ist, mit Ausnahme beim Einschneiden in den Brustkorb. Bei den eben genannten Tieren eröffnet man den Brustkorb nicht durch Mediansehnitt, sondern mat 


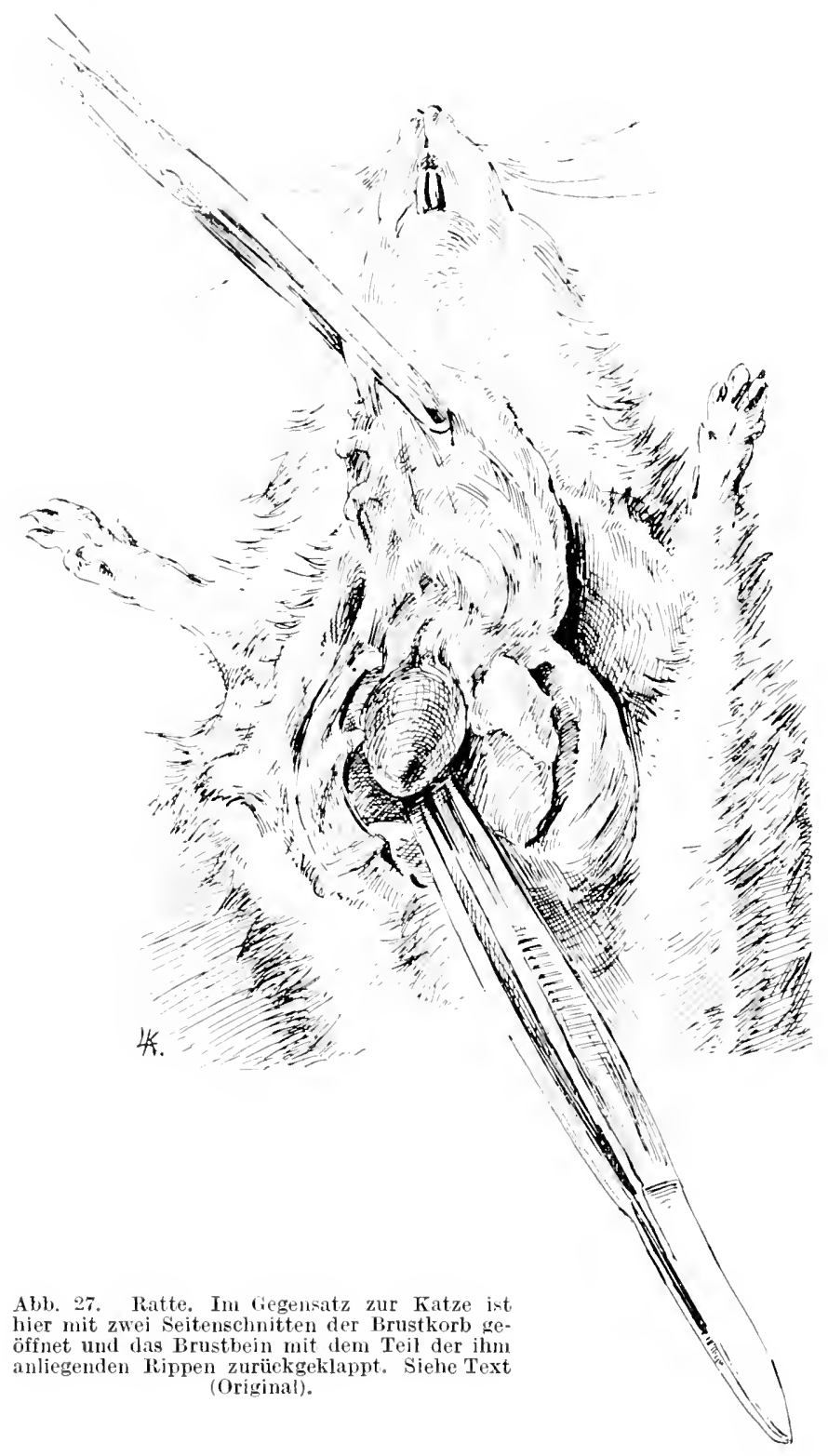

sehneidet beiderseitig beim Rippenkniek ein (Abb. 27), den Knopf der Schere nach unten geriehtet, klappt dann das gelöste Stïck rostat ${ }^{\top} \mathrm{zu}$ rïck und befestigt es mittels einer Klammer. Alle weiteren Handgriffe sind den bei der Katze beschriebenen gleich.

LAmbert und Hanes geben eine ausgezeichnete Anleitung, wie bei kleineren Tieren schnell Plasma aus Gefäßen gewonnen wird. Sie prä- 
parieren z. B. bei der Maus die Karotis frei, binderi sio oberhalb der Einscheneidestelle ab und befestigen sie unten mit einer Arterienklammer. Dann wird scharf in die Karotis eingeschnitten. Die Ränder des Einsehnittes werden mit feinen Klammern festgehalten und das Gefäß ganz durehtrennt. Das Ende des GefäBes und die es haltenden Klammern sind mit Olirenöl bedeckt. Dann wird die Klammer unterhalb geöffnet. und das Blut kann jetzt in die paraffinierten GlasgefäBe von sehr schmalem Durehmesser flicßen. Das Zentrifugieren und die übrigen Operationen sind den früher gesehilderten gleich. Die ersten Tropfen worden nieht gebraueht. Junge Ratten geben gewöhnlich I ecm Blut, wenn das 'Tier getötet werden soll, so kann man zweimal soviel nehmen, aber man soll solehes Bhut nicht gebrauchen, wemn man $T$ m m unitäts. studien machen will.

Beim Mensehen benutzt man, wie sonst bei der Blutentnahme üblieh, die Armvene. Das Mensehenplasma, das ohme Narkose ja leicht gewomen werden kann, wie auch ja bei dem Hund, verflïssigt sich leicht, ohne Zusatz von Hühnerplasma ist es unbrauchbar.

Besonders eingehend möehte ich die Gewimnung ron Hühnerplasma schildern. Da fast das ganze Jahr Hühnerembryonen zu haben sind und man mindestens dreimal dasselbe Huhn zur Plasmagewinnung brauchen kann, so empfichlt es sich, dies besonders zu üben.

Man soll sich zur Reget machen, daß alte Tiere, welche man zur Plasmagewinnung gebrauchen witl, mindestens einige 'Tage vor der Operation im Stall selbst zu heobachten. Man füttere sic in dieser Zeit mit Nahrung, die viel Wasser enthält. Wenn man seine Tiere seibst aufzicht, was ja bei der zumeist gebranchten Ratte sehr leicht ist, wird man am sichersten sein, normale, noch zu keiner anderen Operation gelorauchten Tiere zu haben.

Operation am Huhn: Beim Huhn gewinnt man zunächst Plasma durch Blutentnahme aus einer Flügelvene, um das Tier zu schonen und für mehrere Blutentnahmen zu gebrauchen. Man legt das Tier auf dem Rïcken auf den Operationstiseh nieder, nachdem man ihm sorgsam eine Watteunterlage untergelegt hat, damit es nicht zut sehr auskühlt. Nun bindet man die Beine und darnach die Flügcl mit Binden fest, recht behutsam, ohne das Blut zu stauen. Unter den Flügel, in den man hineingehen will, legt man eine Watterolle, um ihm eine erhöhte, sichere Lage zu geben. Die Operationsstelle befreit man vorsichtig von allen Federn, die man nicht abreißen, sondern abschneiden soll. Sodann reibt man das Operationsfeld kräftig mit einem Wattebausch und steriler Kochsalzlösung ab, um allen etwa anhaftenden Schmutz zu entfernen. Nachdem man das Huhn beruhigt, im Notfalle ihm eine leichte ('hloroformmarkose gegeben hat, hebt man die Flïgelhaut mit der Pinzette auf und schneidet mit einer seharfen Knopfschere (Abb. 28) ïber dem Gefäße in die Haut ein, drängt stumpf ab und klemmt links und rechts mit je einer PéAsschen Klammer die Hautränder fest. So erhält man eine ziemlich weit offene Operationsstelle (Abb. 29), an der man das Gefäß deutlich liegen sieht. Das Gefäß wird num vorsichtig hochgehoben und der Blutstrom mit einer Arterien- 
klemme abgestaut. Beror man nun zur Blutentnahme einsticht, wird es nötig sein, die Narkose zu verstärken. Man muß das Tier gut beobachten und die Stärke der Narkose genau austarieren, so daß das Tier zwar ruhig liegt, aber auch die Narkose gerade so leicht wie

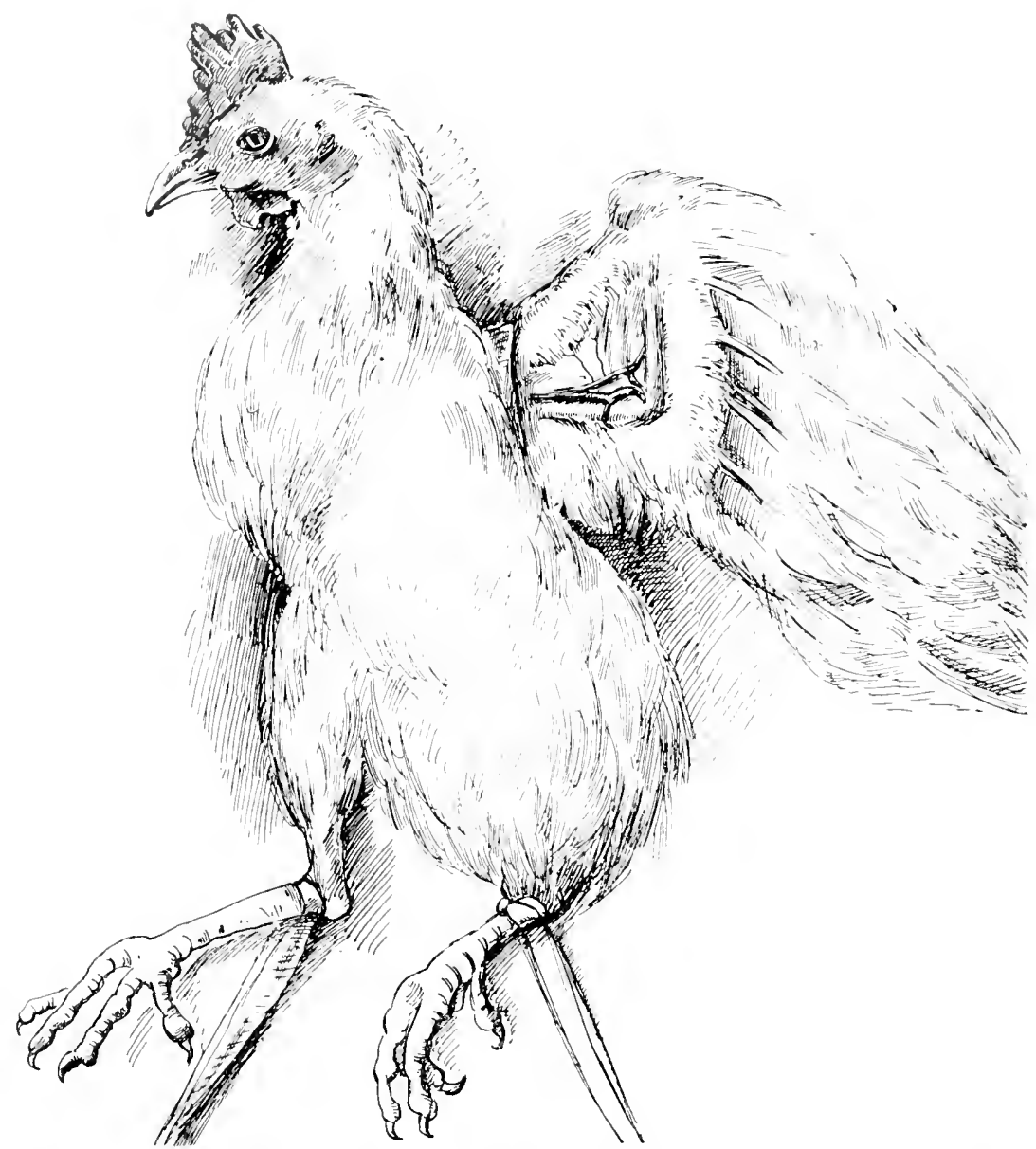

Abb. 28. Huhn zur Operation vorbereitet. Die Rolle, welche den Flügel hebt, ist nicht sichtbar. Auch das den Kopf bedeckende Tuch ist fortgelassen. Siehe Text (Original).

möglich ist. Schnareht das Huhn, so ist die Narkose gut gelungen. Sobald der Blıtstron angestaut ist, stieht man mit der eisgekühlten Spritze in das Gefäß ein und löst im gleichen Augenblick die Klammer, so daß das Blut sehnell in ziemlieh großer Menge einströmt. Die Zentrifugenröhrchen, welehe zum Auffangen des Blutes dienen, müssen beim Huhn in größerer Anzahl bereitgestellt werden. Man nimmt aueh etwas größere Plasmaröhrehen, da man mit größeren Blutmengen zu reehnen haben wird. 
Im allgemeinen unterseheiden sieh die einzelnen Handgriffe und die Art der Arbeit nicht wesentlich von der Art der Plasmagewinnung, die vorher sehon bei anderen 'Tieren besehrieben ist, bis auf alle rlie Einzelheiten, die dureh die Besehaffenheit des Tieres scllsst bedingt

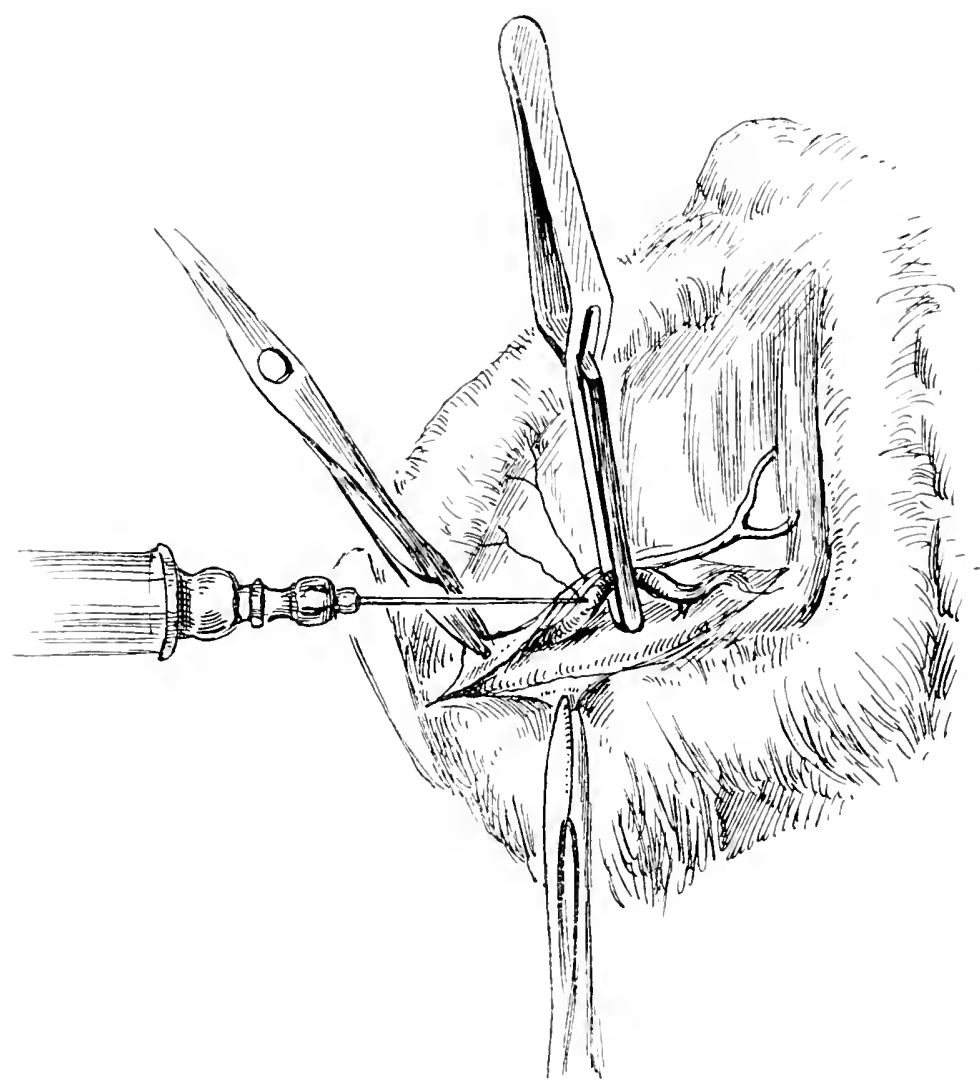

Abb. 29. Flügelvene des Huhnes zur Blutentualıme vorbereitet. Die beiden PEANschen Klammern rechts und links klemmen die abpräparierte Haut zurïck. Die zum Stauen des Blutes benutzte Arterienklemme darf nicht zu massiv sein. Siehe Text_(Original).

werden. Zu sagen wäre nur noch, daß beim Huhn, ganz glejeh, ob man aus einem Gefäß oder aus dem Hühmerherzen das Blut gewimnt, noch raseher gearbeitet werken muß als etwa bei der Ratte, da die Temperatur des Hühnerblutes $38^{\circ} \mathrm{C}$ ist. Ist das Tier sehr jung, so braucht man beim Blutentnehmen aus den Gefäßen meist nieht in die Muskulatur einzusehneiden, bei älteren Tieren dagegen muB das Gefäß stmmpf und unblutig freigelegt werden. Zu junge Tiere sind für die Operation ungünstig, weil ihre Hant leicht cinreiBt, am besten verwendet man 7-8 Monate alte Tiere. Dasselbe Huhn kann öfter zur Blutentnahme benutzt werden. Man entnimmt aus den Flügelgefäßen erst an einer, dann an der anderen Seite und zuletzt aus dem Herzen. Am besten 
wird das T'ier nach der Entnahme aus dem Gefäb sofort rerbunden. Man läBt es bis zur nächsten Entnahme etwa $1 / 2$ Jahr laufen. Dabei gelingt es, da 3 man ein paarmal aus demselben Gefäß Blut entnehmen kann, oft aber vernarlot die schon früher benutzte Stclle nicht gut und die Verwachsungen stören dann, wenn man diese Stelle später wieder benutzen will.

Weiter lranchen wil auBer Physiologischer Kochsalzlösung, Ringerscher lösung, LoKE-LEwssscher Lösung, alles natürlich für säugetiere angeset\%t, Embryonalextrakt, den wir auf folgende Weise hereiten.

Emliryonalextrakt: Die bequemste Art ist folgende: Aus dem trïchtigen [terus beim Säugetier oder aus dem Ei beim Vogel wird der Embryo steril entnommen und in steriler Ringerlosung algespoult. Das so vorbereitete Tier wickelt man in ein steriles Gazeläppehen, von dem die lingerlösung zim gröbten Teil wieder aufgesogen wird. Der Embryo wird dann in sterilen GlasgefäBen mit sterilen Instrumenten schnell zerschnitten und verrichen und der Embryonalbrei in ein steriles, mit einem Deckel rersehenen Filter gebracht, a uf dem man vorher ein steriles, mit Ringer angefeuchtetes stück Filtrierpapier leicht angedriielst hat. Da der Embryo sehr wasserreich ist, werden sich immer 'Tropfen ron Flüssigkeit abfiltrieren, die möglichst sofort, ver'dïnnt wie 1:3, zu benutzen sind, höchstens aber einige Stunden auf Eis gehalten werden können, da sonst die wachstumsbeschleunigenden Substanzen nicht mehr bei späterer Verwendung zu wirken scheinen. AuBer dem geschilderten Verfahren, Embryonal-Extrakt zu gewimnen, wird noch folgende Methode nach DREw empfohlen:

Man sehmeidet Mäuse- oder Ratten-Embryonen in feine Stückchen und bringt sie in ganz wenig Drewsehe Flüssigkeit (siche S. 104). Diesen Brei läßt man 2-3 mal frieren und anftanen, damit die Zellen so viel wie möglich sich aus dem Verbande lösen. Dann zentrifugiert man, bis eine klare oder schwaeh opaliszierende Fliissigkeit sich absetzt. Drew empfichlt 2 Teile dieser Flïssigkeit und 3 Teile der Drewschen Flïssigkeit, die das Plasma ersetzen soll.

\section{A. Auswanderung der eingepflanzten Zellen gezeigt an der Milz.}

Nachelem wir erst in Gedanken ms die nachfolgenden Schritte des Experiments zurechtgelegt, alle Instrumente und Lösungen bereitgestellt haben, so nehmen wir die bis zu diesem Zeitpunkt auf Eis gestellte Milz. Gerade hicr ist die Auswanderung der Zellen am besten zu beobachten, und die Anfertigung von Deckglaskulturen bei Milz und auch bei Knochenmark ist verhältnismäBig leieht. Um Tiere zu sparen, benutzt man dasselbe Tier zuerst zur Plasmagewinnung, nimmt die Milz dann steril heraus und bewahrt sie, bis man sich die Glasschalen, sterile Instrumente und Lösungen zum Kulturenansetzen zurechtgestellt hat, auf Eis auf. Hat man 2 Zimmer zur Verfügung, so stellt man diese Dinge schon ror der Operation auf. Je schneller man arbeitet, je besser. Nachdem die Milz - man nimmt entweder 
Katzen-, Ratten-, Meerschwơn- odrry Hühnermilz, nur nieht Mäusemilz, weil die Zellen sehr klein sinel - aus dem sehwach narkotisierten, besser gescliächteten - falls cin frisches Tier verwandt wird - Tiere herausgenommen ist, wirel mit dem Ansetzen der Kulturen in der früher geschilderten Weice verfahren. Man wirk gut tun, die Milz cin parmal in Rixgerscher lösung abzuwaschen und dann aus dem Inneren der Mlik kleine Stückehen in das Nährmedium einzusetzen. Wir ziochten als dritte Uhmeng die Milz:

in arteigenem Plasma,

in Plasma und Rixaerselere Lösmeng,

in Plasma und Embryonalextrakt,

in reiner Ringerseler Lösung.

in reinen serum.

Man wälle am besten möglichst gleichgrolse Stïcke, damit man später einen Anhalt hat, wie stark die Auswanderung der Zellen stattgefunden hat.

An nächsten Tage wird man deutlich, schon mit bloßem Auge, weibliche Ringe um das eingepflanzte Stückehen sehen können. Der Durchmesser dieses Kreisringes ist wahrseheinlich größer bei den in Serum eingesetzten Stïekehen. Gerade hier wandern die Zellen am sehnellsten aus. An dichtesten ist der Zellenkranz bei den Plasmamedien, auch haben hier die Zellen ein nor-

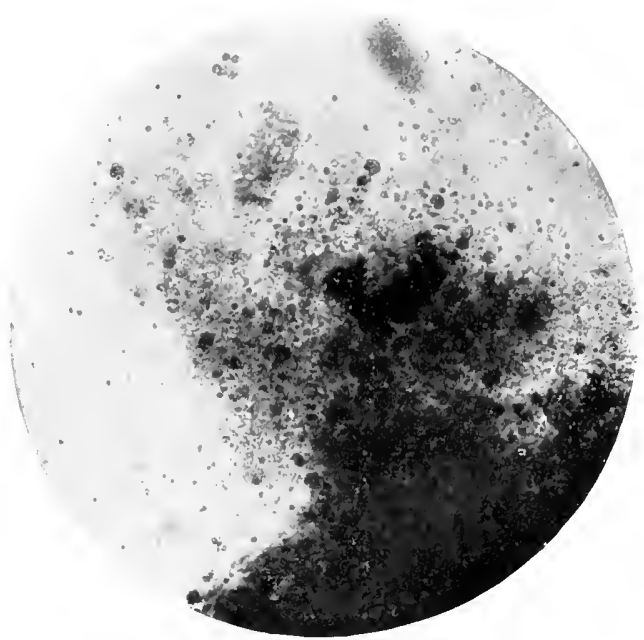

Abb. 30. Auswanderung der Zelien der erwachsenen Katzenmilz in homogenem Plasma, 3 täg ge Kultur, ein Teil des Hofes ist zweeks Umpflanzung sehon abpipettiert und auf ein neues Deckglas gebraeht (im Präparat hinks). llikrophotogramm nach dem Leben (Original).

males Aussehen, während in dem Serum abenteuerlichen Pseudopodien, stark ausgezogenes Zellplasma und blasse Kerne sich zeigen. Viele Zellen sterben ab. In dem Plasma der Katze können die Milzzellen sehr lange leben und es fällt besonders der Reichtum an eosinophilen Leukozyten auf. Am übernächsten Tage wird man diesen Zellenkranz unter der Lupe mit einer feinen Kapillarpipette absaugen und in ein neues Medium bringen (Abb. 30). So ist man sicher, nur ausgewanderte Zellen zu erhalten, die dam nach weiteren ? Tagen wieder in neues Medium verpflanzt werden müssen. Unter Umständen findet auch eine Vermehrung einiger Elemente statt.

Die er wa ch sene Milz, , die Stätte des Unterganges vieler Erythrozyten und der Neubildung vieler weißer Blutzellen" enthält außer" 
Bindegewebszellen, die uns hier nicht interessieren, infolgedessen viele

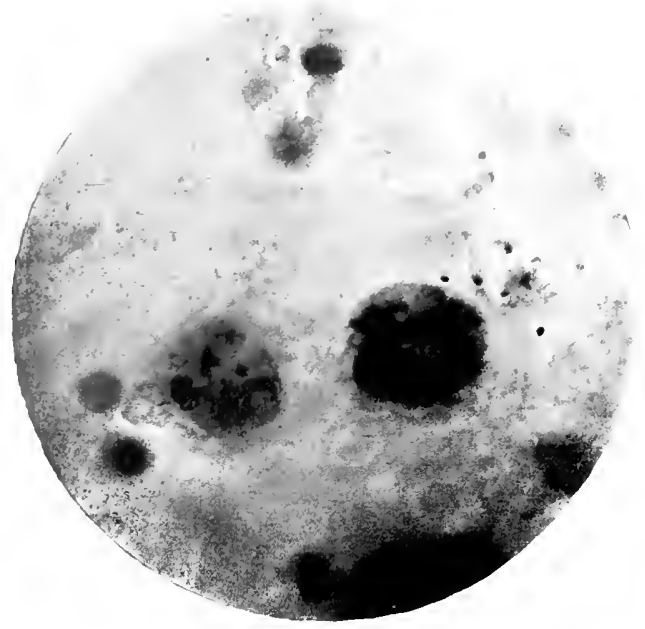

Abb. 31. Katzenmilz. Zellen des Reticulums aus der Peripherie des Hofes. Nikrophotogramm nach einem mit riemsa geiärbten Totalnräparat (Original).
Erythrozyten und viele weiße Blutzellen. Dazu kommt - und das ist für uns besonders wichtig - ein weitverzweigtes Venen - und Arteriensystem. Die Wand der kapillaren Milzvenen ist eine durchbrochene. Sie enthält retikulär angeordnete Zellen, welehe ein Masehenwerk bilden (Netzsyncytium). Betrachten wir mser eingebettetes Stück am ersten Tag, so finden wir eine ganze Reihe von großen blasigen Zellen, deren Kern sieh mit Giemsa blau färbt. Diese Zellen sind Zellen aus dem Reti. kulum. Sie können phagozytieren. Am zweiten Tage findet man in ihnen sehr häufig die Reste roter Blutkörperehen (Abb. 31). Sowobl die eosinophilen Le u k ozy ten

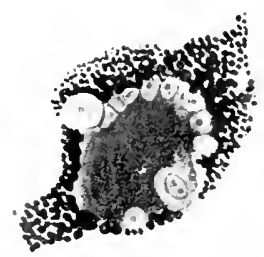
der Milz als auch des Knochenmarks teilen

Abb. 32 1. 32 a. Riesenzellbildung in der Rattenmilz in Menschenplasma 5 Tage gezüchtet. In der Mitte der beiden vielkernigen Riesenzellen eine vaknolige sphäre, um welche sich viele Kerne lagern. Un dea Kernkrauz Fettgrannla. Nach LAMBER'T und HANES, 197. Journ. exp. Med., Bd. 14 . 
sich schnell hintereinander in den ersten drei von uns gewählten Medienbis sie als kleine, punktgroße Einheiten endlich zugrunde gehen. Sie können auf zweierlei Arten sterben. Entweder sie sterben durch Ausstoßen sämtlicher eosinophiler Granula oder auch durch Ausstoßen des Kernes, der vorher pyknotisch geworden ist. Nach 2 Wochen ungefähr finden sich nur kleine Lymphozyten und retikuläre Zellen und eventuell Bindegewebszellen der Milzkajsel vor. Eine progressive Entwicklung der Zellen machen nur die $L$ y m phozyten in einem Plasmamedium mit Serum durch bis zu ihrem schon morphogenetiseh vorgeschriebenen Ziele, nämlich in Plasmazellen; eine Rückbildung der Lymphozyten in Bindegewebszellen ist von mir nicht beobachtet worden. Man hüte sich, Milzläppchen mit etwas Fett einzupflanzen, weil dadureh die an sich schon schwierige mikroskopische Deutung der Bilder noch kompliziert wird. Die dem eingepflanzten Milzstiickchen eigenen Riesenzellen wandern sehr selten in den freien Zellenhof. Man findet sie aber noch in Schnitten durch das im Plasma eingepflanzte Stück. Doch bilden sich auch vielkernige Riesenzellen in der Milz (Abb. 32 u. 32a). Hat man die eingepflanzten Stücke
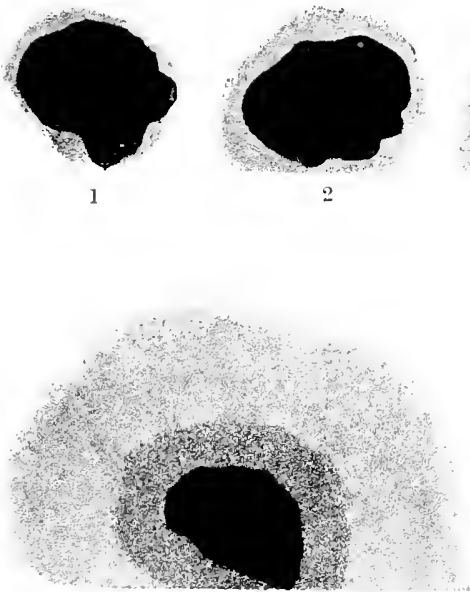

5

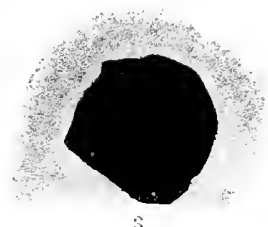

\$

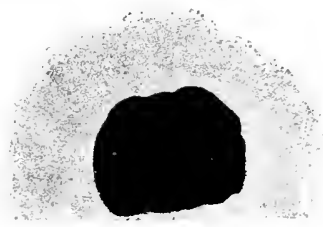

1

Abb. 33. Fmbryona'e Milz vom 16 Tage alten Embryo. 1. drei Tage gezichtet in Ringer allein, 2. in Ringer und $2 \%$ Agar, 3. in Serum, 4 in frischem Serum und $2 \%$ Agar, 5. in auf $50^{\circ} \mathrm{C}$ erhitztem Serum und $2 \%$ Agar, 6 . in auf $50^{\circ} \mathrm{C}$ erhitztem Hünerplasma. Nach INGEBRIGTSEX, 1912. Journ. exp. Med. Bd. I6.

sehr häufig umgebettet, so bleibt schließlich nur das retikuläre Gewebe zurück, von dem kleine, basophil sich färbende, lymphozytenähnliche Zellen sich ablösen.

So wenigstens verhält es sich bei der Milz der Katze, der Ratte, des Meerschweinchens, des Hubnes. Es kann sein, daß das Milzgewebe anderer Tierarten wieder andere Erscheinungen hervortreten läßt. Die embryonale Milz (Abb. 33) kann - falls vorlianden - als Vergleichsobjekt betrachtet werden. 
4. C'bung. Man nehme die Milz eines 16 Tage alten Hühnerembryos mol habe folgende a Medien zurechtgestellt:

Rixrersche Lösung, Rixressche lösung mel $20 \%$ Agar, auf $50^{\circ}$ C erhitztes Hïhnerserum 11. 20 Agar nicht (rhitztes Hühnerserum u. 20. Agarn. Hühnerplasma.

Agarlösnng. Eine 20, Lösung Agar in destilliertem Wasser bält man im Waswerbad zwischen 60--6.5 C flïsig. Hat man das sermm bereitet, so nimmt man die Agarlösmeg ans dem Wasserbade und läBt sie bis ca. 40 C abkühlen. Dann mixcht man die Agarlösung vorsichtig mit dem Serum in der gewïnschten Zhsammensetzung. Sofort müreen dann die Kulturen ange setzt werden. Find in der

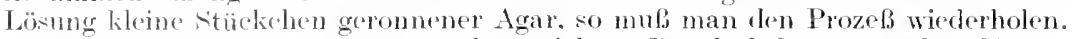

fireum bere it ung. Nan maehe es sich zur Regel, daß man aus dem Herzen des Tireses, von dem man schon 2-4 Röhrehen Blut zur Plasmagewinnung entnommen hat. noch Blut für die Serumgewinmmg entnimmt. Nach ein paar Himuten hat sich das Herz gewöhnlich so voll geschlagen, daß man Blut für clie Sermugewinnung entnehmen kann. I)ies kommt in ein nieht mit Paraffin ansgekleidetes steriles Zentrifugenöhrchen. Nan läbt das Rölnchen ${ }^{1}$, Stunde lang kiihl stehen, stieht dann mit einer ansgeghiuhten Platimnadel den Blutkuchen ab, zentrifugiert, jipettiert ab und rerwahrt das Serum anf Eis.

Abhildung 3:3 1-6 zeigt num, wie stark die Auswanderung in den 6 versehiedenes Dedien ist. Nur in 5 und 6 haben sich die Fibroblasten der Nlilz entwickelt. Es sind also anf Figur $3: 3$ und 6 zwei hichiehten sichthar. Die leicht gran pmoktierten Sichichten sind die ansgewanderten Lymphocyten und cinige cosinophile Leukozyten der Milz auf allen Bildern.

Totalpräparate färbt man mit Giemsa oder auch Hämatoxylin und Sudan III. Es empfichlt sich, auch schnitte durch das eingepflanzte Stück zu machen.

\section{B. Umbildung der Kónochenmarkzellen.}

Besonders lehrreich ist das Verhalten der Knochenmarkzellen im künstlichen Medium und zwar ist das rote, nur wenig Fett enthaltende Mark des jungen Huhnes zum Versuch besonders geeignet.

Die Methode des Ansetzens der Kulturen ist die gleiche wie bei der Milz, nur muB darauf geachtet werden, daßs das Knochenmark direkt aus dem getöteten 'Tier in clas Nährmedium ohne Ringerzusatz gebracht wird. Zu diesem Zwecke wird es sich empfehlen, das Knochenmark des H uhnes, welches wir für dic fünfte Ühung brauchen, auf folgende Weise zu gewinnen. Dem leieht narkotisierten Huhn wird mit einem scharfen Skalpell die Flügelhaut eingeritzt. Mit einer scharfen Knoehenschere wirl der Knochen in der Mitte durchgeschnitten, mit einer Hohlsonde das Knochenmark herausgenommen und sofort in das Kulturmedium gebracht. Man wähle sich ein junges Tier, dessen Knoehen reichlich rotes Knochenmark enthalten, da das weibe Knochenmark durch seinen Fett. gehalt kein gutes Beobachtungsobjekt bietet. Zuerst studiere man das Knochennark in einem Tropfen Plasma, naehdem es ca. 1/2 Stunde im Thermostaten gewesen ist, damit man sieh dic vorhandenen Elemente des Knoehemmarkes einprägt. Man kann le be nd folgende Elemente unterscheiden (Abb. 34):

die Erythrozyten,

die Erythroblasten,

ungranulierte Zellen,

gramulierte Zellen,

Riesenzellen; 
Diese zerfallen sehr licht, sind aber in Inmern des ringeptlanzten Stiickchens anch später noch unveränlert zu erkennen. Die Erythrozyten des Huhnes unterscheiden sich vom den Erythoblasten durch clas vorhandene Hämoglobin. Bei den Erythoblasten, deren Kern und Plasma runellich ist, finclet sich das Hänoglobin nur in sporen. Dos eosinophilen Lonkozyten fallen dureh ibre Cranuliermug auf. Bum Huhn sind sowohl stah-

förmige wie rundliche Granulationen vorhanden. Auch Fettzellen lassen sich lehend unterscheiden (Ab). 34).

Die thehicksale dieser versehiedenen Zellarten im Plasmantedium sind folgende: Die eosinophilen Leuliozyten wandern mit grober Schnclligkeit aus und teilen sich mehrmals hinteremander, so dab viele kleine Zellen entstehen. Diese verlieren sehr oft die Gramula, der Kern wirel pyknotiseh und die Zellen sterben ab. Oder die Granula vergrößern sich, werden Degenerations - Gramula ähnlich und färben sich dann sehr stark mit Neutralrot. Doch gehen auch diese Zellen, wenig-
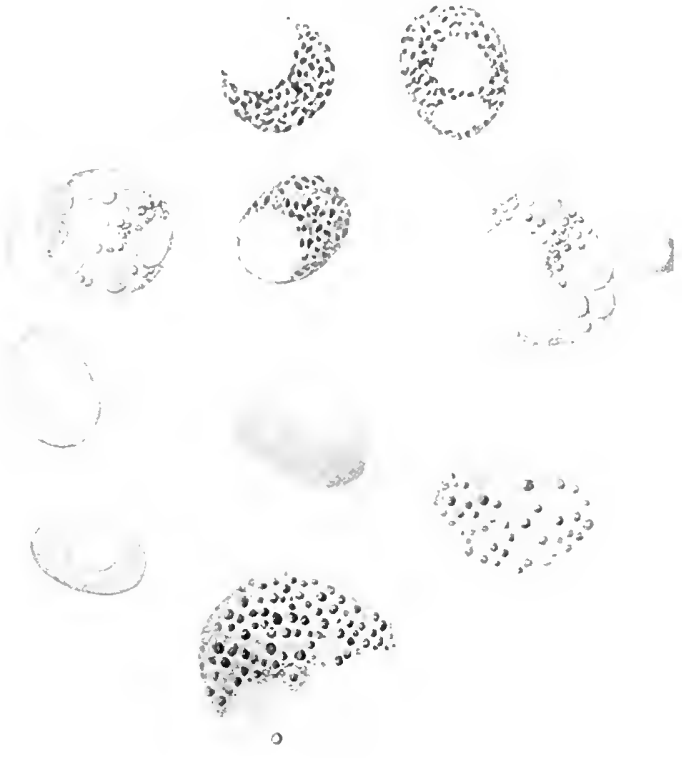

11,. 34, Knochenmark hes erwachenen Huhns I Tag in Plasma gezuchtet. Ausgewanderte Zellen in den Zallkranz. ben drei eosinophile Lenkozyten, einer in Teilung (stäbchenform, unten 2 gramilierte Formen, in der Mitte unglanulierte Form. Links und r, cht - oben 2 Fettzellen. Nach den Leben, (j) ginal. stens beim Huhn, innerhalb von 5 Tagen zugrunde. Beim Meerschwcin warcis noch nach 10 Tagen eosinophile Leukozyten siehthar. Ob diese nun aus den Vorstufen der Leukozyten in der Gewebekultur neugebildet worden sind oder ob es die überlebenden Leukozyten sind, bleiht zu entseheiden. Hat man das Knochenmarkstïckchen nach einigen Tagen ungebettet, so erseheinen besonders vicle kleine, ,L y mphozy te n“ am Rande des eingebetteten Stïckes, die sich damn mit ihren fingerartigen Fortsätzen langsam an die Peripherie des Mediums bewegen. Bei häufigem Umbetten wandern schlieBlich nur ans dem äbrighleibenden Retikulum diese kleinen .Lymphozyten" aus. Sie sint stark basophil und haben bei Giemsafärbung einen vaknoligen Kern, der wenig mit Chromatin gefüllt ist. Der Protoplasmarand ist sehr oft zackig in der lebenden Zelle, nimmt natiorlich ein glattes Ausischen im gefärbten Präparat an. 
Ab und zu findet man auch noch Bindegewebsellen, die aus den KapillargefäBen und aus dem Knochenmarknetzwerk stammen, sowie

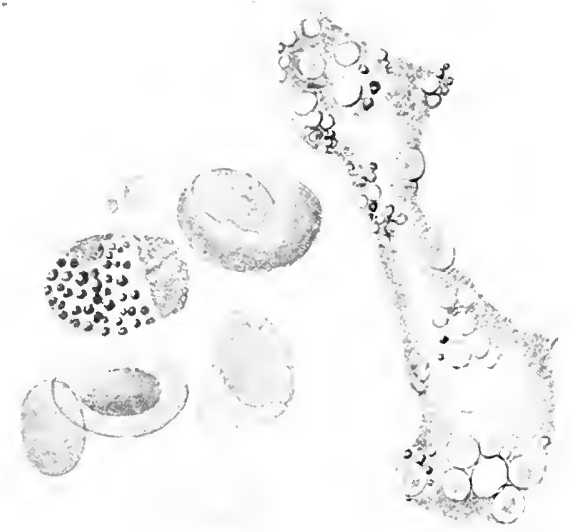

Abb. 35 wie 34 , aber 2 Tage in Plasma gezüchtet. Beachte die wandernde hiesenzelle, die umgewandelte Fettzelle, das rote Blutkörperchen, das semen Kern gerade ausstößt, darunter ein Lymphozyt mit Yaknolen um den Kern. Nach dem Leben, Original.
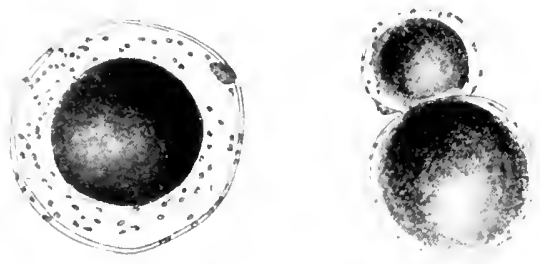

Abb. 36. Ungewandelte Fettzellen in der Gewebekultur. Nach Erdmamn. Original.

Die Bilder 36,36 a $\quad$ u. $36 \mathrm{~b}$ sind naeh 48 Stunden Züeht ung des Hühnerknochenmarks nach mit Osmium fixierten unit Safranin gelärbten Prälaraten dargestellt.
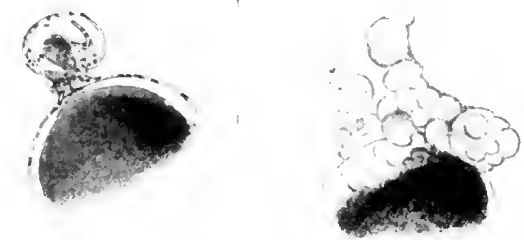

Abb. 36 a. Ungewandelte Fettzellen in der Gewebekultur. Nach Erdmann. Original.

große Endothelzellen. Diese machen genau dieselben Veränderungen durch wie in der Milz und können auch stark phagozytieren. Die Riesenzellen, die mit dem Knochenmark eingepflanzt werden, sind oft am zweiten Tage noch erhalten. Ab und $\mathrm{zu}$ findet man hei jungen Tieren auBertem noch Knochenzellen, die lebend mit ihren vielen kleinen, stark licht. breehenden Knochenspießen einen überraschenden Anblick gewähren.

Das mikroskopische Bild wird beherrscht durch dic abgebauten Fettzellen, falls man fettreiches Knochenmark genommen hat. Die Fettzelle oder Fettblase (Abb. 36) verliert das gespeicherte Fett (Abb. 36a), dieses löst sich schaumartig auf und färbt sich dam später auch nicht mit Osmium. Aus der alten Fettblase löst sich damn eine junge Fettzelle ab, die wieder unter Umständen Fett speichern kann, aber sich durch ihre Kleinheit von derUrsprungsfettzelle unterscheidet (Abb. 36 b).

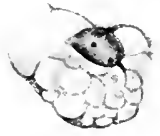

Abb. 36 b. Unugewandelte Fettzellen in der Gewebekultur. Nach Erdmann. Original.
Diese geschil. derten Veränderungen können lebend mit dem heizbaren Objekttisch beobachtet werden. Besonders auffallend ist

die starke Bewegliehkeit der Fettzelle, die mit ihrem Inhalt sich wie eine große Riesenzelle rlurch das Gesichtsfeld bewegt (Abb. 35). Leicht sind dicse Zellen lebend durch die stark lichtbrechenden Fettkugeln 
erkenntlich. Gefärbt fallen sie dureh ihr schaumiges Aussehen auf. In der Gewebekultur findet also der Abbau des Fettes in freic Fettsäuren statt, cine Erscheinung, die sehr oft auch bei pathologisehen Zuständen eintritt.

Man kann, wenn man rechtzeitig das Medium weehselt, die verschicdenen Zellarten getrennt auswandern sehen. Zuerst, wie gesagt, die eosinophilen Leukozyten, dann die Lymphozyten. Hier bietet sieh also Gelegenheit, Experimente mit der gewünschten Zellart zu machen.

Das Knochenmark ist in den versehiedensten Medien vielfach untersucht worden, aber sehr häufig sind Auswanderung und echtes Waehstum gerade beim Studium des Knochenmarks verwechselt worden. Die einzigen Erscheinungen des echten Wachstums sind die Loslösung der kleinen ,Lymphozyten“, die histologisch den Polyblasten Maxnows am näehsten stehen. Alle anderen Erscheinungen haben mit echtem quantitativen Wachstum nichts zu tun, selbst dann, wenn sieh aus den Vorstufen der eosinophilen Leukozyten vollausgebildete Leukozyten in der Gewebekultur entwickehn.

\section{Erscheinumgen der Phagozytose und der Riesenzell- bildung.}

Kein geeigneteres Objekt gilst es, um die phagozytierende Tätigkeit der Zelle im Leben zu zeigen, als die Milz (7. Ubung). Man nehme, wie schon beschrieben, Milz vom Huhn oder vom Menschen und züehte

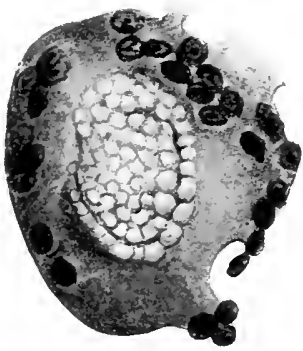

Abb. 37. Schnittbild einer vielkernigen Riesenzelle in welcher s.ch zahlreiche Lykopodiumsporen befinden. Nach LAHBERT, 1912. Journ. exp. Med., Band 15.

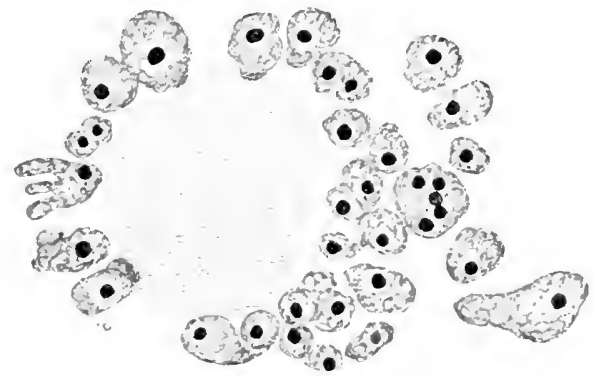

Abb. 38. Phagozyten umgeben einen Haujen von Tuberkelbazillen. Schnitt durch ein sieben Tage in P.asma geziichtetes Gewebestiick aus der Junge eines tuberkulösen erwachsenen Kaninchens. Nach VERATTI, 1919. Sr. 1- Bollettino della Soc. Medic. Chir, di Pavia.

sie in einem beliebigen Medium, Hühnerplasma und Embryonalextrakt einerseits oder für den Mensehen Menschenplasma und Hühnerplasma, dem man sterilisierte Lykopodiumsporen hinzugefügt hat. Es ist dabei zu beachten, daß die Lykopodiumsporen frei im Medium schwimmen und nicht, wie es mitunter getan worden ist, erst auf das Deckglas gebracht werden. Nach 1-2 Tagen sicht man verschiedene Stadien, die zur Bilchung von Riesenzellen führen. Viele kleine Zellen umgeben eine einzelne Spore, manche Zellen haben sich zu emem großen Synzytium 
zurammongeschlosinen, in dessen Mitte I oder mehrere Sporen sieh befinden. Es goht deutlich daraus hervor, daß diese Art von Riesenzellen sich aus viclen Zellen geblelet hat (Abh. 37).

Das sleiche läßt sich auch zeigen, wenn man in die Kultur am zweiten Tage der Züchtung vielleicht Tuberkellazillen einfügt. Auch hier ungeben, wie Abb. 35 zeigt, die Zellen zuerst den Bakterienhaufen, der später aufgenommen wird. Es ist
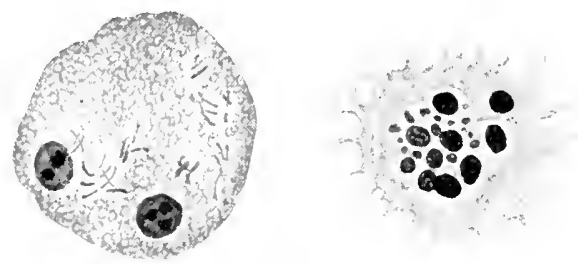

Abb. $39,40.41$. Riesenzellen, vielkernige mit unl ohue Tuberkelbazillen. Material wie auf All. 38 nath VERATTI, 1919.

wichtig, daß man nicht gleich am ersten Tage, nachden die Kulturen angesetzt sind, die Bazillen zufügt, weil frisches Plasma eine stark bakterizicle Tätigkeit ausübt, und erst an zweiten Tage wird ein Gleichgewicht zwisehen Plasma und Bakterien horgestellt. Die Bakterien relbst wïrden, wemn nicht Zellen in dem Plasma sich befänden, allein

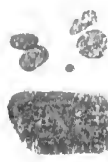

Abb. 42. Mäisesarkonzelle, die große Karminteilchen aufgenommen hat. Vier gröbere sind iiber den vicreckigen Kern kenutlich. Beachte die Prendnpotien. Nach LA IIBER'T Hnd HANES, 1911. Journ. exp. Med., Bi. 14. (Fär bung mit Hänatoxylin, Totalpräparat.) weitergedeihe'n.

Dic phagozytierenden Zellen aber nehmen die Bakterien auf und vernichten eine große Anzahl derselben (Ab). 40 und 41).

AuBer Lykopodiumsporen lassen sich auch Karminteilchen oder ja-

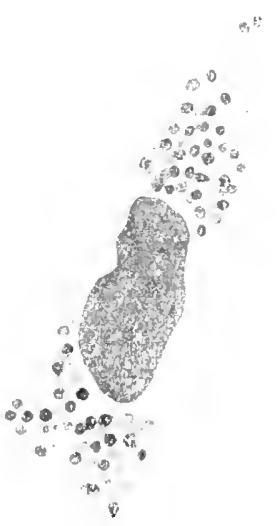

Abb. 43. Mäusesarkomzelle, aus dem gleicheu Präparat, in welcher jur diesog. Degenerationsgranula nach längerer Zilchtung sichtbar werden. panisehe Tusche benutzen. Immer aber kömen diese aufgenommenen, von den später, - wie wir sehen werden in der Gewebezïichtung sich 
bikdenden Granulationskömer - gut unterschieden werden (ADb. 4:3). Die Tumorzcllen zeigen dies deutlieh. Sie sind zuerst auch benutzt worden, un die phagozytierende Täigkeit der Zelle in ritro zu zeigen (Ab), 42).

Wenn die Endothelzellen der Milz und die 'T'umorzelten besonders gute Objekte darstellen, so kamn man aber auch alle anderen Zellarten benutzen. Fast jede llesenchymzelle kam Fremelkörper aufnehmen. daher wird bei der Deutung späterer Befunde dieses Moment stets in Rechnung gezogen werden müssen, denn nicht alle linschlüsse in lang gezüchteten Zcllen sind ron der Zelle selbst gebildet, sondern Kerne, totes Zellplasma, tote Zellen aus der Kultur werden wahllos aufgenommen. Das Nahrungshedürfnis der Zellen in der Gewebekultur ist sehr stark. Besondere Beachtung verdienen die Endothe'sellen, die am schnellsten sich aus ihrer Tmgebung befreien und am heftigsten phagozytieren. Diese Eigenschaft des retikulo-cndothelialen systems verdient besondere Beachtung, da sie ja nicht nur in der Gewebekultur, sondern auch bei vielen pathologischen Zustinden nachzuweisen ist.

\section{Zellteilung der lebenden Zelle und Darstellung ihrer Inlualtskörper.}

Für die 8. Übung werden Deckglaskulturen ron Mesenchymzellen, sei es Huhn oder Meersehwein, die im Plasma oder Lock E-Lewis Lösung geziichtet werden, verteilt, die in dem späteren Verlauf des Praktikums rom Kursisten selbst ausgeführt werden. Jetzt soll an ihnen das Lehendbeobachten und die Darstellung der Inhaltskörper der Zelle geübt werden. Wir heben die Kultur, nachdem wir sie uns bei mittlerer Vergrößerung angesehen und das eingegepflanzte Stück und den neugebildeten Zellsaum momterschieden haben, mit der Kühnschen Pinzette vorsichtig ab und legen sit auf einen sterilen, flachen, auf 37,5 erwärmten

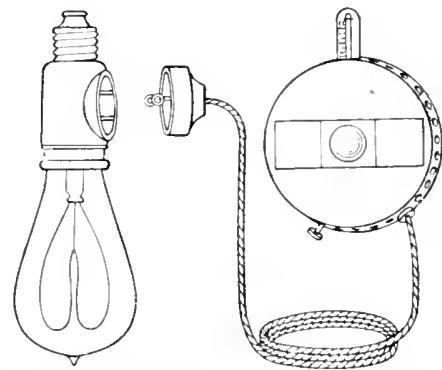

Abb. 44. Heizbarer Objekttisch, beim Durehmustern von Kulturen zul empfehlen.

Objektträger (Brutschrank) und umringen sie neu vorsichtig mit Vaselin. Der halbfeste Plasmatropfen oder die Kulturlösung hält bei richtigem Behandeln die Zellen in ihrer früheren Lage.

Hat man die Mesenchymzellen (Abb. 45) vorsiehtig auf einem flachen Objektträger unter Immersion eingestellt und sie entweder vermittels eines heizbaren Objekttisches (Abb.44) oder, da dieser im allgemeinen nicht für jeden Schüler zu haben ist, auf einer Petrischale mit auf $38-40 \mathrm{C}$ erwärmtem Wasser, das man häufig wechselt, gelegt, so lassen sich an der lebenden Zelle folgende Einzelheiten beobachten. Der gewöhnliche Ruhekern kann ohne jede Schwierigkeit erkannt werden, er ist homogen und stark durehscheinend. Sein Lichtbrechungsvermögen ist dem des 
Zellplasmas ähnlich. Sehr oft kann der Kern nur dureh die Anordnung der Nitochondrien und der Granula um ihn herum crkannt werden und dureh das Vorhandensein der Nukleoli in ihm. Die beiden, den Binde-
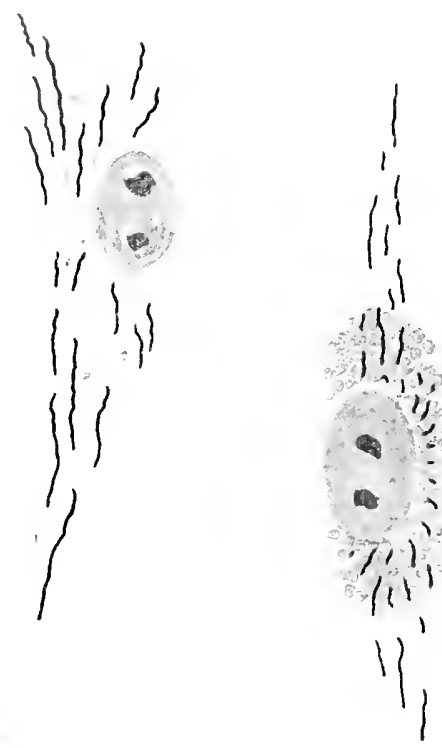

$\circ$

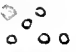

0 \%

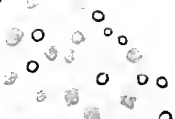

$\rightarrow 00$

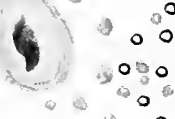

0 o 0

0

0

$\because 0$

$\circ$

Ab). 45. Mesenchymzellen des Hïhnerembryos in LOCKE-LEWIS-Lö-ung verschieden lang gezüchtet, vital gefärbt mit Neutralrot und Janusschwarz nach W. LEWIS, 1919. Johns Hopkins Bull., Bd. 30.

gewebszellen eigenen Nukleoli sind gut erkemnbar. Sie haben eine unregelmäBige Außenstruktur und seheinen lebend zerklüftet. Ganz im Gegensatz zu dem gefärbten Präjarat, in welehem der Nukleolus als runder, seharf umgrenzter Punkt erseheint. Keine Kernmembran ist in der lebenden Zelle erkenntlieh. Trotzdem ist die Grenze zwisehen Kern und Zellplasma in der Periode zwisehen zwei Kernteilungen gut erkennbar. Während der Prophase geht der geschlossene Charakter des Kernes verloren und die Chromosomen sind als traubenförmige Gebilde erkenntlich. Aueh die Spindel, aber nieht Spindelfasern lassen sich erkennen. Der Kernsaft ist allmählich versehwunden und das Zellplasma umringt jetzt die verdichtete Masse des Chromosomenmaterials. Es muß also nach Zellen mit solchen Kernformen gesucht werden. Im Zell- 
teilungsvorgange die lebende Zelle zu studieren wird nur bei la ngsa mem Studium gelingen. Doch lassen sich immer einzelne Stadien des Mitosenablaufs durch die eben gesehilderte Methode aus der Masse der wathsenden Vesenchymzellen finden.

Das Zeliplasma der lehenden Zelle ist selten homogen, fast immer mit Inhaltskörpern heladen. Das eigentliehe Zellplasma, das gewöhnlieb ak halbflüssige substanz angesehen wirk, enthält versehiedenfache Einschlässe, die lehend erkenntlich sind, dic Nitochondrien und die Granula. Dureh die von uns gewählten Zuehtbedingungen, also lier z. B. chureh das Ansetzen der Mesenehymzellen in LockeLEWIs-Lösung, die zu den sehr flüssigen Medien gereehnet werden muB, breiten sich die Zellen unter dem Deekglas ans. Nan kann ein Encloplasma mit staubähnlichen Körnchen und ein fast homogenes Aulienplasma erkemmen. Es ist kein Zentriol als scharf umsehriebener Körper in der lebenden Zelle vorhanden, sondern nur eine klare Zentrosphäre. Doch da ein so scharf und leicht erkenntlicher Körper wie clas Zentriol im gefärbten Präparat erscheint, so müssen wir annehmen, dab das, was in der gefärbten Zelle als Zentriol erseheint, eine Verdichtungs- und Verdünmungszone des Zellplasmas lebend darstellt.

Die Mitoehondrien (Ahb. 45) haben weehselnde Gestalt. Gewöhnlieh sind sie lang und fadenartig und mitunter verzweigt. In älteren Kulturen wachsen die Stäbchen zu kleinen Bröckchen, (lie sich abrunden kömmen. In degenerierenden Kulturen bäufen sie sich um die Zentrosphäre. Chemiseh bestehen sie jedenfalls aus Phospholipin und Albumin. Thre wirkliche Bedeutung im Zellhaushalt ist bis jetzt noch nicht geklärt. Manche Forscher glauben, daßsie nit den Zellfunktionen, wie Atmung, Assimilation, Speicherung ron Nähr- und Abbammaterial zusammenhängen. Andere schreiben ihnen die Bildung von Neuround Myofibrillen oder auch elastischen Fasern zu. Durch Färbung mit Janusgrïn und Janusschwarz sind sie lebent nachweisbar.

Die Granula erscheinen im Laufe der Züehtung in gröberer Masse und werden bei Neutralrot-, Methylenblau (EHricich)- und BrillantKresyl-Färbung so kräftig getönt, dabsie in der lebenden Zelle erkenntlich sind. Diese Granula sind nicht lebende Substanz. Thr Inhalt kann wieder abgehaut werden und vielleicht als Nährmaterial der Zelle während des Aufenthaltes im Züchtungsmedium rerwandt werden. Noch andere Autoren halten sie nur für Ansammlungen von Degenerationsprodukten, wiederum andere für Körnchen, die aus Eiweil3 und Fett zusammengesetzt sind. Auch ibre chemische Struktur harrt noch der Aufklärung. Wem man tote Zellen färben will, werden diese Körner allein nicht tingiert. Wahrscheinlich läßjt das Zellplasma die Farbe nicht dureh.

Totalfärbung: Die Mesenchymzellen sind an dem ersten Tage der Züchtung nur mit wenigen sich mit Neutralrot färbenden Kömehen erfüllt (Abb. 45). Tom zweiten Tage an erseheinen die stark lichtbrechenden Granula reichlich, die sich mit den Mitochondrien in der Zelle bewegen. Diese Körnchen sind von vielen Autoren als Degenerationsgranula angesehen worden. Nikrochemisch sind sie dureh 
folgende Reaktionen grekemneiehnet: Sie nehmen elektiv Neutralrot in der Verdïnnung von $1: 80000$ in Rixgek-Lösung oder Locke-LEWIsIösung auf. Io älter die Kulturen werden, desto stärker rermehren sich die Granulationen und können später ganz die Zelle erfüllen. Aulorer diesen sogenannten Degenerationsgranula sind, wie schon gesagt, in den Mesenchymzellen anch Mitochondrien, die sieh mit Janusgrïn oler Janusschwarz in Verdümnung $1: 40000$ färben. Beicle Färbungen lï̈nnen als Kursübungen leicht nachgeprüft werden, nur muB man geeignete gute Vitalfarben anwenden, die man genau ansprobieren mul.s, wie lange und eventuell wie stark verdünnt man sie am hesten anwendet. Man färbt erst cin Präparat mit Neutralrot, ein anderes mit Janusgrün oder Janussehwarz, hierauf ein drittes Präjarat mit beiden Lösungen hintereinander. Man bringt das Deekglas mit den in dem Medium liegenden Gewebestück anf einen flachen
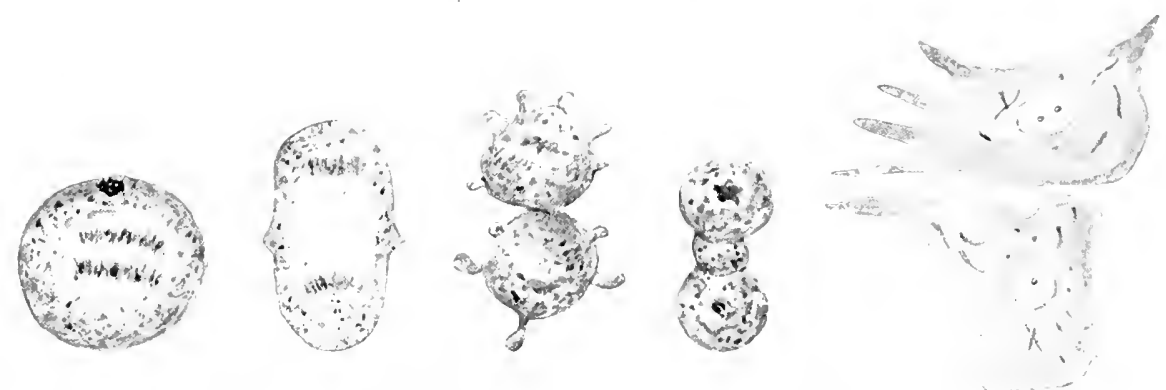

Abb. 46. Teilung der Fibroblaten des embryonalen Hulnes, von $x^{35}-10^{50}$ beobachtet. Nach LEVI, 1919. Arch. ital. Anat. Embrol., Bd. 15.

Objektträger, so, daß das Material nach oben liegt und sangt mittels einer Kapillarpipette das Medium vorsichtig ab. Hierauf beschiekt man das Gewebestück mit einem Tropfen der oben erwähnten Farblösungen und läBt die Vitalfarben einen Augenbliek auf das Gewebe einwirken. Non wird das Deckglas umgedreht auf den Objektträger gelegt, mit Vaselin geringt und das gefärbte Cewebe mittels Olimmersion betrachtet. Ist die Färbung etwas schwach, so kann man nachträglich mit der Kapillare noeh etwas Farblösung vorsichtig unterfließen lassen.

In doppelt gefärbten Präparaten zeigt sich folgende Tönung: Die Degenerationsgranula sind rot. die Nitochondrien sind dunkelgrün oder schwarz. Sjäter, nach:3-4 Tagen, finden sich in diesen Zellen sehr viele Vakuolen. Man nimmt an, daB die Degencrationsgranula wieder abgebaut werden, um der Zelle als Nahrung zu dienen. Der Vakuolenreichtum absterbender Zellen ist erstaunlich, von Plasma ist wenig mehr in cler Zelle zu bemerken (Abb. 45). 
Die Zellteilung: Die wichtigste Lebensäuberung fler Zelle in der Gewebekultur ist ihre Befähigung, sich entweder mitotisch oder amitotisch zu teilen. Wir wählen wierler als besonders gïnstiges Objekt, um die Teilung zu studieren, die in Locke-Lews oder Plasma geziichtete Vesenchymzelle des Huhness und können bei den flach unter das Deckglas ausgebreiteten, langgestreckten Zellen die Kernstrukturen leieht erkennen. In dieser 9. CHhung wird die Teilunge ine rebenden Zelle verfolgt. Wir haben hier einige Ablildungen von LEVT (Abb. 46), der beim gleichen laterial mit auBerordentlicher sorgfalt die Zelltrilungbeobachtet hat, wieclergegeben. Die Bildung der Kernschleifen, das Einstellen der chromosomen in die Kernteilungsfigur, das Auseinanderrïeken der Chromosomenlä Bt sich gut beobachten. In 36 llinuten ist die Biklung der Tochterkerne und ihr Auseinander-

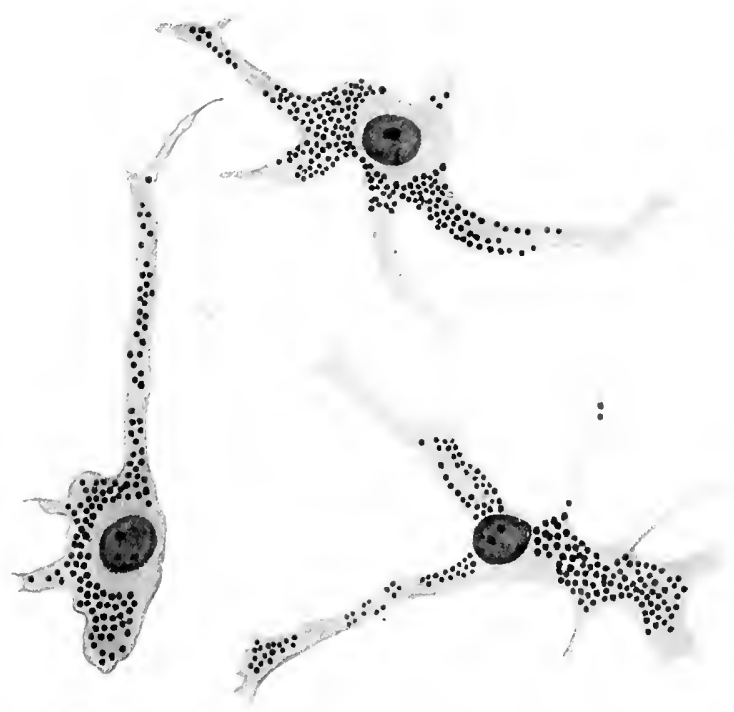

Abb. 47. Rattensarkomzellen in lebhafter Wanderung. Abentenerhiche Psendopodienbildung. Anhäulung von ..Degenerations"körnern in der Zełle. Körnchenströmung. Nach LAdliERT und HANEs, 1911. Journ. exp. Med. Fil. 14.

rïcken erfolgt. An interessantesten aber ist die nun folgende Zellplasmateilung in 99 Minuten. Dic Zellen haben sich während des mitotisehen Vorganges aligerundet und haben kleine Fortsätze gebildet. Diene Fortsätze ziehen aus der Zellkugel mit ihren beiden neugebildeten Kernen zwei unregelnäBige Kugelhälften nach zwei verschiedenen Seiten auseinander. Diese Kugelhälften runden sich erst ab und formen sich später zu einer flachen, kubischen Zelle. Später streckt sich diese kubische Zelle und bekommt die der Mesenchymzelle eigne, langgestreckte Ausgangsform. Ist das Iedium zu flüsicig, so kann keine Zellteilung erfolgen.

Hat man Sarkomzellen irgendwelcher Herkunft vorrätig, so kann man die Strömmng der Degenerationsköner in der Zelle, das schnelle Wandern der Sarkomzellen im Präparat, die fortwährente Psendopodienbilknng leicht beobachten (Ab). 47).

\section{E. Erscheinmugen des Zelltodes.}

Die 10. Übung wird sich mit der Frage befassen, wie äubern sich die Absterbeerscheinungen der Zelle in der Kultur. Kulturen 
von Mesenchymzellen, die erst liurze Zeit wachsen, sind in allen Einzelheiten bekannt: wir legen eine solehe Kultur von wa chsenden Hühnerinesenchymzellen mit dem Deckglas auf einen flachen Ohjektträger und beobachten sie auf einem heizbaren Objekttisch. Jetzt stellen wir mit der Immersion eine geeignete Zelle ein. Dann führt man mit einer feinen Kapillare eine Lösung ron Kaliumpermanganat 1:40000 his $1: 80000$ unter das Deckglas, saugt die ïberschïssige Lösung ab und ringt rlas Präparat mit Taselin wiederein. $K M_{n} O_{4}$ gibt an das Protoplasma freien Sanerstoff ab.

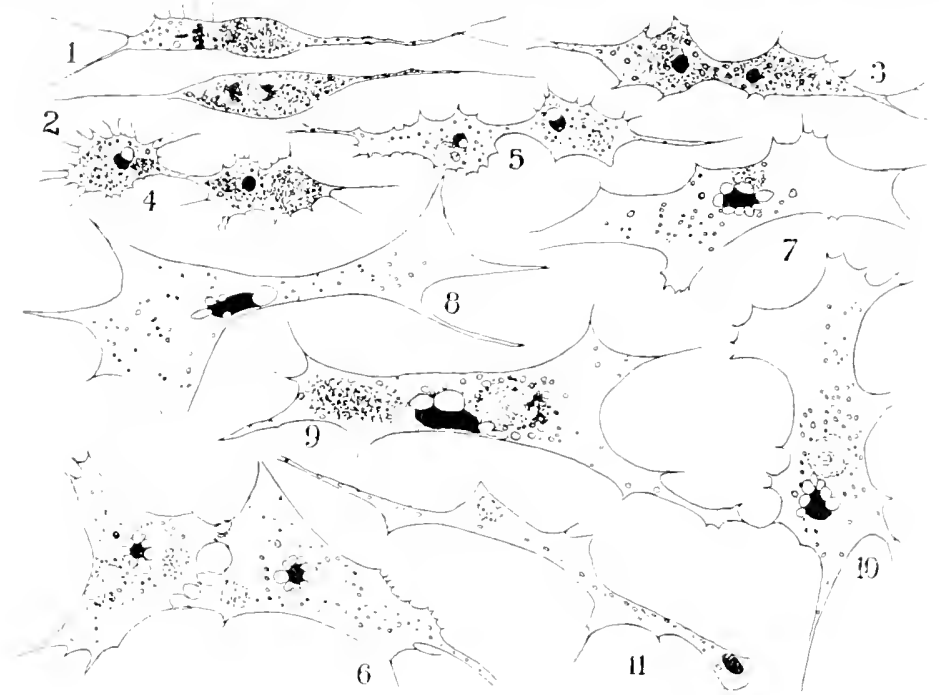

Abl. 48, 1-11. Eine to Stunden alte Kultur von Hühnermesenchymzellen von dem Bein eines 7 Tage alten Hühnerembryos. Mit Kaliumperganat behandelt nnd 16 Minuten darauf fixiert in ZENGERscher Lösung und gefärbt mit Eisenhämatoxylin-Eosin. Nach W. IEWIS, 1921. An. Journ. of Anat., Bil. 28 .

Nun lassen sich Erscheinungen des Zelltodes im Zeitraum ron $1 / 2$ Stunde sehrittweise verfolgen.

Das Chromatin des Kernes konzentricrt sich im Kern (Abb. 48), das Volumen des Kernes verkleinert sich und rings um den Kern sind kleine Vakuolen sichtbar (Abb. 48, 4, 7, 10). Da Kaliumpermanganat ehromatin kondensierend wirkt und man auch in den Vorstadien, welehe der Zellteilung vorangehen, eine solehe Konzentricrung des Kerninhaltes und Wasserabgabe findet, so geht man whl nieht zu weit, wenn man annimmt, daß auch der Sauerst offreiehtum cinen Anstoß zur Kernteilung bildet. Auch jetzt kann man Kernteilung beobachten (Abb. 48, 1, 2, 3).

In der mit Kaliumpermanganat hehandelten Kultur folgen nun weiter Alsterbeerscheinungen in der Zelle sellst, die sieh mit zahlreichen Vakuolen füllt und ganz besonders da, wo in der gefärbten Zelle das Zentriol sich befindet, einen eigenartigen homogenen Hof bildet. Anch die Degenerationskörner und Mitoehondrien gehen allmählieh unter Vakuolisierung und Verklumpung zugrunde, so daßschließlich nur eine strukturlose Masse äbrigbleibt, die früher lebende Zellen vorstellte. 
(A6h, 49, 12, 13, 14, 15). Alle diese Vorginge lassen sich lebend gut beobachten, aber anch das gefärbte Präparat zeigt,wenn essehon behandelt ist, diese Veränderungen. Langsanergehen nun die Alsterbecrseheinungen in nicht mit Kaliumpermanganat behandelten Zellen vor sich, clie sich selbst äberlassen werden und deren Medium nicht gewerharelt wird.

In den in vitro gezüchiteten Mesenchymzellen des Hïhnerembrros treten bei der Denerieration Vakuolen und Körner auf, die sich 110 das Zentriol anhäufen, rlas an einer reite oder einem Ende des Kerns liegt. Parallel mit der Anhäufung der Körner entwickelt sich ein wachsender. heller Hof um das Zentriol, die Zentrosphäre. Nie wirel gröber als der Kern. Die Mitochondrien liegen gewöhnlich mehr ofler weniger radial um das Zentriol und die Zentrosphäre, teils im Zytoplasma zwischen

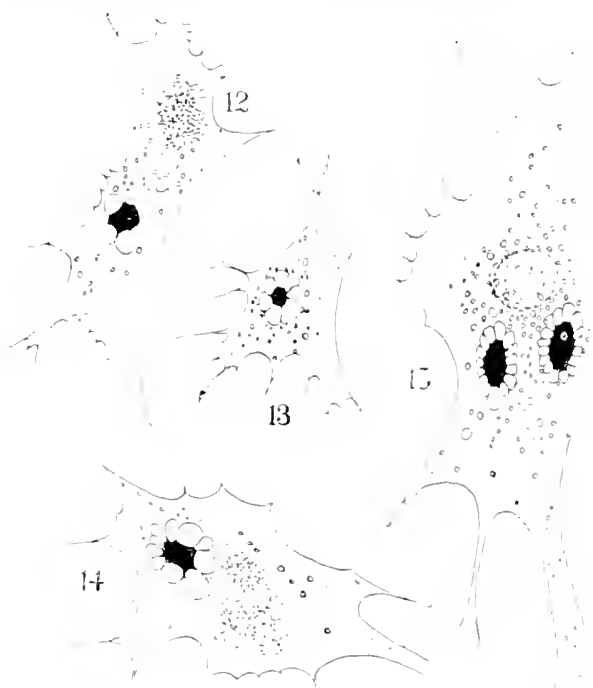

Abb. 49, 12-15. Wie Bihl 48, 1) Absterbetrcheinumgn mehren sich. bie Mitochondrien und liranla werden unkeuntlich.

den Degenerationskömern und - vakuolen, teils in der klaren peripheren Zone, in der es keine Degenerationskömer giht. Bei der Kultur ron Zelten derselben Körperstelle treten abwechsehd zwei Typen des Zellabbaues auf: 1. Der rakuoläre Trp, entweder mit umfangreicher Vakuolisation um die Zentrosphäre, die almählich das ganze Zellplasma vercluängt, oder verbreiteter Sphäre, die gewöhnlich nicht scharf umrandet ist und mit radialer Anordnung der Mitochondrien nm die sphäre herum: 2. der Riesensphärentypus mit geringer Vakuolisation um die sphäre, mit verbreiteter Zentrosphäre, die scharf umrandet ist und Zentriol, Mark- und Rindenzone erkennen läBt, oder mit konzentriseher oder radialer Anordnung der Mitochondrien um die siphäre herum. Stets finclen sich ein oder zwei Körnchen, Zentriolen in der Sphäre; die Markund Rindensehicht aber, die meist aus Degenerationsprodukten bestehen, sind mehr zufällige Gebilde. Strahlungen sind weder im lebenden noch im fixierten Präjarat zu sehen, auch nicht in der sich teilenden Zelle. Bei rem rakuolären Zelltypus ist das zytoplasmatische Netzwerk, tas sich ron der Sphäre aus verbreitet, von halbfester Beschaffenheit und verbindet die halbfeste sphäre mit einer mehr oder weniger dichten peripheren Lage. Die Vaknolen und Granula liegen in dem fliissigeren 'Teil des Plasmas, in dem sie durch ström ungen hin und her getriebon werden. Dic Nitochondrien sind radiär angeordnet und liegen im festeren 
Netzwerk. In Zellen mit verhreiteter Sphäre zeigt sich kein intervakuoläres Netzwerk, aber gewöhnlich ist um die Sphäre ein sich färbendes Zytoplasma gelegen, indem Mitochondrien, Granula und Vakuolen liegen. In normalen Hesenehymzellen findet man nach 20 bis 24stündiger Kultur 1 -2 Zentriolen meist an der einen Seite des Kerns

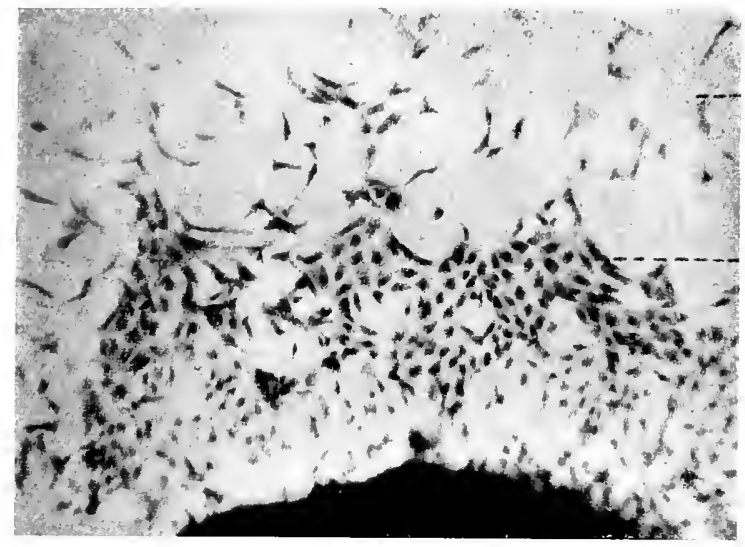

Ab). 50. Mesenchymales liewebe au dem Herzen eines 7 tägigen Hihnerembryos in normaler LOCKE-LEWIs-Lösung (nach HoliCE, 1919. Jouru. exp. Hed., Bd. 30).

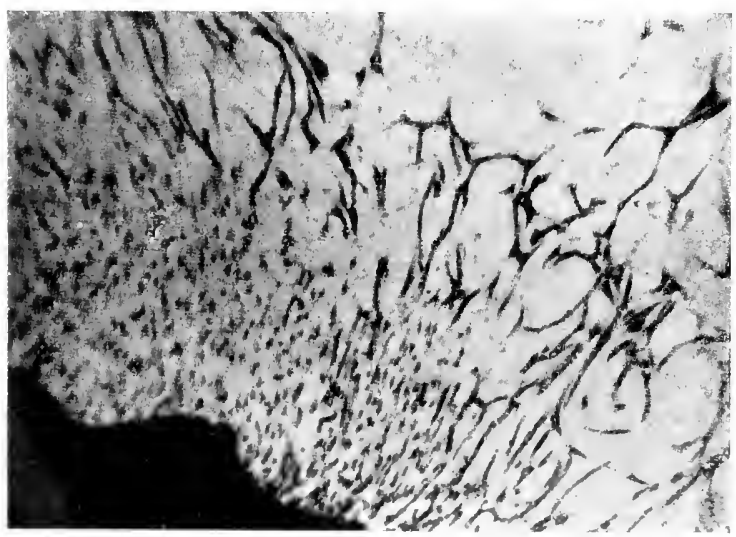

Abb. 51. Ias gleiche liewelye, aber in hypotonischer Lösung 3 Tage gezuichtet, Um das Explantat herum sinl die Zellen gestorben (nach HociUE wie Bild 50).

oder an seinem

Encle, häufig in einer Einbuchtung. Die Mitochondrien sind nicht radiär angeortnet, lang. fadenförmig, oft gegabelt und ohne Bezichungen zum Zentriol. Nicht in allen Kulturen sieht man die Vergrößerung der Zentrosphären: aher ihr Erseheinen kennzeichnet doeh eine sog. ,alte Kultur".

Ebenso interessante Beobachtungen kann man mit Zuchtrersuchenvon hypertonischen und hypotonischen Lösungen anstellen (11. Übung). Man bereite sich aus LOCKE - LEW - Lösung eine hypertonische und eine hypotonische Lösung. Die Zuchtlösung besteht aus 1.5 eem Bonillon, $0,25 \mathrm{mg}$ Dextrose, zu 85 cem von LOCKE - LEWIS - Lösung. Von dieser Stammlösung wird cin bestimmtes Volumen durch Kochen bis $1 / 2$ oder $1 / 4$ des Volumens eingedampft, die hypotonische Lösung aber hergestellt, indem man die Stammlösung mit destilliertem Wasser versetzt. Der Gehalt an Kochsalz werde nun an beiden abgeänderten Lösungen bercehmet. Da Hühnerbonillon praktisch denselben Kochsalzgehalt hat, wie LockE-LEwis-Lösmng, so brauchten keine Extraberechnungen 
hierfür angestellt zu werden. Ian setzt nun drei verschiedene Kulturreihen ron embryonalem Hübnerherzen entweder $6,7,8$ odr 7 ! Tage alt an, indem man $1 / 3$ der Kulturen in normaler Locke-Lewis-Lösung mit Hühnerbouillon, 1/3 in hypertoniseher, 1/3 in hypotonischer lösung vorbereitet. Diese werken nacheinander verteilt.

Das Aussehen der Zellen in normalen Kulturen ist bekannt (Bild 50). Es ist wichtig, zu beachten, daß in ihnen gewöhnlich nach 4s stunden die am weitesten ausgewanderten Zellen zuerst sterben, und dab in der Nähe des eingepflanzten Stiickes die Zellen am längsten leben. Gerade das entgegengesetzte findet sich in hy potonisehen Lösungen. Es sterben zuerst die Zellen um das Explantat, auch ist die Auswandesung in hypotonischen Lösmngen langsamer sls in normaler Lösung, da das Nährntedium nicht konzentriert genug ist. Maeht man die hypertonische Lïsung sehr stark, so daß sie I, , $^{\circ}$, Kochsalz enthält, so sterben alle Zellen, nimmt man aber geringere Konzentration, wie z. B. I,j und $\mathrm{I}, 2^{\circ}$ ', , so zeigten die einzelnen Zellen eigenartige Veränderungen. Sic bildeten fadenartige Fortsätze, die Mitochondrien verschwinden und das Zytoplasma zieht sich zusammen.

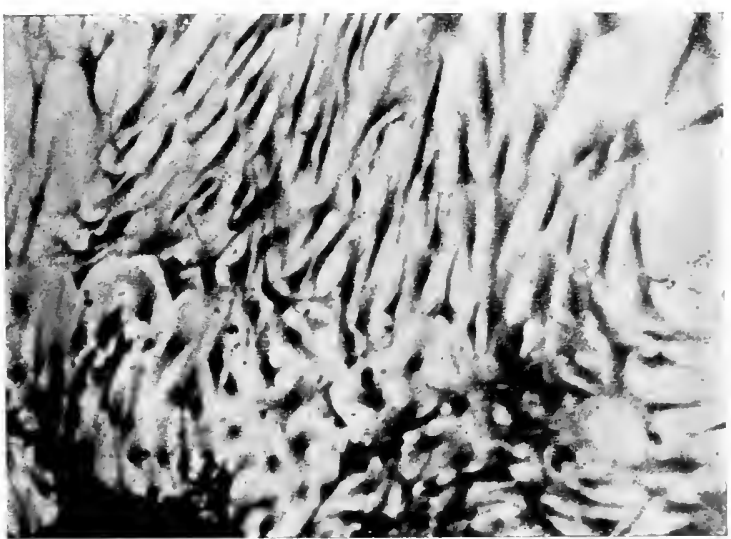

Abh, 52, Das gletche fiewelye, das nach 48 stunden Wach-tum in normaler Lösung mit hypotonischer Lösung ausgewaschen wurde uml dann wieder 24 stumlen in normaler LoCKE-LEWIs-Lösurg weiter gezüchtet wurde. Die nemgebilketen Zellen aus dem ein. gepflanzten ciewebestïck überwachsen lie zuerst ausgewanderten a ligestorbenen Zellen.

Wenn man die Zellen

mit Neutralrot und Janusschwarz vorfärbt, so kann man sehen, daß3 die Mitoehondrien versehwinden, sowie die Zelle stirht. Im Verlauf des Absterbeprozesses wird sie kleiner.

In der hy potonisehen Lösung hat im allgeneinen die Kultur ein verringertes Wachstum bis zu ihrem Tode, da die Nährstoffe weniger konzentriert sind. Doch miissen die Zellen weiter hinaus wandern, um Nahrung zu erlangen. Infolgedessen werden melr Abbauprodukte in das Medium ausgesehwemmt. So ändert sich das Medium und viele Zellen sterben. Die einzelnen Zellen bilden in hypotonisehen lösungen große Vakuolen, besonders um den Kern herum. Das Zellplasma nimmt sehr viel Wasser auf und teilt sieh in einen Granula enthaltenden und einen homogenen Teil. Der Kern ist stark vergröbert. Bei Färbung mit Neutrahot sind hier und da noeh Neutralrotkörner sichtbar. Noch besser der Beobachtung zugänglich sind die Kulturen, wenn man sie erst in normale LockE-LEwis-Lösung setzt und nach 
It Stunden diese absangt und entweder hyper-oder hypotonische lösungen hinzufügt (Abh. 52). Cnter Immersion lassen sich alle diese Torginge in der lebenden Zelle verfolgen.

In diesem zweiten Teil mserer Einführung hahen wir uns überzeugt, dak die Zellen in der Gewebekultur die Lebensäußerungen zeigen, die wir lebenden Zellen im allgemeinen zuerkennen, wir sahen die Zellen sich teilen, phagozytieren, sich forthewegen, wir beobachteten in der Zelle das spiel der wandernden Mitochondrien und Granula, die Taknolenbikhung und das Anftreten von Strukturen, die wir fast immer nur im gefärbten, selten im lobenden Präparat gesehen, wie Kernkörperehen, Teihngsspindel und Clnomosomen. Ohme Nühe können wir die so vernachlässigte Lebend beobachtung in dem isotonischen, vollständig klaren Plasmamedium pflegen. Ein wichtiger Fortsehritt, der weiter verfolgt werden sollte.

\section{III. ̈̈ußerungen echton Wachstums.}

\section{A. Echte Wachstmmerscheinmengen des embryonalen Bindegewebes md Ab- mod Umban des erwachsenen Bindegewebes.}

Im Laufe unserer Betrachtungen haben wir die verschiedensten Zuchtmedien kennengelernt, die fast alle empirisch gofunden sind, wie z. B. die Froschlymphe für das Nervengewehe von Harrison. Mit der Weiterentwicklung der Methodik der Gewebezüchtung aber wurde der Zusammensetzung des Mediums mehr und mehr Bedentung zugemessen und planmäBige Untersuchungen angestellt, welehe Eigenschaften für das Wachstum oder aneh die Differenzierung von Zellen ein Medium haben muB, um allen Anfordermgen zu genügen. Yon CARren ist nachgewiesen, daB, je jünger das Tier, aus dessen Blnt Plasma gemacht wird, ist, desto besser die Nlesenehymzelle waelsen kann. Weiter steht fest, daß über Jahre danerndes Leben von Mesenchymzellen nur in einem Medium möglich ist, in welehem sieh Plasma eines jungen Tieres oder Embryonalextrakt hefindet. Es ist also wohl sieher, daß Wachstumshormone oder Wachstumsenzyme in den Körpersäften dieser Tiere kreisen. Ringersche Lösung, LockeLEwissche Lösung, LifsEgangs kolloidale Lösungen erlauben ein bis zu 14 Tagen andanerndes Wachstiom embryonaler Warmblütler- mol erwachsener Kaltblütler-Zellen bei häufigem Weehsel des Madiums. Dies zeigt, daß in den erwachsenen Zellen selbst der Kaltblütler, wie es ja bei der embryonalen Zelle allgemein angenommen wird, Wachstumsbeschlemiger sich befinden, die im Lanfe dor Zeit aufgehraucht werlen.

Der Ah- und Umban der erwachsenen Warmblütler-Zelle ist bis jetzt nur im Plasmamedimm beobachtet worden und besonders günstig scheint für die Aktivierung der Zelle ein Waschen in arteignem Serm bei täglichem Wechsel des Plasmas nach Cranpy. 
Ganz glob gesprochen, stellen wir ms jetzt die Aufgabe, wie gelangen wir in den Besitz einer Gewebe-, K ult ur" im wahriten Simne des Wortes, eines Aggregats rom Metazoenzellen, die nicht ron ms in das Medium gesetzt wurden. Weiter müssen wir diese nougebiddeten Zellen beliehig oft zum Ansetzen von Tochter-, Enkel- und Generationenfolgen $n^{\text {ter }}$ Potenz benutzen kömnen (12. C'bung).

Diese Forderung ist bis jetzt nur bej der Zü̈htung vom Mesenchymzellen des embryonalen Höhnerherzens erfïllt, aber hier auch rollkommen einwandfrei. Doeh ist von Flscher 192.2 zuerst eine dreimonatliche Züchtung ron Lielepithel berichtet.

Die bis jetzt angestellten Entersuchungen haben die Erscheinungen des Zellebens in mamnigfacher Verschiedenhejt uns klar gemacht, eloch können noch immer nicht die Erscheinungen des echten, also quantitativen Wachstums der Zellen ron den Praktikanten an selbst angefertigten Präparaten sturliert werden. Wir hahen im Laufe eles Kurses zur Beobachtung der lebenden Zelle bei Einübung der Vitalfärhung und weiter bei Beohachtung der Zellteilung Präparate von Mesenehymzellen ansgeteilt, die friseh in dem Meclium gewachsen waren. Es war leicht. an ihnen die neugebilfleten Zellen ron dem eingepflanzten Situck zu unterscheiden. Schwieriger aher ist es, ein solch beweisendes Präparat num selbst anzufertigen.

Wir werlen jetzt das üher Woehen ausgerlehnte Wachstum der emJryonalen Bindegewelszelle studieren und zum Gegensatz oder Vergleich der Erscheinungen der erwachsenen Bindegewelszelle in der Gewebekuttur heranziehen. Zum Studium der embryonalen wachsenden Bindegewehszelle wind gewöhnlich die Mesenchymzetle genommen, die aus dem embryonalen Herzen dre Maus, der Ratte oder des Huhnes herauswächst. Es ist von Vorteil, wenn der benutzte Embryo nicht mehr als ein Drittel seiner Entwicklungszeit churehgemacht hat, das $H$ uhn akso, welches wir als Objekt wählen, nicht mehr als 7 Tage alt ist. Vorder Arheit mub Hühnerplasma, Ringerlösung und Embryonalextrakt rom Huhn hereit sein, reiehlicher Vorrat ron allen diesen Vedien ist eine Haupthedingung. Das Ei wird an seinem stumpfen Pol geöfnet. Man benutzt eine Knopfsehere. Die Polkappe der Eischate, minter weleher' sich die Luftkammer befindet, wird abgeschnitten. Vorsichtig läBt man num den Inhalt des Eies in eine bereitstehende flache, sterile Sehale laufen. Hierbei ist zu beachten, das der Embryo ohen auf dem Dotter ausgelneitet liegt. Jetzt hel,t man mit einer Pinzette und einem spatel den Emhryo in eine frische, kleinere sterile Schale, inden man mit der Pinzette den Embryo rorsichtig anfabt und mit dem sipatel den Embryo stützt, damit er nicht zerfliebt. Der Embryo ist gallertartig, deshalb ist Vorsicht beim Herausheben nötig. Die num zum Abspülen benutyte Ringersche lösung ist auf $37 \mathrm{C}$ angewärmt. In eine sterile Schale bringt man ein steriles fenchtes Gazeläppehen mol breitet vorsichtig den Embryo daraif aus, wenn der Embryo so klein ist, daß man nicht ohne Lupe auskommen kann. Ist der Embryo größer, so nimmt man die Organe, die man züchten will, hier ako das Herz, einfach heraus und legt es in eine sterile Schale. te weniger 
man die Organe mit Instrumenten anfaßt, desto besser, Sehnelligkeit ist hier erste Bedingung. Das Herz wird zerstückelt und wie bei den anderen Übungen entweder mit reinem Plasma, mit Riscerscher Lösmng und Plasma, mit Embryonalextrakt und Plasma oder in Ermangelung von allen diesen Medien mit LockE-LEwisscher Lösung beschickt. Es ist ganz hesonder's bei Warmblütlem darauf zu achten, daB zugleich mit den im Medium befindliehen embryonalen Gewebestïckchen auch Deckgläser mit je cinem

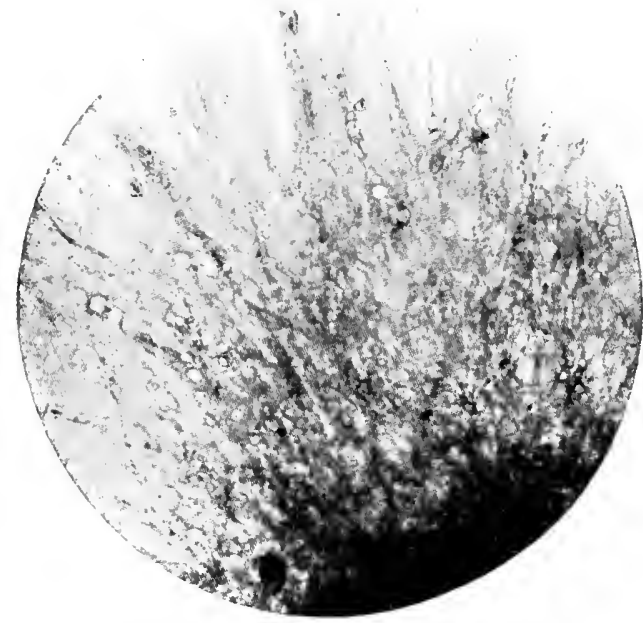

Abb. 53. Mesenchymzellen des Unterhautbindegewebes vom 13 tägigen Hühnerembryo. 8 Tage in Plasma geziichtet. Mikrophotogramm nach dem Leben. Das dunkle Stück unten ist das eingepflanzte, allmählich nekrotisch werdende Gewebe. (Griginal nach ERDMANN.) Tropfen der versehiedenen angewasdten Medien oh ne Material inden Brut ofen gebracht werden, damit man bei etwaigen Verunreinigungen die Quelle der Infektion sicher kennt und sie bei weiteren Versuchen aus. schalten kann. Manche Forseber empfehlen, das Gewebestück zuerst auf das Deckgłas zu bringen und dam den Plasmatropfen, andere dagegen beschicken erst mit Plasma und legen dann das Gewebestück hinein (Снамеу). CHAMPr meint, daß der Embryo auf chese Weise besser Sauerstoff aus der Luft aufnehmen kann. Nach kurzer Zeit, gewöhnlich nach $24-48$ Stunden, breitet sich ein schleierartiger Ring mu das eingepflanzte Stück aus. Dieser sehleierartige Ring besteht zum großen Teil aus Desenchymzellen (Abb. 53), die oft ein rakuoliges Aussehen haben. Sie kömen die abenteuerlichsten Formen annehmen, haben einen blasigen, fast homogenen Kern und verzweigte spitze Ausläufer.

Schneidet man num em Stïck dieses Hofes oder Schleiers aus und bringt iln in neues Medium, so ist man ganz sicher, daß man Mesenehymzellen fast rein bekommt, nachdem die Blut- und Muskelzellen des embryonalen Herzens nicht mit ïbertragen worden sind.

Nur auf tliese Weise ist es möglieh, die Gewebelulturen über längere Zeit am leben zu erhalten, denn die nekrotischen alten Zellen müssen frïher oder später entfernt werden. Auf diese Weise ist es CARreL und Ebezing gelungen, Gewehe in 3ns Passagen durch 18 Nouate am Leben zu erhalten unter guten Wachstumsbedingungen. Im Jahre 1914 wurde die Wachstumsgeschwindigkeit dieses Gewebes, das schon 2 Jahre unter Kulturbedingungen gewesen war, geprüt und es fand sich, daß, verglichen mit cinem neu eingepflanzten Stück embryo- 
malen Hühnerherzens, das solange in Kultur gewesene Herz sehneller sich fortpflanzte, einengröberen Ring von Zellen erzengte, wie ein friseh in Kultur genommenes Stïek. Die Abkömmlinge dieser Zellen leben noelt heute, es sind bis April 19)! 1347 Passagen gemacht worten. Das Merkwürclige dabei ist, dabs sich die Zellen bis jetat nicht elifferenziert haben, sondern Mesenchymzellen, Vorstufen von späterem Bitulegewele. Knorpel, Knochen- odier Muskelzellen sind.

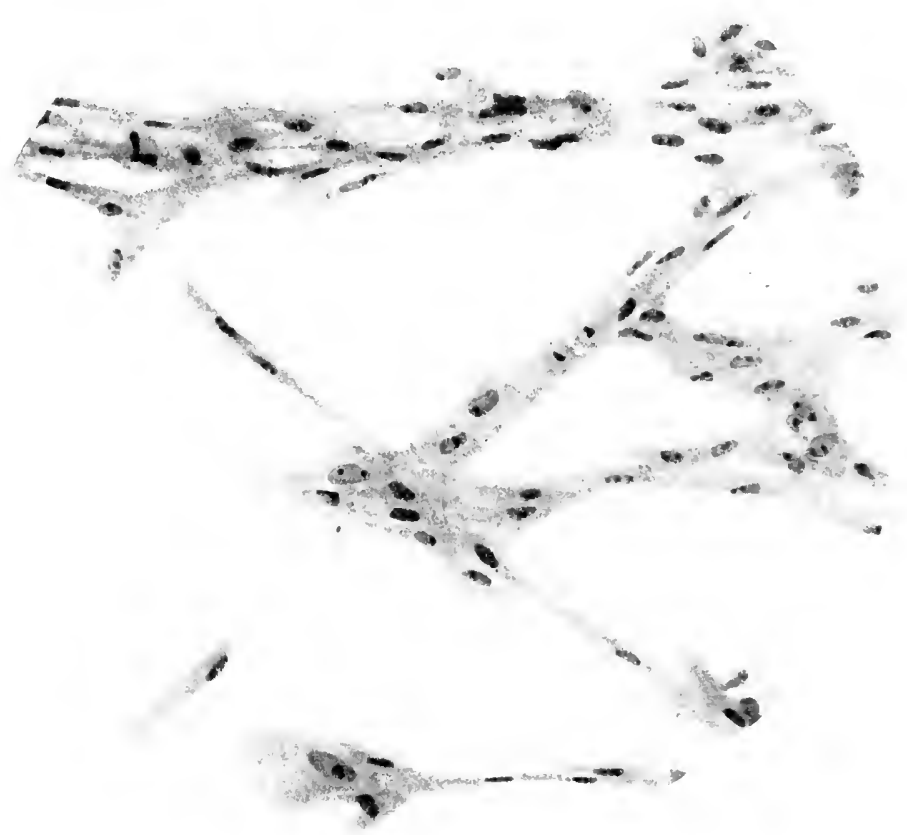

1hb. 54. Gelarbtes Prïparat der 732. Passage (April 1917). Abkömmlinge der an 17. Jan. 1912

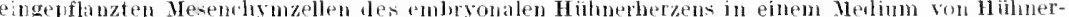
plasma mol Embryonalextrakt wie 1: I. (Nach EBELINi, 1919. Journ. exp. Med., 131. 31..)

L'm quantitatives Wachstum wirklich cinwandfrei nachzuweisen, verfahren wir folgendermaben: Nachelem wir uns Kulturen angelegt haben, zeiehnen wir uns mit einem Zeichenapparat die Lmrisie von innen und messen die beiden gröbten Durchmesser mit einem (Okularmikrometer. Unter jede Kultur legt man direkt in die Schale diene Zeichnonng und seriert sowohl die Kulturen als auch die Zeiehnmengen. Am besten läBt man jetzt die Präparate $24-45$ stunden ruhig im Brut. ofen stehen und kontrolliert clann den ansgewaehsenen Zellenhof, des auBer Mesenchymzellen für gewöhnlich noch embryonate Blutzellen und mitunter Myoblasten enthäl. Jetzt fertigt man sich von cinem Präparat wieder eine Zeichnung an, läbt aber cin Präparat vollständig 
ungestört stehen. Vom :3. Präparat schneidet man sich in jetzt zu besprechender. Weise den Zellenhof ab und pflanzt ihn in gleiches, neues

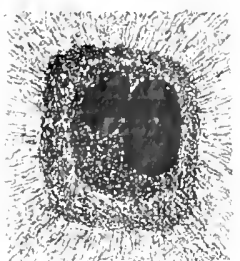

(1)1, 55. All<kchuitt au* gewacheenen Mesenchymzellendes embrvonalen Jühnerherzens is Stumle nach ler iberpllanzung. Jip \%ellen waren $z$ Monate gezuichtet. Nach C'ARLLL 1914 . Jourl exy Vedizin. band ? 1 . Verlium (13. Cbung).

I)as Abschneiten des neugewachsenen Zellhofes erfordert eine gewise Cthang (Abb. 5.5). Den heizbaren Objekttisch legt man auf den Tiseh der binokularen Lupe, setzt sich seine frisch gesehliffenen Instrumente zurecht, hat aufgelöstes Vaselin, aufgelöstes lledium, sterile O!jokektträger and Deckgläscr in Greifnähe. Jetzt dreht man genau so, als oh man die Präparate mit frischem Nährmedium versehen wollte, das Deckgläschen um, entfernt die alte Kulturflïssigkeit vorsichtig and bringt Waschflüssigkeit, entweder art. eigenes Serum oder Rixgerische Lösung sorgsam auf las Präparat. Alle diese Operationen miissen unter

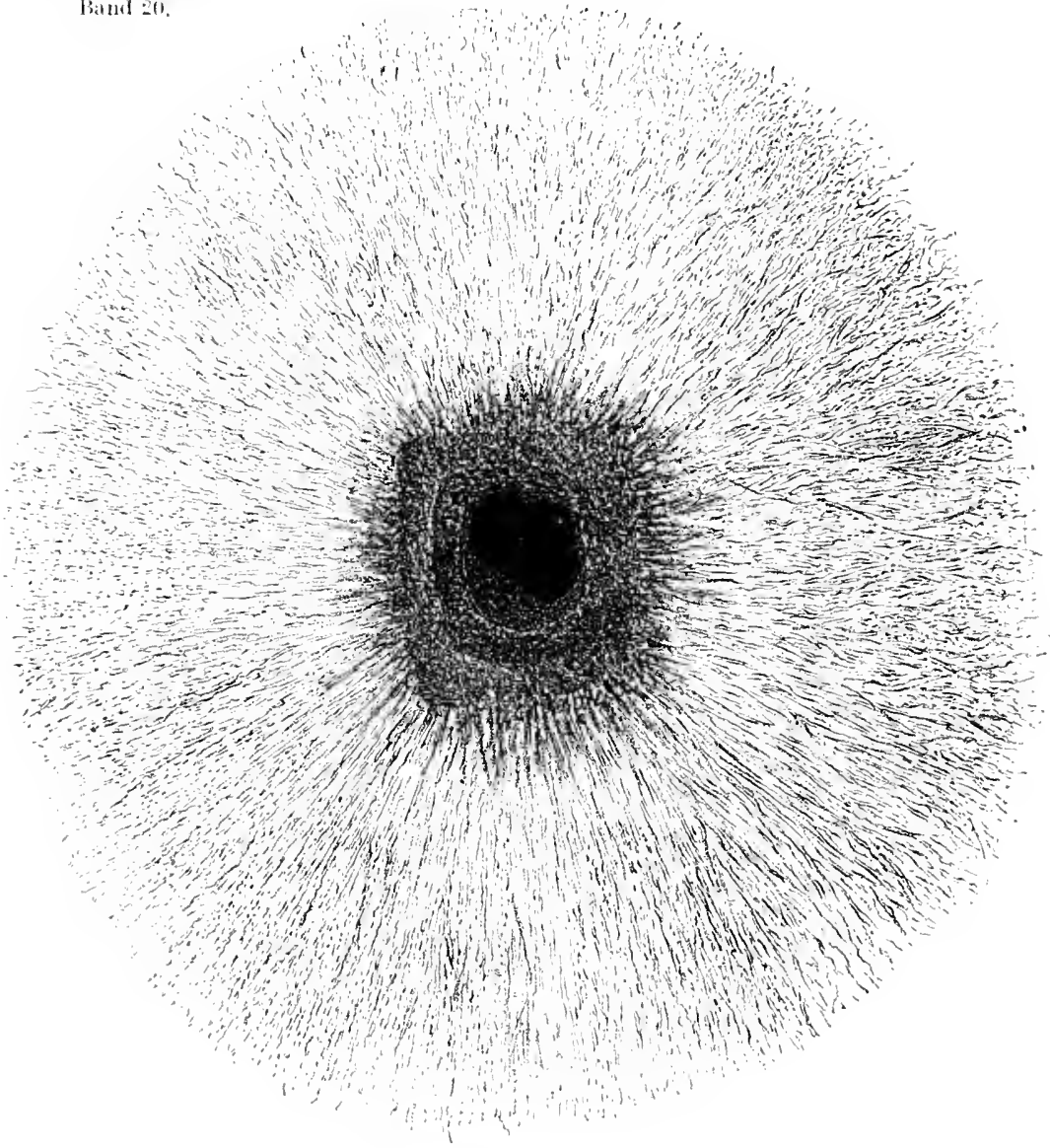

Abb. 56. Das-elle stück nach 48 Stunden. 


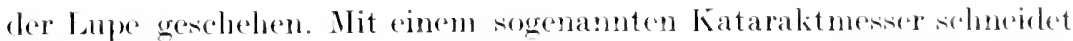
man aus dem Hof ein riereckiges stiuck aus und sotzt es vorsichtig mit einem dreizackithnlichen Messer in ras nene Merlium. Damn int man sicher, nur neu ausewachene Zellen bei der zweiten "berpflanzung iibertragen zu haben. Die embryonalen Bindegewebsedlen vertragen tiese anscheinenel rauhe Behandlung sehr gut. Fis kommt besonders darauf an, sehnell und sauber zu arbeiten unel groblixe Temperaturschwankungen zu rermeiden.

Die Lmbettung muß num je nach dem stande der Kultur jeten :3. oder 4. Tag wiederloelt werden. Ieh habe gefunden, dab das embryonale Meerschweinchengewetse nur jeden 3 . und 4. Tag umgebettet werden muB, während das am meisten gebrauchte Hühnergewebe oft früher das Derlium verflüssigt und sehon nach kïrzerer Zeit eine Cmbettung verlangt. Hat man num einen Zellenstamm sich gezüchtet, rler eine Reihe von L'mbettungen estragen hat, so wird dic Arbeit leichter und leichter, da eine gewisse unbeabsichtigte Selektion der Zellen durch diese Art des Zellebens erreicht worden ist.

Mit soleben Stänmen, die Carres und EBentxg jahrelang, jetzt 9 .Jahre weitergeführt, Iassen sich num die interessantesten Experimente all:führen, die ganz besonders wichtig fün die Ernährungsphysiologie der Zelle werden können. Mlit einer solehen, aus undifferenzierten Mesenehymzellen bestehenden Kultur (Abb. ¿́6) läßt sieh entseheiclen, welche Nährstoffe diese eine Zellenart unberlingt gehraucht. Wir wissen heute schon, dalis ohne Embryonalextrakt ein langdanerndes Zelllehen mmöglich ist. Wir werden sicher noch finden, welche Medien

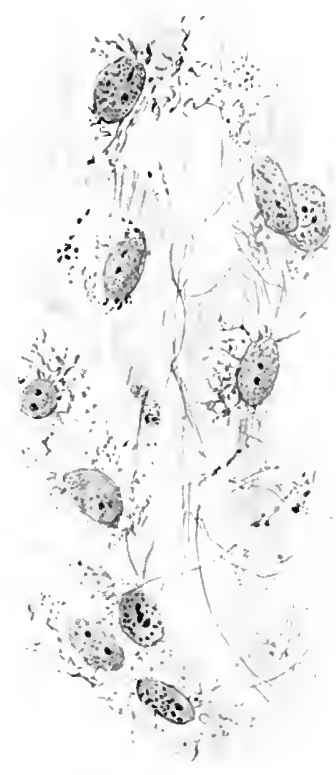

Abb. 57. Merenchymzllen des embryomalen Huhnes. (retärbtes Präparat (Omiumdämple. Eisenhäma toxyliu-Eosin.) In: Präparat ist 70 stunden bebrutet. bie Bindegewebribriblen sime erst im gefäbten Präparal erkenntlich. Diese Zellen sind an einer stelle des Präparates gewachsen. an der genügend Platz war. Xich H. LEWIA, 1917, Publ. Carneg. 1nst. Nr. 2206 . nötig sind, um die Zellen zur Differen-

zierung zu bringen, was bai diesen llesenchynzellen noch nicht gelungen ist, oder zu unterseheiden, ob wirklich erst die ausgeübte Funktion die Zellstruktur bedingt oder ob das Hinzufügen ron Embryonalextrakt der Differenzierung hinderlich ist.

Gut gelungene Präparate dieser Art eignen sich besonders zm Anfertigung ron Totalpräparaten, die eine $\ddot{\mathrm{C}}$ bersicht über die Topographie des eingepflanzten Stïckes und der auswachsenden Zellengeben. 
Es wird heim Konservieren von Totalpräparaten genau wie bei der Froschhaut verfahren, nur mub noch viel vorsiehtiger gearbeitet werden, damit die zarten embryonalen Zellen nicht verletzt werden

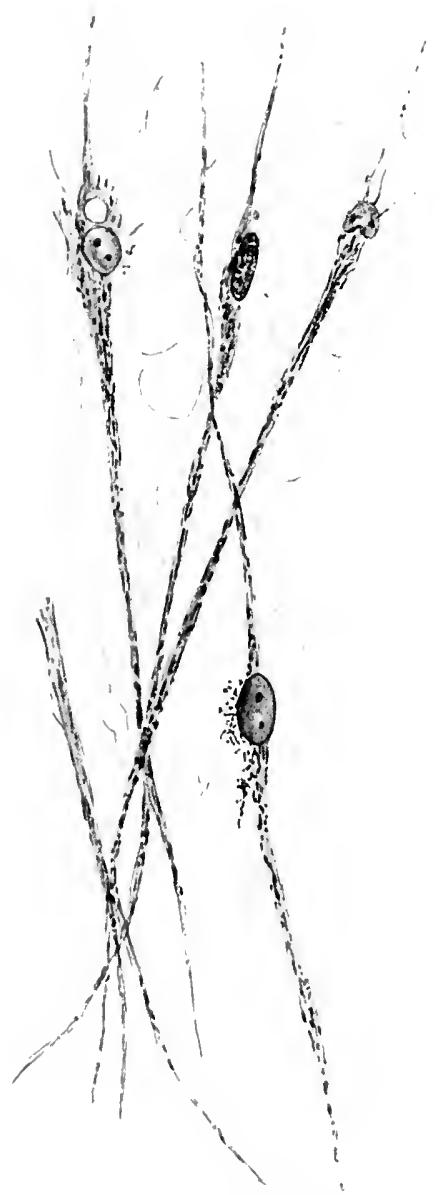

Ab). 58. Nesenchymgewehe des embryonalen Huhnes. Ein ahniliches Präparat wie das auf Abb. 57 abgebildete. Jicht gedrängte Lage bedingt die veränderte form der Mesenchym. zellen. 24 st unden bebrïtet. Nath M. LEW 1 s, 1917, Publ. Carneg. Inst. Nr. 226. (Abb. 57 und 58.)

Man gebraucht zum Fixieren der 'Totalpräparate die gewöhnlich angewendeten Fixierungsflïssigkeiten, man vermeide aber, wenn es irgend angeht, nach $110 \ddot{g}$ lichkeit, Fixierungsflüssigkeiten, in welchen sich Alkohol befindet, da Alkohol ras Plasmamedium ausfällt. Dieses aus gefälltem iviweiß bestehende Fällungsprodukt moüllt die Präparate mit einem feinen Schleier, der bei Betrachten der Stücke mit Immersion stört. Daher babe ich trotz anderweitiger Bedenken besonder's oft mit ORTHschem Gemisch fixiert, weiter mit (arnois, seltener mit sublimatalkohol oder nur da, wo es unberlingt notwendig ist, mit Alkohol, wie bei ler Glykogen- und elastisehen Faserfürbung. Will man Stücke fixieren, die in einer Salzlösung gezüchtet worden sind, so ist es unter Cmständen wichtig, das Salzmedium dureh ein indifferentes Medium, vielleicht Serum auszuwaschen. Ich gebe hier mur die Torschriften für die am leichtesten anwendbaren Darstellungsmöglichkeiten. Die gehräuchlichsten Fixier'mgsflüssigkeiten sind folgende:

\section{ZEXKERsene Flïssigkeit.}

Die Zexkersche Flüssigkeit besteht aus einer. Misehung von:

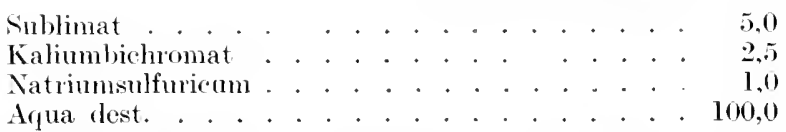

Diese Substanzen werten in der Wärme gelöst. Man setzt ihnen kurz vor Gebrauch 5 Teile Eisessig zn. 
Dic zn fixierenden Präparate werden 24 stunden lang in dic Lösung eingregt, dann 24 Stunden lang grïndlich in flieBendem Masser nachgewaschen. Darnach gehärtet in Alkohol von aufsteigenter Konzentration.

$$
\text { Orthsehes Gemisch. }
$$

Formol 10 proz. (das in den Hantel lommende ist 40 pro\%, man mub es ent. spreehend verelïnnen), MÜLLERsehe Lösung.

Dieses OrTusehe (iemisch ist in Nisehung nur sehr begrenzt halt bar, man mucht es deshatb bei jedesmaliger Anwendung friseh und zwar

Jïllersehe lösmor . . . . . . . . . . . 9 Trile

Formol . . . . . . . . . . . . . . 1 'Teil.

W ÜLLERsche Flïssigkeit.

30 g schwefelsames Natron und 60 g pulverisiertes cloppelchromsaures Kali werden in $3000 \mathrm{ecm}$ destilliertem, vorher aufgekoshtem Waster celöst. Die Lösnng erfolgt bei Zimmertemparatur langsam (in 3-6 Tagen). Man bereite deshalb die Lösung mit exwämt :m Wasser oder stelle die Frasche in die Nähe des ofens.

$$
\text { Fixienung nach CARxor. }
$$

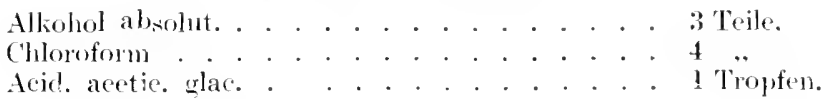

C'H A \P Y sche Lösung.

biese wird hergestellt ans:

1 proz. wässlige Lösung von Acid. ehromie. . . . . . . TTeile,

3 proz. $\quad$. $\quad . \quad$. Kalinm bichromic. . . . . . 7 ".

2 proz. . $\quad$.. $\quad$.. Osmiumsäur . . . . . . . . 4 "

Man konserviert in dieser lösmeg 24 Stmolen und wäscht sehmell in Aqua dest. Jann hereitet man eine Lösung aus: I Teil wässriger lösung von gereinigter Prougallussäure. 2 Teile 1 proz. läsung ron Chomsäne. In dieser Wisehmes bleiben die Präparate 24 stumblen. Darmach wasehen in Aqua dest. 1/2 Stuncle. Man lereitet weiter eine 3 proz. wässerige l dösung von Kalim bichromic. imel lä lat rlarin die l'räparate : Tage liegen. 24 stunden wässern in Aqua dest.

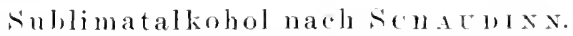

Jan löst 7 g vublimat in loo ecm kochendem destilliertem Masser. mmmt ron dieser konzentrierten wässrigen Lösung 2 Teile. Alkohol absolut. I Teil. Es wird anch del Zusatz von einigen Tropfen Essigsänre empfohlen, den ich nur bei Anphibiengewebe anwende.

$$
\text { Färbung naeh C } \mathrm{I} \text { E Ms } \mathrm{A} \text {. }
$$

Am leichtesten golingen dom Anfänger die abgeänderte Ciemsafärhmog, die ühliche Hämatoxylin-Eosinfärbung, schwieriger schon die Heidenhain-Färbung mit beliebiger Nachfärbung des Plasmas für Tot al präparate.

Die abgeänderte, den Bediirfnissen der Gewehezïchtung angepabte Giemsa-Färbmng ist mur fïr 'Total präparate anzuwenden. Nachdem man das Deekglas mit den Präparat mit der KüHssehen Pinzette umgedreht hat, entfernt man vorsichtig mit ciner feinen Glaspipette das noch vorhandene Plasma und pipettient, vom äuBeren Rande anfangend,

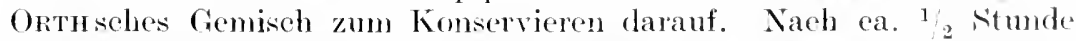
wird dieses abpipettiert, in derselben Weise Aqua dest. und nachdem man dies wieder entfernt hat, Alk. $700^{\circ}$. Ilan keroitet sich dio Farb- 
lösung in folgender Weise: Auf $1 \mathrm{cem}$ Aqua dest. 1/2 Tropfen Giemsalösung und pipettiert nun die Farbe auf, nachdem man den Alkohol in Aqua dest. ausgewaschen, vorsichtig rom Rancle anfangend bis das Präparat beeleckt ist. In dieser Lösung bleibt das Präparat 24 Stunden. Darnach wird mit Aqua dest. gespiilt mittels Pipette und differenziert in $96 \%$ Alkohol. Dies geschieht unter dem Mikroskop und zwar his zum ritlichen Farbumsehlag. Dann bringt man das Präparat in reinen Alk. $916^{\circ}$, in Alk. absol., in Alk. absol. + Xylol, bis das Präparat ganz anfgehellt ist unch schliebi clann in Zedernöl ein.

Färbung mit Hämatoxylin nach Delafield.

Nlan konserviert die Präparate wie vorher angegeben in einer dor Konservierungsfliissigkriten, am gebräuchlichsten ist die Konservierung in OrTnsehem Gemisch, und bringt sie dann in Alk. $70{ }^{\circ}$ ". nachdem sie in Aqua dest. gespült worden sind. Die Farblösung bereitet man aus $30 \mathrm{ecm}$ Aqua dest. und 6 Tropfen Hämatoxylin nach Delafield, Farbdauer 24 Stunden. Spülen in Brunnenwasser, um die Farbe aufzuhellen, differenzieren in Salzsäure - Alkohol 1000 unter dem Mikroskop, bis die Kerne deutlich hervortreten, spiilen in Brunnenwasser, um die anhaftende Salzsäure herauszuwässern, spülen in Aqua dest., Präparate dureh die Alkoholstufen führen; einlegen in Alk. absol. und Xylol: Xylol; einbetten in Zedernöl.

Hämatoxylinfärbung naeh HE IDExHAlx.

Präparate wie schon angegeben konservieren und in Alkohol $70^{\circ}$ bringen. Beizen in folgender Lösung: 2.5 g schwefelsaures Eisenummonoxyd gelöst in 100 cem Aqua dest. Darin bleiben die Präparate 6-12 Stunden; abspilen ein paar stunden in Aqua dest. Färben mit WE⿺GerTs Hämatoxy'in (30 cen Hämatoxylin Werciert + 30 cem Arua dest.) 12_36 Stunden. Abspülen in Brmnenwasser. Nan differenziert nun in der oben schon angegebenen Eisenlösung; zuerst bringt man kurz die Präparate in die Lösmng in der angegebenen Konzentration und verdïnnt diese dann auf $1 / 5$ dieser Konzentration mit Aqua dest. und differenziert darin weiter bis zum deutlichen Hervortreten der Kernstrukturen. (Beobachten unter dem Mikroskop.) Abspiilen in Brumnenwasser ca. 15 Min. Nach der Kernfärbung kann man noch eine Naehfärbung machen mit einer Plasmafärbung (Lichtgrün oder Eosin). Man bringt die Präparate bis zu Alk. 70 ${ }^{0}{ }_{0}$ und fügt den Alk. $96^{\circ}{ }_{0}$ ein wenig Eosin oder Liehtgrïn zu, beobachtet unter dem Mikroskop) diese Färbung und führt dann die Präparate wie vorher angegeben durch die Alkoholstufen, Xylol + Alkohol absol.; Xylol; Zedernöl.

Färbung nach Fixierung von Prexixt, Champy oder Zexker.

Konservieren und Kernfärbung der Präparate wie bei Eisenhämatoxylin Heldenhux angegeben. Nach Differenzierung Nachfärbung mit Erythrosin 4-24 Stmulen. Zum Differenzieren dieser Färbung wird folgende Lösung angewandt:

Orange wäBrige gesättigte Lösıng . . . . . s Teile.

Lichtgrün .. $\quad . \quad$, . . . . . . 4 ,

Alk. abs. . . . . . . . . . . . . . . . . 4 ,"

6 Tropfen gesättigter Zitronensäure.

Präparate durch Alkoholstufen führen; Xylol + Alk. abs.; Xỵlol pur.; Zedernöl.

Anschließend an das embryonale Bindegewebe untersuchen wir die Veränderungen des erwachsenen Bindegewebes und zwar an dem Unterhautbindegewebe eines Säugetieres (14. Übung). Das Unterhantbindegewebe des Kaninchens ist von Maxmow studiert worden, und wir folgen hierseinen Angaben. Nachdem man wie üblich im arteigenen Plasma kleine Stïckchen des Unterhautbindegewebes einige Stunden gezüchtet 
hat, wechselt man das Mectum, indem man vorher das St ïck entwederin Ringerscher Lösung oder in Serum oder in einem Gemiseh von Plasma und Riscerscher Lösung auswäscht. Hierdurch werden alle Inhaltskörper der erwachsenen Bindegewebszelle, die nicht mehr abgehaut werden können, allmählich aus dem eingepflanzten stück entfernt. Die Zelle erhält dadurch einen gewisien Anreiz zu erneuter Tätigkeit, der auch wahrscheinlich durch die Wundhormone, die aus den zerschnittenen Pandzellen auswachsen, verstärkt wird. Nach kurzer Zeit

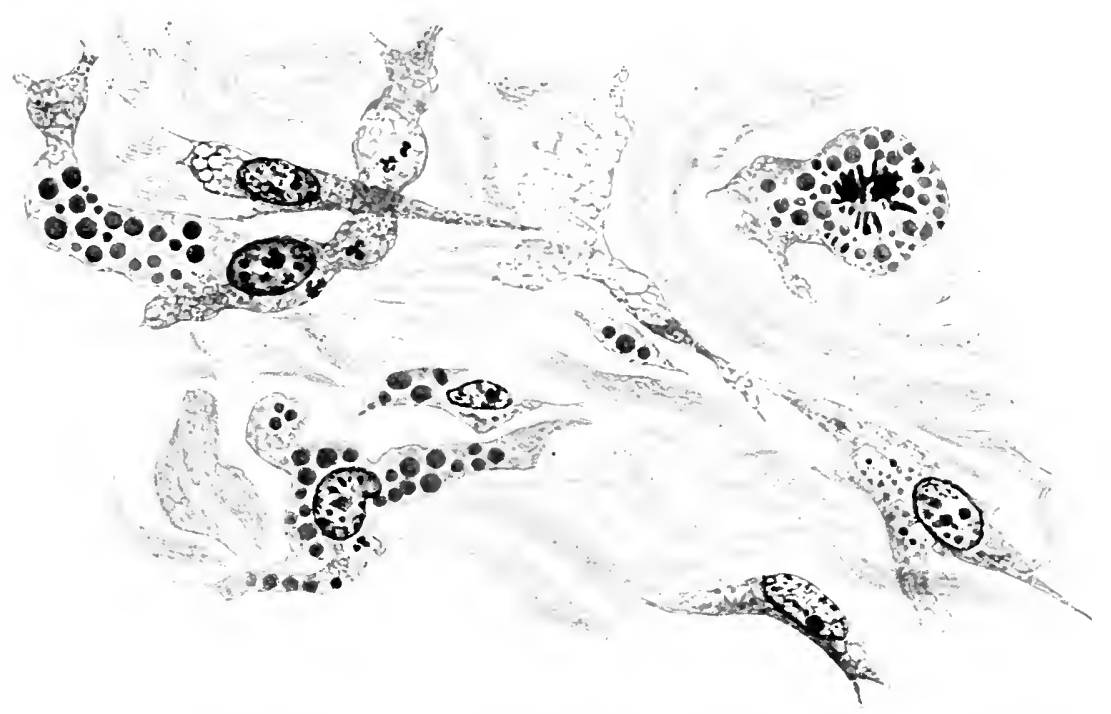

Abb. 59. Interhatbindegewebizellen des erwachenen haninchens. Schnittbild (ZLXKER,

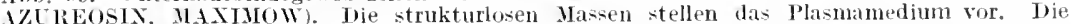
Bindegewebsellen (Fibroblasten) sind mit feinen (iranulationen verschiedenster Art gefült. Ihre form gleicht der enbryonaler Mesenchymzellen. Beachte die Mitose links oben in einer Wabderzelle. Das Präparat ist 5 Tage gezüchtet. Nach MAXIMOW, 1916. Arch. Rusx. Anat. Embriol., Bd. 1.

verlängern sich nun die dem Medium zunächst gelegenen Bindegewebszellen (Abb.59). Thre mächtigen Fortsätze ragen weit in das Medium hinein und sehr bald fangen diese Zellen an, sich zu teilen. Nach mehreren Wechseln kann man nun neuentstandene Bindegewebszellen überpflanzen, die dann wochenlang weitergezüchtet werden kömnen. Es ist also klar, daB das erwachsene Bindegewebe wieder aktiv werden kann und so Eigenschaften zeigt, die gewöhnlich nur dem Säugetierkörper bei der Regeneration eigen sind.

Unter den neugebildeten Zellen finden sich zwei sehr versehieden aussehende Zellarten, mächtige Bindegewebszellen, stark rakuolig, die den gewöhnlichen Hesenchymzellen gleichen und ron Maxinow als ,Wanderzellen" (Abb.60) angesprochene Gebilde, die sich während ihres Verweilens in dem Medium sehr stark mit groben Kömern beladen, die den sog. Degenerationskörnern, wie wir sie auch in den embryonalen 
und arwachsenen Bindegewebszellen während der Zïchtung in geringem Mabe finden, gleiehen. Bei vitaler Neutralrotfärbung nehmen diese Körner die Färbung sehr stark auf. Auch in ihnen finden sich Mitosen, die besonders in Sehnittbildern leieht aufzufinden sind.

Bei dem Studium der erwachsenen Gewebe ist es notwendig, außer den Totalpräparaten, dic nur von schr kleinen und dïnnen Stïckchen angelegt werden können, zur Sehnittmethode zu greifen und zwar unterseheiden wir hier zwei versehicdene Arten, die neu entstandenen Gewebe zur Verarbeitung mit dem Mikrotom vorzubereiten. Entweder wir betten das eingepflanzte Stück und die neuentstandenen Zellen mitiamt dem Medium ein oder nur das eingepflanzte Stück. Die zweite Art unterseheidet sich wenig von der allgemein üblichen Art des Einbettens und Schneidens. Bei der ersten Art ist folgendes zu beachten.

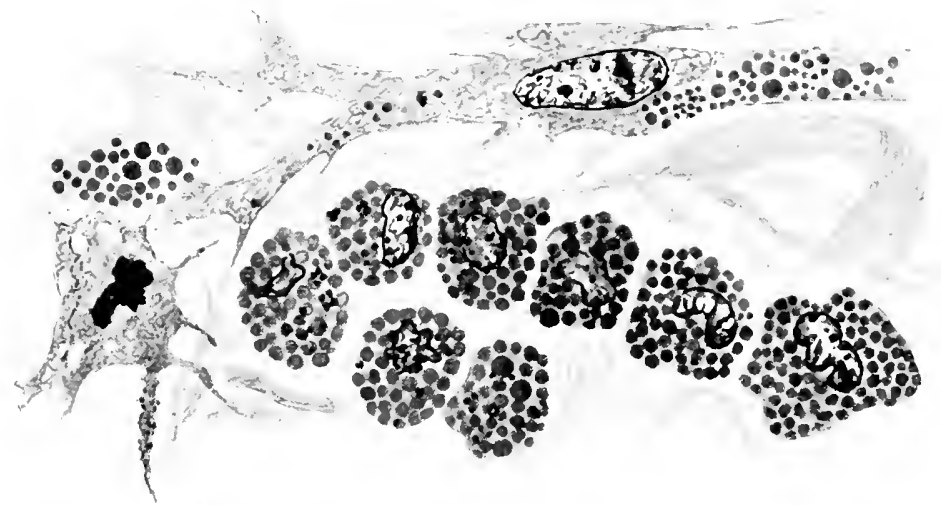

Abb. 60. Dasselbe fiewelse wie auf Abb. 59 dargestellt, aber eine stelle mit vielen Wanderzellen ausgewählt. Beachte die riesengroße Mesenchymzelle mit Vakuolen und die nit groben Granulationen gefinllen Wanderzellen. 2Tag gezühtet. Nach MAXIMOW, 1917, Areh. Russ. Anat. Embriol., Band 1.

Entweder wir züchten dic Stücke schon gleich auf Deekgläsehen, welehe einen Überzug von Zelloidin erhalten haben und dann sterilisiert worden sind; oder es muß darauf geachtet werden, daß die kolloidale Plasmamasse auch konserviert wird, damit die new entstandenen Zellen, auf die es uns besonders ankommt, nicht verloren gehen. Eine allgemeine Regel beim Einbetten dieser kleinen Stücke ist die, daß alles, was an Fliissigkeiten zum Einbetten benutzt wird, vorher filtriert werden muß, auch das verwendete Paraffin, weil man sonst diese kleinen Stückehen nicht herausfinden kann. Man nimmt, wie rorher beschrieben, das Deekgläschen mit dem Gewebe von Objektträger ab, dreht es vorsichtig um und entfernt die übersehïssige Flüssigkeit mit einer Kapillarpipette. Hierauf konserviert man das Stückehen, indem man rund herum um das Medium von der Konservierungsflüssigkeit mit einer Kapillarpipette zutropft und allmählich mit der Konservierungsflüssigkeit immer mehr zur Mitte geht, bis sehließlich das ganze Stück bedeckt ist. Man läßt es $1 / 2$ Stunde stehen, und ebenso vorsichtig entfernt man die Konservierungs- 
mad später die Häıtmugflïssigkeiten. Ist das Stiick in ('hloroform orler in Äther, je nach der gewählten Eimbettungsmethorle (c'hloroformparaffin, Zelloirlin), so wird sich gewöhnlich schom das eingehettete St ück rom dem Deckgläschen lösen, auf dem es bis zu diesam Moment geblieben ist. Sollte es sieh nicht abheben, so entfernt man mit einem feinen Messer das Stïck mit dem Medium ron dem Deekglas mol hat damn ein scheihenförmiges Gebilele vor sich, in dessen Mitte sich das eingepflanzte stüek befindet. Wemn man nun Flachsehnitte macht, erhält man mit clieser Methode ein topographisches Bild der nen entstandenen Zellen, ohne daß eine einzige verloren geht. Wie üblichen Fäbemethoden können num nach den entsprechenden Konservierungsmethoden angewandt werlen. Von M a x i mow wird besonders empfohlen, mit Zenker zu fixieren und mit Azm-Eosin (Maximow) die Schnitte zu färben.

Die zweite Art der Eimbettung wird gewöhnlich angewandt, wemn wenig Zellenauswanderung und Zellemeubildung vorhanden ist und es besonders darauf ankommt, die Vorgänge in dem eingepflanzten Sitück zu studieren (Herzklappe, Muskulatur usw.). Man fixiere mit den für die hetreffenden Färbungen angegebenen Flüssigkeiten. Nachdem das Gewebe darin $1 / 2$ bis 2 Stunclen gelegen hat, bringt man es anfwärts. gehend in die Alkoholreihe, beginnend mit $70 \%$ Alkohol. In jedem Alkohol verbleibt das Stück etwa $1 / 2$ bis 2 Stunden, je nach seiner Größe und nach der Art der Gewebe. Je zarter ein Gewebe ist, desto vorsichtiger müssen die Konservierungsflüssigkeiten zugesetzt werden. Im Alk. abs. läßt man das Stückehen nur etwa $1 / 2$ stunde liegen und bringt es in ('hloroformalkohol und sodann in reines ('holroform, worin es über Nacht liegen bleihen kamn, ohne geschädigt zu werden. Es empfiehlt sich sogar, Stücke, die aus irgendeinem Grumde nicht gleieh his zum völligen Einbetten gehracht werden kömnen, in ('hloroform, dem man dam ein wenig weiches Paraffin zufügt, zu verwahren. Vom ('hloroform bringt man die Stücke in Chloroformparaffin, 1. i. weiches Paraffin mit Znsatz von reinen (hloroform (weiches Paraffin hat einen Schmelzpunkt ron ca. 40-42 (). In Chloroformparaffin läBt man das Material wenigstens 2 stunden liegen, damit es recht anfgehellt werde. längeres Verweilen schadet, wie oben schon erwähnt, nichts. Sodann bereitet man sich zwei kleine Glassehälchen mit weichem Paraffin, bringt die Stücke erst in clas eine, dann in clas zweite Schälchen, flamit alles anhaftende Chlor oform gut entfernt wird, und bringt clas Material sehlieblich in ein drittes, zurechtgestelltes Schälchen mit geschmolzenem harten Paraffin (hartes Paraffin hat einen Schmelzpumkt von ca. 50 bis $52^{\circ} \mathrm{C}$ ). Der Paraffinofen muß genau a uf der Temperatur des Sehmelzpunktes gehalten werden, weil höhere Temperaturen lie Gewebe zerstören.

Zum eigentlichen Einbetten sehmilzt man hartes Paraffin in einem kleinen Glasschälchen, das am besten einen etwas germudeten Boden hat. Dahinein legt man das Gewebestück mitten auf den Borlen mit cler Fläche, an der man mit dem Schneirlen beginnen will, nach unten. Man hält, 1 m das Paraffin schnell zum Erstarren zu bringen, das Gläschen 
mit dem eingchetteten Stück in eine Schüssel mit Eiswasser, sobald sich obenauf eine dünne Haut bildet, läBt man das Eiswasser über das Einbettegefäß fließen und stellt schließlich zum endgültigen Hartwerden das Ganze eine Zeitlang in rlas Eiswasser hinein.

Besonders zu beaehten ist beim Einbetten der Gewebestücke, daß man die zarten, empfindliehen Stüeke nie mit Pinzetten anfaßt beim Umlegen ron einer Flüssigkeit in die andere, sondem man bedient sich eines Spatels, womit man die Stïcke aufhebt, oder besonders kleine Stijcke saugt man mit einer ganz trockenen Pijette auf. Spatel oder Pipette sind beim Umlegen in die versehiedenen Paraffinsorten anzuwärmen. Sind lic Stücke sehr klein, so arbeite man unter der Lupe.

Sehr kleine Stücke des Gewebes, die man im Paraffin schwer finden kann, sind, wemn sie bis zum Alkohol von $96 \%$ gebracht sind, mit einem Tropfen Eosin anzufärben. (Diese Farbe ist später vor dem eigentlichen Färben wieder auszuwasehen, dies geht meist sehon bei der Alkoholbehandlung ror sich.)

\section{B. Echtes Wachstum des embryonalen Muskelgewebes und Ab- und Umbau der erwachsenen Muskulatur.}

Für das Studium des Muskelgewebes wählen wir das Amnion des Hühnerembryos, das Herz und die Skelettmuskel desselben ron am besten 5-6 Tage alten Embryonen (15., 16., 17. Übung).
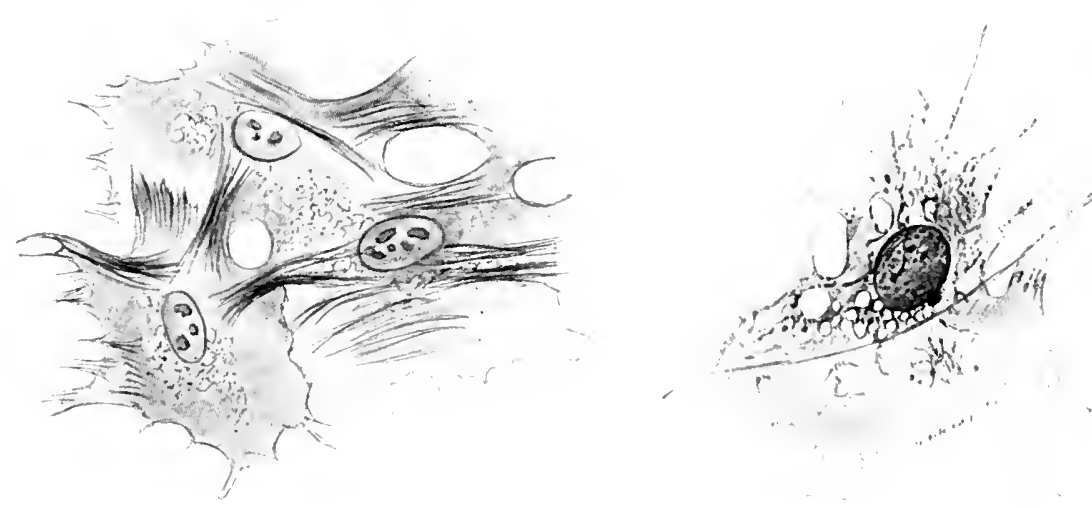

Abb. 61 u. 61 a. Zellen des Amnion eines 5 Tage alten Hühnerembryo, 48 stunden in Kultur (Locke-Lewis) Abb. 61, fixiert mit Joddämpfen, gefärbt nach Mallory, Abb, 61 a. Nach M. Lewis wle Bild 60 .

Die grlatte Muskulatur des Amnion.

Nachdem wir wie gewöhnlich kkeine Stückchen des Amnion in LockE-LEwisscher Lösung oder in Plasma vorbereitet haben, lassen sich schon nach kurzer Zeit der Bebrïtung die verschicdenen Elemente des Amnion erkennen. Das Amnion besteht aus den sog. epithelialen Zellen, die ein einschichtiges Zylinderepithel bilden, dessen Elemente 
Fettropfen und Dotterkngehn enthatten. Sehom die normale, epithelia le" Zelle ist stark vakuolig. Das zweite Element ist die glatte Muskelzolle des Amnion, Nerven sind bis jetzt nicht im Amnion naehgewiesen worden. In der Kultur breiten sich die ,epithelialen" Kellen als grobe, flache, fast immer hexagonale (Abb. (il) Zellen aus. Sie bilden häufig in der Kultur cine Art Ilembran, wähend die Muskelzellen in Form ron schmalen Streifen, eine hinter der anderen, in der Riehtung der Auswanderung dureh das Medium sich sehieben. Alle Muskelzellen sind dureh ihre starke Liehthreehung kenntlich. Sowohl M. Lewis wie LEvi erwähnen, dals die Muskelzelle von den Mesenehymzcllen dureh ihr lichtbreehungsvermögen lebend zu unterseheiden int. Diese bandartigen, langgestreckten, an beiden Enden zugespitzten und nieht verzweigten Muskelzellen sind oft rund herum um rlas eingepflanzte Stüek in rhythmiseher Zusammenziehung. Hat sieh aber eine solche Muslielzelle unter dem Deckglas ausgebreitot, so zieht sie sich gewöhnlich nicht mehr zusammen, sondern wird erst wieder kontraktionsfähig, wenn sie sich aus der ausgebreiteten Lage in die gestreckte Lage zurïekgewandelt hat. In der sich zusammenziehenden, lebenden Nuskelzelle sind keine Fibrillen zu sehen, sondern nur eine Verdickung des Plasmas an den Knotenpunkten der Zelle (Abb. 62).

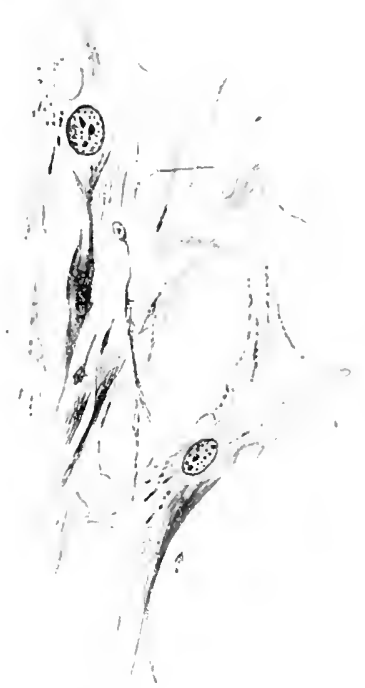

Abb. 62. 3 Muskelzellen des Amnion, deren schlagende Bewegung beobachtet wurde und die später fixiert wurden. Ton einem 8 täqigem Hihnerembryo. 24stindige Kulturin LockeLewis. (Zenker, Eisenhämatoxylin.) Nach M. Lewis 1917. 272. Publ. ('arueg. Inst.

Dauerpräparate der Muskelzelle lassen sich sehr gut nach Fixicrung mit Zenkerscher Lösung und Färbung nach Heidenhaix darstellen.

Die Muskelzelle des Herzens.

Wird embryonales Herzgewebe eingepflanzt, so haben wir schon bei der 13. Übung gesehen, daB in den meisten Fällen mesenchymales Gewebes auswächst. Dieses bleibt in einem Medium, das Plasma und Embryonal-Extrakt enthält, undifferenziert. Von einem 4 Tage lang bebrüteten Embryo züchtete Levi Zellen aus dem Herzgewebe (Abb. 65), die lebhaft auswanderten und über deren Charakter sieh nichts aussagen läßt. Sie können werkende Muskelzellen oder Mesenchymzellen sein. Sie sind in lebhafter Teilung. Dagegen erweisen sich Zellen. die aus dem Herzen eines 6 Tage alten Embryo ansewachsen sind, deutlich sowohl strukturell als auch funktionell als Muskclzellen. Sie wurden 3 Tage lang sehlagend beobachtet und morphologiseh (s. Abb. 66) zeigen 
sie ganz die Eigenschaften der Herzmuskelzellen. In solch zweifelhaften Fallen hat man sich nur an die Funktion zur Stellung der Diagnose zul halten.

Die Herzmuskelzelle des sechs Tage alten Emburo zeigt anch in der Gewebekultur lebend keine streifung, wohl aber in der Bewegung eine Torlickung und Verdiunnume der Plasmamasse nm den Kern hermm. Die sehr kleine Zelle zeichnet sich auch in leben dureh ihre spitzen, selten verzweigten Fortsaitze ans. Während der Zellteilung runden sich diese Zellen al, nnd bleiben nur mit ihren Nachbarn doreh feine Fortsätze verdunden, während sie sonst in der Gewebekultur meist ein Synztimm biklen. Für gewöhulich gilt als charakteristiknm ihr gestreckter Kern. Dieses Kemnzeicben fält in der Gewebcknltur fort. Die Muskelzelle hat meistens einen runden

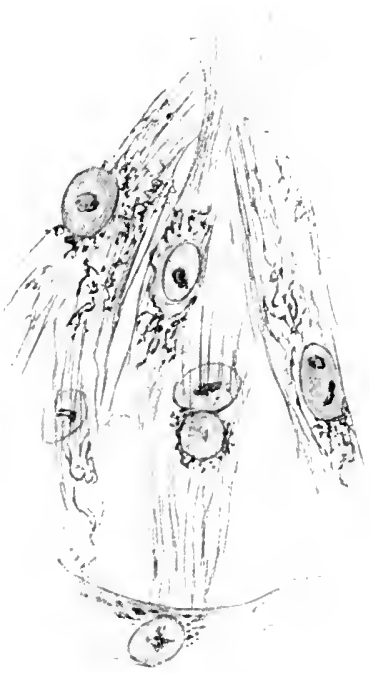

Abb. 63 u. 64. Glatte Muskelzellen des Amnion von einem 4 Tage alten Huhnerembryo. 48 Stunden in Locke-Levis ge. züchtet. Beide Bilder aus derselben Kultur. Bild 63 zeigt die kontraktile Substanz naelı der Färbung als graue Fäilen in der Zelle. Bill of ist aus demselben Präparat aus einer stelle, an welcher sich die Zellen ausbreiten könen. Nach II. LEWIs 1917 wie bei Bild 62.

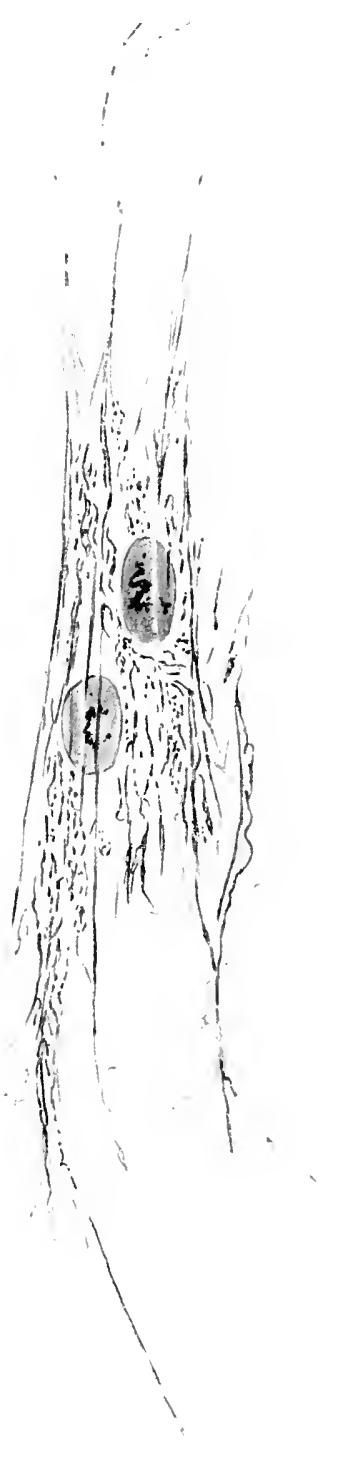

Kern. wahrscheinlieh weil der größere Torrat an Raum in dem flüssigen Medium die weitere Ansdehnung des Zellkernes gestattet. Von Levi (Abb. 66) ist die Entwicklung von Fibrillen, die sich durch Färbung nachweisen lassen, in späteren Stadien des Embryonallebens 
festgestellt worden. Giut gelungene Präiparate zeigen Zellen, die 70-120 mal in der Vlinute schlagen. Cewöhnlich schlagen ganze Zx+llsehichten koordiniert. Auch stiucke des zerteilten embryonalen Heroms

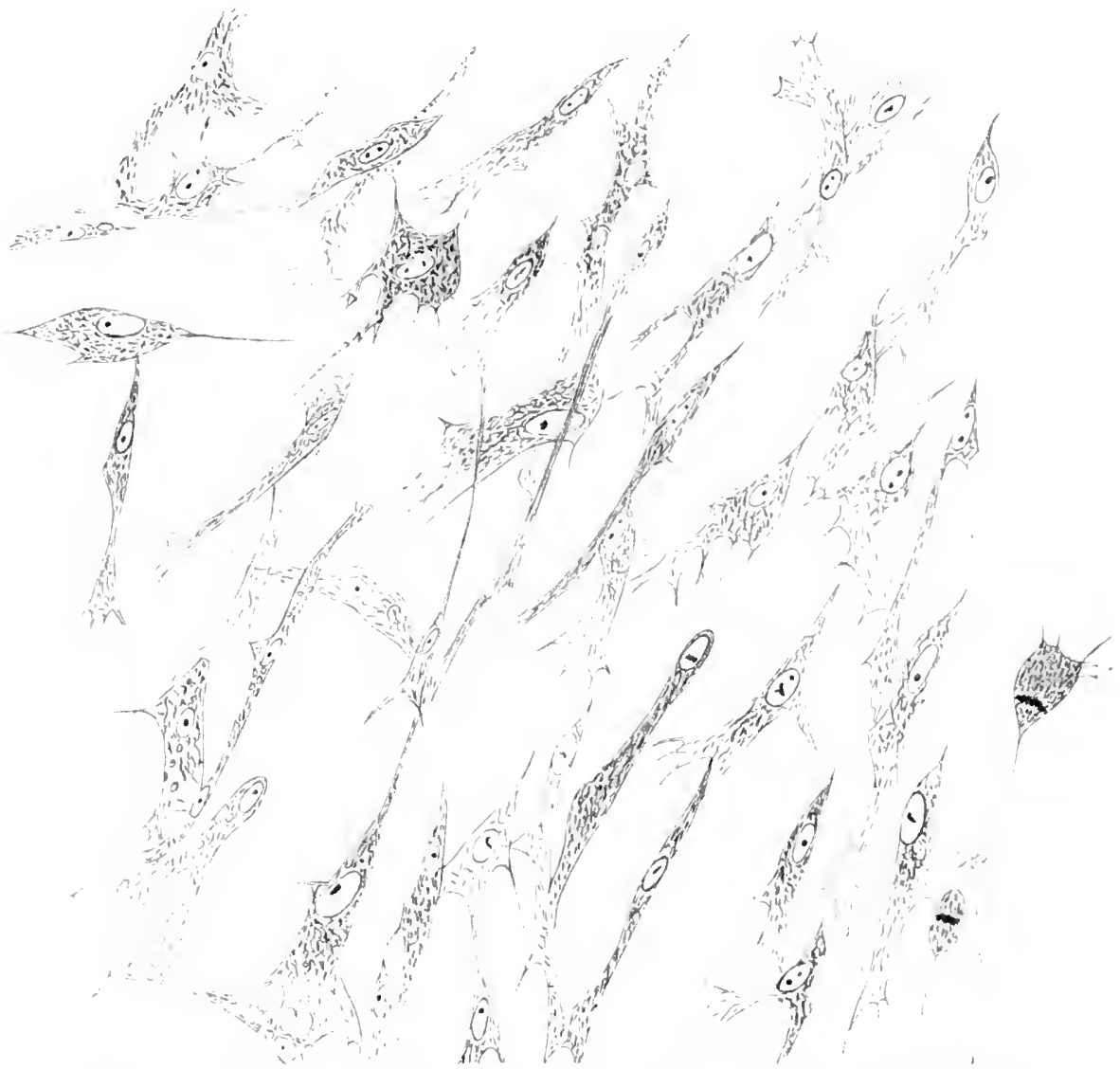

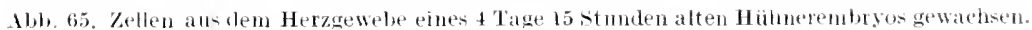

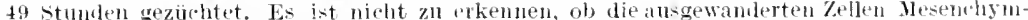
zellen oder Myoblasten sind. Fixiert und gefärbt nach Jaximow, abgeandert nach Levi. Sach Levi 1919. Arch. Ital. di Anat. e di Embriol. 13. 16.

sehlagen in den ron uns gebrauchten Kulturmedien. Teile des Herzens können noch 4-5 Tage nach der Explantation schlagen, und abgeschnittenes und wierler cingepflanztes Herzgewcbe schlägt noeh nach 126 Tagen. Die gleichen Fäıbemethoden, wie beim Amnion angegeben sind, können hier angewancit werden. (Abh. 63 1. 64.)

Die quergestreifte Muskulatur.

sehon dureh die äuBere Art der Bewegung unterscheirlen sich die Myohlasten, die später die Skelettmuskel bilden, von den rorher besehriebenen Zellarten. Ein explantiertes Stüek rom skelettmuskel 
des Huhnes, \& Tage alt, zeigt wie immer Bindegewebsellen, wenig isolierte Muskelfibrillen und viele hier und rla zerstreute Myoblasten. Diese sind synzytial miteinander verknüpft; trennen sich nun ab und

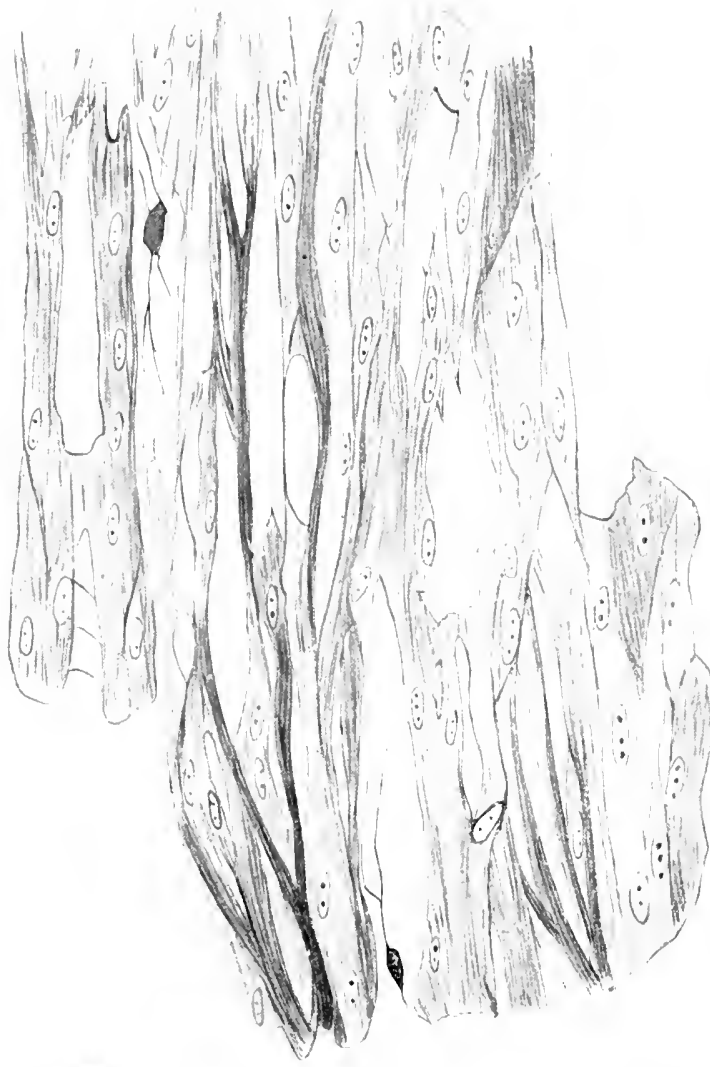

Abb. 66. Zellen aus einem 6 Tage alten embrsonalen Herzen, Die Zellen shlugen bis zum 3. Tage und wurden damn fixiert. Typische Herzniukelzelle. Fixierung, Färbung wie bei Bild 65. Nach Levi 1919 zu Zellen von diesem vielkernigen Synzytium und waudern fort, so entstelit der typische isolierte Myoblast ohne Fibrillen. Man wird also annehmen können, daß die synzytiale Verbindung durch die bei der Fortbewegung ausgesehiedene fibrilläre Substanz gebildet wird. Während nun die Herzmuskelzelle eine schlagende Bewegung ausführt und die Amnionmuskelzellen eine flicbende, führen die Skelottmuskeln eine ruckweise Bewegung aus. Lewis hat in den Zellen des 8 bis 10 tägigen Embryo keine Streifung gesehen und behauptet, daB nur nach dem Tode Verdichtungs- und Verdünnungszentren als Streifen der Muskulatur sichtbar werden.

Vitalfärbung zeigt bei allen drei beschriebenen Zellarten Mitochondrien. Färbung nach Fixierung wie für das Amnion beschrieben, gibt auffallend schöne Bilder.

Dieglatte Muskulatur des erwachsenen Tieres.

Von großer Bedeutung war es, als Сн ам Р y 1914 zum ersten Male gezeigt hat, daß Blasenmuskelgewebe - er nahm die Blase des Kaninchens - einer Entdifferenzierung und späteren mitotischen Teilung fähig ist. Der glatte Muskel entdifferenziert sich auf folgende Weise: Die Muskelzellen bilden eine Art verjüngtes Zellplasma, das um den Kern herum und zwischen den einzelnen Fasern sich sammelt (Abb. 67). Die Enzyme dieses neugebildeten Zellplasmas müssen die Fähigkeit haben, die Muskelfibrillen zu lösen. Sehr bald bleibt nur der obere und 
untere Pol der Zelle mit Fibrillen erfüllt. Die Zellmitte nimmt ein gänzlich undifferenziertes Aussehen an, sie teilt sich unter Bildung von gut ausgebildeten Kernfiguren. Nach 2-3 Teilungen ist es nicht mehr möglieh, die Muskclzelle als solche zu erkennen, wenn sieh nicht ah und zu ganz feine kibrillen in einzelnen Zellen vorfänden. Die neugebildeten Zellen sind rundlich. So erstaunlich dieser Umbau der glatten Muskulatur auf den ersten Bliek auch erscheint, so brauchen nur die sehon bekannten Fähigkeiten der glatton Muskulatur, die sich bei der Regeneration zeigen, zum Vergleich herangezogen zu werden. Auch bei der Regeneration findet sich diese Entdifferenzierung und spätere amitotische oder mitotisehe Teilung der glatten MuskelzelledeserwaehsenenTieres. Gefärbt wird hier besonders nach dem Verfahren von Heidenhain - Prenant nach Fixierung nach C'Hampy (18. Übung). Ehe wir das Wachstum der Epithel - Zelle eingehend
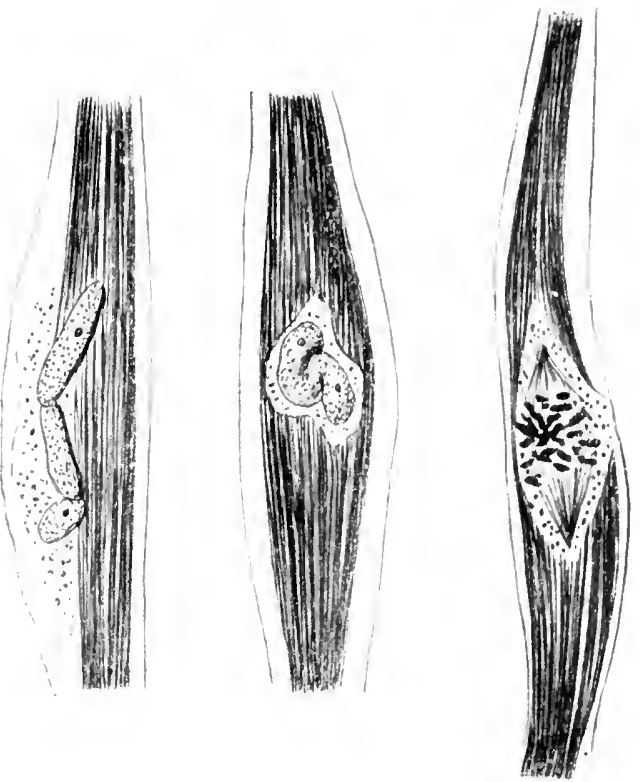

AbJ. 67. Entlifferenziernug der Blanemmu-kulatur des Kaninchens. Fixiert nach Champy, Färbung nach Prenant. Sach Clampy 1914. Arch, de Zool. Exp. et Gen. Bul. 53. Notes et Revue. studieren, fassen wir noch eimmal zusammen, was wir bis jetzt über die Merkmale der Fibroblasten und Myoblasten gelernt haben. Haben wir nur Mesenchymgewebe in der Kultur und erscheinen an beiden Polen scharf zugespitzte Zellen - nadel-oder spindelähnliche Formen, so sind diese stets von e mbr yonalen Muskel zellen abzuleiten. Die Mesenchymzelle oder eigentliche spätere Bindegewebszelle ist durch ihre stark verzweigten Ausläufer, ihren wenig lichtbrechenden Zellinhalt, das Vorhandensein von Mitochondrien und Granulationskörnern im Plasmamedium kenntlich. Die beiden letzten Charakteristica teilt sie auch noch mit den Muskelzellen, deren Formbeständigkeit größer ist als die der Fibroblasten, wenn der Myoblast isol i e r t liegt. Selbstverständlich kann erst die Fähigkeit, sich zusammenzuziehen, die Endentseheidung sichern. Embryonale Herzmuskcln (Abb. 66) sind oft durch ihre synzytiale Anordnung kenntlich und durch ihre plumpen Formen. Das ganz junge embryonale Herz enthält Endothelzellen und Mesenchymzellen, die teils schon in Muskelgewehe umgewandelt sind, teils diese Unwandlung schon physiologisch durchgemacht haben, aber noch nicht morphologisch zeigen, teils auch aus noch nicht diffe- 
renzierien Mesenchymzellon. Es fehlen uns bis jetzt Normentafeln der Gewchezüchtung, in denen z. B. einwandfrei nachgewiesen ist, embryonales Herz rom Huhn, so und so viele Tage bebriitet, liefert diese Formen von Zellen, diese Zellarten wandern zuerst aus dem betreffenden Gewebe, wenn es in dem und dem Medium so und so lange gezüchtet wirl. Sichwieriger ist das Exkennen der erwachsenen, abgehauten formen, und nur geduldiges Beobachten fïhrt zur richtigen l)iagnose.

\section{Echtes Wachstum der Epithelgebilde, gezeigt an dem embryonalen Fpithel und Verhalten der erwachsemen Schilddriisen mol Geschlechtsdrüsen.}

Es ist eigentümlich, daß alle dic Zellarten, die wir rom äußeren Keimblatt ableiten, also Hant-, Sinnes- und Drüsenepithelien, erst spät gezüehtet worden sind und dab die Eifolge, die bei dor Züehtung

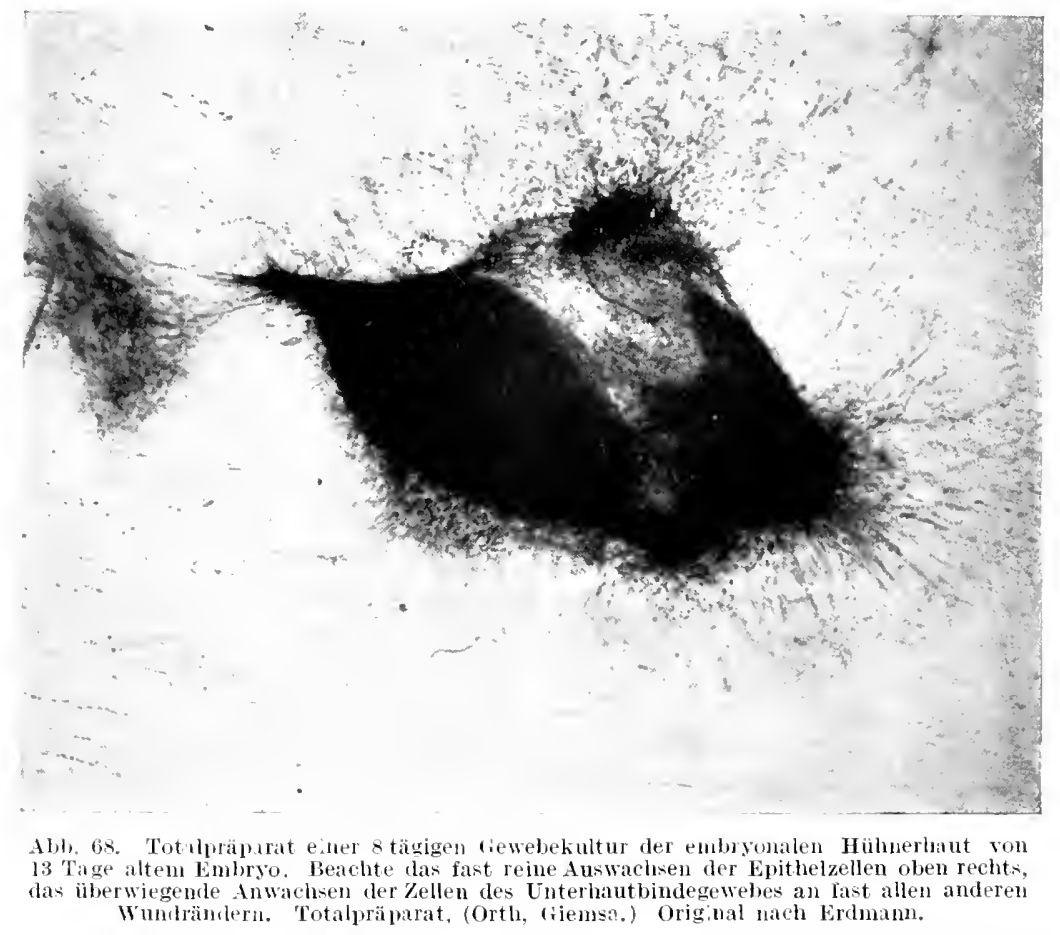

der Haut erzielt worden sind, gering sind und keine echte Kultur, die jahrelang lebt, bis jetzt gelungen ist. Wenn wir z. B. ein Stück embryonale Hühnerhaut von einem Embryo, bei dem die Federanlagen noeh nicht äußerlich erkenntlich sind, in Hühnerplasma mit Ringer im Verhältnis wie 1 : 1 verdünnt legen (19. Übung), so entwickeln sich be- 
sonders stark die Mesenchymzellen mul die Epithelzellen bleiben weitans im Wachstum zurïrek. So wird das embryomble Bindegewebe ans einem stë̈ck Haut herauswachsell (Abb. (6S) und sich nur puml hermm um das Explantat mit einer dünnen S̈ehichene ngebildeter Epithe! zellen berlecken. Diest Epithelzellen nehmen beim Huhn seht oft eine halbmondförmige Gestate an und eignen sich besonders zum, tomlium der $\mathrm{Ni}$ tosen. Wohl nirgends lessen sich die Ditosen des logelgewebes besser nachweisen, als in dein Epithelzellen des Huhnes. Anch int

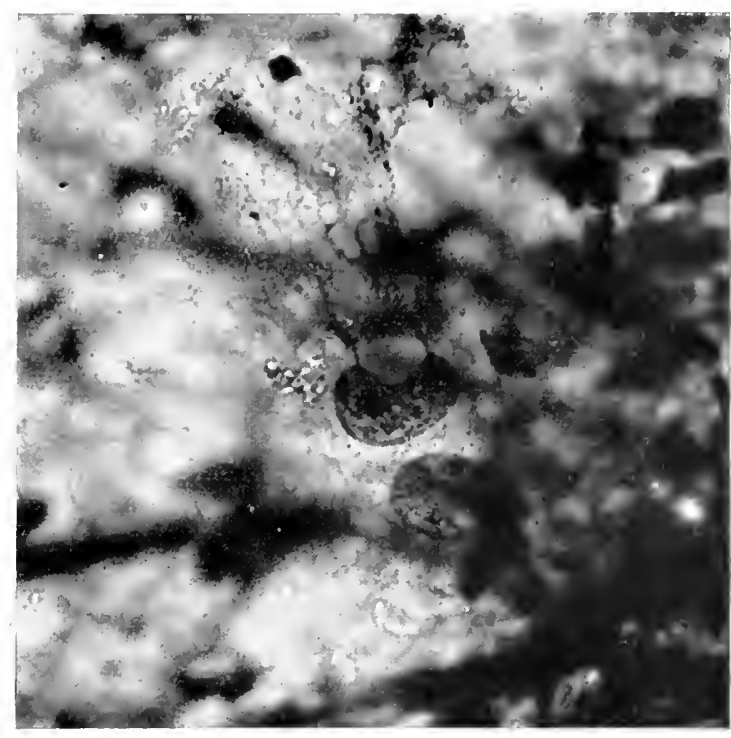

Abb. 69. Evithelzellen au- demellen Präparat

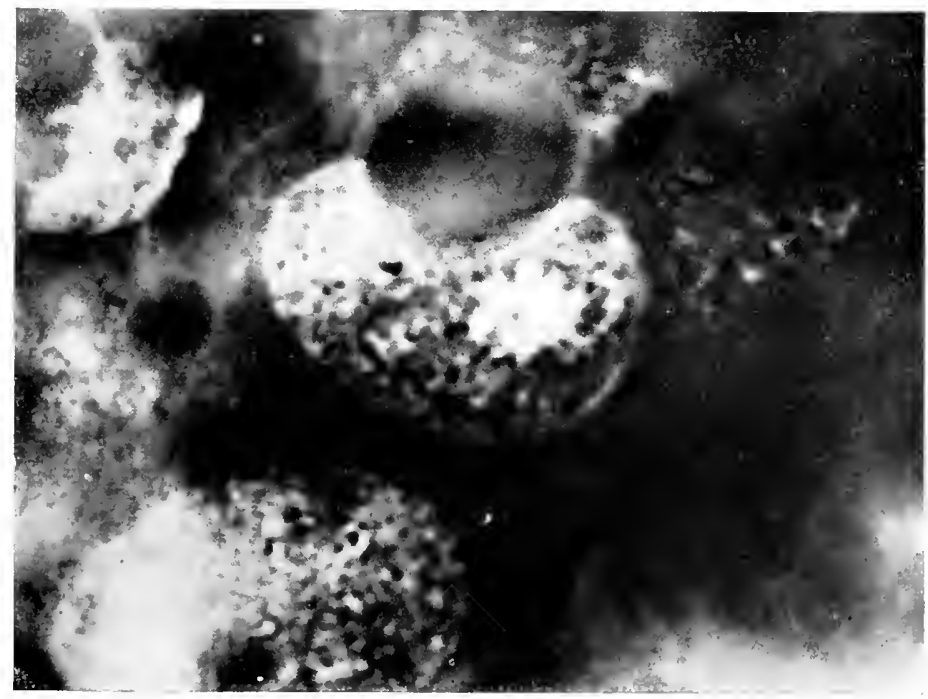

Abb. T0. Stärker vergröberte Zellen der Abbilung 69. un die (hromoson.en währeml der Mt tazhase zu zeigen.

während der Züchtung die Zählıng der einzehen C'hromosomen leicht. während man sonst im allgemeinen schwierigkeiten bei del Zithlung 
der Kernteilungsfiguren hat (Abb. 70). Nanche dieser Zellen zeigen schwarzes Pigment und, was besonders zu beachten ist, sie hahen runde, nicmals scharf gezackte und mit spitzen oder stumpfen Preudopodien versehene Ränder. Diese Glattrandigkeit scheint dem

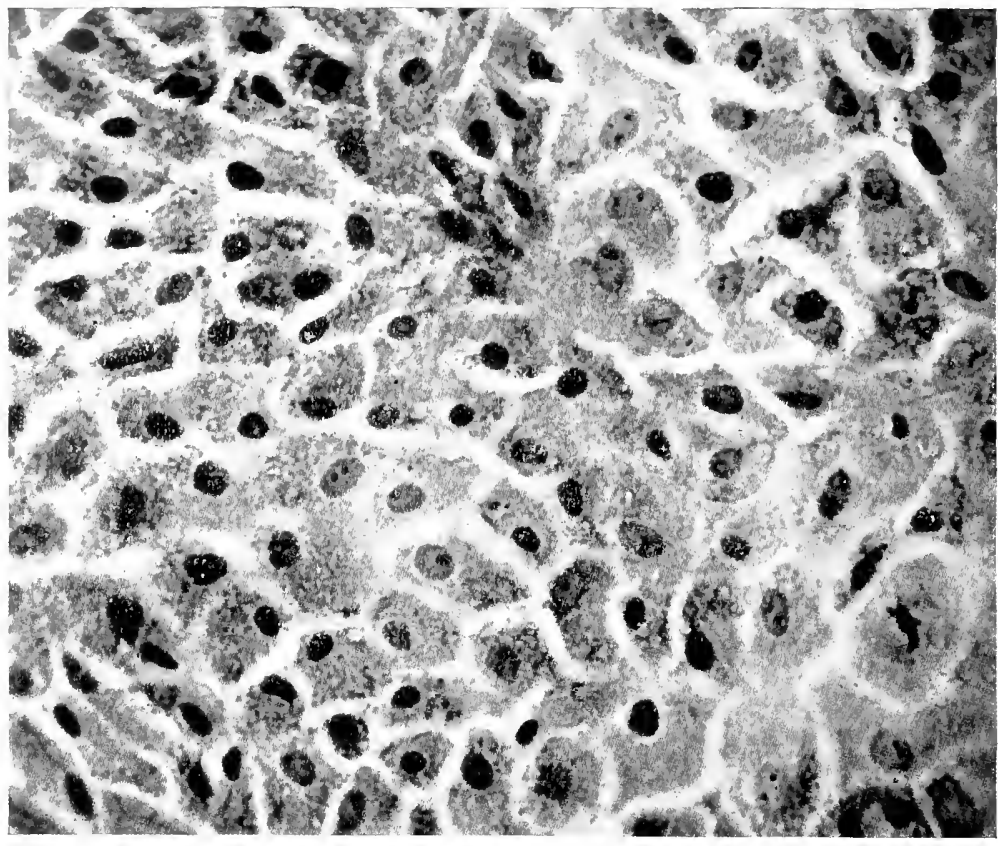

Abb. 71. Reines Epithelgewebe ohne Beimischung von Bindegewebe nach 6 Wochen Züchtung. Nach Fischer 1922. Journ. exp. Me(l. Bil. 34.

Epithelgewebe des Togels eigen zu sein, im Gegensatz zu den Epithelzellen der Froschhaut, deren Gestalt (s. Abb. 24, S. 28) sehr stark weehselt. Noch naeh 8 Tagen bewahrt in der Gewebezüchtung die Epithelzelle ihren Charakter, und die neugebildeten Zellen sind, wie Abb. 69 zeigt, wirklich wieder der Form nach Epithelzellen. Es muß ein gewisser Antagonismus zwisehen Epithelzellen und Bindegewebszellen bestehen. Die Bindegewebszellen mit ihrer starken Wachstumstendenz scheinen die schnelle Vermehrung der Epithelzellen zu verhindern. Beim Froseh (Rana pipiens) sind die Verhältnisse gerade umgekehrt. Hier wächst naeh UhLenhutu das Bindegewebe nur minimal, doeh scheint diese Regel nicht durehgehend $\mathrm{zu}$ sein, denn bei Rana esculenta habe ich oft bei etwas flüssigen Medien aueh Bindegewebswachstum bei Hautkulturen gesehen (s.S. 26).

Präparate von der embryonalen Haut lassen sich sehr gut mit der HELDschen Nervenfärbung färben, jede andere Färbung ist aber auch erfolgreich.

Beim Studium der embryonalen Hühnerhaut fallen die Federanlagen auf. Die Bestandteile der Haarscheide und der Haarkeime 
beginnen sehr oft heftig zu wachsen, besonders wem Teile derselben beim Zersehneiden der Gewebe verletzt worden sind. Auch hier ist das Bindegewelde weitans am stärksten waehsend, wahrseheinlieh weil Bindegewebe sehon an sich den Bedingungen, die der Gewebekultur eigen sind, besser angepaßt ist als die Epithelzelle, die ja an reichliche Luftzufuhr in ihrem ganzen Leben gewöhnt ist.

Heldsehe Nervenfärbungr.

Konservieren der Präparate in 2 proz. Formalin 15-18 Stuncen, abspiilen und beschicken mit Alk. $70 \%$, färben in verdünnter Lösnng (6-8 Tropfen der Farblösung auf $15 \mathrm{ccm}$ (Yasser) von HELosehem Molybdänsäure-Hämatoxylin 12 Stunden. Differenzieren 24 Stel. in Boraxferryerankalilösung von $5-6^{0}$ gelöst in Aqua dest. Abspülen in Brunnenwasser, dureh Alkoholstufen führen. Xylol + Alk. abs.; Xylol ceclernöl.

Fischer gelang es. wie sehon erwähnt, jetzt endlich, im Jahre 19:20.2. reines Epitelgewebe zu züchten, und zwar ging er so ror: Vit einem Katarakt-Messer nahm er aus dem embryonalen Hühnerauge die Linse heraus. Ein feiner, schwarzer Rand der Iris bleibt unbeabsichtigt an der Linse hängen. Die Linse wird dann in $3-4$ kleine Stücke gesehnitten und wie gewöhnlich in einem Nedimm gezïchtet. das aus Embryonal-Extrakt und Hühnerplasma zu glejchen 'Teilen besteht. Die Linscnelemente wachsen nicht, aber mitunter kann nach 48 Stunden eine kleine Wucherfläehe von Epitel unter dem Milsoskop oder der Lupe gefunden werden. Sehr oft aber zeigt sieh erst Epithelwachstmm nach mehreren Lmpflanzungen. Sollte man sehon gleich in dem ersten Medium Fibroblasten entdocken, so ist keine Hoffnung, daß3 man reine Epithelkulturen bekommt.

Zu der 20. Übung also wird man sich Embryonal-Extrakt und Plasma des Huhnes zureeht stellen und aus einein jungen Hïhnerembryo die Linse heraussehneiden. Man bemüht sich, nur die Linse herauszubekommen, denn es bleibt immer cin wenig Gewebe der Iris daran hängen. Ehe man die Linse zersehneidet, macht man sich die hängenden Tropfon zureeht. Da Epithelgewebe einer Unterlage zum Wachstum zu bedürfen seheinen, so setze man erst einen Tropfen ron Plasma und Embryonal-Extrakt auf das Deekgläschen. Sobald dies geronnen ist, lege man das Gewebe auf die Oberfläche des Tropfens. Abbildung 71 zeigt eine 6 Woehen alte Kultur von reinen Epithelzellen, in der man anch Mitosen sehen kann. Diese Kultur ist jetzt sehom über 4 Monate weitergeführt. Und so wird es in Zukunft möglieh sein, mit reinem Epithelgewebe Experimente der versehiedensten Art auszuführen.

Ektoderm der Haut und des Ammion wachsen aus in der Form von Membranen, ebenso das Pigmentepithel der Retina. Aueh die Epithelzellen der Froschhaut sehieben sich in halbflüssigen Medien membranähnlich vor. Die Leberzellen, die Schilddrüsenzellen, das Nierenepithel der Tubuli wachsen oder wandern meistens auch als zusammenhängende Zellflächen aus, während die Blut- und Wanderzellen der Milz, des 
Konochenmarks, der Lymphknoten und der 'Thymus als isolierte Zellen answandern mol isoliert bleiben.

Zum Studium der Drüsenzellen wählen wir die Schilddrüse eines jüngeren Tieres. Die embryonale Schilddı ïse hat kein spezielles Interesse, da sie sich nicht in dem Plasmamedimm ron der erwachsenen schildchüse ahweichend verhält (21. Ủbung).

Hat man sich Schildd üsen-Gewebekulturen von der Schildkrüse des Kaninchens in homogenem Plasma angesetzt, so kann man sehon am nächsten Tage bemerken, daß der kolloida le Inhalt in den Lumina sich zusammenballt und teilweise resorbiert wirl. Die Zellen, welche die Lumina anskleiden, werden im Verlanfe der nächsten Tage höher und fangen an, sich zu teilen, so daß die Lumina fast ganz ausgefüllt sint. Nene kolloirlale Masse wird nicht gebildet. Während dieser Vorgang in den unverletzten Teilen der Schilddrüse vor sich geht beobachten wir, daB der mittlere Teil degenerient, während die Randpartien, in welchen die Tubuli angesehnitten sind, allmählich vernarben, so daß eine gewebeähnliche Verbindung entsteht, die kanm an die frühere Schilddrüse erimnert (Abb. 72). Zellen. die ganz am äuBersten Rande des einge-

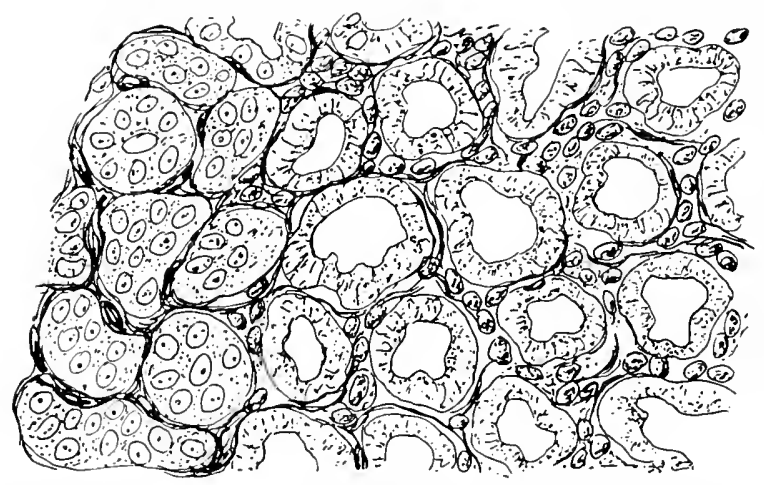

Abb. 72. Narbencrewe, entstanden aus den verletzten 1)rüsenschläuchen der schildrüse (links), rechts die kolloilleeren Iorisenschläche und dazwischen das wuchernde Bindegewebe. Nach Champy 1915. Arch. de Zool. Exp. et Gën. Bd. 55. pflanzten Stückes sind.schieben nene Abkömmlinge in das Medium. Sind Stellen getroffen, die reichlich Bindegewebe enthalten, so findet auch hier ein starkes Wuchern des Bindegewebes und ein Zurïckbleiben des Epithelwachstums statt. Die Thyreoidea ist häufig zu Transplantationen benutzt worden und nach den Arbeiten von Christianis wissen wir, daß die indifferent gewordenen Drüsen sich im Transplantat wieder differenzieren. In der Gewebekultur findet kein Wiederherstellen der Funktion in nengebildeten Zellen statt, wahrscheinlich weil der fehlende Blutstrom die für die Neubildung des Kolloids nötigen St offe nicht herbeiführen kamn, während im Körper des Wirtes dies möglich ist. Selır schleehte Resultate sind bei der Schilddrüse bei heteroplastischer Transplantation erzielt worden, während in dem hä ngenden Tropfen kein grober Untersehied des Verhaltens der Thyreoideazelle in speziesfremclen Medien sich finden läßt.

Besonders interessant sind die im Gewebe auftretenden, sehr normal sich abspielenden Mitosen, die zeigen, daß ebenso wie die Zellen der erwachsenen Muskulatur anch die Zellen der nicht fötalen Drüse latent 
vermehrungsfähig sind. Fs ist notwendig, jeden Tag dio Gewobestïckehen mit Serum auszuwaschen und in frisches Plasma zu tun. In den Plasmahof hinein wachsen Drüscnzellen in Form ron Bändern oder Zellknötehen, die oft noch einen Kutikularsaum zeigen.

Auch das Verhalten der kolloidalen Substanz ist bemerkenswert. Schon nach 24 Stunden hat in den kleineren Drüsengängen eine vollständige Resorption der kolloidalen Substanz stattgefunden. Bis zu 24 bis 48 Stunden hat aher die Irüse noch neue kolloidale Substanz ausgesehieden, so dab sie noeh ungefähr 48 Stunden in der Gewebezüchtung funktioniert. Je größer clas eingeflanzte Drüsenst üek ist, je länger kann man noeh Kolloid in ihm nachweisen, später aber findet die Fntdifferenzierung, der vollständige Abbau der spezifischen Zellstruktur statt, hicrauf fängt das Drüsenepithel an zu wuchern und kann die lumina vollständig ausfüllen. Alle Drïsensehlänche aber, die, alssie in das Plasmamedium gesetzt wurden, verletst worden waren, haben schon nach 2 Tagen ein vollständiges Epithel gebildet, so daß, wenn man einen Sehnitt dureh das eingepflanzte Stïckehen maeht, der Unterschied zwischen den verletzten und den unverletzten Drüsensehläuchen sofort ins Auge springt (Abb. 72). Es finden sich in der embryonalen und in der erwachsenen Schilddrüse in der Gewebezüchtung Mitosen. Im erwachsenen Gewebe, das nicht gezüchtet worden ist, hat man his jetzt noch keine Mitosen gefunden. Mitoehondrien, siderophile Kömehen und Fettkörner existieren noch länger, aber nicht mehr polar angeordnet in der Zelle. Das Bindegewebe, das nach CHAMPY lurch das sehr starke Wachstum des Epithels in einem Zustand der Henmung gehalten ist, also nicht wachsen kann, wird durch die sich ausbreitenden Epithelien stark zusammengedrängt, an Stellen aber, an dencn das Epithel fehlt, finden sich die übliehen Bindegewebszellen. Nach cinigen Tagen aber sind die Drüsenzellen entdifferenziert, sie haben naeh CHAMPY keinen bestimmten Charakter. Thre Form ist eher von dem Nilien als von der genetisehen Potenz abhängig. Sie teilen sich lebhaft nahe an der Oberfläche des Plasmas.

Wir beschränken uns hier nur auf das Studiun der Sehilddrüse, die verglichen mit der Niere ein einfach gebautes Organ ist und sich verhältnismäßig unkompliziert in dem Kulturnedium verhält. Die Niere, sobald sie schon embryonal wirklich funktionell Niere ist, maeht tiefgreifende Veränderungen als embryonales und erwachsenes Organ durch, deren Beschreibung aber hirr zu weit führen würde. Sic ist ein hoch differenziertes Organ, das ganz im Dienste der Funktion steht und einseitig differenziert ist, wie es auch die Regeneration der verletzten Niere zeigt. Dagegen steht die Schilddrüse auf riner tieferen Stufe, gemessen an der Schnelligkeit und Langsamkeit, mit der sieh die Zellelemente sowohl der embryonalen als auch der crwachsenen Drüse an die Gewebezüchtung anpassen. Denn die embryonale Schilddrüse zeigt die gleichen Vorgänge, welehe sich in der 'Thyreoidea des erwachsenen Tieres abspielen, nur sind die Abbanerscheinungen nicht so zahtreich; sonst gehen die eben beschriebenen Vorgänge, ganz verschieden von den in der Niere stattfindenden Vorgängen, sowoht im embryonalen wie auch im erwachsenen Gewche vor sich. 
Ie höher differenziert eine Zelle ist, je einschneidender sind die Änderungen, unter welehen sich der Abhau, der in der Bildung von Zellformen gipfelt, die in dem Kulturmilieu weiter leben können, im Medium sich abspiclt, bis er wic bei sinnesepithelien oder Nervenzellen kanm oder selten mehr vor sich geht.

Nicht nur die Sichilddriise, sondern auch die Prostata des erwachsenen Meerschweinchens funktioniert nur 2 Tage in der Gewebezüchtung. sie erzengt also kein nenes Sekret. Um das nachzuweisen (22.2. Übung), verfahre man auf folgencle Weise:

Man pflanze wie üblich kleine Stïckchen Prostata in arteigenes Plasma und setze sich eine Serie Kulturen, die man am ersten Tage, eine Serie, die man am zweiten 'Tage, eine dritte Serie, die man am dritten oder vierten Tage benutzen will, an. Ehe man die Kulturen ansetzt, entnehme man etwas Samenblasenflüssigkeit, verdünne diese mit Ringerscher Lösung und bringe sie damn mit kleinen Stückchen Prostata eines Mecrschweinchens zusammen. Naeh kurzer Zeit koaguliert die Flüssigkeit. Züchtet man Prostatagewebe, wie schon gesagt, in arteigenem Plasma, so beobachtet man am ersten und zweiten 'Tage noch dieselbe Reaktion in der Samenblasenflïssigkeit. In den Kulturen, die man erst am dritten oder vierten Tage beobachtet, ist sie verschwunden. Ein am vierten Tage der Züchtung boobaehtetes Prostatastück ist lebend, seine Zellen vermebren sich. Die feinen Körnchen, die der normalen Prostata eigen sind, sieht [man nieht mehr. Die Kulturen haben dann ein Aussehen, wie solche Kulturen, in denen Bindegewebe und Epithel gemeinsam gezüchtet werden.

Das sich dic Gesehleehtszellen, soweit sie schon in die Spermienbildung eingetreten sind, diese zwangsläufig beenden, ist schon ron Sundwal, Champr, M. Lewis in den verschiedensten Medien heobachtet worden, aber erst GoLnschmot hat gezeigt, wie die Ergebnisse, die durch die Lebendbeobachtung der Hodenzellen in dem Kulturmedium gewonnen sind, fruchthringend verwertet werden können. Ich halte es für verfrüht, alle möglichen Gewebe zu züchten, wenn man nicht ein bestimmtes Problem lösen will, das nur mit Hilfe der Zïchtung des einen, betreffenden Gewebes gelöst werden kann. Die Schätzung der Methode der Gewebezüchtung leidet, wenn planlose Versuche an allen möglichen Geweben angestellt werden. Das Experimentieren mit Insekten empfiehlt sich, da hier durch die Arbeiten der Forscher genau die zytologischen Stadien, besonders der Geschlechtszellen der Insekten bekannt sind. Wenn man gerade Material hat, so studiere man also noch den Seh metterlingshoden in vitro, und zwar nach den Angaben von Goldschmot. Goudschmot wählte die Puppe von Samia cecropia, die sich ihrer Größe wegen zu diesen Versuchen gut eignet. Wir nehmen, falls diese nicht erbältlich, eine der größeren einheimischen Puppen und betten sie ventralwärts in ein Schälchen mit mit Vaselin, nachdem man die Puppe mit Alkohol abgewaschen und leicht narkotisiert hat. Nit einer feinen aber starken Capillarpipette ziehe man aus dem Herzschlauch die Lymphe, nachdem man vorsichtig ein kleines Fenster in den Chitinpanzer geschnitten hat (23. Übung). Die 
gewonnene Lymphe wird in eisgekïhlte Gefälie getan, zentrifugiert und clann in eisgekühlten Gefäben aufhewahrt. Es ist dringend darauf zu achten, dafo kein Darminhalt die Lymphe rermureinigt, da sonst die Lymphe sehwarz wird. Es empfiehlt sieh auch, mit Glasmessern und - Madeln, statt mit Metallinstrumenten zu arbeiten. Nan berejtert sich zam Auswaschen des Hodens Roxesesche Lösme nach ('LARk, dir folgende Zusammensetzung hat:

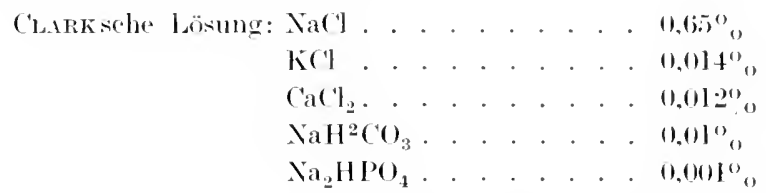

Hierauf entnimmt man steril die heielen ofler das eine Hodenhläschen der Puppe. Die Hoclenhläschen haben gewöhnlich eine sethr starke

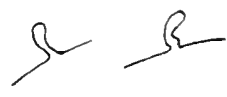

a

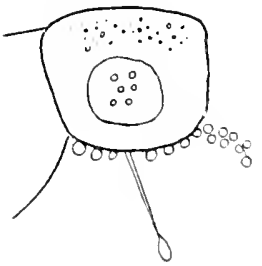

d

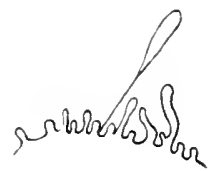

h)

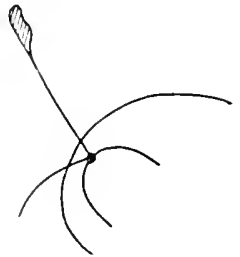

f

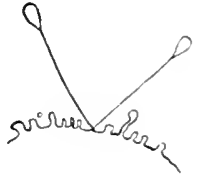

(

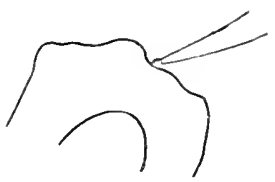

$\sum^{0}$

Abb. 73, a-g. Nacheinanderiolgende Stallien der Achsenfarlenbildung in der jungen, lelsenden spermatocyte. Nach Cioldschmirt 1917. Arch. f. Zelliorschung, Band J4. Beschreibung siehe Text.

Iembran und sehen bej manchen Formen grünlich aus. Bein Präparieren kam man entweder die sehon bemutzte oder eine neue Puppe nehmen. Man öfne ventralwärts die Leibeshöhle in der Nähe des 13. bis 16. Abdominalringes, lege clen Inhalt der Körperhöhle vorsichtig beiseite und ziehe dann mit der Pinzette das Hodenbläschen an seinem Ausfülnungsgange heraus. Man wasche es in Ristienscher Lösung gehörig ab, öffne es und setze Kulturen mit der Lymphe oder in Ringerlösmng in der ïblichen Weise an. In der Lymphe durehlanfen die sipermatogonien alle Stadien der Spermienbildung, die gut im Lehen zu studieren sind, in ungefähr 3 Woehen. Sind ans irgendeinem Grunde die Gesehlechtszellen gerstorben und nur die Follikelzellen lebend erhalten, so wachsen diese sehr stark, während in Kulturen, in welchen die Gesehlechtszellen noch leben, die Follikelzellen in hescheidenen Grenzen gchalten werden. Es besteht hier also eine gegenseitige Beeinflussung zwischen ten Zcllen bindegewebiger und den Zellen epitheliales Natur. 
Will man die Entstehung ter Achsenfäden näher studieren, so wähle man sich junge Spermatoeyten zur Beobachtung aus, wie sie sich in jedem Hoden finclen. Die Achsenfäclen der Spermatozoen erseheinen schon vor den Reifeteilungen in der Zelle und werden dann mit dem Zentrosom fertig vorgebildet auf die Tochterzellen verteilt. In den jungen Spermatocyten beginnt, wenn dic Zelle zur Achsenfadenbildung schreitet, die den Follikelraum zugekehrte Zelloberfläche sich mit zahlreichen Zotten zu bedeeken (Abb. 73a). In Abb. 73 bsind schon viele Zotten zu sehen, eine davon, die nicht gebogen ist, wäehst dann völlig starr aus. Auf skizze d, e sind die Formveränderungen des Auswuehses

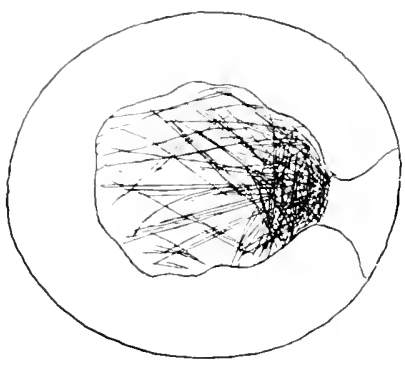

a

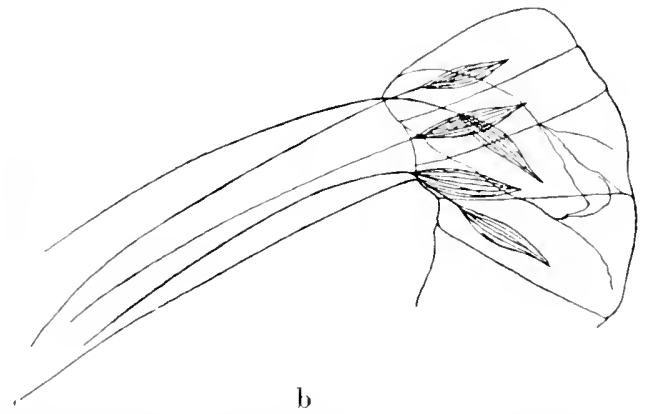

Abl, 74 a u. b. Ausbildung der typischen spermienbünde] in dem mit Spermatiden aus. gekleideten Follikel. a zeigt die noch aufgeknäuelten Achsenfäden, b die in die Follikelhöhle ausgestreckten Achsenfäden der Spermatiden. Nach froldschmidt, wie Abb. 73 .

in einem l5minutigen Zwisehenraum skizziert. Bei e hat sich in derselben Zelle noeh ein zweiter starrer Fortsatz mit einem Protoplasmakïgelchen gebildet. In diesem Zustand verharrt die Zelle. Dann verlieren die Pseudopodien ihren Charakter. Sie fließen ab, und der starre Achenfaden bleibt mit Zentrosom, das hier lebend zu beobaehten sein soll, übrig. Jetzt werden die Achsenfärlen immer länger, bis sie das Follikellumen ganz ausfüllen (Abb. $73 \mathrm{f}, \mathrm{g}$ ).

Will man diesen normalen Verlauf abändern, so nimmt man nach Goloschumt eine Ringerlösung naeh VERNox, die folgendermaken zusammengesetzt ist: $\mathrm{NaCl} 0,75 ; \mathrm{NaHCO}_{3} 0,01 ; \mathrm{CaCl}_{2} 0,024: \mathrm{KCl}$ $0,0.21 \%$.

Die eben beschriebenen Vorgänge traten dann sehon in den Spermatogonien auf. Die Entwicklung einer Ursamenzelle zu einem Spermatozoen ist also nach GoLDschmot eine zwangsläufige physikalische Reaktion, an der zwei Komponenten beteiligt sind, cinmal die Follikelmembran, die die spezifischen osmotischen Verhältnisse schafft, die an jedem Punkt der Spermiogenese einwirkend gemacht werden können und die Zusammensetzung des Plasmas selbst.

Von den Zellen des menschlichen Gewebes an bis zu den Protozoenzellen hat man versueht, die Methode der Gewebeziichtung auszuwerten. Am besten erforscht sind die Frosch-, Hühner-, Meerschweinchen- und Kaninchengewebe. Es wird sich also empfehlen, daß Anfänger nur Arbeiten mit Tierarten vornehmen, die schon durch- 
studiert sind. Aber selbst die Gewebe der erwähnten 'Tierarten sind nicht alle gleichmäBig durchforscht. So sind erst die bänderartigen breiten Zellen, die ans dem endorlermalen Darm des Huhnes auswachsen, sehr spät als sympathisehe Nervenfasern erkannt worden. Es sollen also rom Anfänger zuerst noch keine Gewebe mit sehr gemischter Zusammensetzung zu züchten versucht werden, soutern das embryonale Her'z, Lnterhautbindegewebe und Epithelgewebe als die am besten durchforsehtrin, sollten zuerst studiert werden.

Erst an Stchlusse des Abschnittes also werden wir folgende Übung anstellon (24. Übung). um nachzuprüfen, ob ('HAMPY recht hat, wenn er behauptet, dal3 Zellen, seien sie bindegewebiger, seien sie epithelialer Herkunft in der Gewebezüchtung nach längerem Verweilen sieh sehr ähnlich werden (Abbildung 75).

Wir nehmen also einen ungefähr zehntägigen Hühnerembryo und legen gleichzeitig Kulturen der Haut, der Milz und der embryonalen Nicre, der Schilddriise und des Hodens an, und zwar in reinem Hühnerplasma. Joden Tag wechseln wir das Nährmedium, naehdem wir
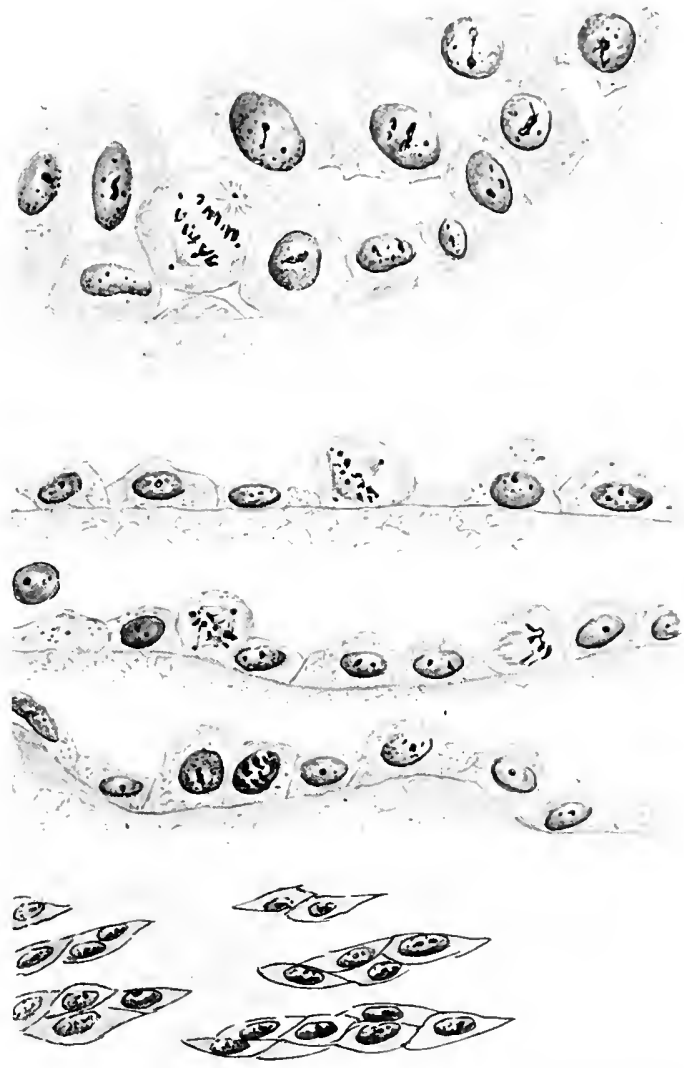

Abb. 75. Schematische Darstellung sog. entoliferenzierter Zellen verschjedenen Ursprunges. Nach Champy, 1914, La presse médicale.

das Gewehe in Hühnerserum ausgespïlt haben. Dies wird 3 Tage fortgesetzt, dann eingebettet, gehärtet und geschnitten. darnaeh gefärbt nach Champr und Prenant (Siche Seite 64). Dann wird sieh zeigen, ob und welehe Gewebearten sich entdifferenziert haben und sieh ähnlich geworden sind. Es ist notwendig, daß der ganze Plasmatropfen gehärtet wird, damit die in das Plasma eingewanderten Zellen mit geschnitten werden. Für das Epithel steht es beim Huhn jedenfalls fest, daß es sich nieht in der Gewebezüchtung nach Form und Struktur so stark verändert, als man es nach CHAwprs Angaben 
glauben sollte. Aweh Levi glaubt nach seinen Erfahrungen beim embryonalen Gewebe nicht. dak die sehon funktionierende Herzmuskilatur sich stark rerändert.

Hierauf schreite man zum zweiten Teile der Ühung und wiederhole die Reihe der Anorelnung für die betreffenden Gewebe des erwachsenen Kaninchens. Hier müssen dann nach C'HAMPr die in das Plasmedium eingedmungenen Zellstränge cine so starke Veränderung der struktur ihrer Zellen erfahren haben, dab die verschiedenen Gewebe nicht mehr leicht roneinander zu unterscheiclen sind. Hierbei stoben wir sehom auf unentschiedene Fragen. Fs wird im Laufe der näehsten Jahre geklärt wer len müssen, welche Gewebe bei Kaltblïtlern und bei Warmblïtlem in der Gewebezïchtung ihre Ausgangsstmlitur erhalten und welche nicht.

\section{Ablanf progressiver und regressiver Vorgänge.}

\section{A. Verhalten der Simnesepithelien in dem Kinlturmedium.}

Es ist mehrfach schon darauf hingedeutet worden, daß die Züchtung der Epithelien wenig geübt worden ist. Die Simesepithelien machen

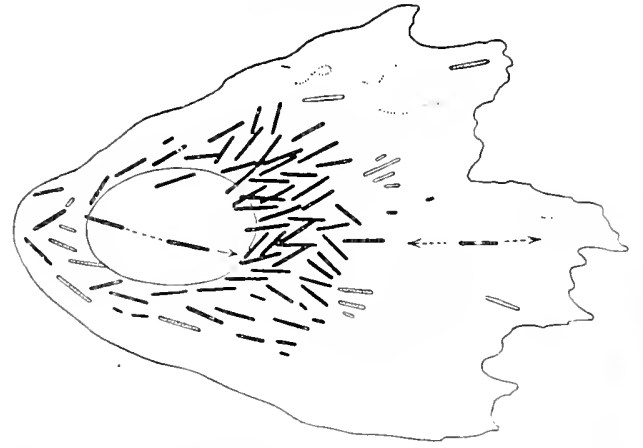

Abl. 76. Sclumatische Darstellung einer Zelle des Pigmentepithels ler Retina. Sämtliche Typen der Pigment granula sind gezejehnet. Die feinen Fäden sind die Mitochondrien. Die gestrichelten Granula stellen die grauen Pigmenturanula vor, während die sehwarzen und umränderten Stäbehen die versehiedenen Gräßen und dieverschiedenen fiestalten der farblosen und der schwarzen Pigmentgramula zeigen sollen. Nach Suith, 1920, Johns Hopkins Hosp.-Bull. Bil. 31.

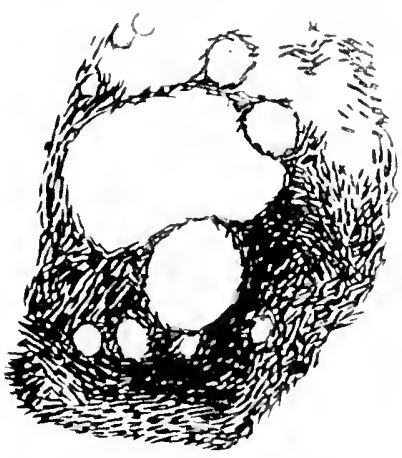

Abb. 77 a. Panentepithelzellen von Rana pipiens. Naelı Thlenhuth, 1916, Tuurn. of experim. med. Bd. 24 .

Abl. 77 b. Eine andere Pigmentepithelzelle, die sich langsam in dem Medium vorschiebt, mit vollständiger (iestaltveränderung, wie Abb. 77 a. 
aber eine Ausnahme, ologleich es sich gezeigt hat, dafs die Pigmentzellen der Retina embryonal und erwachsen sich nicht in der Gewehekultur teilen, lebend im Medium beiben und nur aine $\mathrm{Cm}$ ordnung der Pigmentgranula zeigen. Un diese Änlerung der Polarität der Pigmentgranula darzustellen, verfahre man in folgender Weise:

Man stelle sich Frosehplasma und Augenkammerwasiser her und lege sich Kulturen des Retinapigmentepithels und des hispigmentepithels des erwachsenen Frosches an. Zum Vergleich explantiere man kleine Stückchen des Retinaepithels eines Hïhnerembryos rom Alter ron 5- 15 Tagen entweder in LokeLewis-Lösung oder in Plasma. Man wende bei diesen Präparaten bei späterer Beohachtung bei cinigen $\mathrm{Ex}$ plantaten Mitoehondrienund Neutralrotgranulafärbung wie beschrieben an.

Pigmentzellen der Retina (s. Abb. So). Die Pigmentzellen strecken zuerst feine Protoplasmafortsätze ins Medium, die keine Pigmentgranula enthalten, später reichen die Zellen einzeln oder in syncytialem Zusammenhang schleierartig hervor. Die Granulaarten in dieser Zellform sind verwirrend. Wir sehen stäbchenartige, schwarze oder braune Pigmentgranula, graue als Vorstufen der Pigmentgranula von manchen Autoren gedeutet, Mitochondrien und Neutralrotkörner. Die Pigmentgranula wandern

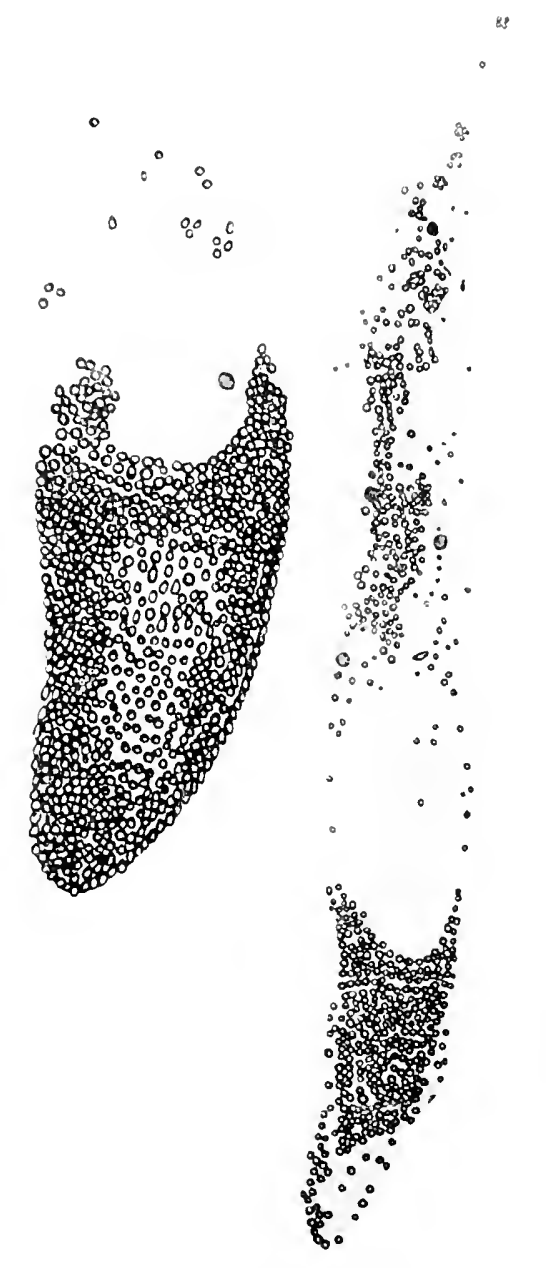

Abb. 78 , a 1 . b. Zwei sich bewegende Irispigmentzellen in einem halbfesten Medium. a ist 11 Tage nach der Explantation gezeichnet, b 12 Tage. Nach Uhlenhuth, wie Abb. 77 . 
in den Zellen in bestimmten Bahnen von der Peripherie der Zelle bis zum Kern, und bis fast zum entgegengesetzten peripheren Rand, aber rin Bezirk der polar angeordneten Zelle bleibt frei von Pigmentkörnem (25. Übung).

Beim Huhn geht die Polarität, die diesen Zellen eigen ist, nieht ganz bei der Züchtung verloren. Dagegen sind die jetzt zu studierenden Zellen des Pigmentepitheis der lris und der Retina rom Froseh stärkerer Umordnmosserscheinungen fähig. Die pigmenticrten Zellen des Retinaepithels, die polar gebaut sind. grenzen mit der pigmentierten Basis an die Retina (Abb. 77, a b). In dem Teil sind gelbe Ölkugeh vorhanden. Die

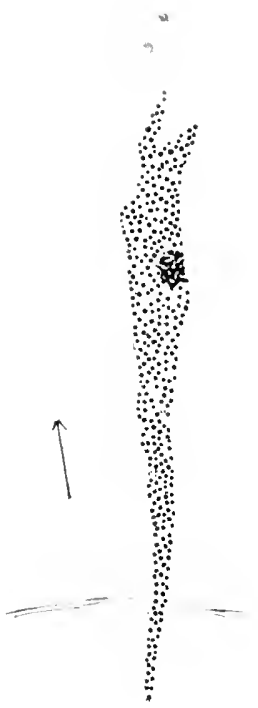

Abb. $78 \mathrm{e}$. Chorioideazelle und Mesenchymzelle des 12tägigen Hühnerembryos. 1.2 Stunden in der Kultur. Nach Luna, 1919 , Arch. ital. di anat.e eli embriol.Bd.1s. Zelle vorliert in der Gewebekultur die ihr zukommende Differenzierung in zwei versehie. dene Alschnitte und beirle Pole der Zelle werden einander gleich. Ebenso rersehwindet das Pigment und die strukturellen Anhänge. Die Zelle nimmt die Form einer Bindegewebszelle an und bleibt nicht mehr hexagonal. Auch für die Pigmentzelle der Iris gilt das gleiche. Alle strukturellen V'ersehiedenheiten versehwinden (Abbildung 78 a. b), die Zellen werden beweglich und spindelförmig. Die beiden Zellarten werden in dem halbflüssigen Kulturmedium einander ähnlicher und nehmen bis zum gewissen Grade die gewöhnliche Form der Bindegewebszellen an. Die Retina selber hat sich stärker hierbei alzubauen wie die Iriszellen. Aber zu einer Teilung kommt es bei dieser Zellgruppe nie in dem Explantat, dagegen fällt die starke Mitosenbildung der bindegewebigen MüLLERsehen Faser auf. Hier (Abb. 79) zeigen sich die gleichen Erscheinungen wie in der Muskulatur der Blase (vgl. S. 67). Auch die Pigmentzellen del Chorioidea verhalten sich in der Kultur bindegewebeartig (Abh. 7Se). Beide Zellgruppen sind im gleiehen Medium und verhalten sich doch so versehieden. Es müssen hesonders hier doeh inhärente Untersehiede der Zellen bestehen, die in ihnen fest verankert sind.

Damit diese beiden geschilderten pigmentierten Zellarten sich ähnlicher werden lïnnen, muß die jigmentierte Retinazelle größere regressive Veränderungen durchmachen als die pigmentierte Iriszelle. UnLENHuth macht für die pigmentierte Retinazelle geltend, daß diese Zelle jetzt von einem allseitig gleichmäBig wirkenden Medium umgeben sei, während sie sonst an den entgegengesetzten Polen versehiedenen Einflüssen unterworfen war.

Beim Hühnerembryo ist dies nicht so stark ausgeprägt, wie wir gesehen haben (Abb. 80 u. 81). Doch wird sich gerade mit Hilfe der 

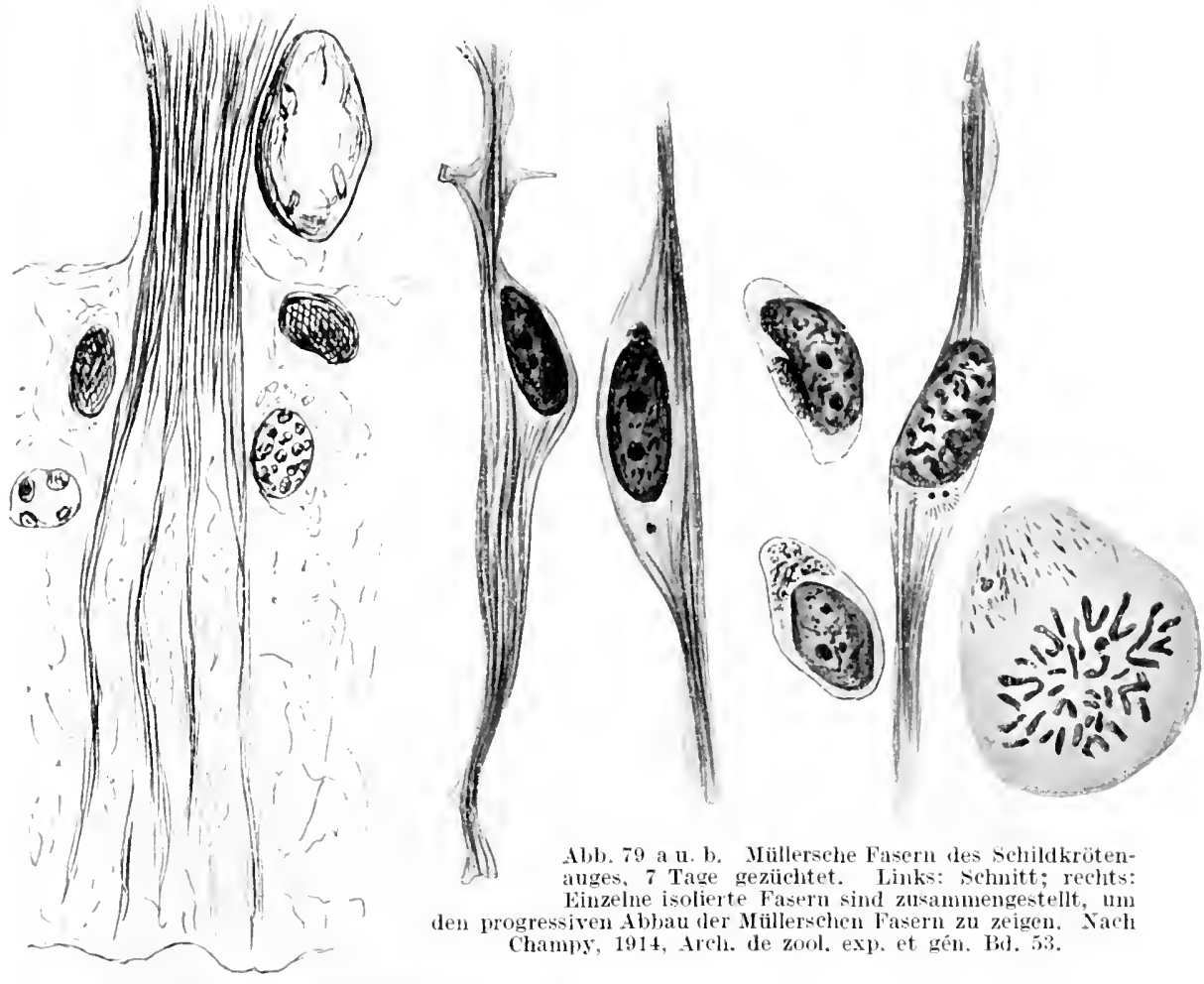

Abb. 79 a u. b. Miallersche Fasern des schildkrötenauges, 7 Tage gezuchtet. Liuks: schuitt. rechts: Einzelne isolierte Fasern sind zusammengestellt, um den progressiven Abbau der Müllerschen Fasern zu zeigen. Sach Champy, 1914, Arch. de zool. exp. et gén, Bł. 53.

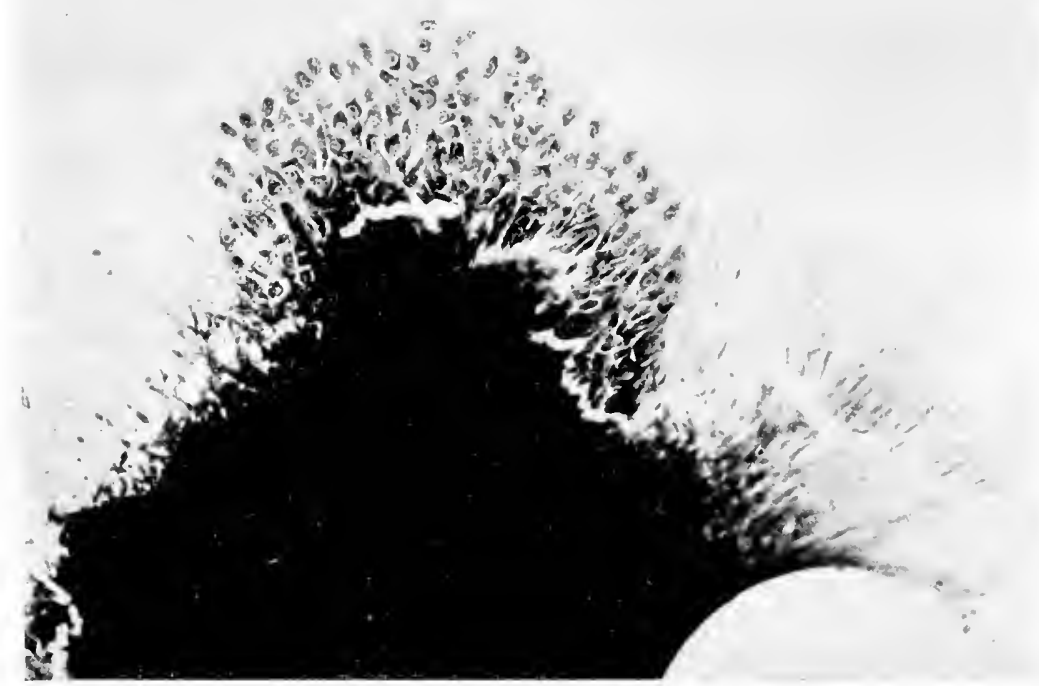

Abb. 80. Photogramm einer 72 Stunden alten Kultur der Pigmentschicht der Retina von enem 8 Tage alten Hühnerembryo in Locke-Lewis-Lösung. Sowohl Pignentzellen als auch Mesenchymzellen sind crkennbar. Nach smith, Abb. wie 76. 
Gewebezïehtung die schwebende Frage, ob die Mitochondrien sich in Pigment unwandeln können, lösen lassen. (Ygl. das Sehema Abh. 7 (i.)

Bis hente sind drei Ansichten vorhanden, wie die Pigmentgranula entstehen kömnen. Sind sie Produkte des Zellkerns, der Mitochondrien, des durch Enzyme umgewandelten Zellplasmas?

Die interessantesten und für theoretisehe Entscheidungen wiehtigsten Aufsehlüsse werden wir durch die Zïchtung der Epithelzelle, die

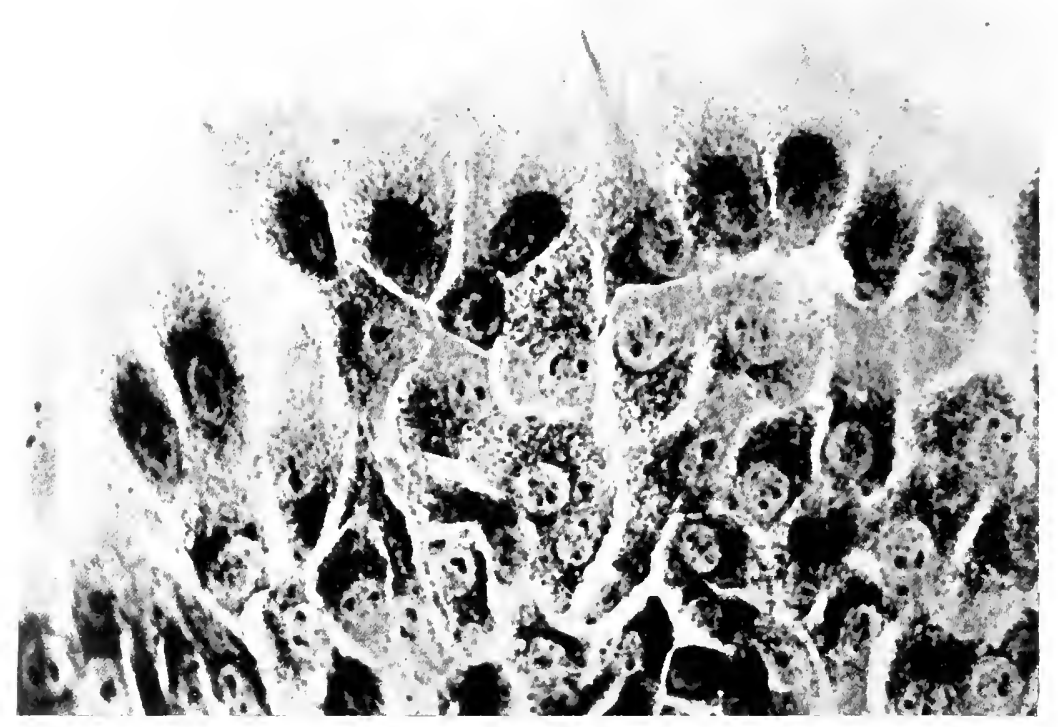

Abb. 81. Tas gleiche Präparat, aber stärker vergröBert. In den meisten Zellen sind die Pigmentgranula um die Zentrosphäre angeor(net an der einen Seite des Kerns. Nach Smith, wie Abb. 76 1. 81.

schon im normalen Leben an verschiedene Medien grenzt, sei es Körperflüssigkeiten und Bindegewebe, sei es Außenwelt mnd Gewebe, erhalten. Ihr ist eine große Ciestaltungsmögliehkeit gegeben. Sie hat die verschiedensten Anhänge, Flimmerhaare, Bürstenbesätze usw., und Inhaltskörper, wie Pigmentkörner und Granula mannigfaltiger Art. Es ist ihr eine ausgesprochene Individualität eigen, daß sie fester organisiert erseheint, wie die schon im Körper potenzenhaltige Binclegewebszelle. 


\section{B. Verhalten der nervösen Elemente.}

Das zwcite C̈hungsgehiet dieses Alschnittes umfalit die Ersedreinungen, die in dem gewählten Mledium in Zellen und strukturen des Ner vengewehes ror wieh gehen. Fribh ist das embryonale Negrengewebe studiert, ja nur rem Wunsehe Harrisoss, die Streitfrage experimentell zu lösen, oh die Nervenfasern Produkte der Ganglienzellen sind oler vom umgelenden Plasma erzeigt worden eine Frage, die noch vor 2.; Jahren zur Klärung stand-verdanken wir, üherhaupt rinen vorsprechenden Anfang der Methode der Gewebepflege zuerst bei Kalthlïtlern (Frosehlarren) und später durch Burrows bei Warmblütlern (Hiihnerembryo). Die Methode wurde

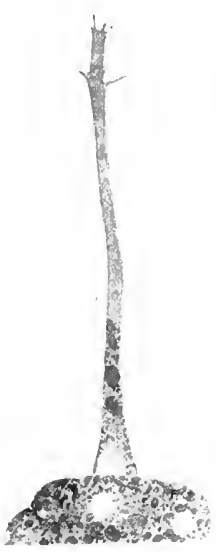

a

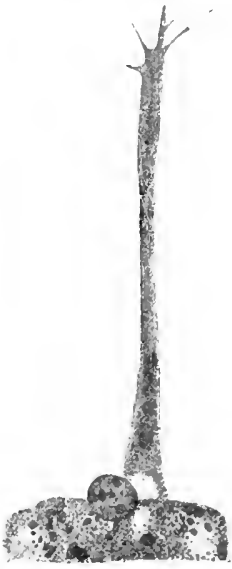

)

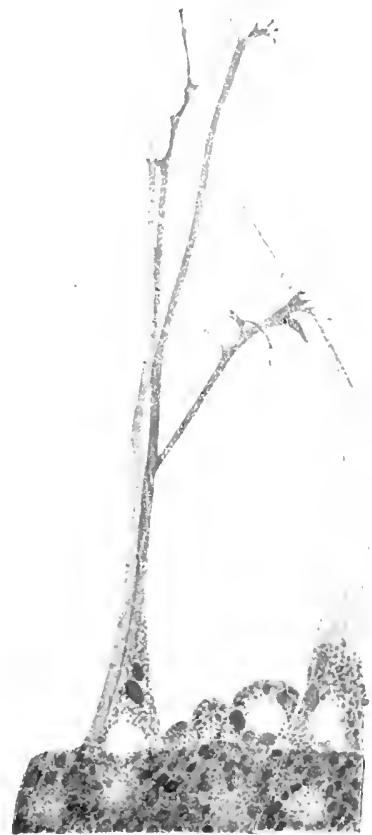

c

Abb. 82, a-e. Kultur aus dem Medullarrohr des embrvonalen Frosches. Entstehen von Ausläufern der ranglienzellen und die Verbindung mit anderen Zellen im tiewebe, fïnt nacheinanderfolgende Stadien desselben Nervenkomplexes. a 24 stunden, b $251 / 2$ Stunden, c 34 stunden naeh der Explantation. Nach Itarrison, 1913. Transact congr. Amerie. Phys, and surg Ix.

aber erst dureh die Plasmagewinnme, die Burrows und CARret rervollkommmeten, weiteren Kreisen beachtungswert. I'm das Auswachsen der Nervenfasern unter dem Deckglas zu beobachten, wird es sich empfehlen, entweder Frosehembryonen oder Hïhnerembryonen zu hemutzen (:6. Übung). Man wählt nach HARrisos Stadien der Embryonalentwieklung des Frosehes, bei denen manehe Zellen des Medullarrohres noeh keine Fortsätze haben. Man überzeugt sich durch einen Gefriersehmitt oder dureh einen Simitt mit dem Rasiermesser unter dem Mikroskop nach Methylenblaufärbung, wie viele Ganglienzellen des Medullarrohres sehon Fortsätze gebildet 


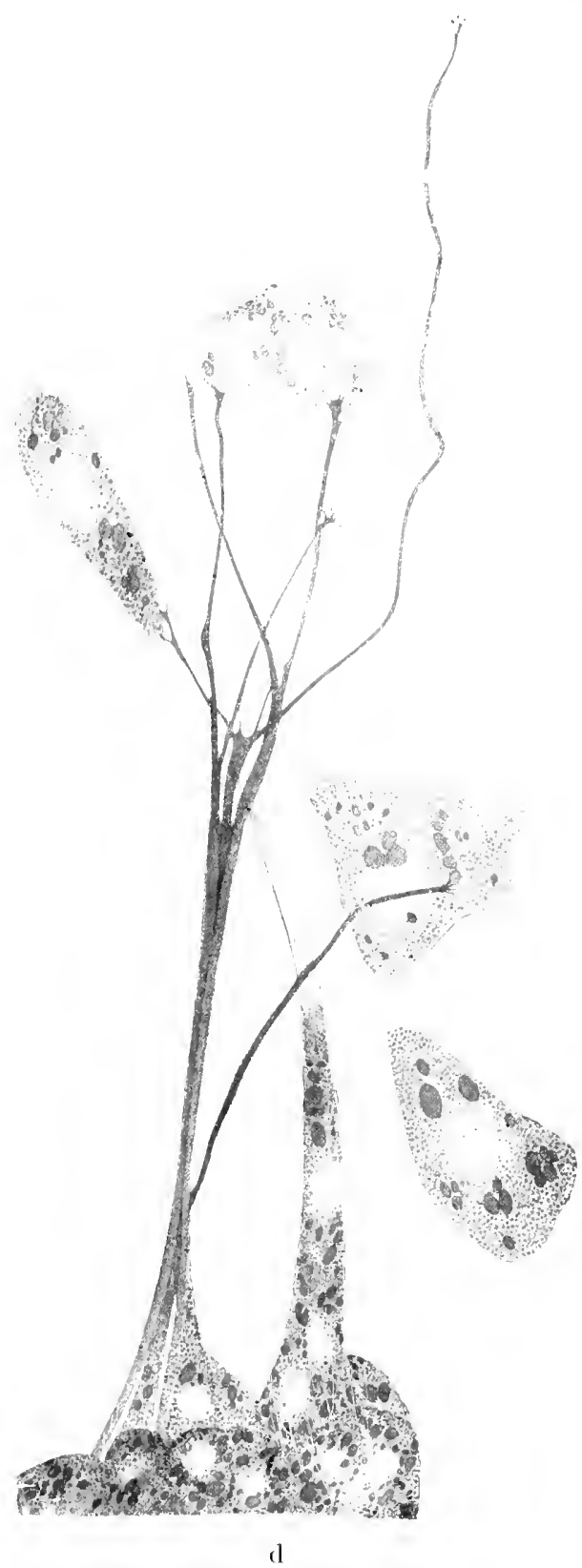

Ahb. 82 d. Kult ur aus dem Medullarrohr des embryonalen Frosches. Entstehen von Ausläufern der Ganglienzellen und die Verbiulung mit anderen Zellen im dewebe. 4. Stadium destelben Nervenkomplexes. 46 Stunden nach der Explantation. Nach Harrison, wie Abb. 88. haben. Dann tremt man das Medullarrohr ron den anderen Geweben des Körpers und teilt es in Stiockchen. die mit dem Bingkular auspräpariert worden sind. Nun sind sie fertig zum Einsetzen in das Kulturmedium. Die stïekchen müissen sehr klein sein. HARrisos, der zuerst diese Experimente gemacht hat, hat dic Stückchen in Froschlymphe gezüchtet. Wir wollen aber aus teehnischen Gründen nicht dieses für Nervengewebe historisch älteste Hedium zur Züchtung benutzen, sondern wirstellen cin Medium aus Frosehplasma und Augenkammerwasser her.

Schon naeh kurzer Zeit sieht man Lebensäußerungen der Zellen. Fine ganze Reihe ron Zellen umgeben jetzt das eingepflanzte Stück und bilden sehleierartige Grwebsinseln. Nach 48 Stunden aber werden die Gewebsschleier durch die Verflüssigung des Plasmas zerrissen und hier und da bilden sich von Zellen freie Räume. Da man im allgemeinen nieht allein Nervengewebe explantiert hat, so ist es wichtig, zu wissen, dals sowohl die embryonale Muskelzelle als auch die Epidermiszelle der Froschlarve sich in dem gewählten Medium differenzieren. Die Muskelzellen der Frosehlarve erwerben Querstreifung, die Ep)ithelzellen Cilien, auch wenn diese Zellen von ihrem IIutterboden getrennt sind. 
Si) kann es nicht erstaunen, wenn dic Ganglienzellen nach 24 stumden dichte plasmatisehe Fortsätze aus dem Zollschleier herrorstreeken. lostimelen später hat sich dieser Auswuchs melshar verlängert und in vier getremute farsern geteilt. Immer länger streckt sich num fler Ais. wuehs, bis er schlieditich iiber 1 mm lang geworden ist. Das Encle jecler Faser zeight fingerförmige unregelmäbige Psendopodien, die inständiger Bewegungsind. Sie bestehen aus amöborden Protoplasma, welches ron der Lrspungsistelle stammt. Diese Endbäumchen der Fasern oder Plaboden sind die Bewegungsmittel der Nervenzelle. Das Plasma wird ungefähr im Zeitraum von 1 Mlinute 1 " weit rorgeschoben, und die Zelle rïekt entweder nach orler die Faser wird stark gestreckt (Ab). S:-).

Diese schon im .Jahre 1904 von HARRIsox gefundenen Ergehnisse sind von vielen Forsehern bestätigt und erweitert. leh erwähne nur hier die Albeiten ron Braus.

Hat man keine Frosehembryonen, so empfiehlt es sich, Hühnerembryonen zu verarbeiten. Das Phombencephalon cines viertägigen Hïhnerembryos eignet sich besonders gut zum Ansetzen von Kulturen. Hicrbei ist äuBerste schnelligkeit nötig und es

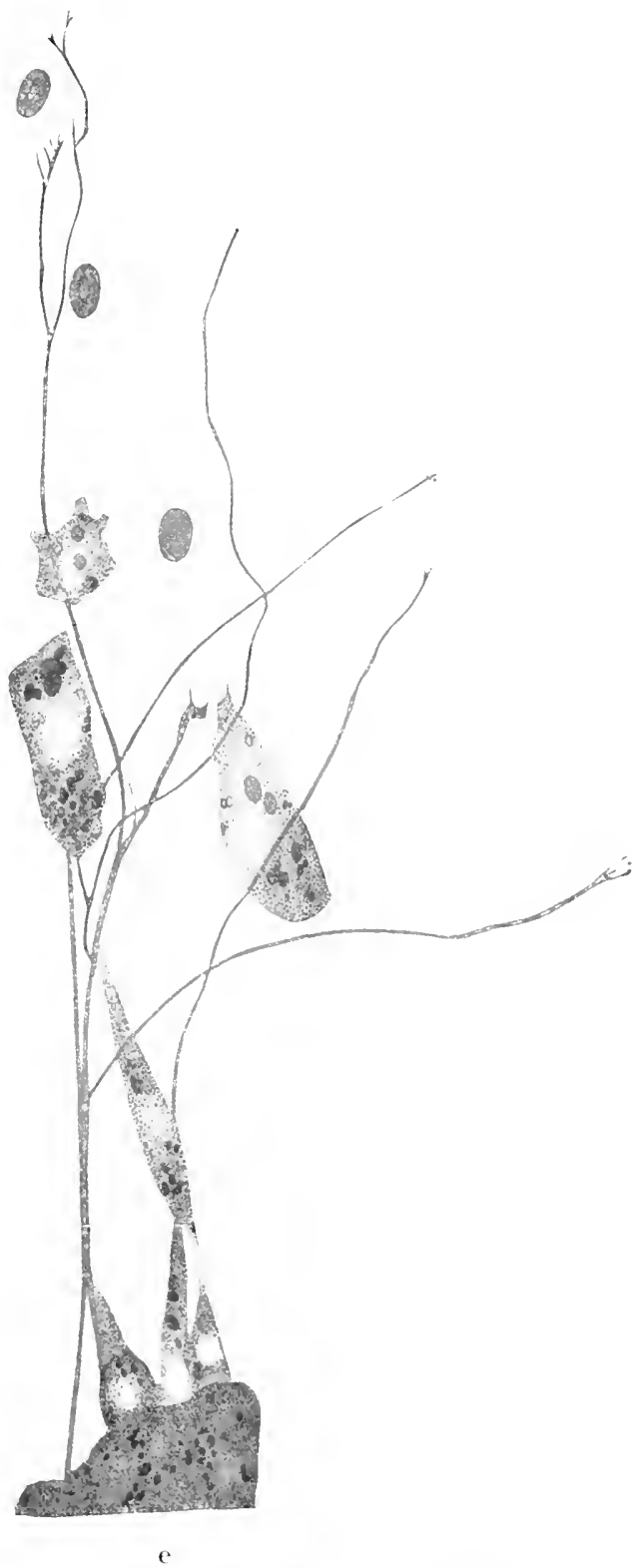

Abb, sze. Kultur ans dem Medullarrohr des embryonalen

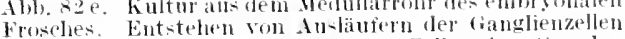
und die Verbinlung mit anderen Zellen im rewebe. 5 . stadium desselben Nervenkomplexts. 58 stumlen nach der bulantation. Diese Abbildung ist weniger stark vergrobert wie die vier vorigen. Fach llarrion, stark vergrobert wie die vier vorig
wie Abb. 8?. 
empfiehlt sich nicht, las exciclierte stückchen erst in Waschflüsigekeiten zu bringen. somdern man zerteilt das fewebe schnell in einem trocknen strilen (ilassebälehen und bringt es in das Kulturmedium.

Leri hat besontlers

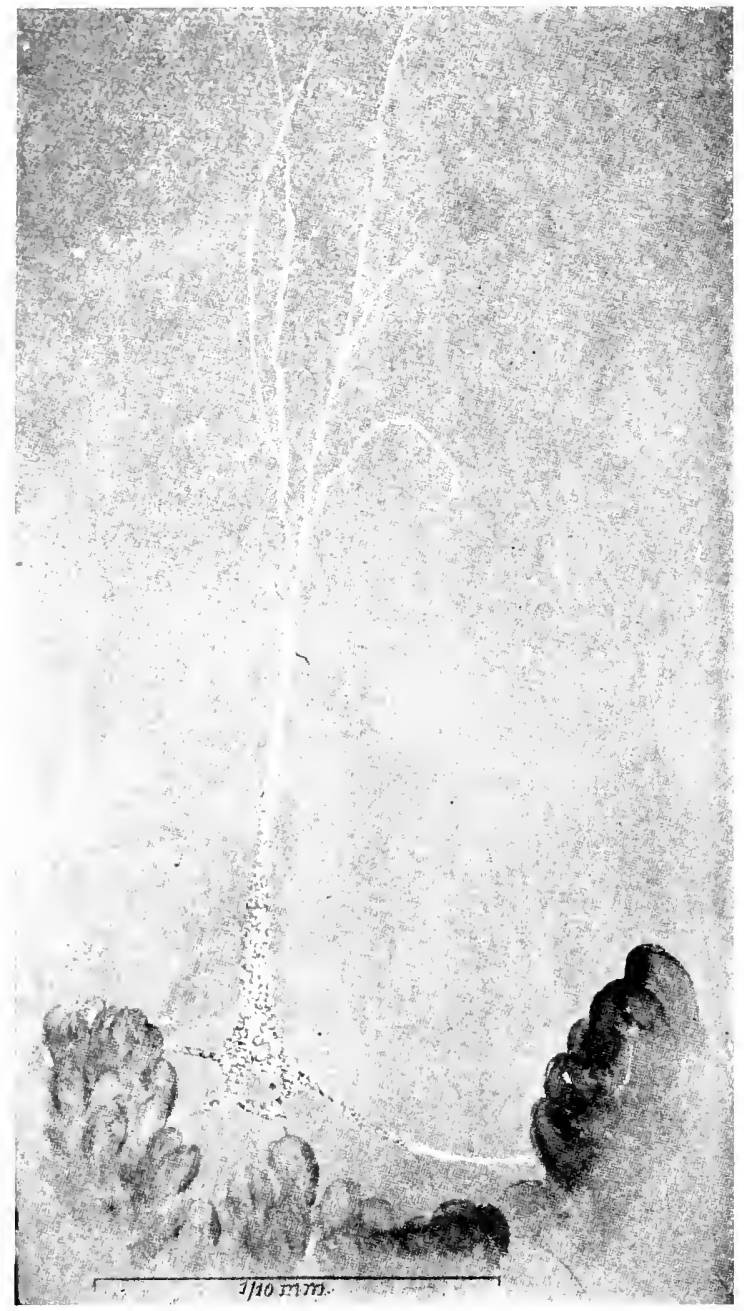

Abb, s3. Ganglienzelle, die sich aus dem ferbande der ibrigen suinalganglien freigenacht hat und grobe fortsätze in das Medimm streck. Vier Tage alte Kultur aus den spinalganglien eines 7 Nonate alten Kannchen. Nach dem Leben. Nach lngebrigtsen. 1913, Journ. of experim. meil. Bil. 17. gute Erfolge slurch diese Methode erhalten und auch die Bildung ron Endbäunchen, auch Faserverflechtungen unel das selbstätige Auswandern von (ianglienzellen gesehen. Eir betont. dabs die Lebensdaue: einer Kultur höchstens 24-4s Stunden beträgt. Man sieht also (laraus, dab rom cinem eigentlichen Wachstum der Warmblittler-Nersenfaser nicht die Rerle sein kann. Die Lebenserscheinungen bestehen nar in der Lmgruppie rung des Zellylasmas. das sich in der explantierten Ganglienzelle schom befindet. INGEBRIGTSEN

züchtet Nervenfaserm aus Spinalganglien des Kleinhims einer ehen gelorenen Katze (s. Abb. 83). Hierfallen im gefärbten Präparat clie vielen Gliafasern und die cine Nervenfaser auf (Abb. 86 ). Lebend läBt sich dieser

Unterschied nicht leicht nachweisen. Ixabrougses hat Formalinfixierung, Hews sche Molybdän.Hämatoxylinfärbung mit nachfolgentel Differenzierung in WEIGErTscher Flüssigkeit zur Darstellung seiner Präparate rerwanrlt, doch war das Resultat nicht ganz befriedigend. Levi fixiert mit Zenker, dam in der MAxmowschen Lösung 


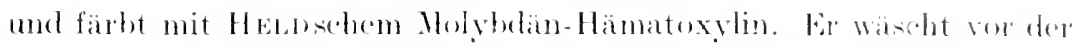

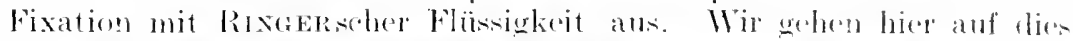

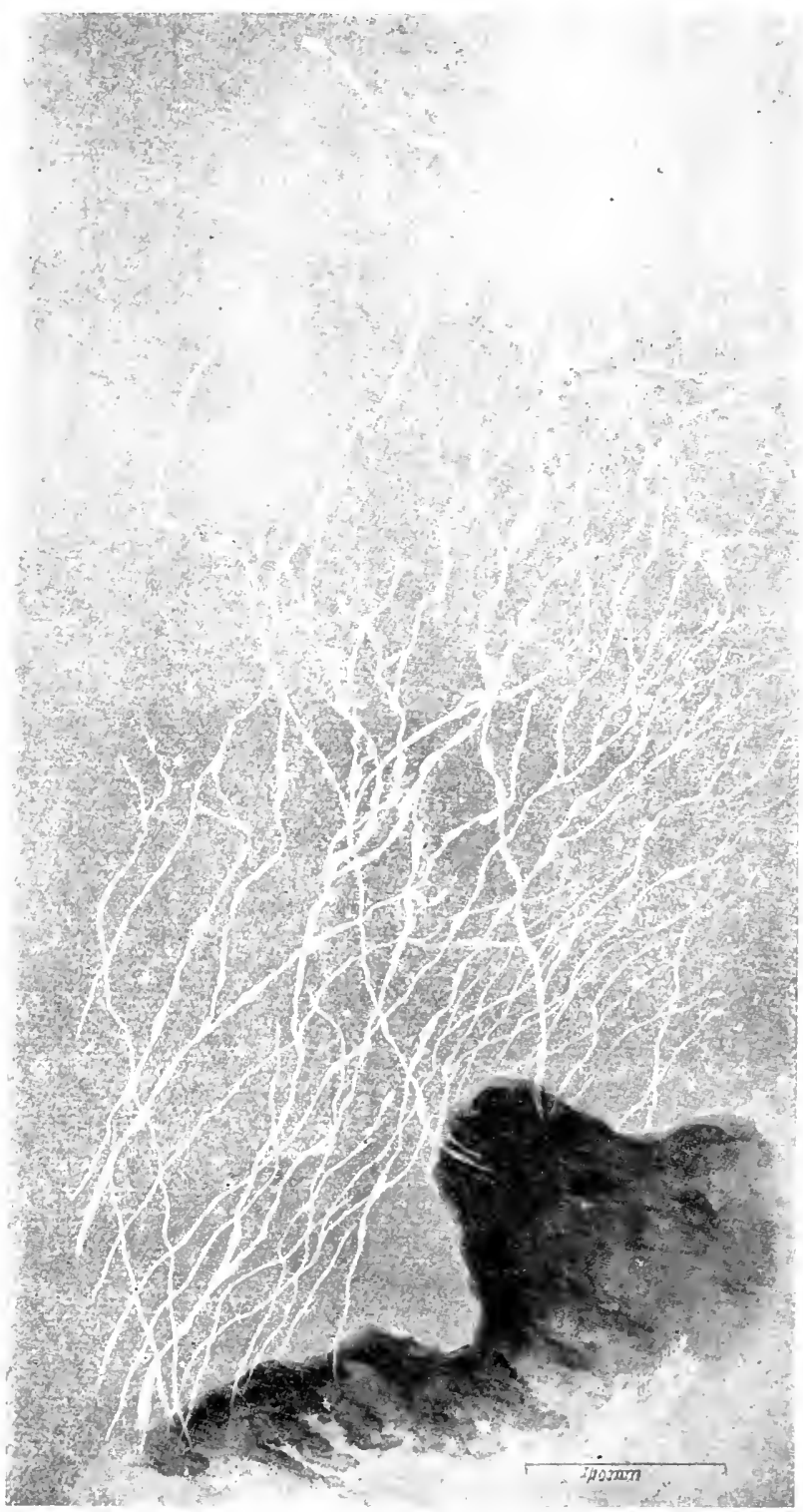

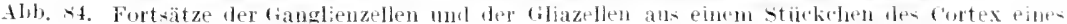
3 Wochen alten Hundes, 3 Tage im Helium. Nach Ingtbrigtan, wio 11,b. 83.

schwierige Gebiet, das Wachstum der Gia- mol Nervenfasern, nicht weiter cin, sondem studieren noch am teheneten Präparat die Bildung von A nastomosen und Endrerzweigungen der Nervenfarern nach G. Lasi. 
In Verlanf ron zwei stunden heobaehtet Levi deutlich in antrigenein Plasma die Bildung ion feinen Faserbrücken zwisehen zwei parallel nebeneinander liegenden Fasern des Rhombenkephalons eines: :3 Tage alten Hölnesembryos im Leben (2.). Cbung). In dieser aus dem Phombenkephalon auswachsenden dicken

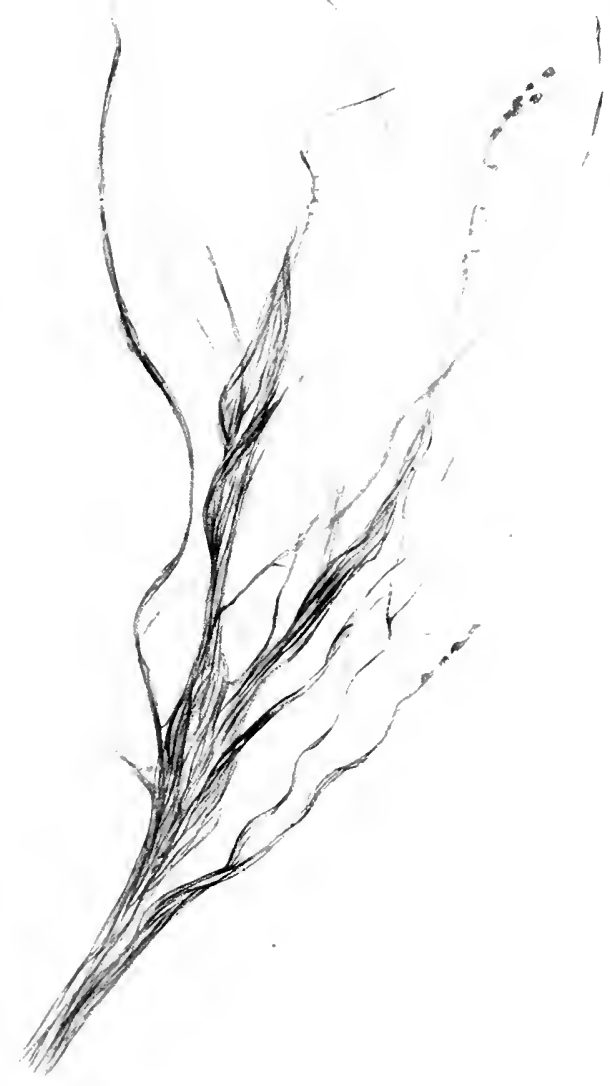

Abb. 85. Nach Levi. Anastomosen- und Plakodenbildung aus dem Rhombenkephalon eines jüngeren Hühnerembryos, 3 Tage gezüchtet. Nach Levi, 1917, Atti della li. Acad. dei Lincei. V. Serie, Bd. 12. Fasern laufen zuerst die Nervenstränge parallel. biese dieke Faser streckt sich im Verlauf ron .j Stunden und wäehst zu einem sehr langen Faden aus. Bei dem untersuchten Beispiel wachsen die beiden Aste des urspriinglichen Nervenstranges nicht mit gleicher Geschwindigkeit. Nie waren im Anfange gleich groß, am SehluB der Beoloachtungszeit ist der eine doppelt so lang wie der andere (Abb. 85). In den schom gebildeten feinsten Fädchens des Endbäumchens bilden sich nene Fäserchen. Diese Fäserchen werden damn mit Plasma gefuillt, und es entsteht ein fächerartiges Cebilde, das sich später strecken und wieder nene. Fasern aus sich herauswachsen lassen kann. So wiederholt sich das Spiel der Bildung ron Endknospen oder Endplakoden fortwïhrend und dient dazu, die Nervenfasern zu verlängern. Aueh kurze Neuriten, deren Verbindungen mit der Ganglienzelle noch sichtbar sind, verlängern sich auf diese Weise. Die Spinalganglien dringen aus dem Gewebe im allgemeinen als dicke, kräftige Zylinder zuerst heraus, in denen man die cinzelnen Fasern deutlich untersclıciden kann. Im Verlauf von ungefähr 7 Stunden ist aus den kurzen Fortsätzen ein langes fädiges Gebilde entstanden, das an seinen Enden zahlreiehe Verästelungen hat.

Um dies naehzuprüfen, beobachte man eine Stelle des Präparats fortgesctzt und zeiehne sie in kurzen Zeitabständen. So sieht man, 
dabeine Nervenfaser zuerst an ihrem einen Aste zahheiche Fudknospen hatte, die sich damn bald in ein Gewirr von vielen Fäden auflösen. sehr häufig entsteht anch durch Bildung von freien Stellen aus einem Nervenplexus ein verzweigtes Fasergeflecht, das zahheiche Anastomosen hesitzt, also der friiher die ganze Fläche ausfüllende Nervenplexus ist aufgeteilt in ein feinstes Gitterwerk. Wierler kïnnen sich diese Fasern zusammenschließen zu einem Nervenstrang und sieh später wieder in feinste Fäserehen auflösen. Einzehe Neuroblasten können aus dem Plasma auswandern und neue Verzweigungen bilden. Es int aber Vorbedingung, da!s feine Verbindungen mit dem L'rsprungsigewebe existieren, ist die Zelle vollstinndig getremnt, so stirbt sie nach kurzer Zeit ab. Es seheint also, als ob sie ihre Nahrung aus dem eingepflanzten Gewebe zieht.

Es wird behauptet, daB das starke Lichtbreehungsvermögendie auswaehsende Nervenfaser kenntlich

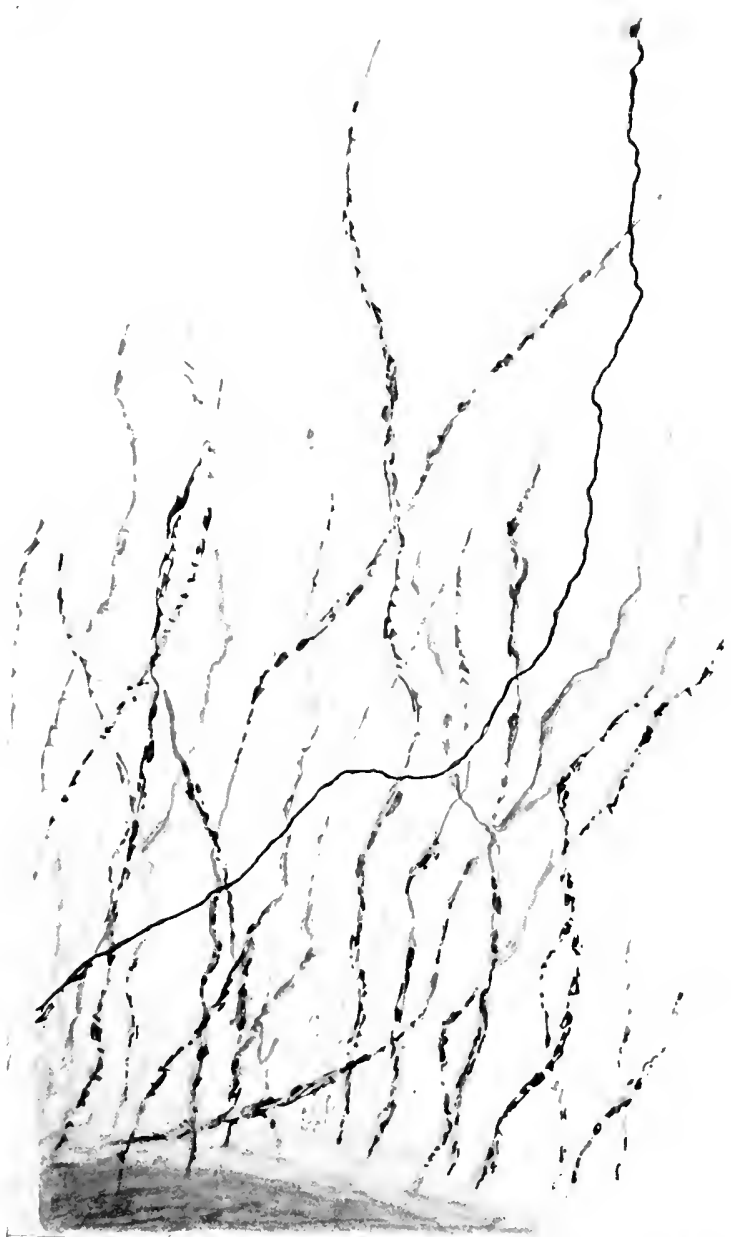

Abb. 86. Auswachson e i ner Faser aus den Kleinlirn eines eben geborenen Meerschweinchens. 2 Taue alte Kultur. liefärbtes Prälarat, das den Unterschied zwischen Nervenfortsätzen und filia. fasern zeigt. Nach Ingebrigtsen. 1913, Journ. of exper. med. Bd. 1s.

macht. Ich möehte lieber raten, zum Einpflanzen nervöses embryonales Gewebe zu exeidieren. Das ist bei der relativen Größe der Strukturen möglich.

Die in fixierten Präparaten erseheinende Gesam theit der Fibrillen existiert nicht im Leben, doeh sind lebend einzehe fibrilläre Fasern beobachtet worden. 


\section{8}

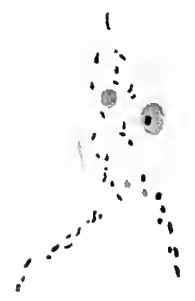

Abb. 87. Auwachsente sympathische Nervenfaser aus

dem Jarmkanal eints 7 täg'gen Hihnerembryos, 2

Tage in Loke-Jewis-Josung. Nach Matsumoto, 19:0, Johus Hopkins Ho:1\%.-13111. X. 349 .
Zum Schluls fertigen wir uns noch Kulturen von den Darmschlingen des Hühnerembryos an (7 Tage alt). Aus ihnen wachsen breite Bänder in der Loke-Lewis - Flüssigkeit. schon in kurzer Zeit heraus. Diese zeigen Mitochondrien und Neutralrotlörner: (x) sind sympathisehe Nerrenfaseln (Abb. 87).

Die Hinfälligkeit der nervösen Elemente in allgemeinen ist groß, echtes Wachstum, manifestiert dureh mitotische Teilungen, ist nicht heobachtet worden. So haben wir von den Mesenchymzellen des embryonalen Hïhnerherztens lis zu den nerrösen Elementen der Retina eine Reibe, die wieder die Abhängigkeit von Funktion und Zelldifferenzierung zur Potenzgrößse zeigt. Je größer die funktionellen Ansprïche an eine Zelle sind, je differenzierter sie ist, je geringer ihre Cmbildungsfähigkeit und Lehensdauer in dem Explantat. Je höher das Gewebe in der Wirbeltierreihe steht, je friber tritt schon diese Potenzbeschränkung ein, wie wir bei Froseh und Huhn sehen.

\section{Verhalten des Herz- klappengewebes.}

Es ist sehon seit ('oHNHEIM stuittig, ob alle bei der Entzïndung erscheinenden Rundzellen der Pathologen lympho- oder lenkocytären Crsprungs sind, oder ob das umgebende Bindegewebe Rundzellen ausschmilzt. 
Die Herzklappe der erwachsenen Katze, Ratte orler Ringelnatter eignet sich zun Studium des Abbaues des Bindegewebes oder dor clastischen Fasem, bei dem auch Rundzellen frei werclen, wie schon lange won Grawtz betont. Man bereitet sich Ringelnatterplasma oler je nach Wahl Ratten-oder Katzenplasma vor (207. C̈bung). Bei der Zubereitung des Ringelnatterplasmas mul.3 man hesonders darauf achten. dals das Plasma selbst keine dem Blut rorher schon eigenen Bakterien enthält. cla das Blut der weehselwarmen Tiere mit kommensalen Balsterien beladen ist, die damn natïrlich bei der Plasmabereitung mit in das Plasma gelangen. Es empfiehlt sich also, gleich nach Bereitung des Mediums einen Ausstrich zu machen, um zu sehen, ob man reil oder wenig Bakterien im Plasma hat.

Das Herauspräparieren der Herzlkappe ist nur unter der binokulaven Lupe möglich. Nan öfnet mit einem Sektionsschnitt das Herz-

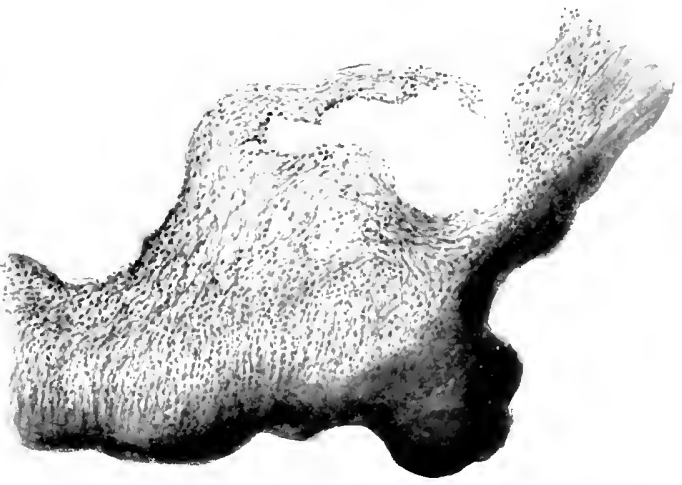

Ahb. 8s. Normale Herzklapye der Schlange. Zeigt den

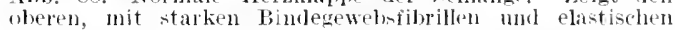
Fasern versteiften Teil und den unteren s.blpiorartigen Teil. Xarh Erdmann 1921, Arch. f. Entwieklumgsmech. 1. (1ru., Bd, 48. sagittal und sieht dann die Mitralis unter der Lupe frei in das Lumen des Ventrikels hineinhängen. Sie ist durch ihre weißliche Färbung im Gegensatz zu dem rötlichen Herzgewehe kenntlich (Abb. S8). Man schneidet die Mitralis oder irgendeine andere Klappe an einer Ansatzstelle ab und zerteilt sie in Rixgerscher Lösung in kleine Stückchen. Es empfichlt sieh. ehe man das Gewebe zerstückelt, die schicierartige Cnterhälfte abzuschneiden und in einem besonderen Sehälchen getrennt zu zerstückeln. Ebenso die steife, durch derbe Bindegewebsfibillen gestützte andere Hälfte.

Man soll die Stücke nit der binokularen Lupe durehmustern und sehen, ol, man nicht Stiickehen der Herzklappe bekommen hat, in denen sich kleine Gefäbe befinden. Diese müssen ausgemerzt werden, weil sie später bei der Deutung der Veränderungen nur Verwirung anrichten könnten.

Man beobachte die Kulturen in Abständen lebend und konserviere nach 6 , 1s oder 24 Stunden die Stïckchen in Alkohol für elastische Faserfärbung, in ORTHschem Gemisch oder nach CARxor für die anderen Färbungen. Die Lebendheobachtung der Herzklappe zeigt dem ungeiabten Beschauer nur wenig Veränderungen in den ersten Tagen, später aber sieht man mittelfeine und feine Fibrillen einen Schleier um das eingepflanzte Gewebestück bilden. Ihrem Lichthrehungsvermögen nach sind sie elastische Fasern und lassen sich auch im Schnitt gut färberisch darstellen. In den ersten Tagen zeigen zur Kontrolle lergestellte Totalpräparate Auswanderung von runclen Zellen. Bei günstiger Wahl kann 


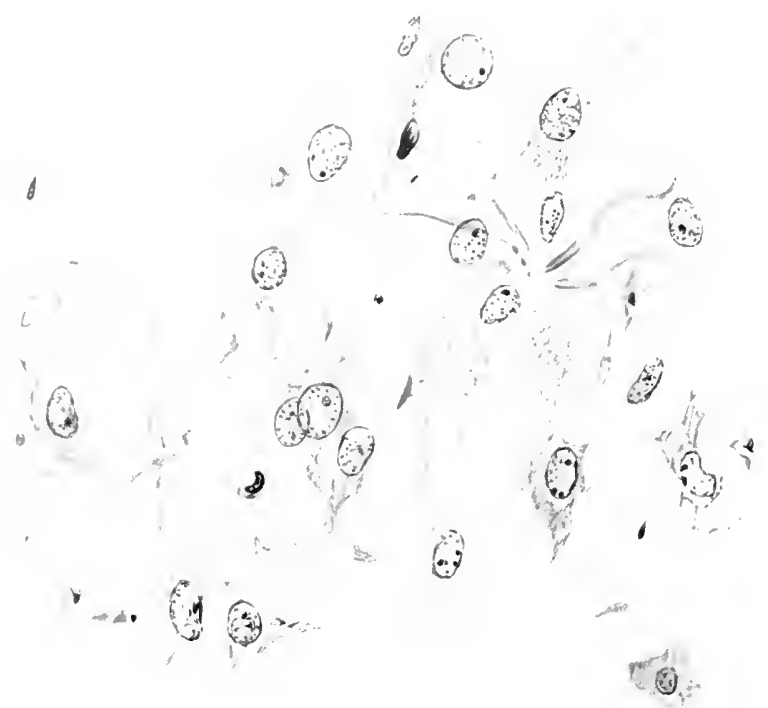

Abb. s9. Thaselhe Haterial 3 Tage beinutet, zeigt die Auf'ockerung des fiewhes und die füllung der kerne mit kernsait. Nach krdmann 1921, wie Bill Ron.

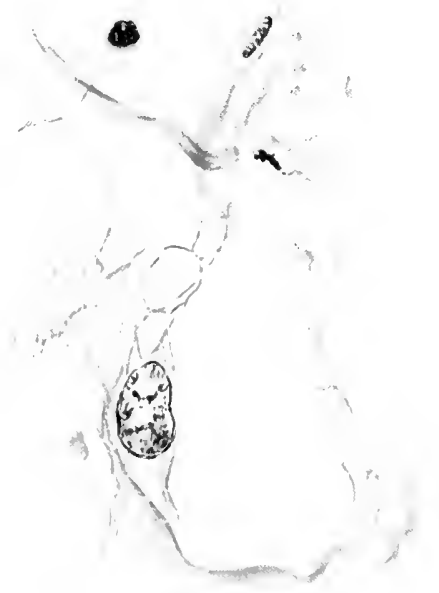

Abb. 90. Dasselbe l'raiparat bei stärkerer Vergröberung. Nach Erduann 19?1, wie likld 8s. 89. mansehen.daßdie. se runden Zellen aus vorher langsam sich bewegenden Binclegewebszellen entstanden sind. Diese runden Zellen zeigen. daBsich die Kitt. Bindegewels- und elasticche sub. stanz des eingepflanzten Stïckes im Plasmamedium gelöst hat. Hierdurch werden flie erwachsenen Bindegewetszellen frei und wandern langram in das umgrenzendePlasmamedium. Durch die Auflösung der erwähnten Substanzen erscheinen große $\mathrm{Ya}$ kuolen in den eingepflanzten Stïck (Ab). 89 u. 90). Die Veränderungen lassen sich gut an Schnitthildern nachweisen. Man sieht die Bindegewolszelle mit ihren langen derben Fortsätzen, die aus ihe herauswachsen, umgeben ron Vakuolen, frei liegen. In manchen Zellen kann man ein amitotisehes Zerbrechen der Kerne erkennen, aus denen höchstwahrscheinlich neue kleine, runde Zellen, die später reichlich im Prïparat sind, gebildet werden. Letztere kann man besonders gut an Präparaten der Herzklappe der Ratte beobachten. Die runden, ausgewanderten Zellen differenzicren sich später wieder in Zellen (Abb. 91) mit präkol- 


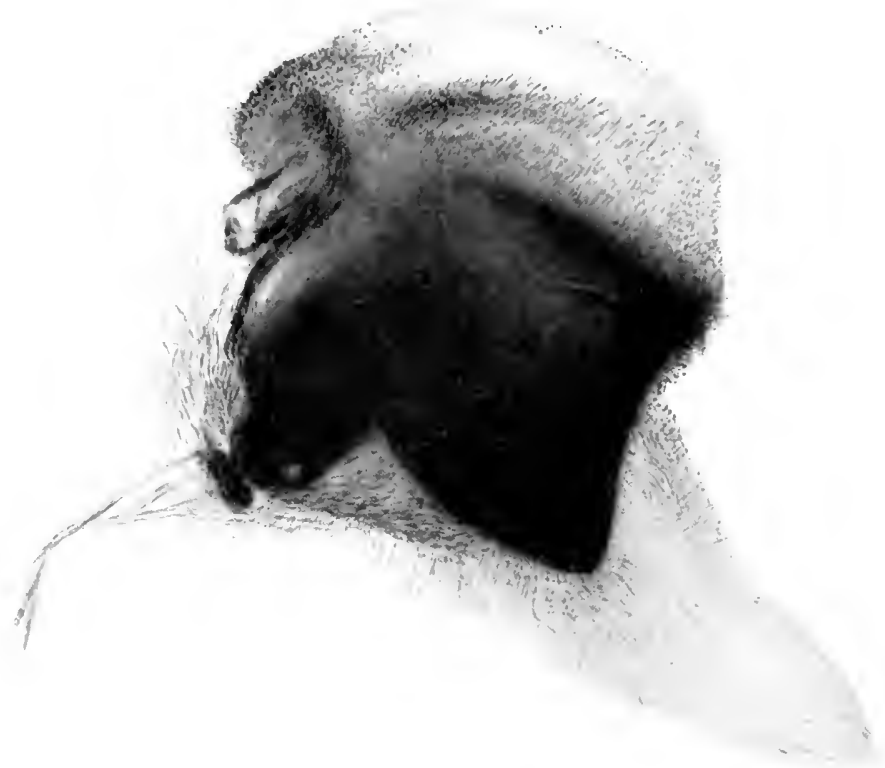

Ahb. 91. In Plasma eitgeptlanztes fiewebestückchen der Herzhappe der erwachentu Schlange nach 14 tägigem Verweilen im Plasmanedium. Ilan beachte den Tntersehifd zwischen den neugebildeten und den eingepflanzten lebenden fiewebsteifen. Nach Erdmann 1921, wie die vorigen Biker.

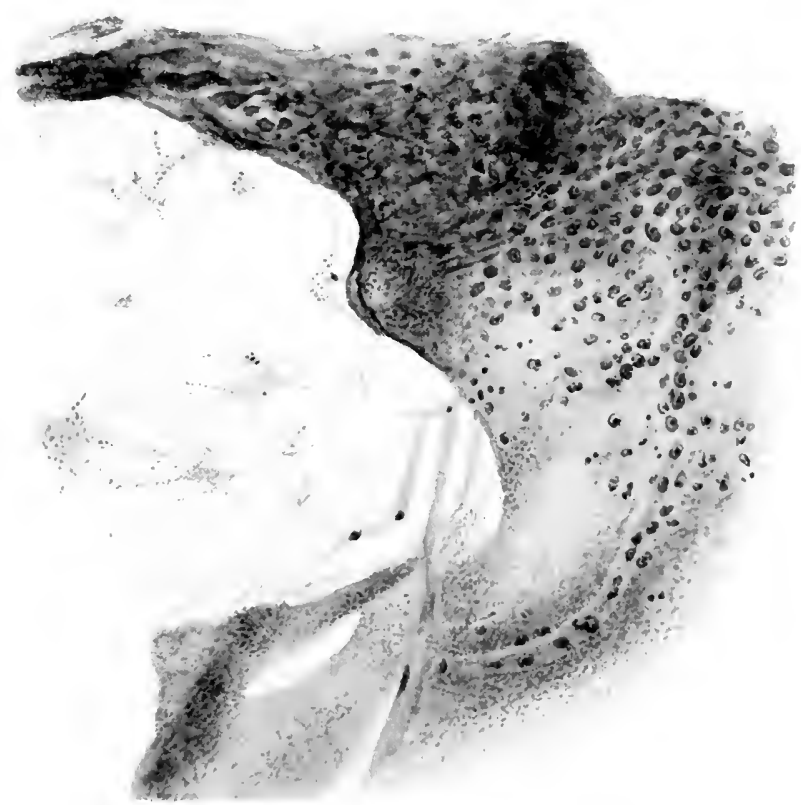

Abb. 92. Totalpräparat der Sehlingenherzktappe. Zeigt die Erweiehungsbahmen, 3 Taze gezüchtet. Nach Erdmann, wie die vorigen Bilder. 
lagenen Farem zuriëls. Da wir kein Diagnostikum haben, ob die Fibrillen bindegewebig oder dastisch sind, denn sic färben sich nicht bei den entsprechenden Färbungen, so können wir sie mit (HAxry ,präkollagen" nennen. Sie werden durch Färbung nach VAN Gitsox getblich gefärbt. Die präkollagene Substanz bildet wahrscheinlich die Matrix für kollagene und elastische Fasern.

Eis zeigt sich also deutlieh, daß das erwachsene Herzklappengewebe einschneidender Veränderungen, die als $\mathrm{Ab}$ - und Umbau gedentet werden kömnen, fähig ist. Man färbt die Schnitte, die man sich aus gezüchteten Stückehen rom 1, 2, 3, 4 usw. Tage hergestellt hat. mit Bindegewebsfärbungen (rax GiEsos) und elastischer Fasernfärlung bei der schlange.

Blane Elasticafärbung modifiziert fïr Herzklappen cher Schlange.

Diese Färbung wird nur für Schnitte angewandt. Man bringt das Material, num es zum Sehneiden vorzubereiten, in:

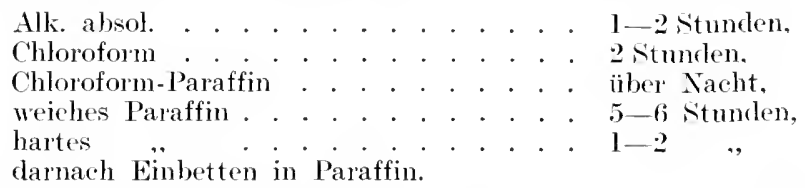

Die gewonnenen sichnitte werden vorgefärbt in Lithion-Karmin 24 stunden; ausspïlen in Aqua dest.: Nachfärbung in blauer Elastieafärbung 10-16 Stunden. Die Farbmischung bereitet man aus: $100 \mathrm{ecm}$ Salzsäure-Alkohol $+5 \mathrm{cem}$ Fuchselin. Kurz differenzieren in Alkohol $96_{0}^{\circ}$ und weiterführen der Präparate, wie bei den vorher beschriebenen llethoden angegeben.

\section{Nutzbarmachung der Methode der Gewebeziichtung zur Lösung noch strittiger Fragen.}

Mit Hilfe der Methode der Gewebezüchtung sind bis jetzt eine Reihe von Versuchen ansgeführt, die fest umschriebene biologische Fragen zu lösen versuchten. Es soll hier gesagt werden, daß besonders solche Probleme in Angriff genommen werden sollten. die nur mit Hilfe der Methode gelöst werden können. Stehen dem Experimentator andere Wege offen, so muB er natürlich diese auch gehen und erst als Ergänzung sich der Methode der Gewehezüchtung bedienen. Die Methode der Gewebezüchtung kann nur in eng umsehriebenen Grenzen angewandt werden, sie ist kein Allheilmittel, um neue Ergebnisse zu finden und darf auch keine Modesache sein.

So crschien es schr aussichtsreich, Tumorgewebe zu züchten. Trotz der Benühungen vieler Forscher ist es noch nicht gelungen, Tumorgewebe jahrelang oder monatelang zu züchten. wie es bei der embryonalen Bindegewebszelle oder der embryonalen Epithelzelle möglich ist. 
Man kam Tumormaterial his jetzt nur einge Wochen zïchten. Dire Frage, die clureh diese Versuche gelöst werlen soll. ist die: Wie unterseheiden sich Tumorzellen und Stromazellen? Wie unterscheiden sich Sarkom- und Karzinomzellen in hezug auf ihre Potenzen?

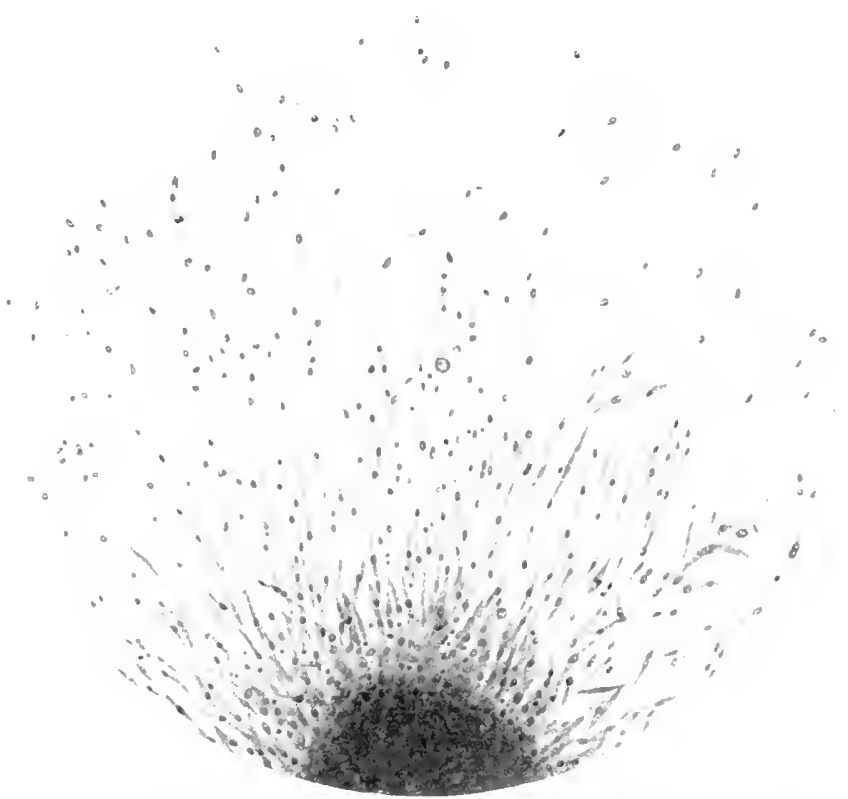

Abb. 94. Rattensarkomzellen, 3 Tage in Taubenplasma gezüchtet. Tas Anfangswachstum im rremden Plasma nicht gestöt, später zeigen sich cehädigungen. Sach Lambert und Hanes 1911. Journ. ol exl. med. Bil. 14.

Hat man Tumormaterial irgendwelcher Art zur Verfügung, so empfichlt es sich. anch dieses verschiedenen Züchtungsbedingungen zu unterwerfen. Es ist gerarle von T'mmorzellen behauptet worden, das die Spezifität des Nährmediums bei ihnen nicht besonders ansgeprägt zu sein scheint. So wächst nach Thousos menschliches Karzinom in Hühnerplasma und Embryonalextrakt des Huhnes (vergl. anch Abl, 94, 95, 97). Mäusekarzinome ind salkome sind fast immer in Rattenplasma gezüchtet worden, doch haben die Plasma-Medien his jetzt wich sehr ungünstig für die Zücht ung erwiesen, weil die Verflüssigung des Plasmas schon in wenigen Stunden bis zu einem Tage geschehen kann, so dab ein häufiges Weehsehn des Mediums notwendig ist. Bei den ron T'Honsos und Drew gebranchten Medien soll das nicht der Fall sein. Wäre dies richtig, so würde eher der physikalische als der chemische Charakter des Mediums einen besseren oder schlechteren Erfolg bei der Ziichtung verursachen. Doch wird stets Embryonalextrakt hinzugofügt.

Um Tumorkulturen anzusetzen, narkotisiere man schwach das betreffende Tier und nehme steril den Tumor heraus, spüle ihn in RixaER- 
scher lösung ab und schneirle die weiblichen, nicht neksotischen Teile fiir die Bearheitung ab (ös. Chrmes). Sie werlen dann genau so, wie jerles andere fienster in kleine stiickehen zerteilt und in die hetreffenden Moelion gotan. Ex empfichlt sich nicht, menschliche Tumoren, die

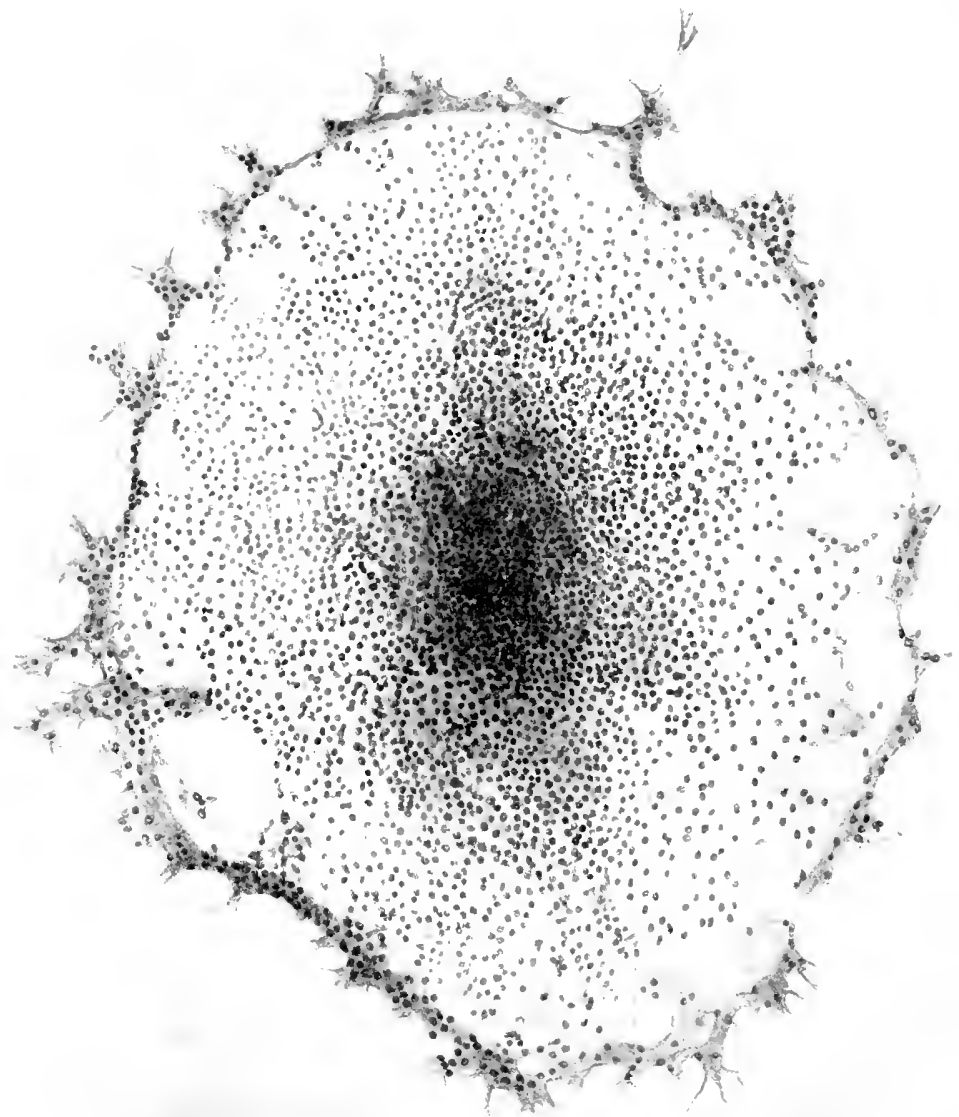

Ab. 9. Mäusekarzinomzellen, 5 Tage in Taubenplasma gezuchtet. Nach Lambert u. Hanes 1911. dourn. of exp. meil. Bit. 14.

ja verhältnismäßjog leieht aus jeder ehirurgisehen Klinik zu bekommen sind, zu nehmen, da diese sehr häufig sehon nekrotisch sind und Bakterien enthalten. Am leichtesten wird ein Mäusesarkom zu beschaffen sein.

Interessant ist die ron vielen Forschern gemachte Beobachtung, daß das Stroma des Tumors cine andere Auswandermngsgeschwindigkeit hat wie die Tumorzellen (Abb. 96). Diese sind fast immer an der äu Bersten Peripherie des Jediums zu finden, wo sie in diehtem Kranze 
gelagert erscheinen. Will man ïberpflanzen, so muth man an dieste Zone die Zellen sammeln. Die Stromazellen dagegen wandern languam aus. Ihre bindegewebige Natur ist hesonder's bei dem aberebileteten Humdekarzinom erkenntlich. Hat man dieses Hundekanzinom :3 Ifoehen

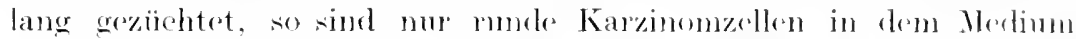

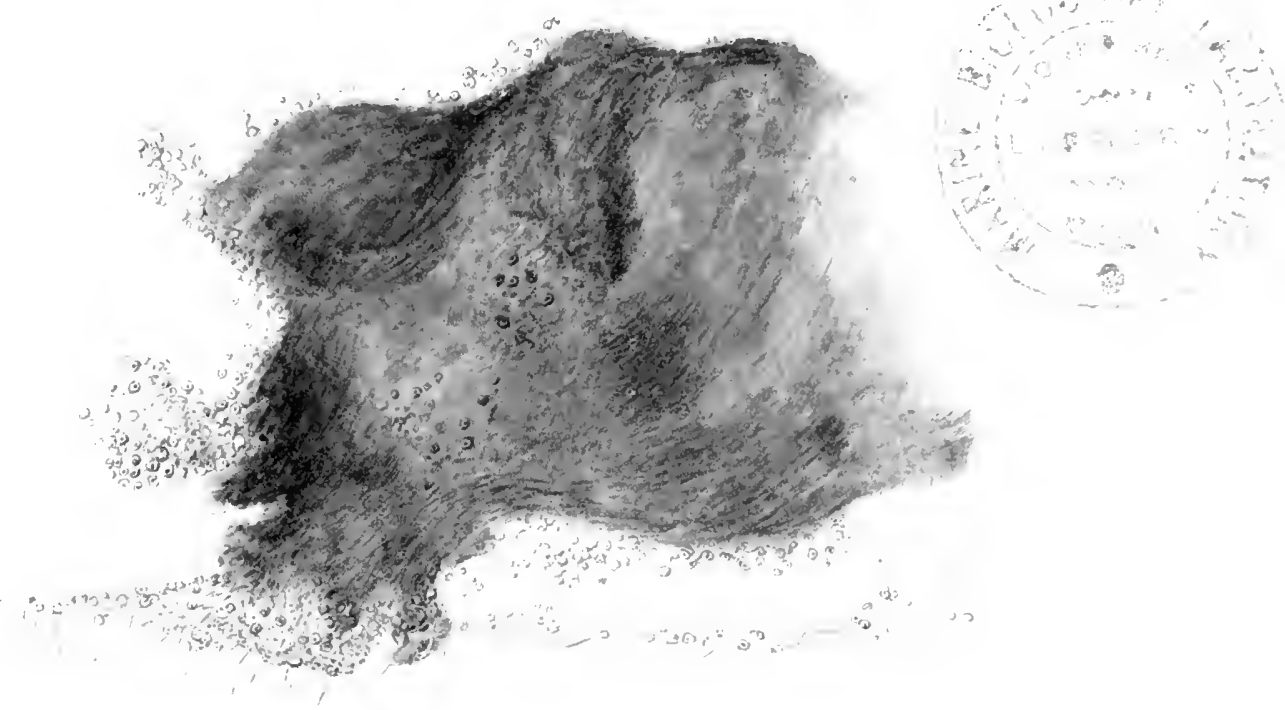

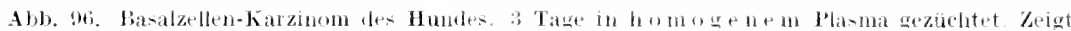
deutlich die Tremung der karzinsm- und der strmazellen. Weitaus die mejoten zallen des Karzinoms sind in das Plasma ausewandert, das soh an drei seiten um das eingeplanzte Crsoungsidiek schon verilis-igt hat. Sach dem l.eben (Erdmann. (riginal).

vorhanden, die obne bindegewebigen Zusammenhang das Medium erfüllen. Genau so wie die Epithelien wächst das Karzinom in Schleiern, rlas Sarkom ist dem Bindegewebe ähnlicher und wächst in einzelnen Strängen.

Die einzehe Tumorzelle, die sich also frei im Plasma (Seite 46, Ahb. 42 ? u. 43) bewegt. ist von anderen Gewebsellen durch mehrere Eigensehaften ausgezeichnet. Selten gibt es Zellen, deren Pseudopodien solehe abentenerliche und groteske Form annehmen wie die der Tumorzelle. Auch die Gröbe der Tumorzelle imponiert im allgemeinen. Granula der vorschiedensten Art finden sich reichlich in ihnen. Lebend beobachtet man die stark lichtbrechenelen sog. Degenerationsgranula und die durch ihr verschiedenes Lichthrechungsvermögen kenntlichen fiettiügelehen. Beide lassen sich auch getrennt färberiseh darstellen. Zellteilungen nit sonderbaren Kernteilungsfiguren sind in den Tumorzellen häufig Doeh sind auch regelmälige Nitosen reichlich vorhanden.

Totalpräparate werden am besten mit Hämatoxylin-kosin angefertigrt und liönnen besonders bei Karzinomen gut mit starken Vergröberungen 
beobachtet werden, weil der sehleierartige Gewebskomplex höchstens 2-3 Zellschichten dick ausgelmeitet ist. (Siehe Abb. 9.5.)

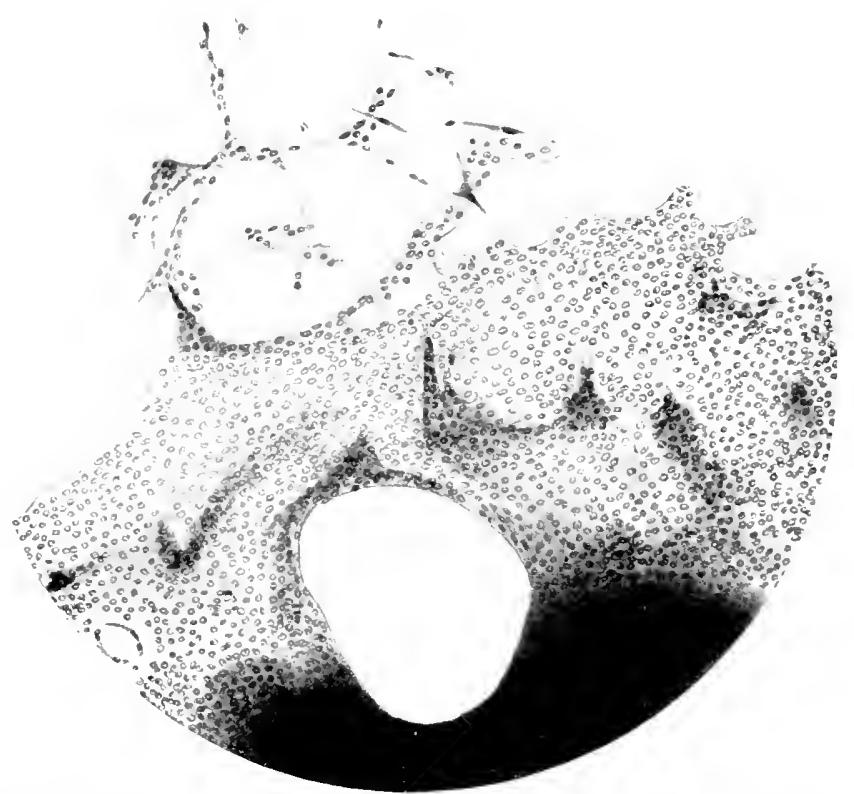

Abb. 97. Mäusekarzínomzellen, stärker veroröbtrt, in Meerschweinchenplasma gezürhtet. Nach Lambert und Hanes wie Bill 95.

Auch stellen die Tumorzellen ein geeignetes Objekt dar, um vermittels Lykopodimsporen oder Karmin usw. die Phagocytose nachzuweisen. Man bringt Lykopodiumsporen, Karmin oder japanische Tusche in das Medium (Seite 45 1. 46, Abb. 37-43) und sieht alsbald, wie die Zellen diese aufgenommen haben.

DREw'sche Lösung.

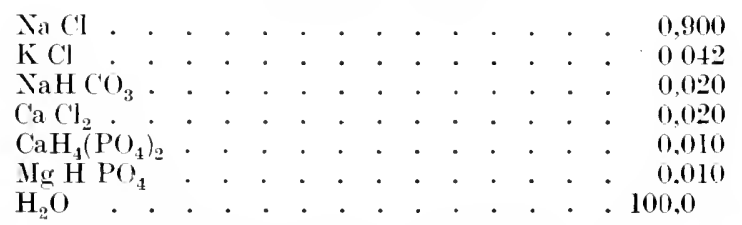

Man hält sich Salzlösnngen 10 mal so stark als sie später gebrancht werden, in Flaschen. Also: $\mathrm{NaCl}, \mathrm{K} \mathrm{Cl}, \mathrm{Na} \mathrm{H} \mathrm{CO}, \mathrm{CaCl}_{2} . \mathrm{CaH}_{4}\left(\mathrm{PO}_{4}\right)_{2}$. $\mathrm{Mg} \mathrm{HPO}_{4}$. Dann fülle man $10 \mathrm{cem}$ dieser Lösungen in eine Flasehe und tüge 40 cem dest. Wasser dazu. Die Ca $\mathrm{Cl}_{2}$-Lösung, die $\mathrm{CaH}_{4}\left(\mathrm{PO}_{4}\right)_{2}$-Lösnng und die $\mathrm{Xa} \mathrm{HCO}_{3}$-Lösung sind gerade vor dem Gebrauch angesetzt und dann im Dampftopf kurz sterilisiert. Es ist nicht riehtig. diese Lösungen in Autoklaven zu sterilisieren. Dann füge man auch $10 \mathrm{ccm}$ von jeder dieser Lösungen hinzu. Die fertige Lösung soll schwach blan opalezieren. Will man doch den Autoklaven benutzen, so soll man nur dann die Lösungen benutzen, wemn sie kein Präzipitat zeigen. 
Färbung von Fett mit sindan Ill oder sicharlach R.

Die Präparate werden wie üblich bei der Fettfäbung mit nicht Fett lisen. den Flüssigkeiten konserviert (Osminmsäne, Formol usw.), gewässest in appa dest. und 5 Min. in Alkohol jo $0^{\circ}{ }_{0}$.

Als Farblösumg verwendet man sudan III oder Seharlach R, die bejele in gessättigter löstung angewandt werden und fertig im Handel zu haben sind; Färl, laucr: 10 Min. bis $1 / 2$ Nitunde. Abspiilen in Alkobol 50proz., auswaschen in Aqua dest. Nachfärbung mit Hänatoxylin Delafield, wie dort angegeben; nach dem l)iff('lenzieren bringt man die Präparate in Brumrenwasser, wo sic nachblanen, führt sic turch die Alkoholstufen; Alk. abs. + Xylol; Xylol; Zedernöl.

Glykogenfärbung naeh Best nach Fixierung mit $96 \%$ Alkobol.

Vorfärbmng mit Hämatoxylin Delaficld, wie angegeben; darnach Färbung in folgender, stets frisch zn bereitender Mischung:

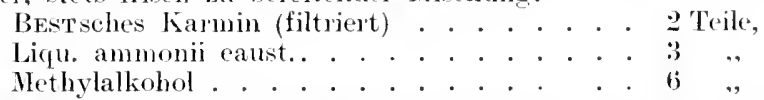

Diese Misehung, die, wie sehon gesagt, jedesmal vor der Färbung frisch zu br. leiten ist, darf nieht filtriert werden.

Färbdauer: 1 situnde.

Zum Entfärben bereite man sich folgende Lösung:

Methylalkohol . . . . . . . . . . 2 Teik,

Alkohol absol. . . . . . . . . . . . . 4 , .

Aqua dlest. . . . . . . . . . . . . . 5 ,

Die Entfärbung dauert ca. 10-12 Minuten, während der Entfärbung soll man die Misehung ein parmal weebseln. Abspiilen in $80^{\circ}$. Alkobol; darnach Alk. 96 proz.; Alk. absol.; Alk. absol. + Xylol; Xylol; Zedernöl.

Die Karminfarbe, die zu obiger Färbung verwandt wirl, bereite man sich folgenderweise:

Ammon. chlorat. . . . . . $2 g$

Lithion carbonie. . . . . 0,5 g einmal aufkochen lassen.

Aqua dest. . . . . . . $50 \mathrm{~g}$

Sach Erkalten 20 ecm Liqu. ammonii eaust. zusetzen. l)iese Lösung ist im Dunkeln aufzubewahren, sie ist brauchbar et wa rom 3. Tage an und durch einige IVoehen.

Die Frage, wie wirken Bakterien und lebende Zellen aufeinander, wenn sie experimentell zusammengebraeht werden, könmen wir im hängenden Tropfen gut beobachten.

Wie wir gesehen haben, entstehen Vakuolen in Laufe der Züchtung von Mesenehymzellen (Vergl. Abb. 53, S. 58) ganz besonders gerade in dieser Zellart, während die Epithelzellen im Verhältnis zu den Mesenehymzellen vielkleinere Vakuolen haben, ebenso die Myohlasten. Während diese in einer 14 Tage alten Kultur, nachdem man sie fixiert und gefärbt hat, wie ein feines Sieb aussehen, gleiehen die Mesenehymzellen mehr einem durehlöeherten Tuche. Jan nimmt an, daß dic Vakuolen in den Kulturen ganz besonders frïh sieh bilden, wenn die Dext roseder LockELewis-Lösung z. B. aufgebraucht ist oder wenn sie aus experimentellen Gründen fortgelassen ist. Jedenfalls aber steht fest, je kürzer die Zellen in der Kultur sind, je weniger Vakuolen haben sic. Daher zeigt der Versueh von M. Lewrs, die Tuberkelhazillen mit waehsenden Mesenchymzellen zusammen brachte, überrasehende Resultate, denn hiel wurde sehon nach einen Tage, naehdem die Bakterien der Kultur zugefügt waren, eine so starke Vakuolisierung wie sonst nie erreieht (Ab). 98). 
Man verfahre (29. Cloung) wie folgt: Nachelem Kulturen von Hübnermesenely ynzellen hergestellt sind in Lor KE-LEwrs-Lösmg, so lasse man sie 24 stmolen wachsen. Dann füge man rorsichtig mit einem kleinen Spatel rine geringe Anzahl Bakterien hinzu. nachdem man unter dor Lupe tie

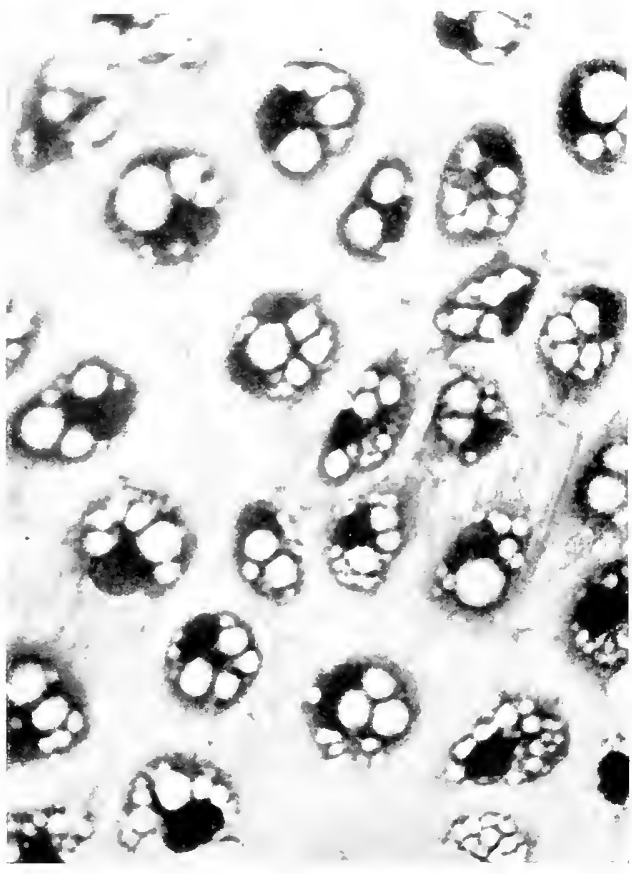

Abb. as. Mesenchymellen des embryonalen Huhnes nach Einïigen von Typhusbaliterien. Beachte die groben Vakuolen in den Zellen. Nach W. Lewis. 1921 Journ. of exp. Iner. ]ir] :33.

Kulturen umgerlreht hat. Hierauf befestige man sie wieder auf einem neuberingten, hohlgeschliffenen Objelitträger. Zwei Momente sind noch zu beachten. Nan lege sich auch Kulturen derselben Bakterien im bängenden Tropfen in LockE-LEWIS-Lösung an, die oh ne Gewebe sind mol lasse anch einige Kulturen ohne Bakterien stehen.

Schon am nächsten Tage sind die Mesenchymzellen voller Vakuolen. Nicht alle Stämme arbeiten so rasch. Es kommt anf die Virulenz des Stammes an, ob schmell sehr viele Vaknolen gebildet werden. Jerlenfalls zeigt dieser Versuch dentlich, daf das Zelleben schäcligende Stoffe von den Bakterien ausgeschieden werden mïssen. Welcher Art sie sind, mul.3 noch erforscht werden. Es gibt auch zum Nachdenken Anlaß, warum man die Bakterien nicht gleich beim Ansetzen der Kulturen mit hineinsetzen kann, denn damn erzielte man kein Bakterienwachstum, rorausgesetzt, daB man nur wenig Bakterien eingesetzt hat. Die bakterizicle Wirkmng ter embryonalen Gewebe ist so stark, daß kein Gleichgewieht zwischen Bakterienzelle und Gewebezelle sich sofort einstellt. Je älter aber die Zelle in der Kultur ist, je schwächer reagiert sie gegen tie Angriffe der Bakteriengifte.

Mit Hilfe der Gewebezüchtung muß sich das Problem lösen lassen, ob, die Zellen des Reticulums in einem genetischen Zusammenhange mit Wanderzellen, Endothelzellen und Riesenzellen stehen. Lewis hat dies durch Züchtung der Lymph knoten des Menschen zu entscheiden versucht.

Die Lymphknoten des Menschen, die leicht zu beschaffen sind, enthalten Lymphocyten mit und ohne gelappten Kern, Lymphoblasten, Plasmazellen, eosinophile Zellen, Mastzellen und tie Zellen des Reticulums und der Lymph- und Blutgefäße nach STöнr. 
Man verfahe brim Inlegen der Kulturen (30. Thung) auf folgende. Weise: Aus cinem eben operierten oder eben gestorbenen menschliehen Köprer entnommene Lxmphknoten präpracre man von allem fett mut Bindegewebe frei mol lege wie üblich Kulturen im menschlichen Plasma mit 1/4 Hühnerplasma gemischt an. Ian will nachweisen, ob, diesog. spindelzellen in einem genetischen Zusammenhange mit Wandergellen Endothelzallen und Riesenzellen stehen.

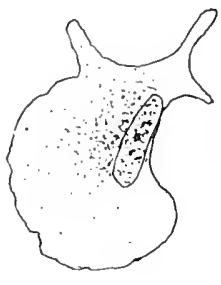

a

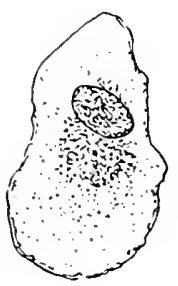

(I

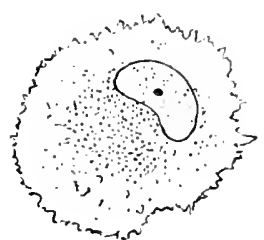

h

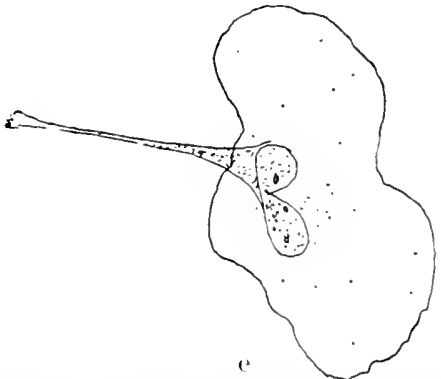

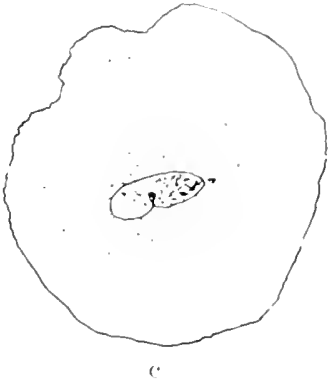

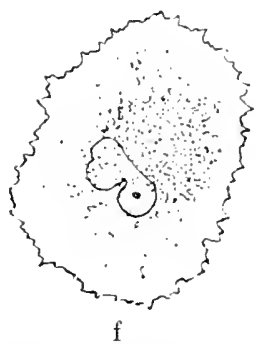

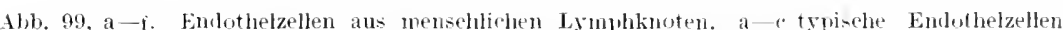
(nach Lewis), 2 Tage in Menschenslasma gezuchlet, d e Itberwangsornen, aus denenspitze spindelzellen werlen. Sach W. Lewis. 1921. Jomru. exil. Med. Bd. 34.

Schon nach limzer Zeit bewegen sieh die Lymphozyten in allen möglichen Formen aus dem eingeflanzten Lymphknotenstückehen heraus. Man tut gut, die Bahn eines solchen zeiehnerisch zu verfolgen. Weiterer Entwieklung sind diese Formen soweit ieh beobachten komnte, nicht fähig.

Die.. Wanderzellen" der Pathologen erseheinen nach den Lrmpho. zyten. Sie bewegen sich schnell aus den Lỵmphknoten heraus und zeigen starke Fornveränderungen. Hierauf folgen cle Endothelzellen, die stark phagocytieren, aber sich langsam bewegen, wie wir schon zugleich mit der Bildung ron Riesenzellen früher (s. Seite 40) verfolgt liaben.

Gewöhnlich sind die Endothelzellen rund. der Kern liegt in der Nitte, er kann eingedellt sein. Das Plasna ist nur mit stanbartigen Körnchen, keinen Granulationen an Anfang ter Zijehtung gefüllt. Oft ist der Rand des Plasmas auch fein gezähnt. In der Kultur werlen nun diese Zellen allmählich auf zwei rersehiedene Arten geändert. Entweder bilden sich aus ihnen die sog. Spindelzellen. die sich nur 
durch die gestreckte Form und den ausgezogenen Kern von den Endothelzellen unterscheiden (Abb.99e). Oder aber durch fortgesetzte Kernteilungen und Vergrölierungen des Plasmas werden Riesenzellen aus diesen Formen. Es können anch mehrere Wanderzellen zur Bildung einer Riesenzelle zusammentreten. Bei all dicsen Zellarten findet kein ZusammenschluB zu cehten Geweben statt.

Es scheint also ein Zusammen hang zwischen Endot helzellen und fibroblastähnlichen Spinclelzellen einerseits und Endothelzellen und Riesenzellen andererseits zu bestehen. Auch schließen sich die Wanderzellen, die höchstwahrscheinlich junge Endothelzellen sind, zu Riesenzellen zusammen. Aber es scheint kein Zusammenhang zwischen Lymphocyten einerseits, Wanderzellen, Endothelzellen und Riesenzellen andererseits zu bestchen, wenn man ihr Verhalten in der Gewebekultur ansieht.

Als letzte Übung werden wir cinige Angaben von HADDA und Rosenthal nachpriifen. Hadda und Rosenthal haben schon 1913 versucht: ,mit Hilfe des Zellzïehtungsverfahrens neue Einblicke in die Wirkungsweise cytotoxischer Sera auf Gewebszellen zu gewinnen". Zwar bestehen nach ihnen — und dieses ist ja schon 1913 geschrieben - noch erhebliche technische Schwierigkeiten, aber wenn diese überwunden sind, so darf die Kultur lebender Zellen außerhalb des Körpers fast als eine Idealmethode der Cytotoxin-Untersuchung bezcichnet werden, denn sie gewährleistet: 1. für lange Zeit die Lebendigkeit der kultivierten Gewebe, 2. schafft sic unter vitalen Bedingungen die Möglichkeit eines tagelangen Kontakts der Gewebezellen mit den cytotoxisehen Substanzen und gibt hierdureh feinste biologisehe Reaktionsmöglichkeiten. HADDA und RosenthaL selbst nun untersuchten den Einfluß haemolytischer Sera auf die Haut und den Knorpel des Huhnes. Es wurde $H$ ïhnerhaut in $K$ aninchenplasma gezüchtet und sie fanden, daß die Organzellen sich außerhałb des Körpers in heterogenem Plasma entwickeln können, doch läßt sich zeigen, daß feinere Unterschiede in der Färbbarkeit bestehen. Dagegen scheinen Zellen des Hïhnerknorpels, die einerseits in Normalplasma, andererseits in Kaninchenplasma gezüchtet werden, stärker geschädigt zu werden als die Organzellen der Haıt. Die gleichen Versuche wurden für Haut und Knorpel einerseits in Normalplasma, andererseits in isolytischem Hühnerplasma ausgeführt. Hier zeigt sich auch bei dem Knorpel kein Wachstum, bei der Haut dagegen ippiges Waehstum. Dureh weitere Experimente kommen die Autoren zu folgendem Ergebnis ihrer Kulturversuche: ,Die Ergebnisse unserer Kulturversuche mit Hühnerknorpel und Hühnerhaut in Hühnerblut-Kaninchenimmunplasma zusammen mit unscren fr ̈̈heren Befunden vereinigen sich zu dem einheitlichen Resultat, daß Plasmen, die Normal-, Iso- oder Immunhaemolysine enthalten, auf die zur Proliferation gelangenden Zellen der lebendigen Hühmerhaut und des lebenden Hühnerknorpels eytotoxiseh $\mathrm{zu}$ wirken rermögen, und daß die proliferierenden Zellen der genannten Gewebekulturen sich durch ihre differente Reaktionsfähigkeit gegenüber den Hämolysinen bis zu einem gewissen Grade gegeneinander abgrenzen lassen. Un diesen Versuch (31. Übung) teilweise nachzuprüfen, stellen wir uns 
Hühner- mel Kaninchenserum und Hühner- und Kaninehenplasma her. Geich grobe Stücke Hühnerhat setzen wir in diese vier versehiedenen Medien, lassen sie 1-2 - Tage darin mol färben dam das Präparat mit einer einfachen Hacmatoxylin-Eosin-Färbung. Es zeigt sich (s. Ahb. Ion u. 101), da lis die Kernmenbran und die Kemkörperehen deutlicher darstellbar sind in arteigenen Medien wie die artfremden.

Noch viel komplizicertere Probleme hat man mit Hilfe der Gewebezüehtung in Angriff zu nehmen versucht. Besonder's aussichtsreich erschienen dic Versuehe, die auf den Gebieten der Serologie, Immmologie und Bakteriologie unternommen worden sind. In der vorletzten Ubung ist das fïr die Bakteriologie gezeigt worden. Doch sind alle diese Versuche noch vereinzelt, da die Enterlage, die Züchtung ron einer Art Zellen und die dauernde Erhaltung dieses Stammes bis jetzt noch nicht allgemein ron den Forschem anf diesen drei eben erwähnten Gebicten geiibt wird. Zwar haben schon STEINHARDT und LAMBERT 1913 rersueht. Poekenvirus in CorneaEpithel zu züchten. Mit diesem, einige Tage gezüchteten embryonalen, infizicrten Material wurde damn auf die übliche N'eise geimpft, d. h. das Material wurde in die rasierte Hant

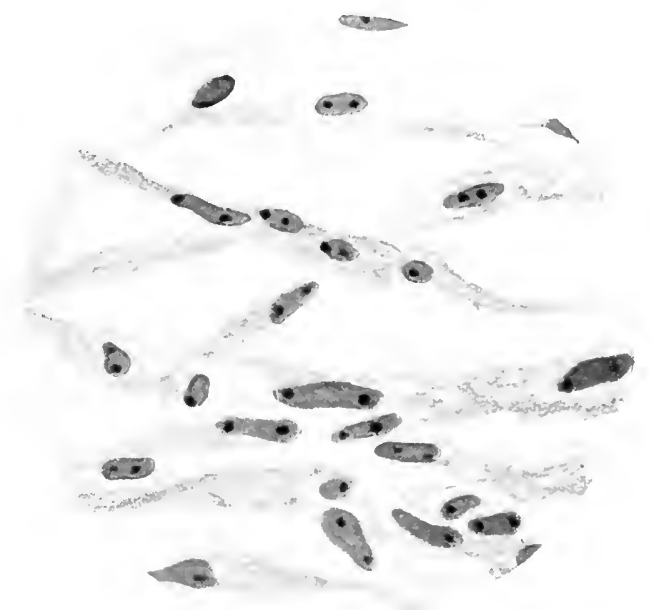
eingerieben. Es zeigten sich eine Reihe ron Pusteln, doch ist nicht nachgewiesen, ob das Pockenvirus sich in rem Znehtmedium ver. mehrt hat.

Einen Schritt weiter ging Eromaxs 1917 and 1920. Hier wurde virulentes Gehimmaterial von an Hühnerpest erkiankten Tienen in 
Hïhnerplasma gezüehtet und virulentes Serum anf normalem embryonal'n Hïhnergewebe gezüchtet. Die Hühnerpest ist eine hoehvirulente Krankheit. Sie tötet das Huhn gewöhnlich in 36-4s Stunden. Mit. dom so gezüchteten Material konnte aher eine Abschwächung des Virus nachgewiesen werden. Wenn man so gezüehtetes Material in nomale Hühnes verimple, so starben sie erst nach 14 Tagen. Geirecknetes fohinmaterial solcher Tiere aber konnte zu erfolgreicher aktiver und passiver Immuniwerung gegen Hïhnerpest verwandt worden. Diese .lethnde der lmmunisierung wird sich wahrecheinlich auch auf alle anderen Krankheiten, die durch filtrierbare Vira erzeugt werden, ibbertragen lassen. 1920 hat auch Kuczinsk versucht, mit Hilfe eines etwas abgeänflerten Merliums Fleckfiebervirus zu züchten. l)iese Versuche sind aber noch nicht abgeschlossen.

Hier werken sich noch viele neue Verwendungsmöglichkeiten der Ziichtung der lebenden Gewebe finden lassen. Damit vielen späteren Forschern diese Methode geläufig wird, mußs sie schon am Schlub des Cniversitäts-Studiums wenigstens in dieser vorliegenden elementaren Weise gelehrt werden. Selbstrerständlich kamn der Forscher mit noch feineren Methoden der Gewebezüchtung, als sie in diesem AnfängerPraktikum der Gerebezüchtung gesehildert sind, arbeiten. So empfiehlt es sich, für Forsehungsarbeiten die Zusammensetzung der Medien auf ihre Hydrogen-Jonen-Konzentration zu prüfen. Am besten sollen die Zedlen in einem Hedium wachsen, was 7,2 Hydrogen-Jonen-Konzentration hat. Man bedient sich der Mlethocie von L. MichaEus oder der Methode von Fexton zur Feststellung der Hydrogen-Jonen-Konzentration. Man gebraucht die erstere, wenn man größere Mengen Flüssigkeit zu untersuchen hat, die andere bei minimalen Quantitäten.

Un feinere Operationen an der Zelle selbst auszuführen, also, um ertl. Fibrillen oder Pseudopodien ahzuschneiden oder Kerne herauszunehmen oder anzustechen, ist der sogenannte Barber-Apparat zu empfehlen: in kurzer Zeit wird ein Apparat von Zeiß auf den Markt gebracht, der noch besser als der Barber-Apparat Mikrosektionen erlaubt. In den 3 Ebenen des Raumes können Nadeln versehoben werden, mit denen dann die Zelle oder das Gewebe zerschnitten oder entkernt werden kann.

Die hier ausführlich beschriebenen Übungen stellen die ersten Versuche dar, die Methode der Gewebezüehtung im Kursbetrieb lehrbar zu machen. Noch bessere Übungen werden sich im Laufe der Zeit finden, die dem Anfänger noch günstigere Resultate sichern.

Eines aber ist gewiß, die Zusammensetzung der Medien wird sich bestimmt ändern. Vergeht doch nicht eine Woehe, in der nicht nene Zusammensetzungen ron analysierbaren Medien empfohlen werden. Es besteht selbstverständlich das Bestreben, alle organisehen Bestandteile des llediums auszuschließen, damit man ein quantitativ bestimmtes Medium hat. So beschreibt Ebelisg 1920 ein Medium, das aus Fibrin, Serum und Embryonal-Extrakt des betreffenden Tieres besteht. Das Fibrin vertritt die Stelle des Plasmas. Es ist durch Fällung aus dem Plasma des Tieres gewonnen und kann infolgedessen chemisch be- 
stimmt werden. doch anch in diesem Medium sind 2 Komponenten. deren chemisehe Zusammensetzung nicht bekannt ist: Serum und Embryonal-Extrakt. Das Serum in groberen Mengen angewandt, hemmt das Wachstmm and darf nur in geringeren Quantitäten verwandt werden. Das Wachstum fördenele ist hier der EmbryonatExtrakt, desien chemische Zusammensetzung ja mubekannt ist mud der mit dem Serum als isotoniseher Flïssigkeit gemischt wird.

Solange man noch Embryonal-Extrakt und Plasma nimmt, sind stets mbekamte GröBen in dem Nedium. Bis jetzt haben wir angenommen, daB Wachstumshormone, die ihren sitz in der lebenden zelle haben, unbedingt notwendig sind, um embryonale oder enteifferenzierte Zellen am Leben zu erhalten. Es ist aueh nicht ausgeschlosen, dab dies vielleieht Wundhormone sein können, denn mit dem Embryonal-Extrakt. der noeh notwendiger zu sein seheint, als das Plasma. werifen stets auch Wundhormone aus den zerenetschten Zellen im Embryonal-Extralit sieh fincien. Ob, Wundhormone oder Wachstumshomone das-elbe sind, ist noch nicht untersucht. Verwandt in ihrer Wirkung werden sic sicher sein. Wir sind heute also noch nicht zu Ende mit dem Ausprobieren der rechten Medien. Wir haben noch nieht die Stufe erreieht, die sehon lange die Bakteriologie kennt, nur mit analysierbaren Medien zu operieren. Doeh auch hier ist fiir die Aufzucht mancher Formen ein gewisses unbekanntes Agens notwendig, das mit dem Bhute. mit der Lymphe oder mit der Aszitesflüssigkeit dem Nährmedium zugefuihst wird.

Wemn nun in Zukunft diese letzte Frage der Auswahl des Mediums vollständig einwandfrei gelöst ist, also die Zusanmensetzung des Mediums ehemisch quantitativ rollkommen analysiembar ist, so wird sich hoffentlich ein anderer Nachteil der Gewebezüchtung überwinden lassen, nämlich der, daßs man nur vorhältnismäbig kleine Stücke ziichten kann. Wird die Methode der Gewehezüchtung erst handlieh, erfordert sie nicht mehr so viel Zeit wie jetzt, so wird man sich an die Lösung schwierigerer Probleme mit Erfolg heranwagen können. Dann erst wird die Enährungsphysiologie feststellen können, welehe Nahrungsstoffe und welche aiuBeren Bedingungen Bindegewebszellen oder Epithelzellen zu ihrer daucrnden Erhaltung bedïrfen. Damn erst wird das katsalanalytische Experiment an Zellen und Geweben in größerem Umfange einsetzen können, sowie hei der Explantation von Organen, Organteilen und Embryonen erst bedeutsame Fortschritte gezeitigt wurden, seitdem Roux dureh die Explantation einen der Grundsteine seiner lawsalanalytischen Forschung, der Entwicklungs-Mechanil, gelegt hat. 


\section{Zusammenstellung des Materials und der ein- schlïgigen Literatur.}

Ehe ich eine Zusammenstellung der Übungen und der dabei gebranchten Materialien gebe, möchte ich für diejenigen. die sich weiter orientieren wollen, folgende Zusammenfassungen erwähnen:

OPPEL. A.. 1914. Gewebekultur und Gewebepflege im Explantat. Sammlung Viewer: . Tagesfragen aus den Gebieten der Naturwissensehaft und der Technik", Heft 12. Oppex sehildert besonders die Anwendung der Gewebepflege als IIttel der kausalanatytischen Forschung. - Erdusxx. Rif.. 1921, Einige grundlegende Ergebnisse der Gewebezüchtung aus den Jahren 1914-1920. Sonderdruck aus: ..Ergebnisse der Anatomie und Entwieklungsgesehichte", Brl. 23 gibt eine fast vollständige Literaturangabe bis zum Jahre 1919. Wertroll ist auch die Zusammenstellung von LEvi. G., 1919. Ricerehe Istologiche sul alcuni tessuti in istato di sopravivenza in vitro. Bollet. 1-2 rella Soeieta Med. (hir. (li Pavia. S. 1-599 1).

Zum tieferen Eindringen in die Spezialprobleme und eine richtige Fragestellung möehte ieh folgende Arbeiten empfehlen: Für die Probleme der Zellbewegung, Zellwanderung und Zellannäherung Rovx, W., Areh. f. Entwicklungsmechanik, Bd. 1. S. 43: Bd. 3, S. 380. - Besonders wichtig sind die gesammelten Abhandlungen über Entwieklungsmechanik der Organismen desselben Verfassers 1895, Leipzig, Bd. 1 und 2 .

Wichtig ist auch für die allgemeine Orientiernng: Drísch, H., 1898, Resultate der Entwicklungs-Physiologie der Tiere. Sonderdruek aus: „Ergebnisse der Anatomie und Entwicklungsgesehichte", Br. 8.

Von Bedeutung wird sich auch L. LoEBs ältere Methote 1898, geronnenes Blut von Limulus als Nährmedium zu brauchen, erweisen. LoEB, L.. 1920. The movements of the amoebocytes and the experimental production of amoebo(yte (eell-fibrin) tissue. Washington Unir. Studies, Vol. s; Seientific Series, Nr. 1, pp. 3-79. - Loes, L., 1921, Amoeboid morement, tissue formation and the consistency of protoplasm. Science. N. S., vol. 53. p. 261.

Auch von Botanikern ist die Methode der Gewebepflege angewandt. So finclet sich eine Zusammenfassung dieser und ähnlicher Materien von HABERL.tHDT, G., 1922, UUber Zellteilungshormone und ihre Beziehungen zur Wundheilung. Befruchtung. Parthenogenesis und Arlventivembryonie. Biologisches Zentralblatt, Brl. 42, Nr. 4, S. 145-172; und Limprecht, iY., Über die Kultur und Transplantation kleiner Blattstïckehen. Beiträge zur allgemeinen Botanik, 1. Bd., 1918.

Als wichtig für die feinere Technik sind folgende beiden Arbeiten zu erwähnen: BARber, M. A.. 1911. Teehnique for inoculation into living cells. Journ. Inf. Diseases 8, 348-360, 5 figs. in text. - Birber, M. A.. 1914. The pipette method in the isolation of single mieroorganism and in the inoeulation of substances into living cells. Philippine Journ. Sei. 9. Ser. B., 307-385, 19 figs. in text. Dazu eine weitere Arheit von Chanbers, R.. 1918, The micro-vivisection method. Biol. Bull, 34, 120-136, 8 figs. in text.

Für die richtige Zusammensetzung des Mediums in bezug auf die $\mathrm{H}$ y drogenIonen-Konzentration sind die Arbeiten von L. Michaelis und Feltox zu erwähnen: Mrciraters, L., Die allgemeine Bedeutung der Wasserstoffkonzentration für die Biologie. In Oppennemer, C.: .,Handbuch der Bioehemie der Menschen und der Tiere." Jena 1913. Suppl. 10; Die Wasserstoff-Ionen-Konzentration. Berlin 1914; Die Bedeutung der Wasserstoff-Ionen-Konzentration des Blutes und der Gewebe. Dentsehe Med. Wochenschrift 1914, Bd. 40. S. 1170. - Feuton, l. D., The Colorimetric Method for Determining the Hydrogen Ion Concentration of Small Amounts of Fluid. From the Patholog. Laborat. Johns Hopkins Med. School. Baltimore 1921, Febr. 1, pag. 299-305.

1) Icl möchte nicht unterlassen auf die kurze, soeben ersehienene Zusammenstellung von II. BRA I'S: Nethoden der Explantation (fewebekulturen in vitro) hinzuweísen. (Sonderabdruck Handb. biol. Arbeitsmetholen, ABDERHALDEX, Lief. 69.) Besonders anf Ziichtung der Kaltbuitergewebe ist hier eingegangen. 


\section{Kusammenstellung der İ̉mugen.}

\section{Chung.}

Seite $19-20$.

Iaterial: Haut des erwachsenen Frosches.

Medien und Wasehfliissigkeiten: Froschplasma, Augenkammerwaser, Ringerlösung, phỵsiologische liochsalzlösung und locke-Lewis-Lösung für Kaltbliitler.

Ejnseluägige Arbeiten: L'mennutr, E.. 19]4, Cultivation of the Skin Epithelium of the Arult Frog. Rana Pipiens. Journ. of exp. Med., Bd. 20, .. 614. ¿hlexhuth, E.. 1916, I) Zellvermehrung in den Hautkulturen von Rana pipiens. Areh. f. Entw.-Neeh., Bel. 42, s. 168 -207. - Gissul, R., lmplantation der explantierten Frosehhaut. 1922, Arch. f. Entw., im Druck.

Seite $26-29$.

\section{Cืung.}

I aterial: Riuckenhant von liana esculenta und Rana fusea.

ILedien und Wasehflissigkeiten: Hïhnerplasma, Frosehplasma, Augen. kammerwasser und Ringerlösung für Kaltblïtler.

Einschlägige Arbeiten: Chlexutri, E., 1915, The Form of the Epithelial Cells in Cultures of Frog skin, and in its Relation to the Consisteney of the Medium. Journ. of exp. Med., .July 1., Bd. 22, s. 76-104.

\section{I'bung.}

Seite $38-41$.

Material: Milz der erwaehsenen Katze.

Medien und Waschflïssigkejten: Plasma und Embryonal-Extrakt der Katze; falls keine Katze rorhanden. Plasma und Embryonal-Extrakt der Ratte, Ringerlösung für Warmbliitler.

Einschlägige Arbeiten: LAMBERT, R. A., 1912, The production of foreign body giant cells in vitro. Journ. of exp. Med., Bd. 15.

\section{4. Übuln.}

Seite $41-42$.

Material: Embryonale Hühnermilz, 16 Tage alt.

Medien und Waschflüssigleiten: Hühnerplasma, Hühnerserm. Ringerlösung für Warmblütler, 2\% A carlösung.

Einschlägige Arbeiten: IxGebrigtsex. R., 1912, Studies on the growth of tissue ontside the organism. Joum. of exp. Med.. Bd. 16, Nr. 4. S. 421-431.

Seite $42-45$.

\section{Ind 6. C̈hung.}

Mat erial: Knochenmark emes jungen und eines gut gefütterten äIteren Huhnes.

Medien und Wasehflïssigkeiten: Hühnerplasma.

Einsehlägige Arbeiten: Foot, X. ('h., 1912, Über das Wachstum des Knochenmarks in vitro. Experimenteller Beitrag zur Entstehmo des Fettgewebes. Zieglers Beiträge zur Pathologie. Bd. 53. ‥446. - Fоoт, X. Ch., 1913, The growth of chicken bone marrow in vitro and its bearing on hematogenesis in adult life. Joum. of exp. Meel., Bd. 17,S.43-60. - ERwmax, Ph., 1917, Some ohservation: concerning chicken bone marrow in living eultures. Proc. Soc. Exp. Biol. and Med., Bd. 14,S. 109-112. Eromaxx, Rh., 1917, Cytologieal obeervation- on the behaviour of ehiken bone marrow in plasma medium. Am. Joun. Anatom. Bul. 2.2. S.73- 124.

Seite $45-47$.

\section{ร. Ühutle.}

Material: Hühner-, Ratten- und Mensehenmil\%.

Medien und Waschflussigkeiten: Das hetreffende Plasma und Embryonal-Fxtzakt des Tieres, das gebraucht wird. Falls man ten Mlensehen nimmt, 
Menschen- und Hühnerplasma. Sterile Lxcopothumsporen, sterile zerriebene Kaminteilchen, japanische Thusche. Ein Röhrhen mit einer Reinkultur von Tuberkethazille'm.

Einschlägige Arbeiten: Verittr, E.. 1919, licherche histologiche sul alemi tissnti in istato di sopravivenza in vitro. Boll. Soc. Meel. Pavia. - LAsnert nnd Hixes, 1911. Nigration hy amoboid movement of sareoma cells growing in vito and its bearing on the problem of the sprearl of malignant growth in the

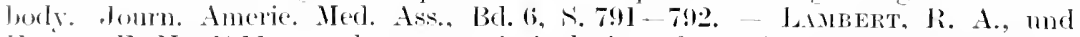
H.XEs, F. II., 1911. On the pragocytic inelnsion of carmin particles ly sareoma cells growing in vitro with eonseruent staining of the eell granules. J'roe. soc. exper. Biol. Mlecl., Bul. s. s. 113-114.

Sieite $47-50$.

\section{8. İbung.}

Material: Fertige Kulturen ron Nosenehymzellen des Huhnes oder des Veerschweinehens, Jannsgrün, Janussehwarz, Nentralrot gelöst in Locke-LewisLösmg ohne Dextrose in Verdümmngen: Janusgrïn: 1 : 40 000): Neutraliot: 1 : 80000 : Ring(elösmlng.

Einschlägige Arbejten: Lewrs, M.. I9]7, Development of comnectivetissnes fibres in tisisues eultures of chick embryos. Contrib. of Embr. N. 17. Extracted from l'ubl. 2.26 of the Carnegie Institution of Washington. - Lewrs. W. H.. 1920. The effert of potassium permanganate on the mesenchyme cells of tissue cultures. Amerie. Jomm. Anat., Brl. 28 .

Seite $30-51$.

\section{Cllung.}

Material: Fertige Kulturen von Iesenehymzellen des Huhnes oder des Meersehweinchens, Janusgrün, Janusschwarz, Nèntralrot, gelöst in Locke-LewisLösung ohne Dextrose, in Verdïmnngen: Janusgriin 1 : 40000; Nentralrot 1: 80600 : Ringerlösmng.

Einsehlägige Arheiten: Levi, G., lonti. Il ritmo e le modalita della mitose nelle cellule viventi coltivate in vitro. Areh. Ital. Anat. Embriol., Bul. 15.

Seite $51-53$.

\section{Uंดนเ上.}

Material: Mesenchymzellen des Hïhnerembryos, in Locke-Lewis-Lösung gezïchtet, hỵertonische und hypotonische Lösmgen von Locke-Lewis-Lösung̈, Ringerlösung.

Einsehlägige Arbeiten: Hoace, 1l. I., 1919, The effect of hypotonic and hypertonic solutions on fibroblasts of the embryonic chick heart in vitro. Journ. of exp. Med., Bel. 30. S. 617.

Sieite $73-56$.

\section{1. ÜH111.}

Material: Mesenchymzellen des Huhnes, einige Tage geziichtet. Kal. permanganat-Lösung in Verdiümumg 1:40000-1 : 80000 . Ringerlösung.

Einschlägige Arbeiten: Lewis, W. H., 1921. The effect of potassium permanganate on the mesenchyme eells of tissue cultures. Amer, Journ. Anat., Bd. 28.

Seite $36-6 \%$.

\section{Innd 13. Übuns.}

Material: Hühnerembryonen rom 13. - 18. Tage.

Nährlösungen nnd I'asehflïssigkeiten: Hühnerplasma, Embryonalextrakt, Locke-Lewis-Lösung, Ringerlösung.

Einsehlägige Arbeiten: Cirrel. A.. 1914. Present conditions of a strain of comnective tissue 28 month old. Journ. of exp. Mecl., Bd. 20, Nr. 1, S. ] -2. Ebelixa, A. H., 1919, A strain of connective tissue 7 years old. Journ. of exp. Hed., Bel. 30, S. .331-537. 


\section{CHane.}

Siate $6:-74$.

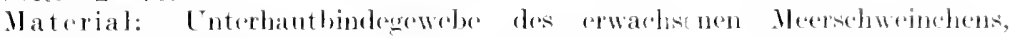
Kaninchens oder Huhnes.

Xithrlösungen und Waschfliissigkeiten: Plasma des betreffonden Tieres. Embryonal-kxtrakt, Ringerlisumy.

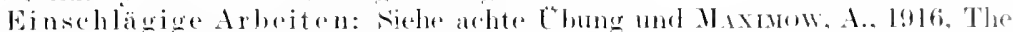
cultivation of comnective tissue of arlult mammals in vitro. Areh. russ. dinat., Histol. ot Embriol.. Bd. I.

\section{1.). 16. und 1\% l'bung.}

Seite 6 s 72 . (i) Tiage

Inaterial: Hühnerembryonen, versehieden lang bebrïtet, am besten is bis ไösเmต.

Ẍ̆hlösungen und Waschfliissigkejten: locke-Lewis-Lösung. Ringer-

Einschlägige Arbeiten: LewIs. 11.. 1917. Nuscular (ontraction in Tissue Cultures. 272. Publ. Carneg. Inst. - LEw Is, H. 1917, Behaviour of eross striated muscle cells in tissue cultures. An. Journ. of Anat., Bil. 22. - Levi, G. 1919, Riecrehe Istologiche sul aleuni tessuti in istato di sopravivenza in vitro. Bollet. 1 - della Soeieta Mee. ('hir. di Pavia, p. 1-599.

\section{5. (') Hung.}

Sieite $72-74$

Inaterial: Blasenmuskulatur rom Kaninchen.

Nährlösungen unel Waschflïssigleiten: Homogenes Plasma und Serum. Ringertösung.

Einschlägige Arbeiten: Cunupy. C.. 1913, Notes de biologie cytologique. Généralités I, Le muscle lisse II. Areh. de zool. exp. et gén., Bil. 42. S. 53.

\section{9. und 20. C'buns.}

Seite $74-7 \pi$.

Naterial: Hiihnerembronen von 10-13 Tagen oder Heersehweinembronen.

Nährlösungen und Wasehflïssigkeiten: Homogenes Plasma und Embryonal-Extrakt des betreffenden Tieres. Ringerlösmng.

Einsehlägige Arbeiten: Fischer. A., 1922. A three montho old strain of epitehum. Journ. of exp. Med.. Bel.24. S. $366-373$.

\section{I'bung.}

Seite $77-79$.

Material: Schibthrüse eines jungen Kaninchens.

Nährlösungen und Waschfliissigkeiten: Homogenes Plasma und Serum, Ringerlösung.

Einschlägige Arbeiten: Cunpy, ('.. 1915, Quelques resultats de la methode des cultures des tissues. I. La glande thyroide. Areh. de \%ool. Exp. et Général, Bd. 5.5. S. $16-79$.

\section{C̈bung.}

Seite $79-80$.

Ilaterial: Prostata des Meersehweinchens. Samenblasenflïssigkeit des Meerschweinchens.

Nährlösungen und Wasehflüsigkeiten: Plasma, Serum. Ringerlösung.

Einseh]ägige Arbeiten: ('munpr, ('., 1919. Perte de la séercition spéécifique des cellules cultivées in vitro. Compt. rend. Soe. Biol., Bd. \$3. s. 84.2. 


\section{2:3. C14ung.}

Sieite $80-82$.

Il aterial: l'mpern eines größeren schmetterhings, am besten Samia cecrobia.

Xïhrlösungen und 1 aschflüssigkciten: Clark- und Vernonssche Lösmg nach Vorschrift, siche S. Sl. Ringerlösmng.

Einschlägige Albeitrn: Golnscmumt, R., 1917. Versuche zur Sipermatogenesse in ritro. Areh. f. Zellforschmng. Bd. I4, S. $421-450$.

\section{IhIme.}

Sieite $83-84$.

Ilateriat: a) Hiihnerembryo, ea. 15 Tage alt. Haut, Milz. Niere sehildriuse. Hoden: b) erwachsenes Kaninchen, Unterhautbindegewebe, Milz, Niere, Sehilddriise. Hocken.

Nährmedien unel Waschflüssigkeiten: Hïhner-und Kaninchenplasma, Hiihner- und Kaninehenserum, Ringerlösung.

Einsehlägige Arbeiten: ('Humpr. C., 1913, La dédifférenciation des tissues cultive's en dehor's de l'organisme. Bibl. anat., Bd. 23.

\section{5. Ċhung.}

Seite $84-88$.

Material: Erwachsener Frosch, Hïhnerembryo.

Nährmedien und Wasehflüssigkeiten: Froschplasma. Hühnerplasma, Augenkammerwasser des Frosches, Locke-Lewis-Lösung, Ringerłösung.

Einsehlägige Arbeiten: [thenshutr, E.. 19]6, Changes in Pigment Epithelium Cells and Iris Pigment C'ells of Rana Pipiens. Induced by Changes in Envirommental Conditions. Journ. of exp. Med., Bd. 24, s. 689-699. - SмIтH, Divin 'T., 1920. The Pigmented epithelium of the Embrvo Chicks Ere studied in vivo and in vitro. The Johns Hopkins Hosp., Bull., Bd. 31, Nr. 353, .'. 239 _- 246. - LrNs, E., 1917, Note citologiea sull epitelio pigmentate della retina cultivate in vitro. Areh. Ital. d'Anat. ed di Embr. XV. - C'HAmpr. (.., 1914, Quelques resultats de la mothode de culture des tissues. III. La rétine. Areh. de Zool. Expér. et Générale, Bd. 53, 今. 5.

\section{6. Ühนแng.}

Seite $89-96$. schwein.

II terial: Froschlarve, Hiihnerembryo, eben geborene Katze oder Meer-

Nährmedien nnd Waschflïssigkeiten: Plasma und Serum des betreffenden Tieres, Ringerlösung.

Einschlägige Arbeiten: H.rreison, R. G., 1906/07, Observations on the living developing nerve fiber. Proc. soc. exp. Biol. and Med., Bd. 4, S. 140. Harrisox, R. G., 1910, The development of peripheral nerve fibers in altered surroundings. Arch. f. Entw.-Mech., Bd. 30, S. 15-33. - Harrison, R. G., 1911, The outgrowth of the nerve fiber as a mode of protoplasmic movenent. The Journ. of exp. Zool., Bd. 9, \$. 787-848. - Levi, G., 1916, Sull'origine rete nervose nelle culture di tessuti. R. Aec. Lineei, Bd. 25, Serie 9, 1. Sem., Blatt 9. INGEBRIGTSEN, R., 1913, Regeneration of axis eylinders in vitro. Com 1, and 2. Journ. of exp. Med., Bd. 17, \$. 182. and Bd. 18, S. 412. - Br.ts', H., Die Entstehung der Nervenbahnen. Samml. wiss. Vortr. Geb. Nat. u. Med. (Vogel, Leipzig), 3. Heft. - MAтs'moto, T., 1920, The Granules, vacnoles and mitochondria in the sympathic nerve fibers, cultivated in vitro. Bull. Johns Hopkins Hosp., s. $91-93$. 


\section{?. Ühıแ1.}

Seite $97-100$.

Ilaterial: Ringelnatter, Ratte, Katze.

Nährmedien und Waschfliissigkeiten: 1)as zu jedem Tiere gehorige l'lasma, Ringerlösung.

Einschlägige Arbeiten: Gruwtz. l'.. 1914, Abbau und Entzindung des

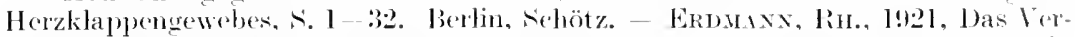
halten der Herzklapen der Reptilien und Mammalies in der Gewebekultur. Arch. f. Entw.-Merh., Bd. 46 .

Seite 10010.10.

\section{9. (h)112.}

Material: Ein Tiersarkom, ein Tierkarzinom.

Nährmedien und Wasehfliissigkeiten: Was zu dem betreffenden Tier gehöriger Plasma, Hühnerplasma, Drewshe Lösmes. Enbryonal-Extrakt rom Huhn, Ringerlösunщ.

Einsehlägige Arbeiten: l.nuberT, R. A.. 1913. ('omparative sturlies upon cancer cells and normal eel. 11. The character of growth in vitro with special reference to the cell divisions. Journ. of exp. Met. 17, Bd. 5, S. 499-510.

DREW, A. H., 1922, A comparative study of nomal and malignant tissuse, grown in artifieial culture. Brit. Journ. exp. Path., Bd. 3. s. 20-29.

Seite $105-106$.

\section{9. İlıIIIs.}

Material: Hiilmerembryo, ein Stamm Tuberkelhazillen. lösung.

Nährmedien und Waschflüsigkeiten: Locke-Lewis-Lösung, Ringer-

Einsehlägige Arbeiten: Lews. 11., 1920. The formation of vacuoles due to Bacillus typhosus in the cells of tissue of the lntestine of the Chick embryo. Journ. of exp. Med., Bal.31. S. 293-311. - Sirtu, H. F., 1915, The reaction between Bacteria and animal tissues under condition of artificial cultivation. tourn. of exp. Med., Bd. 21, S. 103; Sirth, H. F., 1916, The reaction between Baeteria and animal tissue under condition of artificial cultivation. The cultivation of tubercle baeilli with animal tissues in vitro. Jonrn. of exp. Mled.. Bd. 23, s. 283.

Seite $106-107$.

\section{0. ثंb111}

Material: Menschliehe Lymphknoten.

Nährmedien und Wasehflüssigkeiten: Menschenplasma, Hühnerplasma, Ringerlösung.

Einsehlägige Arbeiten: Lewr, W. H., and Webster, L. T., 1921, Giant. eells in cultures from human lymph nodes. Journ. exp. Med., vol.33. - LEWr, WT. H., and Webster, L. T., 192I, Migration of lymphocytes in plasma eultures of human lymph nodes. Journ. of exp. Med., vol. 33, Nr. 2, pp. $261-270$.

Seite $108-109$.

\section{IH1112.}

Material: Hühnerembryo.

Nährmedien und Waschfliissigkeiten: Kaninehenplasma, Hühner. plasma, Ringerlösung.

Einsehlägige Arbeiten: H.ıpbs, s. und RosextmsL, F., 1913, studien iiber den Einfluß der Hämolysine auf die Kultur lebender Gewehe außerhall, des Organismus. Zeitschrift fuir 1 mmunitätsforschung n. exp. Therapie, Bd. 16. s. $524-548$. 
Druck der spamerschen Buchdruckerei in Leipzig 
Verlag von Julius Springer in Berlin Wy

\title{
Vorträge und Aufsätze iiber \\ Entwicklungsmechanik der Organismen
}

\author{
unter Mitwirkmug von zahlreichen Gelehrten \\ herausgegeben von Professor Wilhelm Roux
}

Heft 21: Das Kontinuitatsprinzip und seine Bedeutungs in der Biologie. Voll Jan Dembowski. $1919 . \quad$ Preis 11. 18.-

Heft 22: Die Regulationen der Pflanzen. Ein system der teleologischen Begriffe in der Botanik. Von Dr. phil. Enil Ungerer. 1919.

P'reis $11.26 .-$

IJeft 23: Restitution und Vererbung. Experimenteller, kritiseher und synthetischer Beitray zur Frage des Determinationsproblens ron Professor Dr. Vladislav Ružička, Vorstand des Instituts für allgemeine Biologie und experimentelle Morphologie der Medizinischen Fakultät in Prag. I919.

Preis N. 10.-

Ileft 24: Die quantitative Grundage von Vererbung und Artbildung. Von Professor Dr. Riehard Goldsehmidt (Kaiser Wilhelm-Institut fiir Biologie, lierlin-Dahlem). Mit 28 Textabhildungen. 1920. Preis N. 38.-

Heft 25: Teratologie und Teratogenese. Nach Torlesungen, gehalten an der Wiener Universitit im Wintersemestel 1911/12 von IIans Przibram. 1920.

Preis M. 24. -

Heft 26: Die Grundprinzipien der rein naturwissensehaftliehen Biologie und ihre Anwendungen in der Physiologie und Pathologie. Yon Dr. Erwin Baluer, Prag. 1920. Preis M. 28.-

Heft 27: Das Erolutionsproblem und der individuelle Gestaltungsanteil am Entwicklnngsgeschehen. Von Professor Dr. Franz Weidenreich, früher Straßburer, z. Z. Mannheim. 1921. Preis M. 48.-

Heft 28: Über die Vorstellbarkeit der direkt bewirkten Anpassungen und der Vererbung erworbener Eigenschaften durch das Prinzip der virtuellen Verschiebungen. Ein Beitrag zur theoretischen liologie von Dr. Otto Jackmann. Mit 15 Textabbildungen. 1922.

Preis 11. 66.-

Ileft 29: Die allgemeine Biologie als Lehrgegenstand des medizinischen Studiums. Ein Gntachten vorgeleet den Regierungen Mitteleuropas von Professor Dr. Vladislav Ružicka in Prar. 1922. Preis M. 18.-

Heft 30: Die Prinzipien der Streifenzeichnung bei den Säugetieren. Abgeleitet aus Untersuchungen an den Einhuferm ron Dr. phil. et med. Hans Krieg in Tübingen. Nit 58 Abbildungen im Text. 1922. Preis M. $75 .-$

Heft 31: Die Geltung der von W. Roux und seiner Schule für die ontogenetische Entwicklung nachgewiesenen Gesetzmäßigkeiten auf dem Gebiete der phylogenetisehen Entwicklung. Ein Beitrag zul' Theorie der Stammesentwicklung. (Theorie des phylogenetischen Wachstuns.) Von Hermann Kranichfeld. 1922.

Preis M. 57.-

Archiv für Entwicklungsmechanik der Organismen. Organ für die gesamte kausale Morphologie. Herausgegeben von Professor Dr. Wilhelm Roux in Halle a. S.

Das Arehiv erscheint von Bd. 44 ab in Verlag von Julius Springer in Berlin in zwanglosen, einzeln berechneten Heften und zwangloser l'olge; nit etwa 40 Bogen wird ein Band abgeschlossen. 
Die laweknablokeit in der Entwicklungsgeschichte. Eno finale

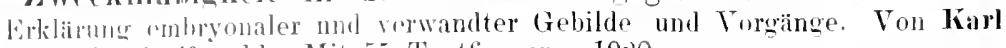

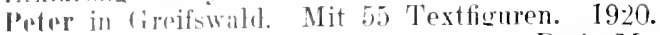

Preis M. 30.-; gebunden N. 36.-

Drl Begrifi der lienese in Physik, Biologie und Entwicklnmgsunschiolite. Eine Intorsuchune zur vergleichenden Wissenschaftslehre. Ton Mr. lint Lawin. Privathozent der Philosophie an der Lniversitit Jurlin. Mit 45 znm Teil farbigen Textabildungen. 1922. I'reis M. 136.-

Einfiihrung in die Experimentalzoologie. Ton Professor Dr. Burnhard Iiirkpll, Zoulougisch-Zoutomisches Institut der Universität (iöttingen. Mit 224 'Textahbildungen. 1919.

I'reis M. 28.-; gebunden M. 32.-

Dir angewanlte Koologie als wirtsehaftlieher, medizinisch-hygieniseher und kinlureller Faktor. Von Professor Dr. J. Wilhelmi, wissensehaftlinhes Mitolied der Landesanstalt für Wasserhygiene in Berlin-Dahlem. 1919.

Preis M. 5.-

íller die drilungsäihigen Driiseneinheiten oder Adenomeren, sowie iiber die Grumdbegriffo der morphologischen systemlehre. "/nglejeh Beitray $\mathrm{V}$ zur synthetiseben Morphologie. Ton Martin Heilemhain in 'Tübingen. Nlit 82 Textablilınngen. (Sunderabdruek aus, Arehir für Entwicklungsmechanik der Orwanismen".) 1921.

Preis N1. 126.-

Mikrohiologisches Praktikum. V'on Professor Dr. Alfred Koch, Direktor des landwirtsehaftlich-bakteriologisehen Instituts der Universitait Göttingnn. Mit 4 Textabbildungen.

Erscheint im Sommer 1922

Die Variabilitait niederer Organismen. Eine deszendenztheoretisehe Studie. Vou l)r. Ilans P'ringsheim. 1910.

Preis M. 7.-

Dir Mblerhaldensche Reaktion. Ein Beitrag zur Kenntnis von Substraten mit zellspezifischem bau und der auf diese eingestellten Fermente und zur Methodik des Narhweises von auf Proteine und ihre Abkömmlinge zusammengesctzter Natnr eingestellten Fermente. Ton Geheimem Medizinalrat Limil Norlurhaldrn, Professor Dr. mell. et phil. h. c., Direktor des Physiologischen lnstituts zn Halle. (F ü nfte Auflage der "Abwehrfermente".) Mit 80 Textabbildungen mol 1 Tafel. 1922.

Preis 11. 195.-

Allgemeimp Pluysiologie. Eine systematisehe Darstellung der Grundlagen sowie der allgemeinen Ergebnisse unt Probleme der Lehre vom tierisehen und pthanzlichen Leben. Ton 1. von Tschermak. In zwoi Bänden.

1. Band: Grumblagn der allgoneinen Physiologie. 1. Teil: Allgemeine ('halmateristik des Lehens, physikalische und chemische Besehaffenheit der leboulen Substanz. Mit 12 Textabbildungen. 1916. I'reis M. 10.-

1. Band, 2. Teil: Morploblogisehr Eigenschaften der lebenden Substanz und /orlularphysiologia. Nit etwa 110 Textabbildungen.

Erscheint im Sommer 1922

IJierzu Teuerungszuschläge 


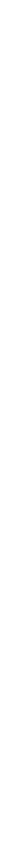




\title{
Vorträge und Aufsätze iiber \\ Entwicklumgsmechanik der Organismen
}

\author{
unter Mitwirkung ron zahireichen Gelehrten \\ herausgegeben von Professor Wilhelm Roux
}

Heft 21: Das Kontinuitätsprinzip und seine Bedeutung in der Biologie. Ton Jan Dembowski. 1919.

Teft 22: The Regulationen der Pflanzen. Tin bystem der teleologischen Begriffe in der Botanik. Von Dr. phil. Emil Ungerer. 1919.

Preis M. 26. -

Heft 23: Restitution und Vererbung, Experimenteller, kritischer und synthetischer Beitrag zur Frage des Determinationsproblems von Professor Dr. Vhulislav Rużicka, Vorstand des Instituts fur allgemeine Biologio und experimentelle Morphologie der Medizinischen Fakultät in Prag. 1919. Preis 1. 10.-

Heft 24: Die quantitative Grundiage von Vererbung und Artbildung. Von Professor Dr. Richard Goluschmidt (Kaiser Wilhelm-Institut für Biolocie, Berlin-Dahlem). Mit 28 Textabbildungen. 1920. Preis M. 38.-

Heft 25: Teratologie und Teratogenese. Nach Vorlesungen, gehalten an der Wiener Universitat im Wintersemester 1911/12 ron Hans Przibram. 1920.

Preis M. 24.-

Heft 26: Dlo Grundprinzipien der rein naturwissensehaftlichen Biologle und ilire Anwendungen in der Physiologie und Pathologie. Von Dr. Erwin Baver, Prag, 1920.

Preis M. 28.-

Heft 27: Das Frolutionsprobiem und der Individuelie Gestaltangsanteil am Entwicklungsgeschehen. Von Professor Dr. Franz Weldenreich, friber Straßbirg, z. Z. Mannheim. 1921. Preis M. 48.-

Heft 28: Uber die Vorstellbarkeit der direkt bewirkten Anpassungen und der Vererbung erworbener Eigensohalten durch das Prinzip der virtuellon Verschlebungen. Ein Beitrag zur theoretischen Biologie von Dr. Otto Jackmann. Mit 15 l'extabbildungen. 1922.

Preis N. 66. -

Heft 23: Die allgemeine Biologie als Lehrgegenstand des medizinischen Studiunis. Fin Gutachten vorgelegt don Regierungen Mitteleuropas von Professor Dr. Vladisiav Ružlcka in Prag. 1922. Preis M. 18.-

Heft 30: Die Prinzipien der Streifenzelelnung bel den Säugetieren. Abgreleitet ans Untersuchungen an den Einhufern von Dr. phil. et med. Hans Krieg in Tubingen. Mit 58 Abbildungen im Text. 1922.

Preis M. 75.-

Heft 31: Die Geltung der yon W. Roux und seiner Schule für dícontogenotische Lntwicklung nachgewiesenen GesetzmäBigkoiten auf dem Geblete der phylogenetischen Entwieklung. Ein Beitrag zur Theorie der Stammesentwicklung. (Theorie des phylogenetischen Wachstums.) Von Hermann Kraniehfeld. 1922.

Preis M. 57.-

Arehiv für Entwieklungsmechanik der Organismen. Organ fur die igesamte kausale Morphologie. Herausgegeben von Professor Dr. Willejm, Roux in Halle a. S.

Das Archiv erscheint von Bd. 44 ab im Verlag von Julius Springer in Bntlin in zwanglosen, einzeln bereehneten Heften und zwangloser Folge; mit "wa' 40 Bogen wird ein Band abgeschlossen. 